\title{
[1] tinbergen
}

\section{On Risks and Opportunities}

in Financial Markets

Simon D. Lansdorp

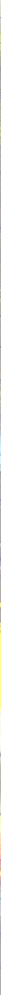


On Risks and Opportunities in Financial Markets 
ISBN: 9789036103244

Cover illustration: (C) Jack Liemburg - www.jacksart.nl

Cover design: Crasborn Graphic Designers bno, Valkenburg a.d. Geul

This book is no. $\mathbf{5 4 3}$ of the Tinbergen Institute Research Series, established through cooperation between Thela Thesis and the Tinbergen Institute. A list of books which already appeared in the series can be found in the back. 


\title{
On Risks and Opportunities in Financial Markets
}

\author{
Over risico's en kansen binnen financiële markten
}

THESIS

\author{
to obtain the degree of Doctor from the \\ Erasmus University Rotterdam \\ by command of the \\ rector magnificus
}

Prof.dr. H.G. Schmidt

and in accordance with the decision of the Doctorate Board.

The public defense shall be held on

Thursday, November 292012 at 15:30 hrs

by

SIMON DIRK LANSDORP

born in

Epe

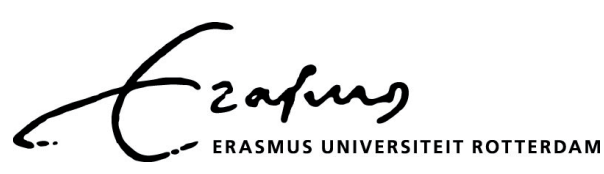




\section{Doctoral Committee}

Promotors:

Other members:

Copromotor:
Prof.dr. M.J.C.M. Verbeek

Prof.dr. W.F.C. Verschoor

Prof.dr. N.P.B. Bollen

Prof.dr. T.B.M. Steenkamp

Prof.dr. M.A. van Dijk

Dr. J.J. Huij 


\section{GOED GEVOEL}

"Goed GEVOeL" NOT only is the name of the painting printed on the cover of this thesis, it also describes my emotions at the end of a long journey of writing this thesis. A good feeling, the translation for "Goed Gevoel", is what I get if I think back on the time I was a PhD-student at the Erasmus University; it is the feeling I get from thinking about the result of more than four years of work, the result that is given physical form by means of this thesis; and perhaps even more importantly, a good feeling is what I get if I think about the opportunities this thesis provides me for chasing my dreams.

Without a doubt, the completion of my $\mathrm{PhD}$ has benefited from the help and support of many and I could not have done it without them. Therefore, I would like to thank the following persons in particular.

First, I would like to thank my two promotors, Marno Verbeek and Willem Verschoor. Marno, thank you for all your time you spent in supervising me and in helping me becoming a better researcher. I thank you for accepting me as your student during a turbulent period of my $\mathrm{PhD}$. It turned out you were the right person in the right place and you have been an important stimulus for me. Willem, even though your role has been more on the background, your positive words and the faith you have given me have been tremendous. Moreover, I thank you for all the support you have giving me such that I could visit several nice conferences abroad and combine the $\mathrm{PhD}$ with a position in the financial industry.

My biggest gratitude goes to Joop Huij for all his support over the past four years. Joop, as my co-promotor, you have been supervising me from the very beginning of my $\mathrm{PhD}$ and are co-author of three of the chapters in this thesis. It has been and still is a great pleasure working with you. Your enormous drive and enthusiasm always gave me a boost of positive energy, which at several times along the way in writing this thesis, I could really use.

I thank the other committee members, Nick Bollen, Tom Steenkamp and Mathijs van Dijk, for their time and their valuable feedback on an earlier draft. Also, I thank Thierry Post and Pim van Vliet for being co-author of Chapter 2. Thierry, you have given me the inspiration for starting the $\mathrm{PhD}$ in the first place. I have learned a lot from your intelligence combined with your creative mind. Your urge of sorting matters out to the bottom really pushed me to my limits and beyond. Thank you for that. To Pim, even though you are 
perhaps the most atypical financial empiricist ever, you have learned me a lot on this respect. Moreover, I also learned a lot from you on more general matters of doing the PhD-track and thank you for your 'mentorship' in that sense. And David Blitz, my co-author of Chapter 3 of this thesis, thanks for all your valuable inputs. Moreover, thank you for giving me the opportunity to combine writing this thesis with a part-time position at the Quantitative Strategies department of Robeco. This has been a learningful experience which I can recommend to anybody.

Next, I would like to thank several others that have not been (that much) involved in the content of this thesis but have given me all the support needed for completing the PhD. Cem, I thank you for your friendship. Looking back, our many conversations in which we shared our mutual understandings of all the 'enjoyments' that come with the $\mathrm{PhD}$ have been great. Please send my regards to grandfather Gene. I wish all the best to you and your wife Anil. Also, I would like to thank Karim for the nice atmosphere at the 'ninth'. The daily coffee breaks we shared downstairs have been very valuable to me (as well as to the Douwe Egberts Café). To Nalan and Rui, thank you for being such nice persons. I really enjoyed the hours we have spent together in the Smitse. Marcel, I thank you for sharing the office. It has been a pleasure sharing both our frustrations if things did not went the way we planned and in sharing our spontaneous happiness in the many times we thought we were one step closer to winning the Nobel-price. Guido, I thank you as well for sharing your insights with me, as well as the fun times we had. And Philippe, I enjoyed teaching a course with you. Furthermore, I thank Amit, Diana, Felix, Hendrik, Jorn, Nuno, Thijs and Viorel for the pleasant environment on the ninth floor. Finally, I thank Jack Liemburg for making such a nice piece of art which makes this thesis, at least from the outside, unique in its kind.

I cannot imagine having written this thesis without the endless support of Inge. Thank you for being there by my side. It is you who really gives me a "goed gevoel".

Simon Lansdorp

Bleiswijk, October 2012 


\section{CONTENTS}

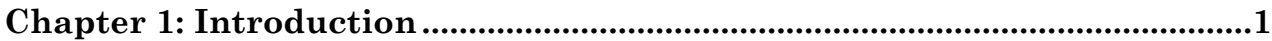

Chapter 2: Sorting Out Downside Beta ...................................................... 11

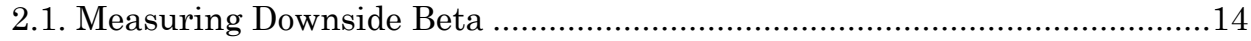

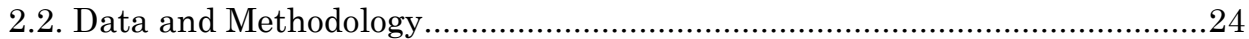

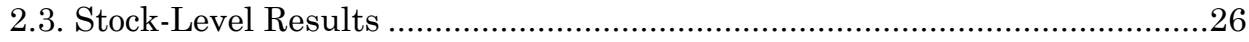

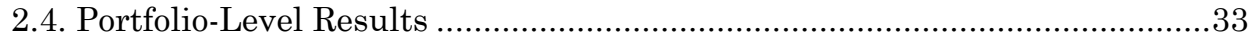

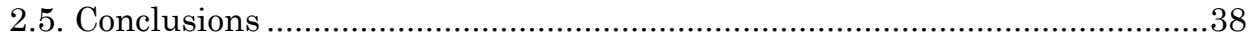

Chapter 3: Short-Term Residual Reversal.................................................. 39

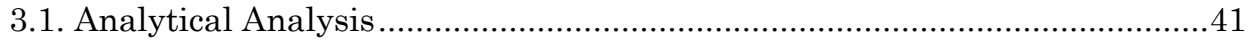

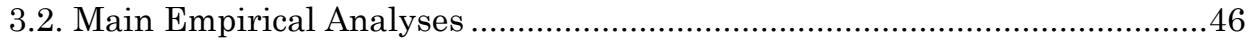

3.3. Reversal Profits and Trading Costs ..................................................57

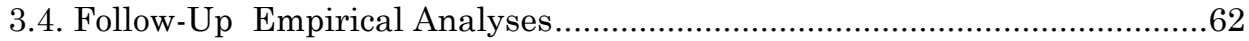

3.5. Explanations for Short-Term Stock Reversals ....................................72

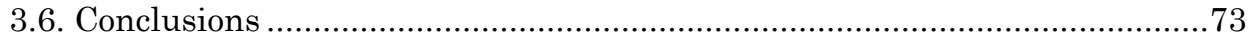

Chapter 4: Mutual Fund Performance Persistence, Market Efficiency, and Breadth ....................................................................................... 75

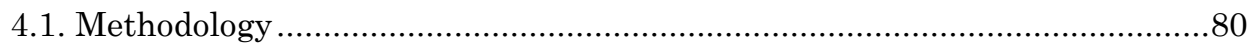

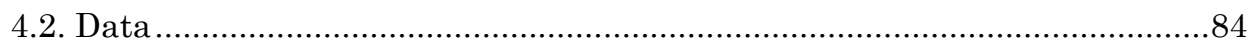

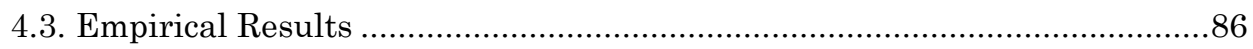

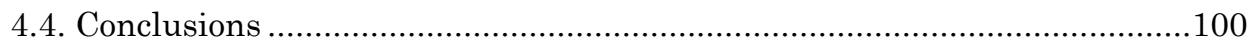

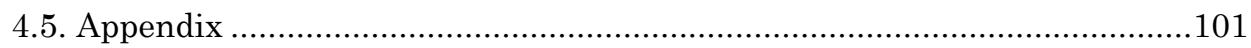


Chapter 5: Managerial Turnover and the Behavior of Mutual Fund

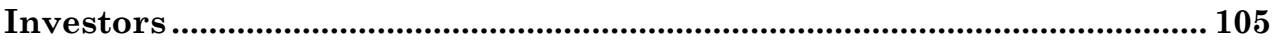

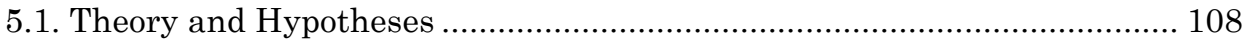

5.2. Data and Sample Characteristics …………................................................ 111

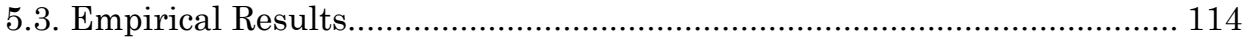

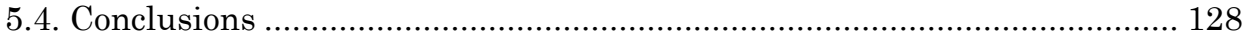

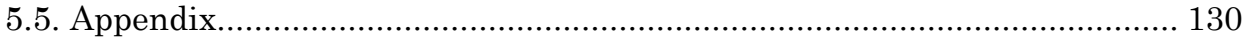

Chapter 6: Summary and Conclusions............................................................ 135

Samenvatting (Summary in Dutch)................................................................. 139

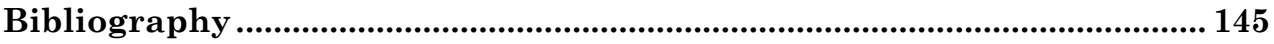

Tinbergen Institute Research Series ............................................................... 157 




\section{CHAPTER 1 INTRODUCTION}

WE STAND TODAY sixty years since the publication in the Journal of Finance of Harry Markowitz's seminal paper, "Portfolio Selection"; marking the beginning of modern financial economics. Markowitz (1952) was the first to give a precise definition of risk and return. By means of a mathematical formalization he showed that risk can be reduced by diversification without changing expected portfolio returns. It was not this insight but more so the mathematical formalization that makes the paper, with hindsight, so groundbreaking. The benefits of diversification, after all, were by then already known and applied in practice for two centuries. For instance, the aim of the first ever mutual fund, originating from Holland and dating back to the $18^{\text {th }}$ century ${ }^{1}$, was to provide small investors the opportunity to diversify their risks by investing in securities in a variety of countries (see Rouwenhorst, 2005).

Built upon the insights of Markowitz's mean-variance framework, the capital asset pricing model (CAPM) was developed independently by Sharpe (1964), Lintner (1965a, b) and Mossin (1966). ${ }^{2}$ The main result that follows from the CAPM is the positive relation between the expected risk premiums on individual securities on one side and their systematic risk on the other side. Under the assumptions of the Capital Asset Pricing Model, the CAPM, the market risk (the component of a security's total risk that is systematic) is the only relevant risk for an investor; the remaining risk (or the idiosyncratic risk component) is irrelevant, because this can be diversified away. The systematic risk component of a security is measured by the standardized covariance with the market and is called market beta. The risk premium investors demand for holding a certain security is this market beta multiplied by the market risk premium (or equity premium); the expected return on the market portfolio above the riskless rate. The portfolio evaluation models of Sharpe (1966) and Jensen (1968) are based on the CAPM and are still widely used in academia and the investment industry.

\footnotetext{
1 The name of the fund was Eendracht Maakt Magt, meaning 'Unity Creates Strength', the maxim of the Dutch Republic.

${ }^{2}$ In 1990 Harry Markowitz and William Sharpe won the Nobel Prize for their work.
} 
Another major scientific contribution to the field of finance is the efficient market hypothesis (see, e.g., the survey article of Fama, 1970). The efficient market hypothesis states that security prices at any point in time fully reflect all available information. That is, markets accurately and instantaneously incorporate all available information into market prices. As a consequence one cannot generate abnormal returns using information that is already publicly available (such as historical prices, earnings announcements or new stock issues, etc.).

Over the past decades, the field of 'asset pricing' has also experienced some major developments on theoretical, methodological, and empirical issues. The widely available high-quality financial databases, the sophisticated econometric techniques and the enormous increase in computing power, combined led to a much better understanding of the pricing of stocks, bonds, derivatives and other financial securities. One such finding is that the CAPM does a poor job in describing security returns in empirical studies. For instance, the relation between market betas and mean returns is found to be too flat compared to what theory predicts. Low beta stocks are underpriced relative to a mean-variance CAPM while high beta stocks seem to be overpriced.

This thesis adds to the financial literature by providing four different empirical studies within the theme of this thesis: 'risks and opportunities in financial markets'. While each of the next four chapters are self-contained and can be read independently, the studies are presented in a particular order. The first part of the thesis analyzes monthly U.S. stock returns over a more than eighty-year period. The first study, described in Chapter $2^{3}$, examines the historical risk/return relation using different risk measures. In Chapter $3^{4}$, we examine risks that are inherently involved by following a conventional reversal investment strategy and introduce a new (but comparable) investment strategy that has more desirable risk characteristics and seems to be an interesting investment opportunity for gaining high returns. The second part of the thesis is on institutional investment management and actively managed mutual funds in particular. Actively managed mutual funds continuously search for new, profitable investment opportunities. In Chapter $4^{5}$ we examine the 'breadth' of investment opportunities across various asset classes and

\footnotetext{
${ }^{3}$ This chapter is based on Post, van Vliet and Lansdorp (2012).

${ }^{4}$ This chapter is based on Blitz, Huij, Lansdorp and Verbeek (2012) which is forthcoming in the Journal of Financial Markets.

5 This chapter is based on Huij and Lansdorp (2012).
} 
relate differences in mutual fund performance persistence to the funds' investment opportunity sets and the relative efficiency of the asset classes in which the funds operate. The final study, described in Chapter $5{ }^{6}$, looks at capital flows of mutual fund investors following replacements of mutual fund portfolio managers. Finally, Chapter 6 provides a summary.

To be more precise, in Chapter 2 of this thesis we provide a rigorous empirical analysis of the role of beta for the cross-section of U.S. stock returns. That is, we examine why some stocks have higher returns than other stocks, on average, and use the stock betas as the explanatory variable. Besides analyzing the role of regular market beta that follows from the CAPM, we also examine and compare several 'downside-beta' measures that are found in the literature. Over fifty years ago, Markowitz (1959) already advocated replacing variance by semi-variance as the measure of investment risk. While variance assigns the same weight to upward and downward deviations from the mean, semi-variance only measures the average squared downward deviation from a certain return threshold (for instance the risk-free rate of return), which intuitively sounds more appealing. Based on the semi-variance measure, we consider a downside beta measure, the semi-variance beta, which emphasizes on the co-movements of individual stock returns with the market during market downturns. Also, we judge the economic justification and empirical strength of two other downside beta measures that are proposed in the literature.

Using monthly U.S. stock return data from 1926 to 2010, we find that the estimated risk/return relation is steeper if risk is measured by the semivariance beta compared to the regular market beta or the two other downside beta measures. This result holds irrespective of the period under consideration (the period pre-1963 and the period post-1963) and also after controlling for other stock characteristics including size, value and momentum. Moreover, we show that the semi-variance beta is consistent with a marginal utility function that has the properties of non-satiation, global risk aversion and decreasing absolute risk aversion. On the contrary, the other two downside risk measures violate the non-satiation property and/or the (decreasing absolute) risk aversion property and thus are not economically meaningful. Hence, while the empirical relation for regular beta and stock returns is found to be flat, this relation is positive if regular beta is replaced by semi-variance beta. Thus, in line with the positive risk/return relation that finance theory suggests (but not

${ }^{6}$ This chapter is based on Huij, Lansdorp and Verbeek (2012). 
supported by empirical studies using regular market beta), we indeed find that risk aversion explains why high-risk stocks yield higher average returns than low-risk stocks, ceteris-paribus.

Besides the empirical flat relation that is found between regular beta and stock returns, over the past years many researchers have also reported return patterns that cannot be explained by the CAPM. Some of the wellknown anomalies are, for instance, the long-term reversal effect, the momentum effect, the size effect, the value effect and several calendar effects.

The long-term reversal effect, documented by De Bondt and Thaler (1985), implies that stock returns tend to revert in a three to five year period. And stocks that were among the past six to twelve month winners (losers) tend to have higher (lower) average returns the following six to twelve months, i.e., the momentum effect (see, e.g., Jegadeesh and Titman, 1993). Banz (1981) and Reinganum (1981) showed that smaller sized firms have higher average returns compared to larger firms, even after controlling for market beta risk. Also, value stocks (i.e. stocks that trade at relatively low prices compared to their fundamentals) tend to have higher average returns than growth stocks do (see, e.g., Rosenberg et al., 1985; and Fama and French, 1992). Moreover, several studies have shown that there are also calendar effects on return patterns (see, e.g., French, 1980, on a weekend effect; Keim, 1983, on a January effect; and Gultekin and Gultekin, 1983, on seasonal patterns).

"In the beginning, there was chaos; practitioners thought one only needed to be clever to earn high returns. Then came the CAPM. Every clever strategy to deliver high average returns ended up delivering high market betas as well. Then anomalies erupted, and there was chaos again."

Perhaps the biggest anomaly, in terms of abnormal returns, known today is the short-term reversal effect (see, e.g., Jacobs and Levy, 1988, for a comparison on the returns on different anomalies). ${ }^{7}$ The return on a stock in period $t$ - 1 is typically negatively correlated with its return over the following period, period $t$. This means that stocks with low (high) returns the previous month tend to have high (low) returns the next month (a possible explanation is that investors initially overreact to firm-specific news which is corrected

\footnotetext{
${ }^{7}$ I refer here to 'paper' returns, i.e. hypothetical returns that do not incorporate for instance transaction costs and market impact costs. The net expected pay-off of implementing a strategy based on the reversal effect will be much lower and might even disappear (see Avramov et al., 2006).
} 
over the following month). Hence, it is optimal for a mean-variance investor (see Markowitz, 1952) to tilt its portfolio towards stocks with recent low returns as these have a high expected return for the following month. Obviously, this violates the weak form of market efficiency (see Fama, 1970) since investors can obtain a superior mean/variance performance by simply making use of information on historical returns. Short-term reversal investment strategies will be the topic of Chapter 3 of this thesis.

In Chapter 3 we show that conventional short-term reversal strategies exhibit significant time-varying exposures to common factors. ${ }^{8}$ A conventional short-term reversal strategy is long in stocks that underperformed the market (losers) over the recent past month, and short stocks that outperformed the market (winners) over the past month (see, e.g., Lehmann, 1990; and Jegadeesh, 1990). The following illustrative example shows the reason why this introduces exposures to common factors. Suppose the market return over the past month was very positive, then high beta stocks are more likely to be among the recent winners stocks while low beta stocks are more likely to be among the recent losers stocks. Hence, in such a month, the long portfolio, in general, has a lower market beta compared to the short portfolio. As a result, the long-short reversal portfolio is negatively exposed towards the return on the market the following month.

Building on these insights, we introduce a novel reversal strategy that is based on residual stock returns instead of total stock returns. Residual stock returns are the returns of stocks that cannot be explained by the common factors, including the market and the two Fama and French (1993) factors: size and value. Thus, residual returns are the stock-specific returns and are orthogonalized with respect to the three common factors. As a result of sorting stocks on residual returns, factor exposures of a long-short residual reversal strategy portfolio are largely eliminated. We show that this characteristic has some appealing properties compared to a conventional reversal strategy that is based on total stock returns.

We find that the residual reversal strategy systematically outperforms the conventional reversal strategy. First, conventional reversal returns are, on average, lower since this strategy effectively bets against persistence in factor returns. This 'bet' is the consequence of having factor exposures that are

\footnotetext{
8 The CAPM asserts that there is only one common factor, the market factor. Fama and French (1993) introduced a three factor model that, besides the market factor, also includes a size factor and a value factor. They show that this model explains a large part of the cross-sectional return differences.
} 
inversely related to the lagged factor return and is detrimental for the performance since factor returns tend to persist in the short term of one month. Second, having (dynamic) factor exposures contributes for a large part to the total variability in the reversal profits. Combined, we find that these two empirical properties result in risk-adjusted residual reversal profits that are twice as high compared to the risk-adjusted profits of the conventional reversal strategy. Our results have important implications for the notion that markets are efficient. For instance, we find that the residual reversal profits are economically and statistically significant even after taking trading costs into account. Moreover, profits are high even if we restrict the investment universe to the 100 stocks with the biggest market capitalization. This finding rules-out that liquidity or lead-lag effects are driving the reversal in stock returns. On the other hand, the results are consistent with the hypothesis of overreaction to firm-specific news.

If markets are efficient, contrary to the evidence shown in Chapter 3, passive management would be the only relevant investment strategy for all investors. For instance, if the CAPM holds in reality (or the meansemivariance CAPM), and the market is the only priced risk factor, this would mean that every investor would hold a fraction of the market portfolio. For example, retail investors would participate in mutual funds that passively hold the market portfolio and pension funds would also simply invest in the market. Still, there is an enormous amount of capital allocated to actively managed investment pools. As of the end of 2010, there are close to 70 thousand different mutual funds around the globe with more than $\$ 24$ trillion of assets under management (see Investment Company Institute, 2011a). Cremers et al. (2011) show that the largest fraction of all equity mutual funds engages in active management. Hence, this is evidence that many investors believe that markets are not efficient and try to exploit these inefficiencies by pursuing active strategies like the reversal strategy. Clearly, the anomalies explained above are just a few examples of possible investment opportunities for gaining expected returns with a superior risk/return tradeoff. The fourth chapter of this thesis analyses the performance of actively managed mutual funds, within different asset classes, pursuing a wide range of investment strategies in order to try to beat their benchmark.

More specifically, in Chapter 4, we analyze the persistence in performance of actively managed mutual funds across different asset classes and examine the importance of breadth and market efficiency for the 
persistence in the fund returns. According to the fundamental law of active management (see Grinold, 1989; and Grinold and Kahn, 2001), breadth, defined as the number of independent investment opportunities for gaining abnormal returns, is an important determinant for the value of active management. Also, many researchers and investors believe that gaining positive active returns is easier within inefficient, less developed markets like the emerging markets of, for example, Brazil, China, Indonesia and SouthAfrica. The objective of this study is to advance the understanding of what is driving the value of active management in the context of these competing (but not mutually exclusive) hypotheses.

For this study, we use a comprehensive sample of mutual funds that invest in one of twenty different asset classes. The different asset classes include seven bond asset classes, six equity classes belonging to different geographical regions, six asset classes within U.S. equity that differ in their capitalization and/or growth versus value characteristics, and finally U.S. real estate equity. First, in each of the asset classes, we find strong persistence in performance. Second, the persistence in performance in some asset classes (like U.S. small-cap equity) is much higher compared to other asset classes (for instance, U.S. large-cap value equity). Third, if we relate differences between performance persistence across asset classes with differences between asset class efficiency, we find no relation. Hence, the added value of active management is unrelated to market efficiency. Interestingly, we find that differences across the persistence in performance can largely be explained by differences between the breadth of asset classes. That is, asset classes with more breadth show stronger persistence in performance. We also find that breadth is important in driving the dynamics in persistence; in periods with more breadth past winners outperform their benchmark and their peers by a greater extent. From these results, we conclude that the fundamental law of active management seems to hold and that breadth is indeed important for the value of active management.

In the final study of this thesis, described in Chapter 5, we again examine actively managed mutual funds. In this study we analyze capital flows subsequent to the replacements of portfolio managers of domestic U.S. equity funds, i.e. U.S. funds that primarily invest in U.S. equities. It is by now a well-known empirical fact that investors chase past winners (see, e.g., Chevalier and Ellison, 1997; and Sirri and Tufano, 1998). That is, funds that are among the top performing funds attract the biggest capital flows from 
investors. Berk and Green (2004) assert that investors update their beliefs about managerial skill based on the performance of the fund. As a consequence, after a strong (poor) performance the expected skill of the manager is updated upwards (downwards) and capital is allocated to (withdrawn from) the fund. However, this seems only relevant in case the portfolio manager stays at the fund. If, on the contrary, a star manager, a manager with an excellent track record, leaves the fund, it is expected that flows will be lower to this fund compared to funds with a similar performance that retained their star managers. For the replacement of poorly performing managers, it is less straightforward what to expect. First, if poorly performing managers are replaced by managers that are expected to have better investment skills, one might expect a positive flow response following the change in management. On the other hand, if investors perceive the change in management as a bad signal, investors might be reluctant to invest in the fund or even withdraw capital from the fund.

Using a sample of domestic U.S. equity mutual funds and manager changes taking place between 1993 and 2006, we find strong evidence that investors respond to these managerial replacements. We find that the top performing funds that have a change in management subsequently have lower flows compared to funds of which the manager is retained. On top of that, we find that funds replacing their poorly performing manager subsequently have lower flows compared to poorly performing funds with a continuing manager. Hence, this latter finding is inconsistent with a world of rational expectations as in that case we would expect to find a positive flow response. The finding is, however, in line with the signaling hypothesis. Interestingly, flows are lower for poorly performing funds with a change in management, while we find evidence that fund performance increases following the replacement of poorly performing managers (whereas poorly performing funds that retained their manager persistently have a poor performance). This is consistent with the findings of Jin and Scherbina (2011) who show that new managers sell-off the 'inherited' loser stocks at a higher rate and as such suffer less from the negative momentum return on these stocks. A final interesting insight is that the results are very similar for institutional funds and retail funds. This is surprising given that institutional investors, in general, are better able to closely monitor the performance of mutual funds than retail investors and are expected to rely less on behavioral biases in making investment decisions. 
In summary, this thesis provides several new insights into risks and opportunities in financial markets. First, we find that investors dislike downside risk and that downside risk is priced in U.S. equity markets. Secondly, we find that conventional short-term reversal strategies exhibit significant dynamic risk exposures. Eliminating these exposures provides investors an interesting opportunity to outperform the market portfolio. The potential for active managers to persistently add value and outperform their benchmarks depends on the number of independent investment opportunities, or breadth, available to the manager, not, however, market efficiency. And finally, the replacement of active managers by a new manager is not going unnoticed by mutual fund investors. In general, these fund investors seem to dislike managerial replacements, even if poorly performing managers are replaced. 

A WELL-KNOWN CONCERN about variance as a measure of investment risk is that it assigns the same weight to upward and downward deviations from the mean. The same argument also casts doubt on market beta as a measure for the systematic risk of individual stocks. For example, a stock that has gone up faster than others during market upswings and has gone down slower than others during market downswings, will be considered by most investors as a low-risk stock. It is well known that variance and beta generally are not consistent with first-order stochastic dominance, a minimal (normative and descriptive) choice criterion (see, e.g., Levy, 1992).

An appealing candidate to replace variance is semi-variance (SV), already advocated by Markowitz (1959). SV measures the average squared downward deviation from a return threshold, and is also known as the secondorder lower partial moment (LPM). Hogan and Warren (1974), Bawa and Lindenberg (1977) and Lee and Rao (1988) developed a market equilibrium based on this risk measure. In their model, the regular market beta is replaced with a downside beta (or co-lower partial moment) that emphasizes the comovements of individual stocks with the market during market downturns as a measure of systematic downside risk.

Price et al. (1982) show that the historical downside betas of U.S. stocks systematically differ from the regular betas. Specifically, the regular beta underestimates the risk for low-beta stocks and overestimates the risk for high-beta stocks. This finding may help to explain why low-beta stocks appear systematically underpriced and high-beta stocks appear systematically overpriced in empirical tests of the mean-variance CAPM (see, e.g., Black et al., 1972; Fama and MacBeth, 1973; Reinganum, 1981; and Fama and French, 1992).

Despite the intuitive and theoretical appeal of downside beta and the empirical problems of regular beta, there are several unanswered questions regarding the empirical relevance of downside beta for explaining and predicting stock returns. Notwithstanding many important contributions in 
this area, several issues related to data and methodology of earlier studies do not allow for an unambiguous conclusion.

First, an early study of the mean-semi-variance (M-SV) equilibrium model by Jahankhani (1976) focuses on the relatively short sample period 1951-1969 that does not include the important bear markets of the 1930s, 1970 s and 2000s. This may critically affect the conclusion that the model does not fare any better than the CAPM. Price et al. (1982) demonstrate the divergence between regular beta and downside beta, but they do not analyze the cross-sectional explanatory power of downside beta.

Second, some studies claim to empirically test the lower-partial-moment beta of Bawa and Lindenberg (1977) but in fact use very different beta measures. For instance, Harlow and Rao (1989) examine a generalization of the M-SV equilibrium model, based on general lower partial moments. Regrettably, their regression-based asymmetric response model (ARM) does not estimate the lower partial-moment beta, as explained in the next section, and behaves very similar to regular market beta. Ang et al. (2006a), estimate downside beta based on the conditional second-order centered co-moment, or downside covariance, with the market, rather than the second-order co-lower partial moment, leading to deviations from the SV beta definition and, perhaps more worryingly, violations of the conditions for coherent risk measures (see, e.g., Artzner et al., 1999).

Third, some studies focus on in-sample analysis and do not cover the estimation of downside beta from prior data and out-of-sample prediction of expected returns. These issues seem particularly relevant for downside risk measures, because these measures generally use only part of the available time-series observations - the downside observations. Ang et al. (2006a) report a strong contemporaneous cross-sectional relation between stock returns in a given year and downside beta estimates based on the daily returns of the same year. They find however limited out-of-sample predictive power; past downside beta estimates are not persistent and yield poor predictions for future stock returns.

We argue that the lack of predictive power is largely the result of the abovementioned issue regarding conditional centered or non-centered comoments. Estimating downside covariance requires stock-level estimates of conditional expected returns, which generally cannot be estimated accurately in small samples. Indeed, more accurate estimates are obtained when estimating downside beta, as the M-SV model requires, based on the second- 
order co-lower partial moment, or conditional non-centered second-order comoment, which does not depend on conditional expected returns.

The purpose of this study is to analyze the out-of-sample predictive power of downside beta for future stock returns, taking into account the abovementioned issues. To the best of our knowledge, this is the first study to rigorously analyze the predictive power of the SV beta in the cross-section of U.S. stock returns. We use the multivariate regression methodology of Fama and MacBeth (1973) to evaluate several market-beta measures and to control for other stock characteristics, including market capitalization, valuation multiples and past return measures. Using stock market data from 1926 to 2010, we find that downside risk, when properly defined and estimated, explains a significant part of the cross-sectional variation of out-of-sample stock returns. Depending on the precise model specification, the premium is estimated to be roughly four to seven percent per annum for SV beta, compared with only zero to three percent for regular beta. Using the ARM regressions or covariance-based definition lowers the estimated premium and worsens the statistical fit, consistent with our theoretical and methodological concerns about these definitions for measuring downside risk.

Our conclusions are not affected by the inclusion of a series of other stock characteristics and plausible changes in the cross-section and sample period. We also examine the return predictive power of downside market beta for single- and double-sorted beta portfolios and for Fama-French benchmark portfolios formed on market capitalization of equity (Size) and book-to-market equity ratio (BtM). The high turnover of these latter portfolios creates dynamic betas that change with the portfolio composition. After accounting for this dynamic pattern, the portfolio-level analysis confirms the stock-level analysis; downside beta explains a significant part of the cross-sectional differences in out-of-sample return between the portfolios, and it dominates regular beta.

The results of our study have several important implications. First, we show that downside-covariance based measures as used in, for example, Ang et al. (2006a), are not in line with basic economic principles and lack predictive power for U.S. stock returns. Using this measure for estimating downside beta, therefore, is not recommended. Second, we show that the theoretical positive relation between risk and return is confirmed empirically if systematic risk is measured by SV beta instead of regular market beta. Moreover, SV beta captures priced risk that is not captured by the other betas, and the other betas don't capture any priced risk that is not captured by SV beta. 
The remainder of this chapter is structured as follows. Section 2.1 first discusses the various ways to define and estimate downside beta. Among other things, that section shows that the ARM regressions and covariance-based definition generally do not produce the SV beta of the M-SV model, and, perhaps more worryingly, raise questions regarding to their economic meaning. Section 2.2 discusses our data and regression methodology. Next, Section 2.3 presents our main results. Section 2.4 shows the results for sizevalue benchmark portfolios. Finally, Section 2.5 summarizes our findings and provides our conclusions from this study.

\subsection{Measuring Downside Beta}

This section introduces semi-variance (SV) and the associated downside beta. It also introduces the asymmetric response model (ARM) beta and the downside-covariance (DC) beta and gives the formal conditions under which these alternative betas equal the SV beta. A simple numerical example illustrates the differences between the various estimates of systematic downside risk. We will also derive implied pricing kernels for the different downside-beta measures.

\section{A. Semi-variance Beta}

Semi-variance measures the average squared downward deviation from a return threshold:

$$
S V \equiv E\left[(R-k)^{2} \mid R \leq k\right]
$$

In this expression, $R$ is the investment return in excess of the riskless rate and $k$ is a return threshold that separates "losses" from "gains". This risk measure is also known as the second-order lower partial moment. ${ }^{9}$

For nominal returns, plausible values for the threshold range from zero (the investor benchmarks against the initial value of her portfolio) to the average market return (the market portfolio is the benchmark). Hogan and Warren (1974) and Bawa and Lindenberg (1977) choose $k=0$ for their equilibrium model. Since the threshold is applied to excess returns, this choice

\footnotetext{
${ }^{9} \mathrm{SV}$ is a special case of the general lower partial moment $L P M(k, t) \equiv E\left[(R-k)^{t} \mid R \leq k\right]$, where $t$ is the relevant order. We also considered systematic downside risk measures based on other LPM orders. The first-order LPM, or Expected Loss, and the third order LPM yield very similar results as SV, but LPMs of order zero and four lead to deterioration and seem less relevant as downside risk measures for stocks.
} 
boils down to using the riskless rate as the threshold for nominal returns. In this chapter, we will adhere to this specification. Fortunately, the empirical results are very robust to the use of alternative plausible thresholds. In order to significantly change the empirical results, we need to select a threshold from the left tail or the right tail of the return distribution. However, a threshold from the left tail generally excludes too many return observations to allow for accurate estimation of downside beta, and the beta no longer measures downside risk when the threshold is taken from the right tail. Not surprisingly, large deviations from $k=0$ lead to significant deteriorations in the empirical goodness-of-fit.

The equilibrium model of Hogan and Warren (1974) and Bawa and Lindenberg (1977) preserves all key characteristics of the CAPM, including the two-fund separation principle, efficiency of the market portfolio and the linear risk-return relation. The key difference is that SV replaces variance as the relevant portfolio risk measure. The following "SV beta" arises as the relevant measure of systematic risk for an individual stock (see, e.g., Bawa and Lindenberg, 1977, p. 196, Eq. 5):

$$
\beta_{S V, i} \equiv \frac{E\left[R_{M} R_{i} \mid R_{M} \leq 0\right]}{E\left[R_{M}^{2} \mid R_{M} \leq 0\right]}
$$

The numerator of this expression is the second lower partial co-moment between the stock return $R_{i}$ and the market return $R_{M}$ and measures the comovements with the market during market downturns. This co-moment is standardized with the SV of the market. The resulting beta measures the contribution of the evaluated stock to the SV of the market portfolio, in the same way that the regular beta measures the contribution to the variance of the market portfolio.

Since the SV beta is based on market downswings only, it is more difficult to estimate empirically than the regular beta. For example, the CRSP all-equity index, our proxy for the market, yielded a negative excess return in roughly $40 \%$ of the monthly observations in our sample from January 1926 to December 2010. Regular betas of individual stocks are often estimated based on the past 60 months. Using this estimation window, SV beta is estimated based on 24 market-down months on average. However, the difference in statistical accuracy between the two betas is generally smaller than what the number of observations suggests. In case of independent and identically 
distributed observations, the standard error of SV-beta estimates can be expected to be $58 \%$ (or $\sqrt{60} / \sqrt{ } 24-1$ ) higher than the standard error of regularbeta estimates. However, the correlation with the market tends to be higher for market-down observations than for market-up observations, which reduces the standard error. One practical way to quantify the accuracy is to divide stocks into quantiles based on their past beta estimates and to compute the frequency with which stocks migrate from one quantile to another. Table 2.1 in Section 2.3 below shows that the migration frequencies for 60-month SV beta are only slightly higher than those for 60-month regular beta in our sample. In addition, unreported results show that increasing the length of the estimation period to 120 months in effect eliminates the difference in forecasting power between the two betas.

The following linear risk-return relation applies in equilibrium:

$$
E\left[R_{i}\right]=\beta_{S V, i} E\left[R_{M}\right]
$$

It should be stressed that this relation links the unconditional expected returns $E\left[R_{i}\right]$ and $E\left[R_{M}\right]$. The motivation for focusing on downside beta is that the sensitivity of stock returns to the market may change with the level of the market returns, leading to an asymmetric risk profile. Therefore, conditional versions of the risk-return relation, such as $E\left[R_{i} \mid a \leq R_{M} \leq b\right]=\beta_{S V, i} E\left[R_{M} \mid a \leq R_{M} \leq b\right]$, generally do not apply. This insight will prove essential to understanding the differences between SV beta and other measures of downside beta.

\section{B. Asymmetric Response Model (ARM)}

Regular betas are often computed by estimating "characteristic lines" using linear regression analysis. Harlow and Rao (1989) design a regression model to estimate the betas of a general lower partial-moments equilibrium model. Unfortunately, this asymmetric response model (ARM) generally does not produce the correct lower partial-moments betas.

Applying their model to the case of SV and using our notation, Harlow and Rao (1989, Eq. 10) employ the following bivariate regression model to estimate their downside beta:

$$
R_{i}=\alpha_{A R M, i}+\beta_{A R M, i} X+\gamma_{A R M, i} Z+\varepsilon_{i},
$$


where $X \equiv\left(R_{M} 1_{R_{M} \leq 0}+E\left[R_{M} \mid R_{M}>0\right] 1_{R_{M}>0}\right)$ and $Z \equiv\left(R_{M} 1_{R_{M}>0}-E\left[R_{M} \mid R_{M}>0\right] 1_{R_{M}>0}\right)$. In these regressors, $1_{R_{M} \leq 0}$ is a market-down dummy and $1_{R_{M}>0}$ is a market-up dummy. The expected values of these dummies are the probabilities of downs and ups: $E\left[1_{R_{M} \leq 0}\right]=\operatorname{Pr}\left[R_{M} \leq 0\right], \quad E\left[1_{R_{M}>0}\right]=\operatorname{Pr}\left[R_{M}>0\right]$; the expected values of the regressors are simply $E[X]=E\left[R_{M}\right]$ and $E[Z]=0$.

Since $X$ and $Z$ are independent by construction, the ARM beta equals the univariate regression coefficient for $X$ :

$$
\begin{aligned}
\beta_{A R M, i} & =\frac{E\left[X R_{i}\right]-E[X] E\left[R_{i}\right]}{E\left[X^{2}\right]-E[X]^{2}} \\
& =\frac{E\left[R_{M} R_{i} \mid R_{M} \leq 0\right] \operatorname{Pr}\left[R_{M} \leq 0\right]+E\left[R_{M} \mid R_{M}>0\right] E\left[R_{i} \mid R_{M}>0\right] \operatorname{Pr}\left[R_{M}>0\right]-E\left[R_{M}\right] E\left[R_{i}\right]}{E\left[R_{M}^{2} \mid R_{M} \leq 0\right] \operatorname{Pr}\left[R_{M} \leq 0\right]+E\left[R_{M} \mid R_{M}>0\right]^{2} \operatorname{Pr}\left[R_{M}>0\right]-E\left[R_{M}\right]^{2}} .
\end{aligned}
$$

In contrast to the SV beta, this expression includes several terms that are affected by the return values during market upswings. These terms enter because the ARM regressor takes a non-zero value during market upswings, that is, $X=E\left[R_{M} \mid R_{M}>0\right]$. This is a first indication that the ARM beta may not be a pure measure of downside risk, but rather mixes upside deviations and downside deviations.

Assuming that the M-SV model applies, it can be shown that the two betas are identical if and only if the following condition applies:

$$
E\left[R_{i} \mid R_{M}>0\right]=\beta_{S V, i} E\left[R_{M} \mid R_{M}>0\right] .
$$

This equation basically assumes that the unconditional risk-return relation (2.3) also applies during market upswings. In this case, the upswing terms in Equation (2.5) can be shown to cancel out and do not affect the definition of downside beta. Unfortunately, this condition generally is violated if the stock has a different market beta for losses than for gains. Hence, the ARM beta $\beta_{A R M, i}$ generally differs from the SV beta $\beta_{S V, i}$.

The ARM beta not only reflects co-movements during market downswings, but also co-movements during market upswings, because the $\mathrm{ARM}$ regressor equals the conditional average market return $X=E\left[R_{M} \mid R_{M}>0\right]$ during upswings. The ARM beta will therefore be higher if the stock yields higher returns during market upswings. Indeed, the ARM regressor generally 
is highly correlated with the market return and the ARM beta is highly correlated with the regular market beta. The numerical example below and the empirical results in Section 2.3 will further illustrate this point.

\section{Downside Covariance (DC) Beta}

Some earlier studies interpret downside beta as the standardized covariance during a falling market: 10

$$
\begin{aligned}
\beta_{D C, i} & \equiv \frac{\operatorname{Cov}\left[R_{i}, R_{M} \mid R_{M} \leq 0\right]}{\operatorname{Var}\left[R_{M} \mid R_{M} \leq 0\right]} \\
& =\frac{E\left[R_{M} R_{i} \mid R_{M} \leq 0\right]-E\left[R_{M} \mid R_{M} \leq 0\right] E\left[R_{i} \mid R_{M} \leq 0\right]}{E\left[R_{M}^{2} \mid R_{M} \leq 0\right]-E\left[R_{M} \mid R_{M} \leq 0\right]^{2}} .
\end{aligned}
$$

Whereas the definition of SV beta is based on a second-order lower partial moment, this definition is based on a conditional measure of variance. This means that returns during down markets are computed in deviation of the average return during down markets, and that the central tendency of losses plays no role in the definition of risk. This property is not consistent with the criterion of monotonicity for coherent risk measures (see, e.g, Artzner et al., 1999); lowering the mean return during market losses increases the value of coherent risk measures, but it does not affect downside variance. Related to this, a portfolio model that balances mean return and downside variance would not be consistent with non-satiation and risk aversion, two basic criteria for investor preferences. In addition, the implied pricing kernel of an equilibrium model that balances mean return against DC beta would not always be positive and decreasing, contrary to what asset pricing theories require.

Similar to SV beta, DC beta relies on the market-down observations only. However, DC beta estimates generally are substantially less reliable than SV beta estimates, because they rely on the expected returns during down markets. Unfortunately, these conditional expected values are difficult to estimate in a small sample as the distribution of market losses is highly negatively skewed (the mode is close to zero). In our sample, the migration

\footnotetext{
10 Ang et al. (2006a) use the mean excess market return $\left(E\left[R_{M}\right]\right)$ rather than zero as the threshold for excess returns. An excess return of zero is the relevant threshold value in the MSV equilibrium model. Still, our arguments apply with equal strength for every target rate of return. Furthermore, the empirical effect of replacing the riskless rate with the mean market return typically is very small.
} 
frequencies of 60-month estimates for DC beta are substantially higher than the values for 60-month estimates of regular beta and SV beta. In addition, finding accurate DC beta estimates seems to require a window size that is not available for most stocks in our sample.

The conditional-covariance and SV definitions are equivalent if and only if the following condition applies:

$$
E\left[R_{i} \mid R_{M} \leq 0\right]=\beta_{S V, i} E\left[R_{M} \mid R_{M} \leq 0\right] .
$$

Similar to Equation (2.6), this equation is a conditional version of the unconditional cross-sectional relation (2.3). The relation is now assumed to apply also during market downturns. In this case, the above problem of ignoring the central tendency of losses indeed does not affect the definition of risk. Unfortunately, the conditional relation generally does not hold when a stock has an asymmetric risk profile. Consequently, the DC beta $\beta_{D C, i}$ generally differs from the SV beta $\beta_{S V, i}$.

\section{Numerical Example}

The differences between the three downside betas can be demonstrated by means of a simple example with a market index and an at-the-money call option on the market index. This setup represents for example an index investor who considers writing covered call options to generate additional income without increasing downside risk. For simplicity, we consider only four states-of-the-world of equal probability and assume that the riskless rate is zero. The returns are as follows:

\begin{tabular}{cccc}
\hline State & Prob. & ATM Call Option $\left(R_{i}\right)$ & Market Index $\left(R_{M}\right)$ \\
\hline 1 & $25 \%$ & $-100 \%$ & $-15 \%$ \\
2 & $25 \%$ & $-100 \%$ & $-5 \%$ \\
3 & $25 \%$ & $+110 \%$ & $+15 \%$ \\
4 & $25 \%$ & $+250 \%$ & $+25 \%$ \\
\hline
\end{tabular}

For a classical binomial distribution with two states-of-the-world, the payoffs of the call option can be replicated by investing in the market index and borrowing, and the equilibrium value of the option is independent of the risk preferences. In our example with four states-of-the-world, this result does not 
apply. We have set the market price of the option at $1 / 14^{\text {th }}$ of the value of the market index, in order to be consistent with the M-SV equilibrium model.

The following table is helpful for computing the various betas:

\begin{tabular}{cccccccccc}
\hline State & Prob. & $R_{i}$ & $R_{M}$ & $X$ & $R_{i}^{2}$ & $R_{M}^{2}$ & $X^{2}$ & $R_{i} R_{M}$ & $R_{i} X$ \\
\hline 1 & $25 \%$ & -100 & -15 & -15 & 10,000 & 225 & 225 & 1,500 & 1,500 \\
2 & $25 \%$ & -100 & -5 & -5 & 10,000 & 25 & 25 & 500 & 500 \\
3 & $25 \%$ & 110 & 15 & 20 & 12,100 & 225 & 400 & 1,650 & 2,200 \\
4 & $25 \%$ & 250 & 25 & 20 & 62,500 & 625 & 400 & 6,250 & 5,000 \\
& & & & & & & & & \\
$E[\cdot]$ & & 40 & 5 & 5 & 23,650 & 275 & 262.5 & 2,475 & 2,300 \\
$E\left[\cdot \mid R_{M} \leq 0\right]$ & & -100 & -10 & -10 & 10,000 & 125 & 125 & 1,000 & 1,000 \\
$E\left[\cdot \mid R_{M}>0\right]$ & & 180 & 20 & 20 & 37,300 & 425 & 400 & 3,950 & 3,600 \\
\hline
\end{tabular}

The regular market beta in this case amounts to

$$
\beta_{R, i}=\frac{E\left[R_{i} R_{M}\right]-E\left[R_{i}\right] E\left[R_{M}\right]}{E\left[R_{M}^{2}\right]-E\left[R_{M}\right]^{2}}=\frac{2,475-40 \cdot 5}{275-5^{2}}=9.1
$$

This value is higher than the regular beta of a typical stock, because the call option involves more extreme negative and positive returns than a typical stock. The effect of including a call option in the portfolio is however mitigated by the value of the call option being only a fraction of that of the underlying index.

Since the call option is more sensitive to the market index when the market index goes up than when it goes down, we may expect the downside betas to give lower values. Indeed, the SV beta in this case takes the following value:

$$
\beta_{S V, i}=\frac{E\left[R_{i} R_{M} \mid R_{M} \leq 0\right]}{E\left[R_{M}^{2} \mid R_{M} \leq 0\right]}=\frac{1,000}{125}=8.0 .
$$

Thus, buying a dollar worth of call options adds eight times as much downside risk as investing a dollar in the market index. Conversely, writing a dollar worth of call options offsets the downside risk of eight dollars invested in the market index. 
This example is constructed to be consistent with the M-SV equilibrium model, that is, to obey the unconditional equality (2.3). However, the conditional equality (2.6) does not apply, because the call option has an asymmetric risk profile. Indeed, the ARM beta differs from the SV beta:

$$
\beta_{A R M, i}=\frac{E\left[R_{i} X\right]-E\left[R_{i}\right] E[X]}{E\left[X^{2}\right]-E[X]^{2}}=\frac{2,300-40 \cdot 5}{262.5-5^{2}}=8.8
$$

This value is close to that of the regular market beta. This is not surprising given that the correlation between the ARM regressor and the market return is $97.5 \%$ in this example.

The asymmetric risk profile of the call option also implies that the conditional equality (2.8) is violated. Hence, the conditional-covariance beta also differs from the SV beta:

$$
\beta_{D C, i}=\frac{E\left[R_{i} R_{M} \mid R_{M} \leq 0\right]-E\left[R_{i} \mid R_{M} \leq 0\right] E\left[R_{M} \mid R_{M \leq 0}\right]}{E\left[R_{M}^{2} \mid R_{M} \leq 0\right]-E\left[R_{M} \mid R_{M} \leq 0\right]^{2}}=\frac{1,000-(-100) \cdot(-10)}{125-(-10)^{2}}=0.0 .
$$

The value of zero suggests that a long position in the call option would reduce downside risk. Although the call option reduces the uncertainty about the magnitude of possible losses (which is always -100\%), it does not reduce the probability of those losses and clearly increases the magnitude of the losses.

\section{E. Implied Pricing Kernels}

The equilibrium relation (2.3) is the first-order condition for M-SV portfolio optimization. It can be rewritten as

$$
E\left[\theta_{S V}\left(R_{M}\right) R_{i}\right]=0
$$

using the following piecewise linear pricing kernel:

$$
\theta_{S V}(x)=\left\{1-\left[\frac{E\left[R_{M}\right]}{E\left[R_{M}^{2} \mid R_{M} \leq 0\right] \operatorname{Pr}\left[R_{M} \leq 0\right]}\right] x \quad \begin{array}{rl}
1 & x \leq 0 \\
1 & x
\end{array}\right.
$$

This formulation is useful because it highlights which joint values of the stock return and the market return are assigned the highest weight in the risk- 
return trade-off. One possible interpretation of this kernel is that it represents the marginal utility function of the representative investor. Indeed, the function exhibits all properties of a well-behaved marginal utility function: it is positive, decreasing and convex, necessary conditions for non-satiation, global risk aversion and decreasing absolute risk aversion (DARA).

The economic justification for the ARM and DC betas is not immediately clear. Still, we can infer the pricing kernel that would be implied by a model that replaces the SV beta with one of these betas in the equilibrium relation (2.3). If we replace the SV beta with the ARM beta, the implied pricing kernel is:

$$
\theta_{A R M}(x)=\left\{\begin{array}{cc}
1-\left[\frac{E\left[R_{M}\right]}{\operatorname{Var}[X]}\right]\left(x-E\left[R_{M}\right]\right) & x \leq 0 \\
1-\left[\frac{E\left[R_{M}\right]}{\operatorname{Var}[X]}\right]\left(E\left[R_{M} \mid R_{M}>0\right]-E\left[R_{M}\right]\right) & x>0 .
\end{array}\right.
$$

This kernel generally exhibits a discontinuity at $x=0$, where the kernel drops by an amount of $\left[\frac{E\left[R_{M}\right]}{\operatorname{Var}[X]}\right] E\left[R_{M} \mid R_{M}>0\right]$. Clearly, such a drop would violate convexity, a necessary condition for decreasing absolute risk aversion.

If we replace the $\mathrm{SV}$ beta with the DC beta, the implied pricing kernel changes as follows:

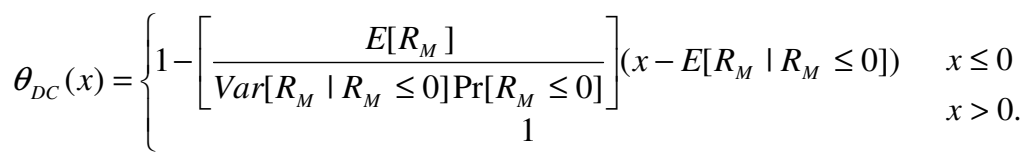

This kernel generally is steeper in the loss domain than the SV kernel, because the slope is based on the downside variance $\operatorname{Var}\left[R_{M} \mid R_{M} \leq 0\right]$ rather than the downside second moment $E\left[R_{M}^{2} \mid R_{M} \leq 0\right]$. In addition, the kernel generally exhibits a discontinuous jump at $x=0$ from $\theta_{D C}(0)<1$ to $\lim _{x \downarrow 0} \theta_{D C}(x)=1$. This jump generally leads to violations of risk aversion and convexity.

Figure 2.1 shows the three pricing kernels associated with the empirical distribution of monthly excess returns to the CSRP total return index from January 1926 to December 2010. For the sake of comparison, the kernels have 


\section{Figure 2.1: Pricing Kernels}

This figure shows three different pricing kernels implied by the SV beta, ARM beta and DC beta, respectively. These pricing kernels are associated with the empirical distribution of monthly excess returns to the CRSP total return index from January 1926 to December 2010 (1020 monthly observations). The kernels have been normalized to have an average value of one. The pricing kernel implied by the regular beta is plotted in grey.

Panel A: SV-beta kernel

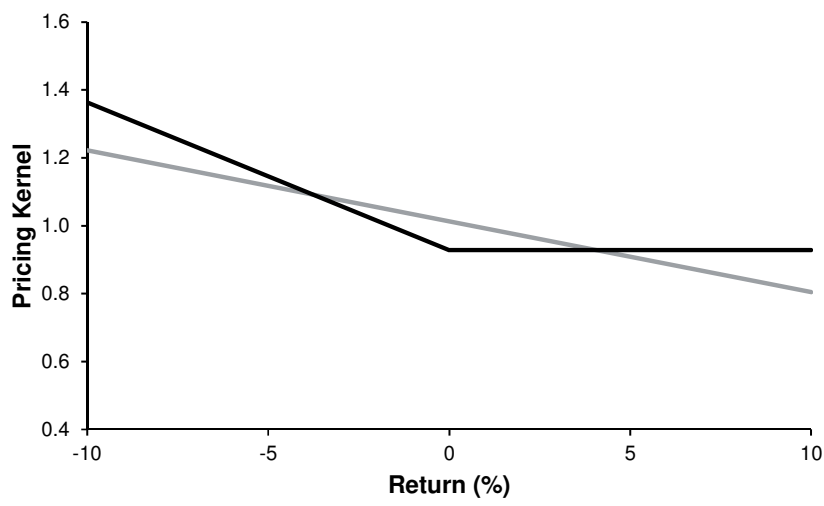

Panel B: ARM-beta kernel

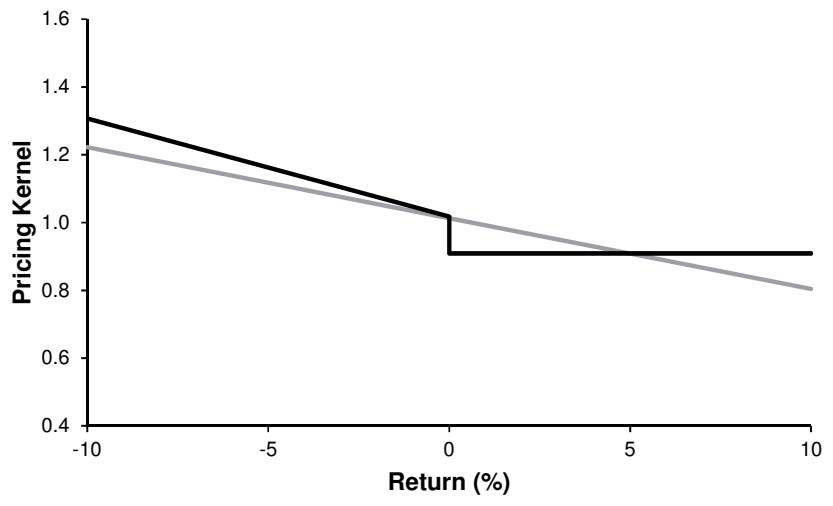

Panel C: DC-beta kernel

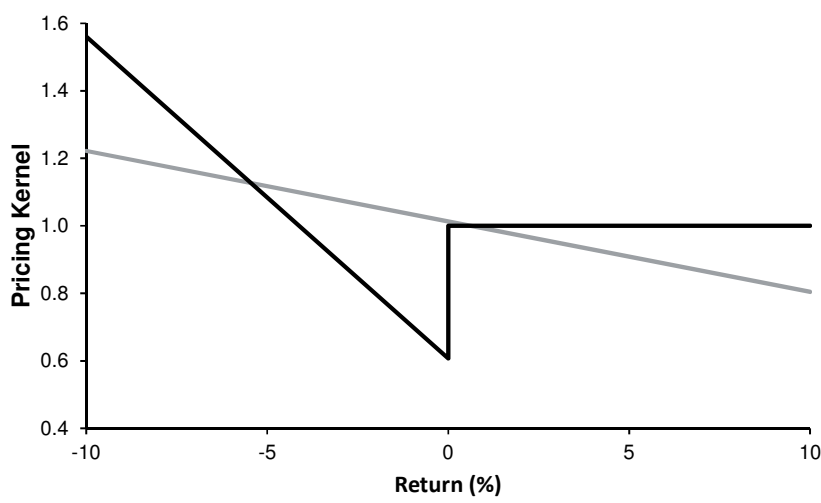


been normalized to have an average value of one and they are plotted against the standard, linear kernel associated with the regular beta. Clearly, the three kernels differ in a non-trivial way. The SV kernel assigns much higher weights to losses than the regular kernel. Still, the kernel is "well-behaved"- positive, decreasing and convex. Interestingly, the ARM kernel lies somewhere between the regular kernel and the SV kernel, confirming our earlier conclusion that the ARM beta generally measures upside risk in addition to downside risk. As expected, the ARM kernel exhibits a discontinuous drop at $x=0$, violating convexity. The shape of the DC kernel is even more problematic, showing a large discontinuous jump at $x=0$, introducing risk seeking on a very large return range. Clearly, this kernel is not economically meaningful and one may therefore question whether the DC-beta definition is suitable for investment analysis.

\subsection{Data and Methodology}

In our empirical analysis, we use monthly stock returns (including dividends and capital gains) and information on stocks' market capitalization (price times number of shares outstanding) and monthly trading volumes from the Center for Research in Security Prices (CRSP). The CRSP total return index is used as the market index and the one-month U.S. Treasury bill rate from Ibbotson and Associates is used as the riskless rate. For the book values of equity, we make use of two different sources: the Compustat database and the Moody's Industrial Manuals.

In practice, regular beta and the three downside-beta measures are highly correlated. In addition, the analysis needs to control for several other stock characteristics that are known to affect the cross-sectional variation of expected stock returns, including firm-level Size, Value and past return measures. To disentangle the effects of the competing stock characteristics, our main analysis will use the multivariate regression methodology of Fama and MacBeth (1973), which is used nowadays not only in asset pricing but also in many other areas of finance, accounting and economics. Shanken (1992), Jagannathan and Wang (1998), Shanken and Zhou (2007) and Petersen (2009) provide important discussions of the statistical properties and performance of this approach. The Fama and MacBeth analysis can establish whether there exists a positive cross-sectional, out-of-sample relation between expected returns on the one hand and the four beta measures on the other hand. We stress that we do not try to test whether the intercept of the relation is zero 
and the slope equals the equity premium, as is assumed in Equation (2.3). These particular coefficient values arise only under strong simplifying assumptions, such as the possibility to borrow against the riskless rate, and a positive beta-return relation applies more generally. In addition, the presence of other stock characteristics affects the relation between beta and expected returns.

The four measures of market beta are estimated using the conventional estimation period of the past 60 months. As discussed in Section 2.1A, the DC beta (and to a lesser extent also the SV beta) could benefit from using a longer estimation period, in order to include more market-down observations. However, the effect of additional observations quickly diminishes (by the square-root-of-N law). In addition, extending the estimation period also reduces the cross-section of stocks for which the required observations are available, which would make it more difficult to compare the results with existing studies.

Our analysis controls for a series of stock characteristics that are commonly used in the empirical asset pricing literature: Size, Value, Momentum, Reversal, Idiosyncratic Volatility, Co-skewness and Illiquidity. Size is measured as the logarithm of market capitalization (price times the number of shares outstanding) at the end of the previous month. Value is measured using the logarithm of the Book-to-Market ratio (BtM), defined as the book value of common equity of previous calendar year's fiscal year-end divided by the market value of equity at the end of previous calendar year, updated at the end of June each year. For Momentum and Reversal, we use the Fama and French (1996) past eleven-month returns lagged one month $\left(\mathrm{R}_{12-1}\right)$ and past 48 -month returns lagged twelve months $\left(\mathrm{R}_{60-12}\right)$ definitions, respectively. Idiosyncratic Volatility (IVol) is estimated over a 60-month period with respect to the market model. Co-skewness is estimated over a 60-month period using the definition of Kraus and Litzenberger (1976). Following Amihud (2002), we control for Illiquidity measured as the sum over the previous twelve months absolute returns divided by the monthly dollar volume of shares traded.

Following the convention, our analysis focuses on ordinary common U.S. stocks listed on the New York Stock Exchange (NYSE), American Stock Exchange (AMEX) and Nasdaq markets, excluding ADRs, REITs, closed-endfunds, units of beneficial interest, and foreign stocks. We require a stock to have 60 months of monthly observations for estimating the betas (and some 
other stock characteristics). A stock is excluded from the analysis if price information is no longer available. In that case, the delisting return or partial monthly return provided by CRSP is used as the last return observation.

Following Fama and French (2008), among many others, we include an additional analysis without micro-cap stocks, defined here as stocks with a market capitalization below the 20th size percentile of NYSE stocks. Together, the micro-cap stocks represent less than 1.5 percent of the total market capitalization in the average month in our sample. Relatively high transaction costs and low liquidity further reduce the economic relevance of this market segment. In addition, data for this market segment are known to be relatively noisy and contain anomalous patterns that seem to defy rational explanation and could potentially drive our results.

Our analysis is based on the period from January 1931 to December 2010, drawing also on the period from January 1926 to December 1930 to estimate the betas for January 1931 to December 1935. This long sample period seems particularly useful for a study of downside risk, because it includes the bear market of the 1930s in addition to the bear markets of the 1970s and 2000s. The data before 1963 is sometimes excluded from the analysis to avoid known biases associated with the Compustat database, which is the usual source of data on the book value of equity. We therefore complement the Compustat data, for which book values are not available prior to 1950 , with Moody's data. ${ }^{11}$ In addition, we analyze the robustness of our results in the later period from July 1963 to December 2010, as for this period the Compustat data is generally considered to be reliable and these results are more easily compared with many other studies that focus on the post-1963 sample.

\subsection{Stock-Level Results}

Panel A of Table 2.1 shows a correlation matrix for the betas and other stock characteristics in our analysis. The correlation between the regular beta and the SV beta of individual stocks is 85 percent in our sample. By contrast, the correlation between the regular beta and the ARM beta is as high as 94 percent. This illustrates our earlier point that the ARM beta picks up upside potential in addition to downside risk and has limited use as a downside

11 The hand-collected data from the Moody's Industrial Manuals is taken from Kenneth French' website and is explained in more detail in Davis et al. (2000). 


\section{Table 2.1: Descriptive Statistics}

Panel A shows time-series average correlations between regular beta $\left(\beta_{\mathrm{R}}\right)$, SV beta $\left(\beta_{\mathrm{sv}}\right)$, ARM beta $\left(\beta_{\mathrm{ARM}}\right), \mathrm{DC}$ beta $\left(\beta_{\mathrm{DC}}\right)$, and other stock characteristics. The (regular or downside) betas are estimated using the past 60 months of returns. The other stock characteristics include the firm's log market capitalization (Size), the log book-to-market ratio (BtM), one-month lagged 11-month return $\left(R_{12-1}\right)$, past 60 -month idiosyncratic volatility $(I \mathrm{Vol})$, past 60 -month coskewness $(C o s k)$, 12-month lagged 48-month return $\left(R_{60-12}\right)$, and past 12-month illiquidity (Illiq). Panel B shows historical migration frequencies for beta quintiles. At the end of every 60-month period, all stocks are sorted into quintiles based on one of the four beta measures. The migration frequencies measure the relative frequency with which stocks that are allocated to a particular quintile migrate to another quintile in the first non-overlapping sample, or 60 months later. The sample period is from January 1931 to December 2010 (960 months) and the sample consists of all common NYSE, AMEX and Nasdaq stocks that satisfy our criteria.

Panel A: Time-Series Average Correlations

\begin{tabular}{lccccccccccc} 
& $\beta_{R}$ & $\beta_{S V}$ & $\beta_{A R M}$ & $\beta_{D C}$ & Size & BtM & $R_{12-1}$ & IVol & Cosk & $R_{60-12}$ & Illiq \\
\hline$\beta_{R}$ & 1.00 & 0.85 & 0.94 & 0.56 & -0.14 & 0.05 & -0.01 & 0.48 & 0.38 & 0.04 & 0.00 \\
$\beta_{S V}$ & & 1.00 & 0.93 & 0.70 & -0.21 & 0.13 & -0.15 & 0.40 & 0.45 & -0.21 & 0.04 \\
$\beta_{A R M}$ & & & 1.00 & 0.62 & -0.17 & 0.06 & -0.03 & 0.48 & 0.45 & 0.01 & 0.01 \\
$\beta_{D C}$ & & & & 1.00 & -0.14 & 0.01 & 0.00 & 0.33 & 0.50 & 0.05 & 0.00
\end{tabular}

Panel B: Transition Frequencies

\begin{tabular}{lccccc} 
& Low & Q2 & Q3 & Q4 & High \\
\hline Regular Beta Quintiles & & & & & \\
Low $(\mathrm{t}+60)$ & $\mathbf{0 . 5 1}$ & 0.24 & 0.12 & 0.07 & 0.04 \\
Q2 $(\mathrm{t}+60)$ & 0.25 & $\mathbf{0 . 2 9}$ & 0.24 & 0.16 & 0.09 \\
Q3 $\mathrm{t}+60)$ & 0.13 & 0.24 & $\mathbf{0 . 2 7}$ & 0.25 & 0.16 \\
Q4 $(\mathrm{t}+60)$ & 0.07 & 0.15 & 0.23 & $\mathbf{0 . 2 9}$ & 0.27 \\
High $(\mathrm{t}+60)$ & 0.04 & 0.07 & 0.13 & 0.23 & $\mathbf{0 . 4 4}$ \\
SV Beta Quintiles & & & & & \\
Low $(\mathrm{t}+60)$ & $\mathbf{0 . 4 2}$ & 0.25 & 0.14 & 0.10 & 0.06 \\
Q2 $\mathrm{t}+60)$ & 0.26 & $\mathbf{0 . 2 8}$ & 0.23 & 0.17 & 0.10 \\
Q3 $(\mathrm{t}+60)$ & 0.16 & 0.22 & $\mathbf{0 . 2 6}$ & 0.24 & 0.16 \\
Q4 $(\mathrm{t}+60)$ & 0.10 & 0.16 & 0.22 & $\mathbf{0 . 2 6}$ & 0.26 \\
High $(\mathrm{t}+60)$ & 0.06 & 0.09 & 0.14 & 0.23 & $\mathbf{0 . 4 1}$ \\
ARM Beta Quintiles & & & & & \\
Low $(\mathrm{t}+60)$ & $\mathbf{0 . 5 0}$ & 0.25 & 0.12 & 0.08 & 0.04 \\
Q2 $(\mathrm{t}+60)$ & 0.25 & $\mathbf{0 . 2 9}$ & 0.25 & 0.17 & 0.09 \\
Q3 $(\mathrm{t}+60)$ & 0.13 & 0.24 & $\mathbf{0 . 2 7}$ & 0.25 & 0.16 \\
Q4 $(\mathrm{t}+60)$ & 0.08 & 0.15 & 0.23 & $\mathbf{0 . 2 8}$ & 0.27 \\
High $(\mathrm{t}+60)$ & 0.04 & 0.07 & 0.14 & 0.23 & $\mathbf{0 . 4 3}$ \\
DC Beta Quintiles & & & & & \\
Low $(\mathrm{t}+60)$ & $\mathbf{0 . 2 8}$ & 0.24 & 0.20 & 0.16 & 0.13 \\
Q2 $(\mathrm{t}+60)$ & 0.25 & $\mathbf{0 . 2 4}$ & 0.22 & 0.19 & 0.15 \\
Q3 $(\mathrm{t}+60)$ & 0.20 & 0.22 & $\mathbf{0 . 2 2}$ & 0.21 & 0.19 \\
Q4 $(\mathrm{t}+60)$ & 0.16 & 0.18 & 0.20 & $\mathbf{0 . 2 2}$ & 0.24 \\
High $(\mathrm{t}+60)$ & 0.12 & 0.13 & 0.16 & 0.21 & $\mathbf{0 . 2 9}$ \\
\hline
\end{tabular}

risk measure (see Section 2.1B). Not surprisingly, our empirical results for regular beta and ARM beta are very similar, and, for the sake of brevity, we will therefore not discuss the ARM results separately (although our tables will still include these results). The correlation between the SV beta and the DC beta is only 70 percent. As discussed above, the divergence between these two 
betas arises from DC beta being invariant to the central tendency of losses (see Section 2.1C).

The betas are not independent of the other stock characteristics. If these characteristics carry a premium, the correlations may affect the estimation of the beta premiums, introducing the need for a multivariate analysis. Not surprisingly, small-cap stocks are associated with higher beta risk than large caps. This relation is strongest for the SV beta and the DC beta. Interestingly, the correlation between beta and BtM is negative for regular beta and DC beta, but positive for SV beta. A possible explanation for this pattern is that the default risk of (some) high BtM stocks introduces downside risk without comparable upside potential, creating an asymmetric risk profile. The SV beta correlates negatively with the past return measures $R_{12-1}$ and $R_{60-12}$. By construction, the SV beta of a stock tends to be lower (higher) if the stock's average return in the beta estimation period is higher (lower), all else equal. ${ }^{12}$ A similar negative correlation does not arise for regular-beta, DC-beta and ARM-beta estimates, because these estimates rely on returns in excess of the average return. Not surprisingly, the betas are highly positively correlated with IVol. Similar to regular beta, IVol is based on all observations, and hence the correlation with regular beta is higher than with SV beta and DC beta which are based on the market-down observations only. There also exists a positive correlation between the betas and Co-skewness; high-beta stocks to increase not only the variance but also the skewness of a portfolio. The betas are not correlated with the illiquidity measure.

Panel B shows historical migration frequencies for the four betas. For example, a stock that falls in the first quintile of regular beta estimates in a given month, has a 51 percent chance of falling in the same quintile 60 months later, and there is a four percent chance of migrating to the fifth quintile. Despite the SV beta estimates being based on only 24 market-down observations on average, the migration frequencies for SV beta are only slightly higher than for regular beta. This finding presumably reflects the higher correlation of stock returns with market returns during market downswings. By contrast, the migration frequencies for DC beta estimates (also based on 24 market-down observations) are substantially higher than for

\footnotetext{
${ }^{12}$ For example, increasing all returns of a stock with a fixed value of $\mathrm{c}>0$, decreases the stock's SV beta (2) with a value of $c \frac{E\left[R_{M} \mid R_{M} \leq 0\right]}{E\left[R_{M}^{2} \mid R_{M} \leq 0\right]}<0$. This term is strictly negative, because $c>0$, $E\left[R_{M} \mid R_{M} \leq 0\right]<0$ and $E\left[R_{M}^{2} \mid R_{M} \leq 0\right]>0$.
} 
regular beta and SV beta. For example, there is a 12 percent chance of migrating to the first quintile of DC beta estimates to the fifth quintile in a 60 month period. This pattern presumably reflects the difficulty of estimating expected market-down stock returns based on a small sample.

The results of the Fama-MacBeth regressions in Table 2.2 show that the estimated SV-beta premium dominates the premiums for the other betas, in terms of both economic and statistical significance. The top panel shows the results of univariate regressions with only one of the four betas as regressor. Consistent with Fama and French (1992), the first regression finds a flat and insignificant relation between average return and regular beta; the beta premium is estimated to be 20 basis points per month, or 2.40 percent per annum, with a $t$-statistic of 1.40 . Interestingly, the relation between risk and return is restored when regular beta is replaced by SV beta; the monthly SVbeta premium is 44 basis points, or 5.28 percent per annum $(t$-statistic $=2.55)$. The DC beta yields a more modest monthly premium of 24 basis points, or 2.88 percent per annum $(t$-statistic $=2.79)$, a first indication that it is less relevant as a risk measure for stocks.

The second panel shows the results of a multivariate regression that includes Size, BtM and $\mathrm{R}_{12-1}$ as additional regressors. Consistent with what is documented elsewhere in the empirical literature, we find a significantly negative premium for Size and significantly positive premiums for BtM and $\mathrm{R}_{12-1}$. The inclusion of these variables reduces the estimated beta premiums by 1.32 to 1.80 percent per annum. The smallest reduction occurs for SV beta, which remains economically significant (3.96 percent per annum) and statistically significant $(t$-statistic $=2.67)$. The premiums for the other betas have minimal economic or statistical significance in the multivariate regressions. Compared with the regular-beta premium, the SV-beta premium benefits from the negative correlation between $\mathrm{SV}$ beta and $\mathrm{R}_{12-1}$ (combined with the momentum premium), although that effect is partly undone by the positive correlation with BtM (and the value premium).

Adding IVol and Co-skewness does not change these conclusions. In fact, the most notable effect is to further increase the estimated SV beta premium and its level of statistical significance. This improvement is largely attributable to the combined effect of Size and IVol. High-beta stocks include relatively many small, high-IVol stocks, which have an abnormally low return in our sample (see also Ang et al., 2006b). Interestingly, there is a significantly positive premium for Co-skewness when regular beta or DC beta are 
Table 2.2: Stock-Level Cross-Sectional Regressions

This table presents results of Fama and MacBeth (1973) regressions of monthly excess stock returns on individual firm characteristics. Cross-sectional regressions are performed each month from January 1931 to December 2010 (960 months). The sample consists of all common NYSE, AMEX and Nasdaq stocks. In the top panel, the independent variable is one of the four beta measures estimated using past 60-month returns: regular beta $\left(\beta_{\mathrm{R}}\right)$, SV beta $\left(\beta_{\mathrm{SV}}\right)$, ARM beta $\left(\beta_{\mathrm{ARM}}\right)$, or DC beta $\left(\beta_{\mathrm{DC}}\right)$. The other panels present results of multivariate regressions that also include a combination of other firm characteristics including the firm's log market capitalization (Size), the log book-to-market ratio (BtM), one-month lagged 11month return $\left(R_{12-1}\right)$, past 60 -month idiosyncratic volatility $(I V o l)$, past 60 -month co-skewness $(C o s k), 12$ month lagged 48 -month return $\left(R_{60-12}\right)$, and/or past 12 -month illiquidity $($ Illiq). The reported coefficients are time-series averages of the monthly regression slopes multiplied by 100 . The Newey-West corrected $t$ statistics of these averages are shown in italic below the estimated coefficients. The adjusted $\mathrm{R}^{2}$ of the regression model is reported in the final column. The bottom two rows report the time-series averages of the explanatory variables as well as the time-series average standard deviations. All the independent variables are Winsorized each month at the $1 \%$ and $99 \%$ level. Asterisks $* * *$ or $* * *$ indicate that the (downside) beta premium is statistically significant at the $10 \%, 5 \%$ and $1 \%$ significance levels, respectively.

\begin{tabular}{|c|c|c|c|c|c|c|c|c|c|c|c|c|c|}
\hline & Const & $\beta_{R}$ & $\beta_{S V}$ & $\beta_{\text {ARM }}$ & $\beta_{D C}$ & Size & $B t M$ & $R_{12-1}$ & IVol & Cosk & $R_{60-12}$ & Illiq & R-sq \\
\hline \multirow[t]{2}{*}{$\beta_{R}$} & 0.83 & 0.20 & & & & & & & & & & & $2.97 \%$ \\
\hline & 5.09 & 1.40 & & & & & & & & & & & \\
\hline \multirow[t]{2}{*}{$\beta_{S V}$} & 0.57 & & $0.44^{* * * *}$ & & & & & & & & & & $2.85 \%$ \\
\hline & 3.28 & & 2.55 & & & & & & & & & & \\
\hline \multirow[t]{2}{*}{$\beta_{A R M}$} & 0.75 & & & $0.28^{*}$ & & & & & & & & & $3.00 \%$ \\
\hline & 4.47 & & & 1.78 & & & & & & & & & \\
\hline \multirow[t]{2}{*}{$\beta_{D C}$} & 0.81 & & & & $0.24^{* * * *}$ & & & & & & & & $1.44 \%$ \\
\hline & 3.77 & & & & 2.79 & & & & & & & & \\
\hline \multirow[t]{2}{*}{ All } & 0.67 & -0.19 & $2.02^{* * *}$ & $-1.22^{* *}$ & $-0.22^{*}$ & & & & & & & & $4.83 \%$ \\
\hline & 4.00 & -0.78 & 2.88 & -2.01 & -1.68 & & & & & & & & \\
\hline \multirow[t]{2}{*}{$\beta_{R}$} & 2.75 & 0.06 & & & & -0.18 & 0.21 & 0.80 & & & & & $6.55 \%$ \\
\hline & 5.55 & 0.52 & & & & -4.50 & 3.74 & 4.09 & & & & & \\
\hline \multirow[t]{2}{*}{$\beta_{S V}$} & 2.43 & & $0.33^{* * *}$ & & & -0.17 & 0.21 & 0.98 & & & & & $6.43 \%$ \\
\hline & 4.94 & & 2.67 & & & -4.28 & 3.61 & 5.97 & & & & & \\
\hline \multirow[t]{2}{*}{$\beta_{A R M}$} & 2.70 & & & 0.13 & & -0.18 & 0.21 & 0.85 & & & & & $6.56 \%$ \\
\hline & 5.44 & & & 1.13 & & -4.50 & 3.94 & 4.79 & & & & & \\
\hline \multirow[t]{2}{*}{$\beta_{D C}$} & 2.66 & & & & 0.10 & -0.18 & 0.22 & 0.82 & & & & & $5.60 \%$ \\
\hline & 4.97 & & & & 1.45 & -4.31 & 3.74 & 4.20 & & & & & \\
\hline \multirow[t]{2}{*}{ All } & 2.60 & -0.13 & $2.70^{* * * *}$ & $-1.93^{* * *}$ & $-0.37^{* * *}$ & -0.18 & 0.06 & 1.32 & & & & & $7.47 \%$ \\
\hline & 5.40 & -0.58 & 4.93 & -3.79 & -3.75 & -4.59 & 0.97 & 7.91 & & & & & \\
\hline \multirow[t]{2}{*}{$\beta_{R}$} & 3.24 & 0.05 & & & & -0.21 & 0.18 & 0.83 & -2.84 & 0.13 & & & $7.44 \%$ \\
\hline & 7.84 & 0.44 & & & & -6.37 & 3.48 & 4.24 & -2.39 & 2.36 & & & \\
\hline \multirow[t]{2}{*}{$\beta_{S V}$} & 3.15 & & $0.41^{* * *}$ & & & -0.22 & 0.15 & 0.99 & -3.31 & -0.02 & & & $7.44 \%$ \\
\hline & 7.97 & & 3.42 & & & -6.49 & 2.88 & 5.59 & -2.69 & -0.38 & & & \\
\hline \multirow[t]{2}{*}{$\beta_{A R M}$} & 3.26 & & & 0.14 & & -0.21 & 0.18 & 0.85 & -3.00 & 0.08 & & & $7.44 \%$ \\
\hline & 7.94 & & & 1.26 & & -6.45 & 3.48 & 4.42 & -2.56 & 1.50 & & & \\
\hline \multirow[t]{2}{*}{$\beta_{D C}$} & 3.14 & & & & -0.03 & -0.20 & 0.18 & 0.78 & -2.35 & 0.15 & & & $6.86 \%$ \\
\hline & 7.77 & & & & -0.31 & -6.37 & 3.49 & 3.43 & -1.75 & 1.83 & & & \\
\hline \multirow[t]{2}{*}{ All } & 2.49 & -0.09 & $3.00^{* * * *}$ & $-2.28^{* * *}$ & $-0.50^{* * *}$ & -0.17 & 0.03 & 1.27 & 0.22 & 0.16 & & & $8.31 \%$ \\
\hline & 6.92 & -0.21 & 4.49 & -3.27 & -2.74 & -6.06 & 0.55 & 7.54 & 0.15 & 1.01 & & & \\
\hline \multirow[t]{2}{*}{$\beta_{R}$} & 2.79 & 0.08 & & & & -0.17 & 0.10 & 0.85 & -3.86 & 0.14 & -0.19 & 0.17 & $8.35 \%$ \\
\hline & 7.38 & 0.75 & & & & -6.14 & 2.15 & 4.21 & -3.25 & 2.73 & -2.24 & 2.46 & \\
\hline \multirow[t]{2}{*}{$\beta_{S V}$} & 2.73 & & $0.40^{* * *}$ & & & -0.18 & 0.10 & 1.01 & -4.39 & -0.01 & -0.12 & 0.18 & $8.40 \%$ \\
\hline & 7.40 & & 3.43 & & & -6.31 & 1.99 & 5.31 & -3.64 & -0.12 & -1.55 & 2.57 & \\
\hline \multirow[t]{2}{*}{$\beta_{A R M}$} & 2.81 & & & 0.16 & & -0.18 & 0.11 & 0.87 & -3.97 & 0.09 & -0.18 & 0.17 & $8.35 \%$ \\
\hline & 7.44 & & & 1.46 & & -6.22 & 2.18 & 4.40 & -3.38 & 1.74 & -2.19 & 2.50 & \\
\hline \multirow[t]{2}{*}{$\beta_{D C}$} & 2.67 & & & & 0.00 & -0.16 & 0.11 & 0.80 & -3.25 & 0.16 & -0.18 & 0.15 & $7.86 \%$ \\
\hline & 7.12 & & & & 0.01 & -6.04 & 2.24 & 3.42 & -2.36 & 1.86 & -2.28 & 2.17 & \\
\hline \multirow[t]{2}{*}{ All } & 2.16 & -0.02 & $5.27^{\kappa * *}$ & $-4.23^{* * *}$ & $-0.86^{* * *}$ & -0.14 & 0.06 & 1.85 & 0.29 & 0.11 & 0.57 & 0.17 & $9.17 \%$ \\
\hline & 5.73 & -0.06 & 6.32 & -5.14 & -4.59 & -5.38 & 1.18 & 9.33 & 0.20 & 0.82 & 6.33 & 2.52 & \\
\hline \multicolumn{2}{|c|}{ Average } & 1.17 & 1.11 & 1.16 & 1.18 & 11.14 & -0.18 & 0.11 & 0.10 & 1.29 & 0.55 & 2.13 & \\
\hline Stdev & & 0.54 & 0.58 & 0.54 & 0.79 & 1.82 & 0.80 & 0.37 & 0.05 & 2.70 & 1.10 & 6.78 & \\
\hline
\end{tabular}


included in the regression. A theory based on skewness preference would predict a Co-skewness discount rather than a premium. This co-skewness premium however disappears when SV beta is included, suggesting that Coskewness may work as a proxy for downside market risk rather than as a measure of upside market potential.

The bottom panel shows that adding Reversal and Illiquidity to the regression does not materially affect the results for the beta premiums. The coefficients of these two additional stock characteristics are consistent with what is documented in other studies: a significantly negative premium for $\mathrm{R}_{60-12}$, and a significantly positive premium for Illiquidity.

The bottom two rows of each panels show results of 'horse-race' regressions that include multiple betas simultaneously. Remarkably, in every regression that includes the SV beta, the SV-beta premium is positive and significant and the other beta premiums become negative and/or insignificant. ${ }^{13}$ These results suggest that SV beta captures priced risk that is not captured by the other betas, and the other betas don't capture any priced risk that is not captured by SV beta.

We have thus far analyzed our full cross-section of stocks and full sample period from July 1931 to December 2010. The question arises whether our results are robust to the cross-section and sample period under consideration. Table 2.3 summarizes the results after excluding micro-cap stocks and/or the early period from January 1931 to June 1963 from the sample. After excluding micro-caps, BtM, Co-skewness and Illiquidity no longer play a significant role and the premiums for Size, IVol and $R_{60-12}$ are also lower. The SV beta premium changes only by a few basis points per months, and it remains economically and statistically significant and dominates the other beta premiums. The results are also robust for excluding the early period from the sample. The only notable change is a general increase of the beta premiums in the multivariate regressions.

These sub-sample results further support our conclusion that downside risk is relevant for stock investors and that a stock's systematic downside risk is best measured using its SV beta.

\footnotetext{
13 To save space, the table only shows regressions with all four betas included. However, SV beta also drives out the other betas in regressions with any combination of only two or three betas.
} 
Table 2.3: Stock-Level Cross-Sectional Regressions: Subsample Results

This table presents results of Fama and MacBeth (1973) regressions of monthly excess stock returns on individual firm characteristics. The independent variables are one of the four beta measures estimated using past 60 -month returns: regular beta $\left(\beta_{\mathrm{R}}\right)$, SV beta $\left(\beta_{\mathrm{SV}}\right), \mathrm{ARM}$ beta $\left(\beta_{\mathrm{ARM}}\right)$, or DC beta $\left(\beta_{\mathrm{DC}}\right)$, and other firm characteristics including the firm's log market capitalization (Size), the log book-to-market ratio $(B t M)$, one-month lagged 11-month return $\left(R_{12-1}\right)$, past 60-month idiosyncratic volatility (IVol), past 60-month co-skewness $(C o s k), 12$-month lagged 48 -month return $\left(R_{60-12}\right)$, and past 12-month illiquidity (Illiq). In Panel A the sample period is from January 1931 to December 2010 (960 months) and in Panels B and C the sample period is from July 1963 to December 2010 (570 months). Moreover, the sample of Panel B consists of all common NYSE, AMEX and Nasdaq stocks while in Panels A and C the stocks with a market capitalization below the $20^{\text {th }}$ NYSE percentile are excluded. The reported coefficients are timeseries averages of the monthly regression slopes multiplied by 100 . The Newey-West corrected $t$-statistics of these averages are shown in italic below the estimated coefficients. The adjusted $\mathrm{R}^{2}$ of the regression model is reported in the final column. The bottom two rows report the time-series averages of the explanatory variables as well as the time-series average standard deviations. All the independent variables are Winsorized each month at the $1 \%$ and $99 \%$ level. Asterisks *** or *** indicate that the (downside) beta premium is statistically significant at the $10 \%, 5 \%$ and $1 \%$ significance levels, respectively.

\begin{tabular}{llllllllllllll}
\hline \multicolumn{2}{c}{ Panel A: $1931 \mathrm{M} 01-2010 \mathrm{M} 12$ Excluding Micro-Caps } \\
& Const & $\beta_{R}$ & $\beta_{S V}$ & $\beta_{\text {ARM }}$ & $\beta_{D C}$ & Size & BtM & $R_{12-1}$ & IVol & Cosk & $R_{60-12}$ & Illiq & R-sq \\
\hline$\beta_{R}$ & 2.42 & 0.12 & & & & -0.14 & 0.08 & 0.90 & -3.11 & 0.06 & -0.15 & 1.84 & $10.31 \%$ \\
& 6.01 & 1.12 & & & & -5.40 & 1.57 & 4.48 & -2.25 & 1.45 & -1.94 & 0.37 & \\
$\beta_{S V}$ & 2.38 & & $0.34^{* * *}$ & & & -0.14 & 0.08 & 1.02 & -3.63 & -0.03 & -0.09 & 0.82 & $10.34 \%$ \\
& 5.96 & & 2.79 & & & -5.49 & 1.48 & 5.58 & -2.58 & -0.66 & -1.38 & 0.18 & \\
$\beta_{A R M}$ & 2.42 & & & 0.17 & & -0.14 & 0.08 & 0.92 & -3.19 & 0.03 & -0.15 & 1.55 & $10.29 \%$ \\
& 6.00 & & & 1.60 & & -5.42 & 1.58 & 4.77 & -2.32 & 0.69 & -1.91 & 0.33 & \\
$\beta_{D C}$ & 2.44 & & & & 0.07 & -0.14 & 0.09 & 0.86 & -2.71 & 0.06 & -0.15 & 2.02 & $9.65 \%$ \\
& 6.07 & & & & 0.93 & -5.49 & 1.60 & 4.05 & -1.72 & 0.88 & -1.97 & 0.37 & \\
All & 2.14 & -0.22 & 3.98 & -2.90 & -0.65 & -0.13 & 0.04 & 1.65 & -1.00 & 0.09 & 0.39 & 2.92 & $11.21 \%$ \\
& 5.46 & -0.41 & 4.91 & -4.88 & -4.40 & -5.15 & 0.76 & 8.44 & -0.63 & 0.72 & 4.91 & 0.55 & \\
\multicolumn{2}{l}{ Average } & 1.14 & 1.05 & 1.13 & 1.11 & 12.24 & -0.36 & 0.13 & 0.08 & 1.22 & 0.68 & 0.46 & \\
\multicolumn{2}{l}{ Stdev } & 0.50 & 0.52 & 0.49 & 0.68 & 1.29 & 0.71 & 0.32 & 0.03 & 2.24 & 1.13 & 1.04 &
\end{tabular}

Panel B: 1963M07 - 2010M12 All Stocks

\begin{tabular}{|c|c|c|c|c|c|c|c|c|c|c|c|c|c|}
\hline \multirow[t]{2}{*}{$\beta_{R}$} & 2.60 & $0.24^{* * *}$ & & & & -0.15 & 0.11 & 0.85 & -4.10 & 0.08 & -0.13 & 0.26 & $6.16 \%$ \\
\hline & 5.66 & 2.50 & & & & -4.79 & 1.68 & 4.92 & -2.58 & 2.15 & -2.95 & 2.39 & \\
\hline \multirow[t]{2}{*}{$\beta_{S V}$} & 2.58 & & $0.55^{\text {****}}$ & & & -0.16 & 0.10 & 1.04 & -4.49 & -0.07 & -0.05 & 0.28 & $6.22 \%$ \\
\hline & 5.66 & & 3.85 & & & -5.02 & 1.51 & 6.90 & -2.76 & -1.62 & -1.30 & 2.50 & \\
\hline \multirow[t]{2}{*}{$\beta_{A R M}$} & 2.62 & & & $0.33^{* * * *}$ & & -0.15 & 0.11 & 0.89 & -4.25 & 0.02 & -0.13 & 0.27 & $6.16 \%$ \\
\hline & 5.68 & & & 3.01 & & -4.86 & 1.68 & 5.29 & -2.71 & 0.78 & -2.86 & 2.46 & \\
\hline \multirow[t]{2}{*}{$\beta_{D C}$} & 2.50 & & & & 0.11 & -0.14 & 0.12 & 0.80 & -3.16 & 0.07 & -0.14 & 0.24 & $5.83 \%$ \\
\hline & 5.44 & & & & 1.46 & -4.57 & 1.79 & 4.37 & -1.75 & 1.16 & -2.99 & 2.07 & \\
\hline \multirow[t]{2}{*}{ All } & 2.05 & -0.22 & $3.69^{* * *}$ & $-2.44^{* * *}$ & $-0.64^{* * *}$ & -0.13 & 0.07 & 1.67 & -0.67 & -0.06 & 0.44 & 0.27 & $6.71 \%$ \\
\hline & 4.39 & -0.88 & 5.67 & -4.78 & -4.79 & -3.91 & 0.96 & 9.63 & -0.39 & -0.76 & 5.03 & 2.42 & \\
\hline \multicolumn{2}{|c|}{ Average } & 1.11 & 1.06 & 1.12 & 1.19 & 11.85 & -0.42 & 0.08 & 0.11 & 1.34 & 0.42 & 0.45 & \\
\hline \multicolumn{2}{|c|}{ Stdev } & 0.59 & 0.63 & 0.59 & 0.90 & 1.93 & 0.71 & 0.40 & 0.05 & 3.00 & 1.12 & 1.37 & \\
\hline \multicolumn{14}{|c|}{ Panel C: 1963M07 - 2010M12 Excluding Micro-Caps } \\
\hline \multirow[t]{2}{*}{$\beta_{R}$} & 2.80 & 0.16 & & & & -0.15 & 0.09 & 0.84 & -3.89 & 0.00 & -0.09 & 3.11 & $8.65 \%$ \\
\hline & 4.72 & 1.40 & & & & -4.22 & 1.15 & 3.97 & -1.99 & 0.04 & -2.47 & 0.37 & \\
\hline \multirow[t]{2}{*}{$\beta_{S V}$} & 2.79 & & $0.34^{* * *}$ & & & -0.16 & 0.08 & 0.95 & -4.45 & -0.07 & -0.04 & 1.38 & $8.67 \%$ \\
\hline & 4.70 & & 2.34 & & & -4.30 & 1.06 & 4.86 & -2.22 & -1.23 & -1.20 & 0.18 & \\
\hline \multirow[t]{2}{*}{$\beta_{A R M}$} & 2.80 & & & $0.22^{*}$ & & -0.16 & 0.08 & 0.86 & -4.08 & -0.03 & -0.08 & 2.61 & $8.64 \%$ \\
\hline & 4.70 & & & 1.70 & & -4.22 & 1.12 & 4.17 & -2.10 & -0.62 & -2.41 & 0.33 & \\
\hline \multirow[t]{2}{*}{$\beta_{D C}$} & 2.79 & & & & 0.08 & -0.15 & 0.09 & 0.80 & -3.11 & 0.00 & -0.09 & 3.39 & $8.10 \%$ \\
\hline & 4.68 & & & & 0.98 & -4.14 & 1.22 & 3.73 & -1.42 & 0.02 & -2.56 & 0.37 & \\
\hline \multirow[t]{2}{*}{ All } & 2.58 & 0.27 & $2.42^{* * * *}$ & $-1.93^{* * *}$ & $-0.49^{* * *}$ & -0.15 & 0.05 & 1.36 & -2.65 & -0.03 & 0.23 & 4.90 & $9.38 \%$ \\
\hline & 4.48 & 0.95 & 4.35 & -3.78 & -3.26 & -4.08 & 0.61 & 6.53 & -1.37 & -0.26 & 3.40 & 0.55 & \\
\hline \multicolumn{2}{|c|}{ Average } & 1.10 & 1.00 & 1.09 & 1.10 & 13.33 & -0.60 & 0.12 & 0.09 & 1.22 & 0.61 & 0.02 & \\
\hline \multicolumn{2}{|c|}{ Stdev } & 0.52 & 0.54 & 0.53 & 0.76 & 1.26 & 0.63 & 0.35 & 0.03 & 2.37 & 1.20 & 0.03 & \\
\hline
\end{tabular}




\subsection{Portfolio-Level Results}

This section analyzes the role of downside beta using benchmark stock portfolios rather than individual stocks. First, we analyze the return predictive power of (downside) beta by sorting stocks into quintile portfolios using the various (downside) beta measures and by double-sorted (downside) beta portfolios in which we effectively neutralize one of the alternative beta measures. Secondly, we analyze the classical benchmark portfolios of Fama and French (1993) who summarize the cross-section of individual stocks with a set of 25 benchmark portfolios formed by ranking individual stocks based on their Size and BtM.

Some disclaimers seem in order for the correct interpretation of the results. First, the analysis does not correct for the other stock characteristics, despite their importance in the Fama-MacBeth regressions of Section 2.3. In addition, statistical inference and hypothesis testing is complicated by the effect of the sorting procedure on the statistical size and power of the analysis. For example, sorting on an irrelevant beta measure will generally produce small differences in average return and beta, and the analysis will lack statistical power. Notwithstanding these potential limitations, the results are at least qualitatively comparable with those of the Fama-MacBeth analyses of individual stocks.

The results of the beta sorted benchmark portfolios in Panel A of Table 2.4 give a first indication of the potential gross profitability of practical trading strategies and confirm the stock-level Fama-MacBeth regression results from the previous section. While the return on high regular-beta stocks are 28 basis points per month, or 3.36 percent per annum, higher than the returns on lowregular-beta stocks, this return difference is not statistically significant ( $t$ statistic $=1.27)$. Moreover, the average returns of the regular beta portfolios are not monotonically increasing as would be expected. In fact, both the third and fourth quintile portfolios have on average higher returns than the quintile portfolio with the highest regular-beta stocks.

The theoretical positive risk-return relation is restored and most pronounced for SV beta. The return spread between high SV beta stocks and low SV beta stocks is 49 basis points per month, or 5.88 percent per annum, and is statistically significant $(t$-statistic $=2.06)$. Importantly, we also observe a strictly increasing return pattern for the SV beta quintiles. This again indicates that past SV beta is better in predicting future stock returns than regular beta. 
Table 2.4: Portfolios Formed on Stock-Level Beta Estimates

This table presents monthly excess returns on different (downside) beta sorted benchmark portfolios. The single-sorted portfolios in Panel A are constructed by sorting stocks at the end of each month into equally numbered quintile portfolios either on their regular beta $(\beta \mathrm{R})$, SV beta $\left(\beta_{\mathrm{SV}}\right)$, ARM beta $\left(\beta_{\mathrm{ARM}}\right)$, or DC beta $\left(\beta_{\mathrm{DC}}\right)$. The double-sorted beta portfolios in Panels B to $\mathrm{E}$ are constructed by subdividing each quintile beta portfolio into five portfolios based on an alternative beta measure and next aggregated across the first beta-sort. The portfolios consist of all common NYSE, AMEX and Nasdaq stocks for which, at that point in time, we have 60 months of past return observations available to estimate the (downside) betas. The equal weighted return over the following month is calculated from January 1931 to December 2010 (960 months). The reported results are time-series averages of the monthly portfolio returns over the sample period. The final two columns report the return differences between the high (downside) beta portfolio and the low (downside) beta portfolio together with the $t$-statistics of the return differences. Asterisks ${ }^{*}, *$ or $* * *$ indicate that the (downside) beta premium, measured by the spread between the high (downside) beta portfolio and the low (downside) beta portfolio, is statistically significant at the $10 \%, 5 \%$ and $1 \%$ significance levels, respectively.

Panel A: Mean Returns of Single Sorted (Downside) Beta Portfolios

\begin{tabular}{lccccccc} 
& Low & Q2 & Q3 & Q4 & High & Difference & $t$-statistic \\
\hline$\beta_{R}$ & 0.87 & 1.07 & 1.21 & 1.18 & 1.16 & 0.28 & 1.27 \\
$\beta_{S V}$ & 0.85 & 0.95 & 1.12 & 1.22 & 1.34 & 0.49 & $2.06^{\text {** }}$ \\
$\beta_{A R M}$ & 0.86 & 1.04 & 1.19 & 1.21 & 1.19 & 0.33 & 1.45 \\
$\beta_{D C}$ & 0.91 & 1.01 & 1.11 & 1.20 & 1.26 & 0.35 & $2.18^{\text {** }}$
\end{tabular}

Panel B: Mean Returns of Double-Sorts, First Sort on Regular Beta

\begin{tabular}{llllllll}
\hline$\beta_{S V}$ & 0.93 & 0.99 & 1.00 & 1.11 & 1.44 & 0.51 & $3.60^{\text {*** }}$ \\
$\beta_{A R M}$ & 1.03 & 1.06 & 1.04 & 1.09 & 1.27 & 0.24 & $2.41^{\text {*** }}$ \\
$\beta_{D C}$ & 1.05 & 1.02 & 1.06 & 1.14 & 1.21 & 0.16 & $1.94^{*}$
\end{tabular}

Panel C: Mean Returns of Double-Sorts, First Sort on SV Beta

\begin{tabular}{llllllll}
\hline$\beta_{R}$ & 1.29 & 1.14 & 1.05 & 1.00 & 1.01 & -0.28 & $-2.47^{\text {****}}$ \\
$\beta_{A R M}$ & 1.28 & 1.12 & 1.06 & 1.01 & 1.01 & -0.27 & $-2.56^{\text {**** }}$ \\
$\beta_{D C}$ & 1.16 & 1.07 & 1.07 & 1.09 & 1.09 & -0.08 & -0.85
\end{tabular}

Panel D: Mean Returns of Double-Sorts, First Sort on ARM Beta

\begin{tabular}{|c|c|c|c|c|c|c|c|}
\hline$\beta_{R}$ & 1.19 & 1.12 & 1.08 & 1.04 & 1.06 & -0.14 & -1.53 \\
\hline$\beta_{S V}$ & 0.92 & 0.99 & 1.01 & 1.14 & 1.43 & 0.51 & $3.80^{\text {*** }}$ \\
\hline$\beta_{D C}$ & 1.08 & 1.05 & 1.08 & 1.08 & 1.19 & 0.11 & 1.46 \\
\hline
\end{tabular}

Panel E: Mean Returns of Double-Sorts, First Sort on DC Beta

\begin{tabular}{|c|c|c|c|c|c|c|c|}
\hline$\beta_{R}$ & 1.04 & 1.11 & 1.09 & 1.11 & 1.13 & 0.09 & 0.55 \\
\hline$\beta_{S V}$ & 0.94 & 1.02 & 1.06 & 1.11 & 1.35 & 0.41 & $2.08^{* *}$ \\
\hline$\beta_{A R M}$ & 1.02 & 1.07 & 1.11 & 1.11 & 1.18 & 0.16 & 0.94 \\
\hline
\end{tabular}

To disentangle the effect of different (regular or downside) beta measures, we also apply a double-sorting routine. We construct double-sorted portfolios for which the stocks are first sorted into quintile portfolios onregular beta and then subdivide each regular-beta quintile into five portfolios based on one of the three downside beta measures. For sake of brevity, we only report 
returns aggregated across the regular beta quintiles, resulting in five stock groups with similar regular betas but different downside betas; effectively neutralizing regular beta. We find that the risk-return relation is strongest for SV beta with a significant spread of 51 basis points per month, or 6.12 percent per annum $(t$-statistic $=3.60)$. The monthly return spread for DC beta after neutralizing regular beta is only 16 basis points, or 1.92 percent per annum, and is only marginally significant $(t$-statistic $=1.94)$.

Interestingly, if we neutralize the effect of SV beta on the other beta measures, as shown in Panel $\mathrm{C}$, we even find a negative risk-return relation for regular beta and the two other downside betas. This confirms our results from the Fama-MacBeth regressions that include the four betas (and other stock characteristics) simultaneously. SV beta remains strong in predicting future stock returns after neutralizing ARM beta or DC beta, while regular beta does not seem to have any return predictive power. Hence consistent with earlier results, we again conclude that SV beta captures priced risk that is not captured by the other betas and the other betas don't capture any priced risk that is not captured by SV beta.

Fama and French (1993) summarize the cross-section of individual stocks with a set of 25 benchmark portfolios formed by ranking individual stocks based on their Size and BtM. The benchmark portfolios would seem to create a serious challenge for the explanatory and predictive power of marketbeta measures. First, the portfolios exhibit an unusually large cross-sectional variation of Size and BtM relative to the variation of market-beta measures, which can adversely affect the statistical size and power properties of statistical tests. Second, the benchmark portfolios are rebalanced annually (in order to control their Size and BtM characteristics) and have a relatively high turnover. This introduces a dynamic portfolio return distribution and complicates the estimation and prediction of portfolio betas (and other portfolio characteristics) using historical returns. For example, after a bear market period the market capitalization of high-beta stocks will have decreased relative to that of low-beta stocks and a value-stock portfolio (high BtM) will have relatively more high-beta stocks and a relatively higher portfolio beta.

To deal with this second challenge, we use an approach (used, e.g., in Chen et al., 1986) that avoids confounding past returns and past portfolio weights by combining past realized stock returns with the fixed portfolio weights of the evaluated month, or 


$$
R_{P, t-s}=\sum_{i} w_{P, i, t} R_{i, t-s},
$$

where $R_{P, t-s}$ is the $s$-month lagged return of portfolio $P$ at time $t, w_{P, i, t}$ is the weight of stock $i$ in portfolio $P$ and $R_{i, t-s}$ is a lagged return. ${ }^{14}$

At the end of each month we will estimate the regular and downside market betas, past return variables, IVol and Co-skewness of the benchmark portfolios. With the exception of IVol, these stock characteristics combine in a linear way, and our correction in effect is equivalent to taking a weighted average of the characteristics of the individual stocks, using the portfolio weights of the evaluation month $\left(w_{P, i, t}\right)$. Our approach does however yield substantially lower portfolio IVol values than the weighted average of the individual IVols, as it accounts for portfolio diversification effects; the IVol of a portfolio generally is much lower than the weighted average stock-level IVol. Portfolio-level Size is estimated by the log of the average market capitalization of a stock within the portfolio; portfolio-level BtM is estimated by the log of the ratio of total book value of equity (using the book values of each stock's previous calendar year's fiscal year-end) divided by the total market capitalization (at the end of previous calendar year) within the portfolio. Finally, portfolio-level Illiquidity is estimated by the value-weighted average of the individual stock illiquidity estimations.

Table 2.5 summarizes our regression results. Indeed, the results demonstrate that accounting for time-varying portfolio weights gives a similar pattern to what we found for individual stocks. In the beta-only regressions, the SV beta premium is as high as 57 basis points per month, or 6.84 percent per annum $(t$-statistic $=2.00)$, and it dominates the other beta premiums. After including all other stock characteristics, the SV beta premium remains as high as 6.46 percent per annum $(t$-statistic $=1.86)$. As for the individual stocks, the Size-IVol effect reduces the explanatory power of BtM and the negative effect of BtM on the beta premiums.

\footnotetext{
${ }^{14}$ In unreported results in which we do not take the dynamics in lagged portfolio weights into account, we find that the beta measures appear to have no out-of-sample explanatory power for portfolio returns beyond their correlation with the other portfolio characteristics. This is due to the dynamic risk profiles of the benchmark portfolios that cannot be picked up by the beta measures using this approach.
} 
Table 2.5: Portfolio-Level Cross-Sectional Regressions: Simulated Returns

This table presents results of Fama and MacBeth (1973) regressions of value weighted monthly excess returns of the 25 Size / BtM sorted benchmark portfolios on the portfolio characteristics. The 25 portfolios are rebalanced each year at the end of June using the NYSE market capitalization quintile breakpoints (measured at the end of June) and NYSE book-to-market quintile breakpoints (using the previous calendar year's fiscal year-end book value of equity divided by the market capitalization at the end of previous calendar year). The portfolios consist of all common NYSE, AMEX and Nasdaq stocks for which, at that point in time, all the information is available that is needed to estimate their remaining characteristics. Portfolio betas, past return variables, idiosyncratic volatility and co-skewness are computed using the stocks' market capitalization at the formation date as the portfolio weight. Size is estimated by the log of the average market capitalization of a stock within the portfolio; BtM is estimated by the log of the ratio of total book value of equity divided by the total market capitalization of all the stocks within the portfolio; and Illiquidity is estimated by the value-weighted average of the individual stock illiquidity estimations. Cross-sectional regressions are performed each month from January 1931 to December 2010 (960 months). The reported coefficients are time-series averages of the monthly regression slopes multiplied by 100 . The Newey-West corrected $t$-statistics of these averages are shown in italic below the estimated coefficients. The adjusted $\mathrm{R}^{2}$ of the regression model is reported in the final column. The bottom two rows report the time-series averages of the explanatory variables as well as the time-series average standard deviations. Asterisks * $* *$ or $* * *$ indicate that the (downside) beta premium is statistically significant at the $10 \%, 5 \%$ and $1 \%$ significance levels, respectively.

\begin{tabular}{|c|c|c|c|c|c|c|c|c|c|c|c|c|c|}
\hline & Const & $\beta_{R}$ & $\beta_{S V}$ & $\beta_{\text {ARM }}$ & $\beta_{D C}$ & Size & BtM & $R_{12-1}$ & IVol & Cosk & $R_{60-12}$ & Illiq & R-sq \\
\hline \multirow[t]{2}{*}{$\beta_{R}$} & 0.49 & 0.36 & & & & & & & & & & & $17.44 \%$ \\
\hline & 1.69 & 1.26 & & & & & & & & & & & \\
\hline \multirow[t]{2}{*}{$\beta_{S V}$} & 0.29 & & $0.57^{* *}$ & & & & & & & & & & $15.80 \%$ \\
\hline & 1.13 & & 2.00 & & & & & & & & & & \\
\hline \multirow[t]{2}{*}{$\beta_{A R M}$} & 0.39 & & & $0.49^{*}$ & & & & & & & & & $17.88 \%$ \\
\hline & 1.35 & & & 1.68 & & & & & & & & & \\
\hline \multirow[t]{2}{*}{$\beta_{D C}$} & 0.51 & & & & $0.40^{*}$ & & & & & & & & $14.62 \%$ \\
\hline & 1.88 & & & & 1.80 & & & & & & & & \\
\hline \multirow[t]{2}{*}{$\beta_{R}$} & 1.51 & 0.07 & & & & -0.07 & 0.23 & 0.76 & & & & & $39.75 \%$ \\
\hline & 3.06 & 0.35 & & & & -2.26 & 3.56 & 2.81 & & & & & \\
\hline \multirow[t]{2}{*}{$\beta_{S V}$} & 1.29 & & 0.18 & & & -0.07 & 0.23 & 0.66 & & & & & $39.45 \%$ \\
\hline & 2.66 & & 0.94 & & & -2.02 & 3.73 & 2.31 & & & & & \\
\hline \multirow[t]{2}{*}{$\beta_{A R M}$} & 1.42 & & & 0.16 & & -0.07 & 0.25 & 0.73 & & & & & $39.25 \%$ \\
\hline & 2.77 & & & 0.82 & & -2.22 & 3.93 & 2.70 & & & & & \\
\hline \multirow[t]{2}{*}{$\beta_{D C}$} & 1.45 & & & & 0.04 & -0.07 & 0.22 & 0.63 & & & & & $38.66 \%$ \\
\hline & 3.16 & & & & 0.26 & -2.25 & 3.68 & 1.97 & & & & & \\
\hline \multirow[t]{2}{*}{$\beta_{R}$} & 1.46 & $0.42^{*}$ & & & & -0.10 & 0.15 & 0.67 & -8.78 & 0.02 & & & $45.69 \%$ \\
\hline & 3.08 & 1.68 & & & & -3.22 & 2.38 & 2.01 & -2.00 & 0.14 & & & \\
\hline \multirow[t]{2}{*}{$\beta_{S V}$} & 1.54 & & $0.44^{*}$ & & & -0.10 & 0.16 & 0.80 & -7.30 & 0.01 & & & $45.38 \%$ \\
\hline & 3.21 & & 1.65 & & & -3.18 & 2.41 & 2.54 & -1.97 & 0.03 & & & \\
\hline \multirow[t]{2}{*}{$\beta_{A R M}$} & 1.47 & & & $0.41^{*}$ & & -0.10 & 0.17 & 0.72 & -7.95 & 0.04 & & & $45.15 \%$ \\
\hline & 3.09 & & & 1.86 & & -3.29 & 2.58 & 2.15 & -1.98 & 0.27 & & & \\
\hline \multirow[t]{2}{*}{$\beta_{D C}$} & 1.44 & & & & 0.19 & -0.09 & 0.14 & 0.64 & -6.78 & 0.09 & & & $44.81 \%$ \\
\hline & 3.27 & & & & 0.67 & -3.08 & 2.40 & 1.89 & -1.83 & 0.33 & & & \\
\hline \multirow[t]{2}{*}{$\beta_{R}$} & 1.26 & 0.38 & & & & -0.08 & 0.11 & 0.32 & -6.81 & 0.06 & -0.07 & 0.02 & $48.54 \%$ \\
\hline & 2.55 & 1.47 & & & & -2.62 & 1.43 & 0.85 & -1.49 & 0.33 & -0.59 & 1.35 & \\
\hline \multirow[t]{2}{*}{$\beta_{S V}$} & 1.27 & & $0.54^{*}$ & & & -0.08 & 0.13 & 0.46 & -7.45 & -0.03 & 0.03 & 0.03 & $48.56 \%$ \\
\hline & 2.60 & & 1.86 & & & -2.63 & 1.70 & 1.23 & -1.57 & -0.15 & 0.29 & 1.47 & \\
\hline \multirow[t]{2}{*}{$\beta_{A R M}$} & 1.25 & & & 0.31 & & -0.08 & 0.11 & 0.41 & -5.90 & 0.11 & -0.08 & 0.03 & $48.08 \%$ \\
\hline & 2.59 & & & 1.33 & & -2.67 & 1.42 & 1.11 & -1.36 & 0.64 & -0.70 & 1.61 & \\
\hline \multirow[t]{2}{*}{$\beta_{D C}$} & 1.09 & & & & 0.18 & -0.07 & 0.11 & 0.29 & -5.92 & 0.10 & -0.08 & 0.03 & $47.77 \%$ \\
\hline & 2.30 & & & & 0.62 & -2.24 & 1.48 & 0.78 & -1.45 & 0.39 & -0.65 & 1.34 & \\
\hline \multicolumn{2}{|c|}{ Average } & 1.17 & 1.08 & 1.16 & 1.14 & 11.77 & -0.19 & 0.16 & 0.03 & 1.26 & 0.76 & 9.72 & \\
\hline \multicolumn{2}{|c|}{ Stdev } & 0.21 & 0.20 & 0.21 & 0.24 & 1.61 & 0.72 & 0.12 & 0.01 & 0.75 & 0.60 & 27.05 & \\
\hline
\end{tabular}




\subsection{Conclusions}

The M-SV equilibrium forwards the SV beta as the relevant measure of systematic downside risk for individual stocks. This beta generally differs in a subtle way from two commonly employed alternative measures of systematic downside risk: the asymmetric response model (ARM) beta of Harlow and Rao (1989) and the downside-covariance (DC) beta based on the conditional secondorder centered co-moment with the market. In contrast to the SV beta, these two alternative measures generally are not consistent with the first principles of choice theory.

To examine the empirical relevance of downside risk, we consider a broad cross-section of NYSE, AMEX and Nasdaq stocks and a long sample period including the important bear markets of the 1930s, 1970s and 2000s. We find that downside-market beta, when properly defined and estimated, has substantial out-of-sample predictive power for future stock returns, and dominates regular market beta. Depending on the model specification and sample period, the premium is estimated to be roughly four to seven percent per annum for SV beta, compared with only zero to three percent for regular beta. Using the ARM regressions or DC beta definition lowers the estimated beta premium and worsens the statistical fit, consistent with our theoretical and methodological concerns about these approaches to measuring downside risk.

Our conclusions are robust to the inclusion of known co-variates and plausible changes in the cross-section and sample period. SV beta also explains a significant part of the returns of size-value benchmark portfolios after we account for the dynamic nature of the portfolio weights. 


\section{CHAPTER 3}

\section{SHORT-TERM RESIDUAL REVERSAL}

A CONVENTIONAL SHORT-TERM reversal strategy as documented by Lehmann (1990) and Jegadeesh (1990), i.e., a strategy that buys (sells) stocks with low (high) total returns over the past month, exhibits dynamic exposures to the Fama and French (1993) factors. As these implicit factor bets are inversely related to factor return realizations over the formation month, the reversal strategy is negatively exposed to the short-term momentum effect in factor returns of Moskowitz and Grinblatt (1999) and Chen and De Bondt (2004). As a result, the dynamic factor exposures of a reversal strategy are likely to negatively affect its profitability, while, at the same time, contributing significantly to the risks involved.

We introduce a short-term reversal strategy based on residual stock returns that does not exhibit such dynamic factor exposures and find that this strategy earns returns that are higher and substantially less volatile than those of a conventional short-term reversal strategy. More specifically, stock residual returns are computed by adjusting total returns for the stocks' exposures to the Fama-French factors and scaling the residual returns by their volatility. We document that this reversal strategy earns risk-adjusted returns that are twice as large as those of a conventional reversal strategy. Our results also show that the strategy's profitability has been relatively stable over our sample period from January 1929 to December 2010, including the more recent decades, and that profitability remains economically and statistically significant after taking trading costs into account. In addition, we show that residual stock returns have predictive power for future returns above and beyond that of total stock returns.

Several authors have argued that the profits of conventional short-term reversal strategies largely disappear once trading costs are taken into account (see, e.g., Ball et al., 1995; Conrad et al., 1997; and Avramov et al., 2006). Consistent with this stream of literature we find that, indeed, the returns of a conventional reversal strategy net of trading costs are indistinguishable from zero or even negative. However, when we investigate the impact of trading costs on the profitability of residual reversal strategies, we find that the profits 
of the strategy exceed any reasonable level of trading costs by a wide margin. Even though reversal strategies generate high portfolio turnover, we find that residual reversal strategies yield significantly positive returns of more than 7 percent per annum net of trading costs.

The large residual reversal profits we document are remarkably robust over time and the cross-section of stocks. We find that the residual reversal strategy outperforms a conventional reversal strategy during every single decade in our sample in terms of risk-adjusted return. Most notably, the residual reversal strategy earns large positive returns during the two most recent decades, following the public dissemination of the reversal effect, while the conventional reversal strategy earns returns close to zero over the same period. In fact, over the post-1990 period the residual reversal strategy yields large positive returns after trading costs even when we restrict the investment universe to the 500 or only 100 largest U.S. stocks. Also during the five most recent years in our sample, which include the "quant meltdown" of August 2007 and its aftermath, we observe that the residual reversal strategy consistently outperforms a conventional reversal strategy. Moreover, when we evaluate reversal profits within different industries, we find that the strategy based on residual returns outperforms the conventional strategy within each of the ten industries of French (2011).

Our results shed new light on several alternative explanations that have been put forward in the academic literature to understand the reversal effect. Our finding that net reversal profits persist over the most recent decades in our sample, during which trading volumes dramatically increased, does not support the explanation that reversals are induced by inventory imbalances by market makers and that reversal profits are a compensation for bearing inventory risks (see, e.g., Jegadeesh and Titman, 1995b). In addition, the finding that reversal profits are observed among the 500 or even 100 largest stocks is inconsistent with the notion that non-synchronous trading contributes to reversal profits (see, e.g., Lo and MacKinlay, 1990; and Boudoukh et al., 1994) since this explanation implies that reversal profits should be concentrated among small-cap stocks. Our results do not appear to be inconsistent, however, with the explanation that some investors tend to overreact to information and that stock price reversals originate from transitory changes in demand for immediacy by these impatient traders (see, e.g., Lehmann, 1990; and Jegadeesh and Titman, 1995a). Apart from contributing to a better understanding of the origins of the reversal effect, our 
findings also have important implications for the practical implementation of reversal strategies, indicating that in order to generate sufficiently large returns to cover trading costs it is of crucial importance to control for dynamic factor exposures.

Our work is related to the research of Grundy and Martin (2001), who show that intermediate-term momentum strategies exhibit dynamic factor exposures, and the work of Gutierrez and Pirinsky (2007) and Blitz et al. (2011), who find that intermediate-term momentum strategies based on residual instead of total stock returns yield significantly higher risk-adjusted returns. Our work is also related to the strand of literature that re-examines market anomalies after incorporating trading costs (see, e.g., Lesmond et al., 2004; Korajczyk and Sadka, 2004; Avramov et al., 2006; and Chordia et al., 2009) and the contemporaneous work of Da et al. (2011) and Hameed et al. (2010), who show that reversal profits are higher within industries than across industries.

The remainder of this chapter is organized as follows. In Section 3.1 we analytically show that conventional reversal strategies exhibit dynamic exposures to common factors that affect their risks and profitability and we develop the residual reversal strategy. In Section 3.2 we empirically investigate the impact of these factor exposures on the risks and profits of both reversal strategies. In Section 3.3 we gauge the economic significance of reversal profits by evaluating their profitability net of trading costs. In Section 3.4 we conduct several follow-up analyses, including an examination of the comparative strength of both reversal strategies, the profitability of both reversal strategies within industries, the relation between reversal strategies' dynamic factor exposures and their profitability using a non-parametric approach, calendar month effects and the robustness of our results to using alternative portfolio weighting schemes. In Section 3.5 we discuss the implications of our empirical findings for alternative explanations that have been put forward in the academic literature to understand the reversal effect. Finally, we conclude in Section 3.6.

\subsection{Analytical Analysis}

In this section we analytically show that conventional reversal strategies implicitly exhibit dynamic exposures to common factors that affect their risks and profitability. Additionally, we develop a reversal strategy based on residual stock returns that does not exhibit these dynamic factor exposures. 
Let us assume that stock returns are described by the following $K$-factor model:

$$
r_{i, t}=\mu_{i}+\sum_{k=1}^{K} \beta_{i}^{k} f_{t}^{k}+\varepsilon_{i, t}
$$

where $\mu_{i}=\sum_{k=1}^{K} \beta_{i}^{k} \mu^{k}$ is the unconditional expected return of stock $i ; \mu^{k}>0$ is the unconditionally expected return on factor $k ; f_{t}^{k}=r_{t}^{k}-\mu^{k}$ is the return on factor $k$ above its expectation at time $t ; \varepsilon_{i, t}$ is the residual return at time $t$; and $\beta_{i}^{k}$ is the exposure of stock $i$ to factor $k$. Without loss of generality, we assume the $K$ factors are orthogonal, so $E\left[f_{t}^{i} f_{t}^{j}\right]=0$ for $i \neq j$ and $E\left[\left(f_{t}^{k}\right)^{2}\right]=\sigma_{f^{k}}^{2}$. In addition, we assume that $\operatorname{Cov}\left[f_{t}^{i}, f_{t-1}^{j}\right]=0$ for $i \neq j$ and $\operatorname{Cov}\left[\varepsilon_{i, t}, \varepsilon_{j, t-1}\right]=0$ for $i \neq j$.

Because of its analytical tractability, we follow Lehmann (1990), Lo and MacKinlay (1990) and Jegadeesh and Titman (1995a) and consider a (zeroinvestment) conventional reversal strategy that assigns a portfolio weight to stock $i$ at time $t$ of

$$
w_{i, t}=-\frac{1}{N_{t}}\left(r_{i, t-1}-\bar{r}_{t-1}\right)
$$

where $N_{t}$ denotes the number of stocks in the universe at time $t$ and $\bar{r}_{t-1}=\frac{1}{N_{t}} \sum_{i=1}^{N_{t}} r_{i, t-1}$. The expected exposure of the reversal strategy to the $j$-th factor conditional on the return of the $j$-th factor at time $t$ - 1 now equals

$$
E\left[\sum_{i=1}^{N_{t}} w_{i, t} \beta_{i}^{j} \mid f_{t-1}^{j}\right]=-\sigma_{\beta^{j}}^{2} \mu^{j}-\sigma_{\beta^{j}}^{2} f_{t-1}^{j},
$$

where $\sigma_{\beta^{j}}^{2}=\frac{1}{N_{t}} \sum_{i=1}^{N_{t}}\left(\beta_{i}^{j}-\bar{\beta}^{j}\right)^{2}$. Hence, the right-hand side of Equation (3.3) shows that the conventional reversal strategy's common factor exposures consist of a systematic and a dynamic component. The first component indicates that the conventional reversal strategy is systematically negatively 
exposed to factors that have a positive expected return, while the second component implies that the reversal strategy has dynamic factor exposures depending on the demeaned factor returns over the formation period. For example, when the market return is positive over the formation period, highbeta stocks typically earn higher average returns than low-beta stocks, causing the conventional reversal strategy to assign a relatively low weight to highbeta stocks and a high weight to low-beta stocks. As a consequence, the net market beta of the reversal strategy is negative over the subsequent investment period.

The expected profits $\pi_{t}$ of the conventional reversal strategy at time $t$, conditional on the $K$ factor returns at time $t$-1, can now be written as

$$
\begin{aligned}
E\left[\pi_{t} \mid f_{t-1}^{k}, k=1,2, \ldots K\right] & =E\left[\sum_{i=1}^{N_{t}} w_{i, t} r_{i, t} \mid f_{t-1}^{k}, k=1,2, \ldots K\right] \\
& =-\sigma_{\mu}^{2}-\Phi-\Lambda_{t-1}-\Psi
\end{aligned}
$$

where

$$
\begin{aligned}
& \sigma_{\mu}^{2}=\frac{1}{N_{t}} \sum_{i=1}^{N_{t}}\left(\mu_{i}-\bar{\mu}\right)^{2}, \\
& \Phi=\sum_{k=1}^{K} \sigma_{\beta^{k}}^{2} \mu^{k} \operatorname{Cov}\left[f_{t}^{k}, f_{t-1}^{k}\right], \\
& \Lambda_{t-1}=\sum_{k=1}^{K} \sigma_{\beta^{k}}^{2} f_{t-1}^{k}\left(\mu^{k}+E\left[f_{t}^{k} \mid f_{t-1}^{k}\right]\right)
\end{aligned}
$$

and

$$
\Psi=\frac{1}{N_{t}} \sum_{i=1}^{N_{t}} \operatorname{Cov}\left[\varepsilon_{i, t}, \varepsilon_{i, t-1}\right] .
$$

Hence, the profits of a conventional reversal strategy can be decomposed into four different components. The first component, $\sigma_{\mu}^{2}$, is the cross-sectional variance of expected stock returns. This component has a negative impact on reversal profits, which results from the conventional reversal strategy being 
systematically negatively exposed to factors with positive expected returns. The second component, $\Phi$, is the sum of the cross-sectional variances in factor exposures times the persistence in factor returns. This component captures that the systematic exposures towards positive factors are exacerbated when persistence in factor returns is stronger. The third component, $\Lambda_{t-1}$, captures the short-term dynamics in total reversal profits due to the strategy's dynamic factor exposures conditional on the factor realizations at time $t$ - 1 . It is equal to the dynamic factor exposures component, which follows from Equation (3.3), times the conditionally expected factor returns at time $t$. Since the factor exposures of a conventional reversal strategy are inversely related to the unexpected factor returns over the past month, this component can have either a positive or a negative impact on reversal profits, depending on the extent to which factor returns persist. If factor returns exhibit positive autocorrelation, the impact of this component on the total reversal profits is negative. The final component, $\Psi$, results from autocorrelation in the residual stocks returns and is positive if residual stock returns exhibit negative serial correlation.

Our analytical exercise above not only demonstrates that conventional reversal strategies exhibit factor exposures that have a negative impact on their profitability, but can also be used to show that these exposures affect the variability in the strategy's profits:

$$
\begin{aligned}
\operatorname{Var}\left[\pi_{t}\right] & =\frac{1}{N_{t}^{2}} \operatorname{Var}\left[\sum_{i=1}^{N_{t}} w_{i, t} r_{i, t}\right] \\
& =\frac{1}{N_{t}^{2}} \sum_{i=1}^{N_{t}}\left(\left(\mu_{i}-\bar{\mu}\right)+\sum_{k=1}^{K}\left(\beta_{i}^{k}-\bar{\beta}^{k}\right) f_{t-1}^{k}+\left(\varepsilon_{i, t-1}-\bar{\varepsilon}_{t-1}\right)\right)^{2} \operatorname{Var}\left[r_{i, t}\right]
\end{aligned}
$$

Equation (3.9) implies that if the lagged factor returns are more extreme and the magnitude of factor exposures is larger, the variance in expected reversal profits is also higher.

As an alternative to the conventional reversal strategy, we develop a reversal strategy that is based on residual returns instead of total returns. For tractability we consider a strategy that assigns a portfolio weight to stock $i$ at time $t$ of

$$
\gamma_{i, t}=-\frac{1}{N_{t}}\left(\varepsilon_{i, t-1}-\bar{\varepsilon}_{t-1}\right)
$$


In the empirical section, we consider an implementable version of this strategy based on the same logic. The exposure of this strategy to the $j$-th factor at time $t$ equals zero by construction, since

$$
E\left[\sum_{i=1}^{N_{t}} \gamma_{i, t} \beta_{i}^{j} \mid f_{t-1}^{j}\right]=-E\left[\frac{1}{N_{t}} \sum_{i=1}^{N_{t}}\left(\varepsilon_{i, t-1}-\bar{\varepsilon}_{t-1}\right) \beta_{i}^{j}\right]=0 .
$$

The expected profits $\eta_{t}$ of this strategy at time $t$ can now be written as

$$
E\left[\eta_{t}\right]=E\left[\sum_{i=1}^{N_{t}} \gamma_{i, t} r_{i, t}\right]=-\Psi
$$

while the variability for the residual reversal strategy's profits is given by

$$
\begin{aligned}
\operatorname{Var}\left[\eta_{t}\right] & =\frac{1}{N_{t}^{2}} \operatorname{Var}\left[\sum_{i=1}^{N_{t}} \gamma_{i, t} r_{i, t}\right] \\
& =\frac{1}{N_{t}^{2}} \sum_{i=1}^{N_{t}}\left(\varepsilon_{i, t-1}-\bar{\varepsilon}_{t-1}\right)^{2} \operatorname{Var}\left[r_{i, t}\right]
\end{aligned}
$$

Hence, by construction the residual reversal strategy does not have systematic and dynamic exposures to the $K$ factors. Contrary to the conventional reversal strategy, the residual reversal strategy's profits are not reduced by having systematic negative exposures to factors with positive expected returns. Moreover, the strategy's profits do not depend on persistence in factor returns.

Given the stylized fact that factor returns exhibit some persistence (see, e.g., Fisher, 1966; Moskowitz and Grinblatt, 1999; and Chen and De Bondt, 2004), we can deduce that the returns of a conventional reversal strategy are negatively affected by the strategy's negative exposure to the short-term momentum effect in factor returns and that, consequently, the expected return is larger for our residual reversal strategy. A second notable difference with the conventional reversal strategy is that the profits of a residual reversal strategy can be expected to exhibit a lower variability as a result of not having factor exposures. We therefore expect a residual reversal strategy to outperform a conventional reversal strategy in terms of both risk and return. In the subsequent sections we empirically test this conjecture. 


\subsection{Main Empirical Analyses}

In this section we present our main empirical results. We first describe our data. Next we examine the characteristics and performance of a conventional short-term reversal strategy, after which we conduct a similar analysis for our residual reversal strategy. Finally, we discuss the robustness of our findings over time.

\section{A. Data}

Our stock return data are obtained from the monthly CRSP Stock database. We select common U.S. stocks listed on the NYSE, AMEX and Nasdaq markets that (i) have a stock price above $\$ 5$ and (ii) have a market capitalization above the NYSE median at the end of the formation month. We exclude closed-end funds, Real Estate Investment Trusts (REITs), unit trusts, American Depository Receipts (ADRs), and foreign stocks from our analysis. Common factor data are downloaded from French (2011). To be included in our sample at a given point in time we require a stock to have a complete return history over the preceding 36 months. Our sample covers the period January 1926 to December 2010.

\section{B. Factor Exposures of Conventional Reversal Strategies}

In our first empirical analysis we investigate the extent to which conventional reversal strategies based on total stock returns exhibit dynamic exposures to the Fama and French (1993) (henceforth, Fama-French) factors. We use these factors in our analysis since they are widely accepted factors for explaining a large portion of the variability in U.S. stock returns. Reversal portfolios are constructed by sorting stocks at the end of each month into winner and loser portfolios based on their returns during that month. The winner portfolio consists of all the stocks with returns over the past month above the crosssectional average and the loser portfolio consists of stocks with returns below the cross-sectional average, with weights inversely proportional to each stock's past one-month return in excess of the return on the equally-weighted index as in Equation (3.2). Later in our study we employ alternative portfolio weighting schemes, including equal- and value-weighting. As we discuss in detail in Section $3.4 \mathrm{E}$ of the chapter, the outcomes of our study are virtually identical for all these weighting schemes.

Next, we estimate the winner and loser portfolios' exposures to the Fama-French factors at the end of each month by taking the weighted factor 
exposures of all stocks in the winner and loser portfolios. Exposures to the Fama-French factors are estimated over the preceding 36 months $[t-36, t-1]$ from

$$
r_{i, t}=\alpha_{i}+\beta_{i}^{M} R M R F_{t}+\beta_{i}^{S M B} S M B_{t}+\beta_{i}^{H M L} H M L_{t}+\varepsilon_{i, t},
$$

where $r_{i, t}$ is the return of stock $i$ in month $t$ in excess of the one-month U.S. Treasury bill rate; $R M R F_{t}, S M B_{t}$ and $H M L_{t}$ are the three Fama-French factors representing the market factor, the size factor and the value factor, respectively; $\alpha_{i}, \beta_{i}^{M}, \beta_{i}^{S M B}$ and $\beta_{i}^{H M L}$ are parameters to be estimated; and $\varepsilon_{i, t}$ is the residual return of stock $i$ in month $t$.

In Figure 3.1 we plot the estimated factor exposures of the winner and loser portfolios against the returns of the Fama-French factors in month $t$ - 1 . Panel A shows the market betas against the excess return on the market portfolio during the formation month. The solid line in the figure represents the linearly fitted relation between the beta of the loser portfolio and the market return, and the dashed line represents this relation for the winner portfolio. Consistent with the predictions of our analytical model in the previous section we observe a negative relation between the market beta of the loser portfolio and lagged market returns, and a positive relation for the winner portfolio. Hence, a conventional reversal strategy that is long in loser stocks and short in winner stocks exhibits dynamic exposures to the market factor depending on the sign and magnitude of the return on the market factor during the formation month $t$ - 1 .

Likewise, Panels B and Panel C of Figure 3.1 plot the $S M B$ and $H M L$ factor exposures of the winner and the loser portfolios against the formation period returns on the $S M B$ and $H M L$ factors, respectively. We clearly observe that the conventional reversal strategy also exhibits dynamic exposures to these two common factors. In months during which the return on the $S M B$ factor was positive, the winner portfolio typically consists of smallcapitalization stocks while the loser portfolio typically consists of largecapitalization stocks. In months during which the return on the $H M L$ factor was positive, the winner portfolio typically consists of value stocks while the loser portfolio typically consists of growth stocks. The results of our first empirical analysis demonstrate that conventional reversal strategies exhibit dynamic exposures to the Fama-French factors. 
Figure 3.1: Formation Period Loadings of the Conventional Reversal Strategy This figure plots the estimated factor exposures of total return winner portfolios and loser portfolios against the returns of the Fama and French (1993) factors in month $t$-1. Panel A shows the market betas of the winner and loser portfolios against the excess return on the market portfolio during the formation month and Panel B and C show the $S M B$ factor exposures and $H M L$ factor exposures against the formation period returns on the $S M B$ and $H M L$ factors, respectively. The solid line in the figure represents the linearly fitted relation between the factor exposure of the loser portfolio and the factor return and the dashed line represents this relation for the winner portfolio. The sample period is from January 1929 to December 2010 and the sample includes all common U.S. stocks listed on the NYSE, AMEX and Nasdaq markets that have, at the end of the formation month, a market capitalization above the NYSE median, a price above $\$ 5$ and return data for all preceding 36 months.
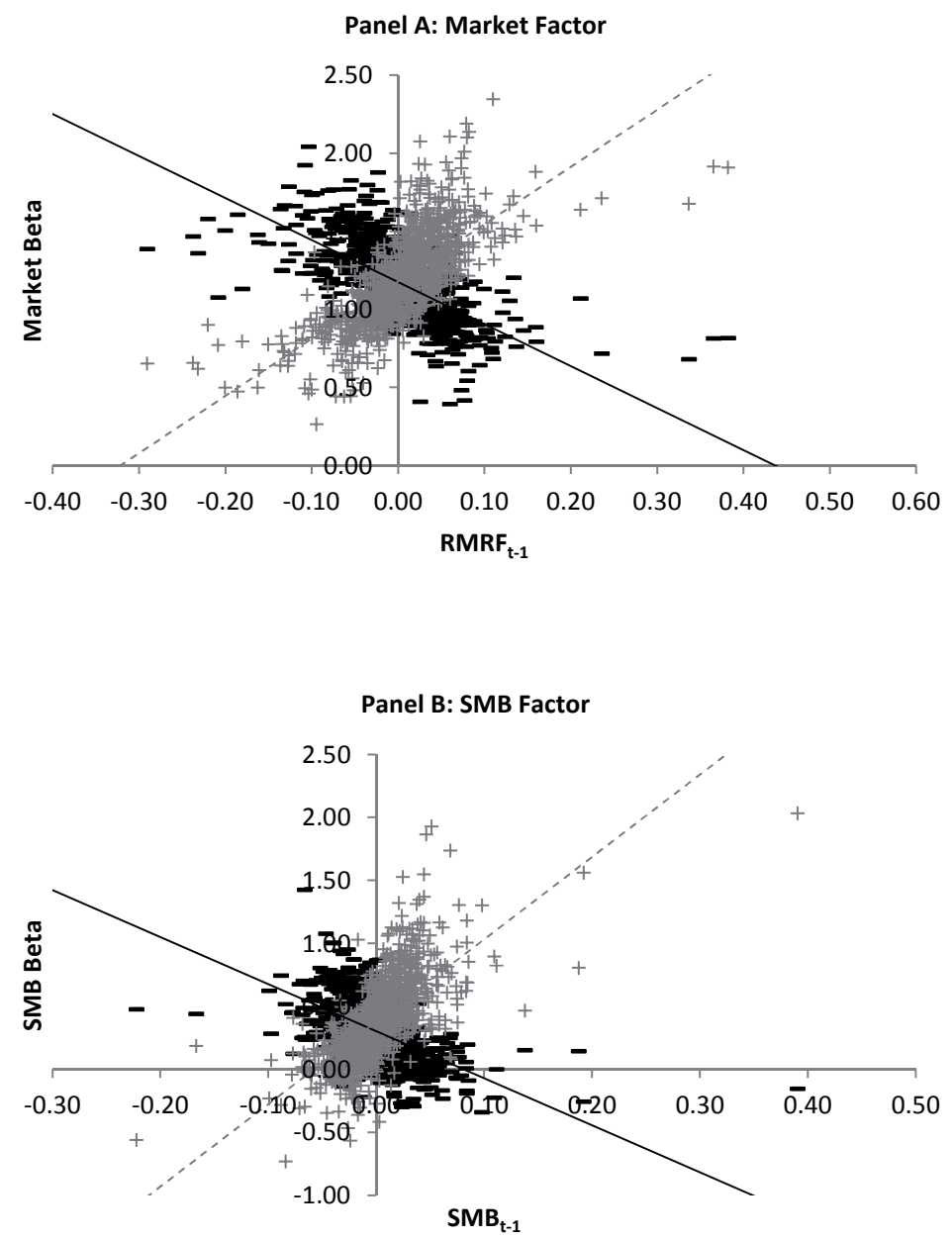

continues on next page 


\section{Figure 3.1 - continued from previous page}

This figure plots the estimated factor exposures of total return winner portfolios and loser portfolios against the returns of the Fama and French (1993) factors in month $t$-1. Panel A shows the market betas of the winner and loser portfolios against the excess return on the market portfolio during the formation month and Panel B and $\mathrm{C}$ show the $S M B$ factor exposures and $H M L$ factor exposures against the formation period returns on the $S M B$ and $H M L$ factors, respectively. The solid line in the figure represents the linearly fitted relation between the factor exposure of the loser portfolio and the factor return and the dashed line represents this relation for the winner portfolio. The sample period is from January 1929 to December 2010 and the sample includes all common U.S. stocks listed on the NYSE, AMEX and Nasdaq markets that have, at the end of the formation month, a market capitalization above the NYSE median, a price above $\$ 5$ and return data for all preceding 36 months.

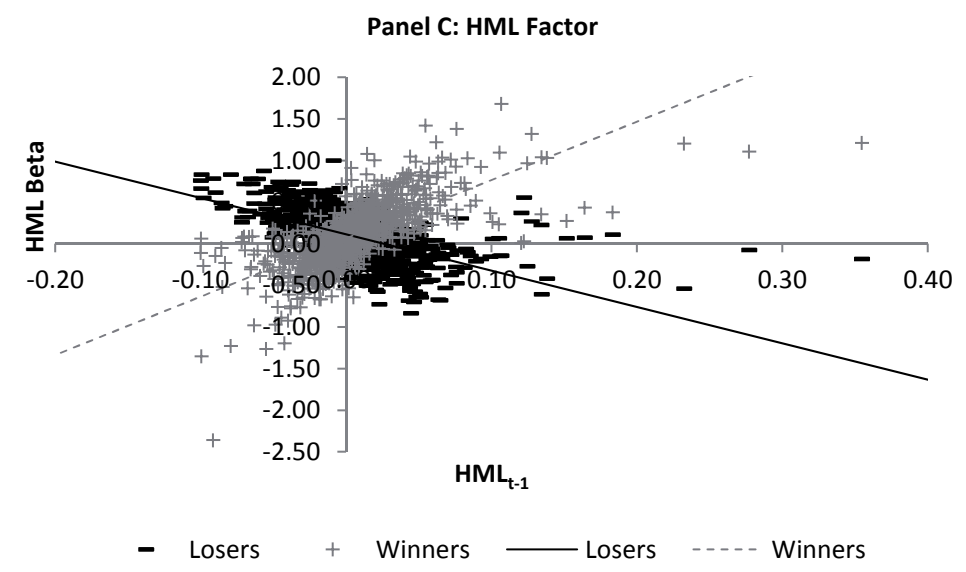

To illustrate the impact of the dynamic exposures to the Fama-French factors on the risks and profits of conventional reversal strategies, we evaluate reversal returns using a conditional factor model in the spirit of Grundy and Martin (2001):

$$
\begin{aligned}
r_{t} & =\alpha+\beta^{1} R M R F_{t}+\beta^{2} S M B_{t}+\beta^{3} H M L_{t}+\beta^{4} R M R F_{-} U P_{t} \\
& +\beta^{5} S M B_{-} U P_{t}+\beta^{6} H M L_{-} U P_{t}+\varepsilon_{i, t},
\end{aligned}
$$

where $R M R F_{-} U P_{t}, S M B_{-} U P_{t}$ and $H M L_{-} U P_{t}$ are interaction variables that indicate the excess returns on the RMRF, SMB and $H M L$ factors in month $t$, respectively, if the returns on the factors are positive in month $t$ - 1 , and zero otherwise. In this setup, finding significantly negative coefficients for the interaction variables is consistent with the factor exposures of reversal strategies being inversely related to the signs of the factor returns over the past month. 
The results of the conditional factor model analysis for the conventional reversal strategy are presented in Panel A of Table 3.1. Consistent with our expectation, the coefficient estimates for $R M R F_{t}$ and $H M L_{t}$ are significantly positive, while the estimates for $R M R F_{-} U P_{t}$ and $H M L_{-} U P_{t}$ are significantly negative. Only the exposures to the $S M B$ factor are insignificant, but this is not surprising in light of the fact that we exclude stocks with a share price below $\$ 5$ or a market capitalization below the NYSE median from our sample. The results of this analysis not only indicate that the dynamics of the conventional reversal strategy's factor exposures are statistically significant, but also that these exposures explain a significant portion of the strategy's risks. More specifically, the adjusted R-squared of 27 percent for our relatively simple conditional regression model indicates that over one-fourth of the variability in the conventional reversal strategy's returns can be attributed to dynamic factor exposures.

Our analytical analysis in the previous section showed that persistence in factor returns hurts the profitability of a conventional reversal strategy. As several authors report persistence in common factor returns (see, e.g., Fisher, 1966; Moskowitz and Grinblatt, 1999; and Chen and De Bondt, 2004), this concern is justified. Consistent with these studies we indeed observe shortterm momentum in common factor returns over our sample period. More specifically, over the January 1929 to December 2010 period, the market, size and value factors show positive persistence in 55, 54 and 56 percent of the months, respectively. ${ }^{15}$ Hence, we expect that the dynamic factor exposures of conventional reversal strategies negatively affect the strategies' profits. Consistent with this notion, we find that the alpha of the conventional reversal strategy following from the conditional model in Equation (3.15) is larger than its raw return. The conventional reversal strategy based on total stock returns earns an average return of 69 basis points per month, while the strategy's alpha is 87 basis points per month. The strategy's negative exposure to shortterm persistence in the Fama-French factors therefore appears to come at the cost of 18 basis points per month (87 minus 69). All in all, the results of this empirical analysis clearly show that the conventional reversal strategy's dynamic factor exposures significantly contribute to the strategy's risk and negatively affect its profitability.

\footnotetext{
${ }^{15}$ We measure persistence by the empirical probability of having two consecutive factor-return observations with the same sign.
} 


\section{Table 3.1: Reversal Returns and Dynamic Factor Exposures}

This table presents average monthly reversal strategy returns, standard deviations and annualized Sharpe ratios as well as coefficient estimates belonging to the conditional factor model explained in Equation (3.15) of the chapter. In Panel A, the results are reported for the conventional reversal strategy and Panel B reports the results for the residual reversal strategy. The sample period is from January 1929 to December 2010 and the sample includes all common U.S. stocks listed on the NYSE, AMEX and Nasdaq markets that have, at the end of the formation month, a market capitalization above the NYSE median, a price above $\$ 5$ and return data for all preceding 36 months. Newey-West corrected $t$-statistics are reported in parentheses.

\begin{tabular}{lcccccccc}
\hline \multicolumn{7}{l}{ Panel A: Conventional reversal strategy } \\
\begin{tabular}{cccccccc} 
Return & Stdev & Sharpe & & & & & \\
\hline 0.69 & 4.21 & 0.57 & & & & & \\
$(5.13)$ & & & & & & & \\
& & & & & & & \\
Alpha & RMRF & SMB & HML & RMRF_UP & SMB_UP & HML_UP & Adj. R \\
\hline 0.87 & 0.40 & -0.01 & 0.39 & -0.56 & -0.02 & -0.69 & 0.27 \\
$(7.41)$ & $(13.49)$ & $(-0.10)$ & $(7.82)$ & $(-13.04)$ & $(-0.23)$ & $(-10.47)$ &
\end{tabular}
\end{tabular}

Panel B: Residual reversal strategy

Return Stdev Sharpe

$0.90 \quad 2.60 \quad 1.20$

(10.85)

\begin{tabular}{cccccccc} 
Alpha & RMRF & SMB & HML & RMRF_UP & SMB_UP & HML_UP & Adj. R \\
\hline 0.90 & 0.12 & -0.03 & 0.02 & -0.08 & 0.08 & -0.12 & 0.04 \\
$(10.89)$ & $(5.54)$ & $(-0.77)$ & $(0.49)$ & $(-2.57)$ & $(1.65)$ & $(-2.48)$ & \\
\hline
\end{tabular}

\section{Factor Exposures of Reversal Strategies Based on Residual Returns}

As an alternative to a conventional reversal strategy based on total stock returns, we propose to construct reversal portfolios based on residual stock returns resulting from performing rolling regressions using the Fama and French (1993) model. More specifically, we construct residual reversal portfolios by sorting stocks into a winner and a loser portfolio at the end of each month based on their estimated residual returns during that month. For each stock $i$ and each formation month $t$-1, we estimate Equation (3.14) using stock returns over the preceding 36 months $[t-36, t-1]$. Next, the estimated residual returns are standardized by dividing them by their standard deviations over the preceding 36 months. Standardization of the residual returns yields an improved measure of the extent to which a given firmspecific return shock is actually news, opposed to noise. This facilitates a better interpretation of the residual as firm-specific information (see Gutierrez and Pirinsky, 2007). Following the portfolio construction for the conventional reversal strategy, the winner (loser) portfolio of the residual reversal strategy 
consists of the stocks with an above (below) average standardized residual return.

Both portfolios are designed to be orthogonal to the Fama-French factors. To investigate the extent to which the factors are actually factorneutral, we plot the factor exposures of the winner and loser portfolios of the residual reversal strategy against the factor returns during the formation month in Figure 3.2. The residual reversal strategy clearly succeeds in avoiding dynamic factor exposures. While Figure 3.1 shows an "X"-shaped relation between the factor exposures and lagged factor returns for the conventional reversal strategy's winner and loser portfolios, such a relation is not observable for the residual reversal strategy's winner and loser portfolios.

Panel B of Table 3.1 shows the conditional regression results for the residual reversal strategy. As expected, the residual reversal strategy outperforms the conventional reversal strategy in terms of both raw returns and risk-adjusted returns. The residual reversal strategy on average earns 90 basis points per month, which is 21 basis points more than the conventional reversal strategy. Moreover, the coefficient estimates of the conditional regression model in Equation (3.15) are much closer to zero compared to coefficient estimates for the conventional reversal strategy. At the same time, the $\mathrm{R}$-squared value of the conditional regression model for the residual reversal strategy is close to zero. As a result, the alpha of the residual reversal strategy is virtually identical to the strategy's return. This observation is consistent with the predictions that follow from the analytical analysis discussed in the previous section. We also note that the alphas of the conventional and residual reversal strategies are almost identical, at 87 and 90 basis points per month, respectively. Assuming the conditional regression model from Equation (3.15) is able to pick up the (dynamics in) factor exposures correctly, this is again consistent with the predictions that follow from the analytical analysis. To see this, compare Equations (3.4) and (3.12) and notice that differences in the expected profits of the two reversal strategies only arise as a result of differences in factor exposures, for which we correct using the conditional regression model. Finally, note that compared to the conventional reversal strategy, the residual reversal strategy's profits are also substantially less volatile. As a result, its Sharpe ratio of 1.20 is more than twice as large as the 0.57 Sharpe ratio of the conventional reversal strategy. Hence, we conclude that ranking stocks on their residual returns is an 
Figure 3.2: Formation Period Loadings of the Residual Reversal Strategy

This figure plots the estimated factor exposures of residual return winner portfolios and loser portfolios against the returns of the Fama and French (1993) factors in month $t$-1. Panel A shows the market betas of the winner and loser portfolios against the excess return on the market portfolio during the formation month and Panel B and $\mathrm{C}$ show the $S M B$ factor exposures and $H M L$ factor exposures against the formation period returns on the $S M B$ and $H M L$ factors, respectively. The solid line in the figure represents the linearly fitted relation between the factor exposure of the loser portfolio and the factor return and the dashed line represents this relation for the winner portfolio. The sample period is from January 1929 to December 2010 and the sample includes all common U.S. stocks listed on the NYSE, AMEX and Nasdaq markets that have, at the end of the formation month, a market capitalization above the NYSE median, a price above $\$ 5$ and return data for all preceding 36 months.
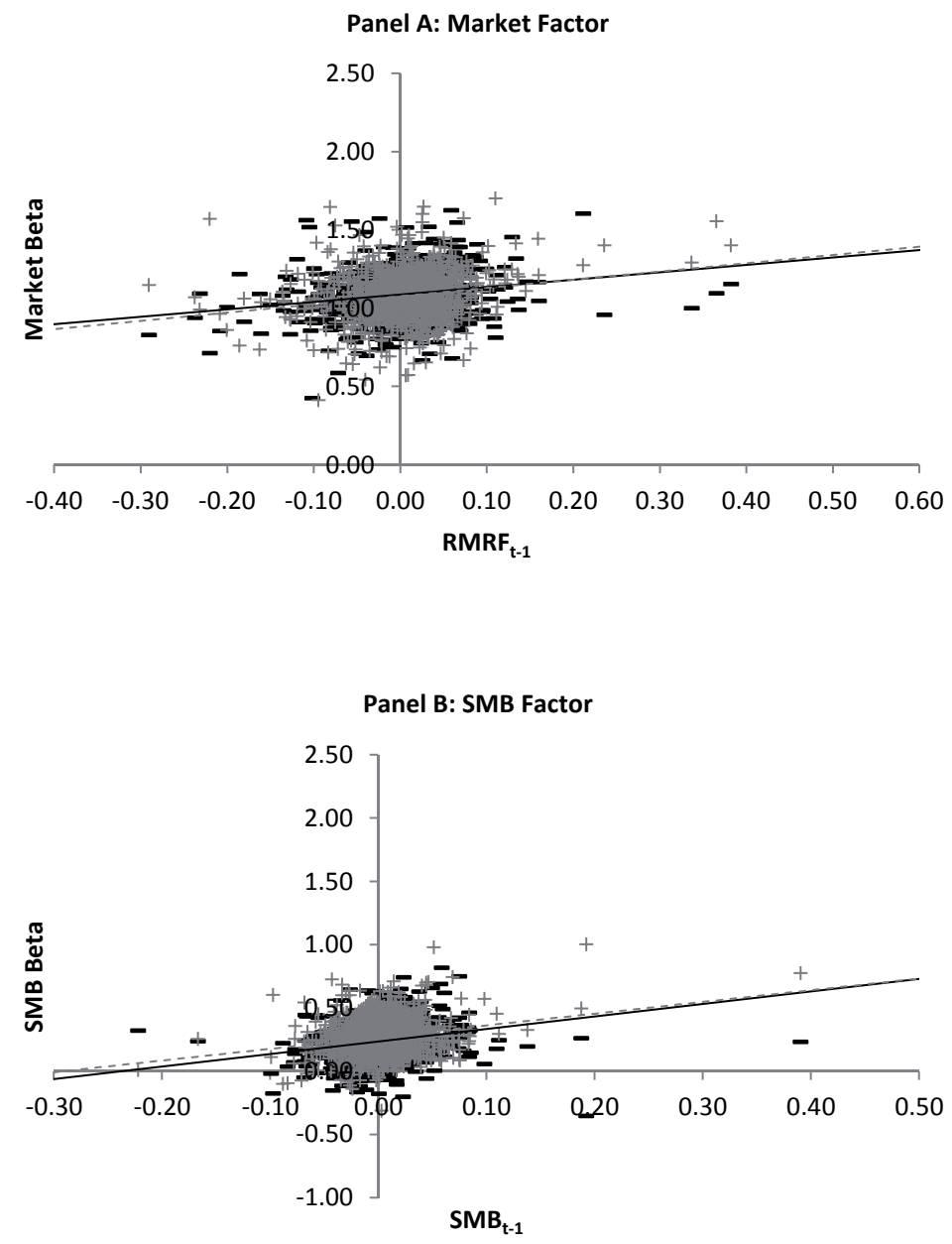

continues on next page 
Figure 3.2 - continued from previous page

This figure plots the estimated factor exposures of residual return winner portfolios and loser portfolios against the returns of the Fama and French (1993) factors in month $t$-1. Panel A shows the market betas of the winner and loser portfolios against the excess return on the market portfolio during the formation month and Panel B and $\mathrm{C}$ show the $S M B$ factor exposures and $H M L$ factor exposures against the formation period returns on the $S M B$ and $H M L$ factors, respectively. The solid line in the figure represents the linearly fitted relation between the factor exposure of the loser portfolio and the factor return and the dashed line represents this relation for the winner portfolio. The sample period is from January 1929 to December 2010 and the sample includes all common U.S. stocks listed on the NYSE, AMEX and Nasdaq markets that have, at the end of the formation month, a market capitalization above the NYSE median, a price above $\$ 5$ and return data for all preceding 36 months.

Panel C: HML Factor

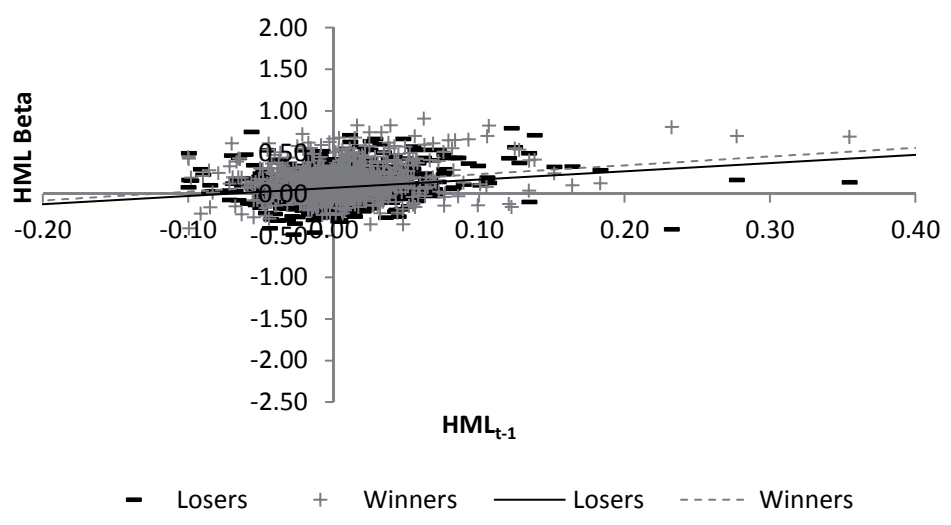

effective approach for neutralizing the dynamic factor exposures that are present in conventional reversal strategies based on total returns.

\section{Robustness over Time}

Our results in the previous subsection are based on the full January 1929 to December 2010 period. We now investigate both reversal strategies' profits over time and in different subperiods. Figure 3.3 displays the cumulative returns for a hypothetical $\$ 1$ invested in each of the two reversal strategies in January 1929. We observe that the graph corresponding to the residual reversal strategy (black) is steeper than the graph corresponding to the conventional reversal strategy (grey). Moreover, whereas the return on the conventional reversal strategy appears to flatten off over the most recent 20 years of our sample, the cumulative return of the residual reversal strategy portfolio continues to increase during the same period. 


\section{Figure 3.3: Cumulative Reversal Returns}

This figure plots the cumulative returns from January 1929 to December 2010 for a hypothetical $\$ 1$ invested in the conventional reversal strategy (grey) and the residual reversal strategy (black). The sample includes all common U.S. stocks listed on the NYSE, AMEX and Nasdaq markets that have, at the end of the formation month, a market capitalization above the NYSE median, a price above $\$ 5$ and return data for all preceding 36 months.

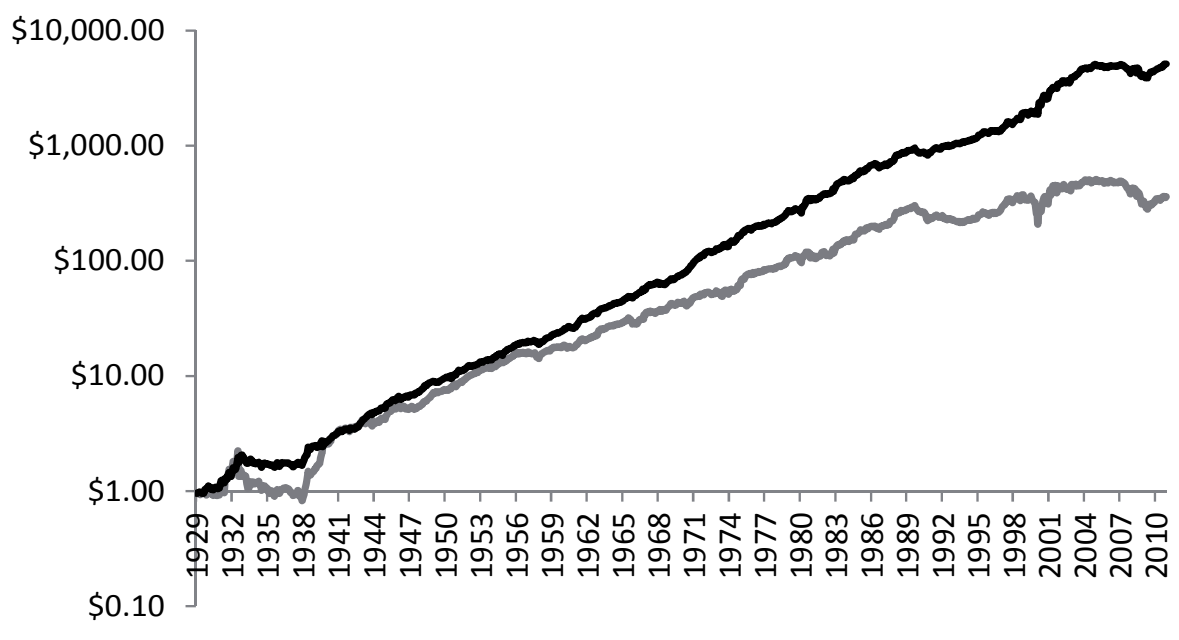

Conventional reversal $\longrightarrow$ Residual reversal

We further examine the performance of both reversal strategies over time by calculating average returns and Sharpe ratios for each decade in our sample. As reported in Table 3.2, the conventional reversal strategy earns significant profits in five of the eight decades. Notably, the strategy is not profitable during the two most recent decades of our sample. This finding is consistent with results of Stivers and Sun (2011) who also document that the short-term reversal effect has substantially weakened over the post-1990 period, following the publication of several papers which describe the effect. In contrast, the residual reversal strategy earns significantly positive returns in each of the eight decades in our sample, including the 1990s and 2000s. Its return over these decades of 0.74 percent per month ( $t$-statistic of 3.89 ) is also not much different from its long-run average return. Even when we consider reversal profits over the most recent five years in our sample, which include the 'quant meltdown' in 2007, we observe that the residual reversal strategy outperforms the conventional reversal strategy in every single calendar year.

We argue that the weakening of the returns of a conventional reversal strategy can largely be attributed to the impact of the strategy's dynamic factor exposures being particularly negative over the two most recent decades 


\section{Table 3.2: Reversal Returns for Different Sample Periods}

This table presents average monthly returns and annualized Sharpe ratios per decade, the pre-1990 period, the post-1990 period and the last five years for the conventional reversal strategy and the residual reversal strategy. The test statistics and $p$-values of the Memmel (2003) corrected Jobson and Korkie (1981) test for equal Sharpe ratios are reported in the final two columns. The sample includes all common U.S. stocks listed on the NYSE, AMEX and Nasdaq markets that have, at the end of the formation month, a market capitalization above the NYSE median, a price above $\$ 5$ and return data for all preceding 36 months. Newey-West corrected $t$-statistics are reported in parentheses.

\begin{tabular}{lcccccccc}
\hline & \multicolumn{3}{c}{ Conventional reversal } & \multicolumn{3}{c}{ Residual reversal } & \multicolumn{2}{c}{ Jobson-Korkie test } \\
Time Period & Return & $t$-Stat & Sharpe & Return & $t$-Stat & Sharpe & z-score & $p$-value \\
\hline $1929-1939$ & 1.01 & $(1.53)$ & 0.46 & 0.82 & $(2.25)$ & 0.68 & 2.94 & 0.01 \\
$1940-1949$ & 0.95 & $(3.90)$ & 1.23 & 1.09 & $(7.32)$ & 2.31 & 7.80 & 0.00 \\
$1950-1959$ & 0.74 & $(4.54)$ & 1.43 & 0.81 & $(5.89)$ & 1.86 & 3.11 & 0.00 \\
$1960-1969$ & 0.75 & $(3.82)$ & 1.21 & 0.95 & $(7.29)$ & 2.30 & 7.14 & 0.00 \\
$1970-1979$ & 0.78 & $(3.21)$ & 1.01 & 1.11 & $(6.71)$ & 2.12 & 9.03 & 0.00 \\
$1980-1989$ & 0.85 & $(2.97)$ & 0.94 & 1.00 & $(4.26)$ & 1.35 & 5.89 & 0.00 \\
$1990-1999$ & 0.00 & $(0.02)$ & 0.00 & 0.69 & $(3.97)$ & 1.26 & 11.15 & 0.00 \\
$2000-2010$ & 0.42 & $(0.80)$ & 0.24 & 0.79 & $(2.39)$ & 0.72 & 8.04 & 0.00 \\
& & & & & & & & \\
$1929-1989$ & 0.85 & $(5.84)$ & 0.75 & 0.96 & $(10.68)$ & 1.37 & 15.50 & 0.00 \\
$1990-2010$ & 0.22 & $(0.72)$ & 0.16 & 0.74 & $(3.89)$ & 0.85 & 13.35 & 0.00 \\
& & & & & & & & \\
2006 & 0.07 & $(0.13)$ & 0.13 & 0.31 & $(0.90)$ & 0.90 & 3.21 & 0.00 \\
2007 & -2.01 & $(-3.62)$ & -3.62 & -1.32 & $(-2.94)$ & -2.94 & 1.38 & 0.15 \\
2008 & -1.19 & $(-0.60)$ & -0.60 & -0.38 & $(-0.24)$ & -0.24 & 2.14 & 0.04 \\
2009 & 0.10 & $(0.09)$ & 0.09 & 0.98 & $(1.25)$ & 1.25 & 3.05 & 0.00 \\
2010 & 0.94 & $(1.21)$ & 1.21 & 1.15 & $(3.87)$ & 3.87 & 2.90 & 0.01 \\
\hline
\end{tabular}

of our sample. To gauge the magnitude of this negative impact we evaluate the performance of a reversal strategy based on systematic, i.e., non-residual stock returns over our full sample period and the period January 1990 to December 2010. ${ }^{16}$ For the pre-1990 period we find a return of -0.05 percent per month (with a $t$-statistic of -0.43), whereas for the period from 1990 onwards we find a return of -0.68 percent per month (with a $t$-statistic of -2.58). It thus appears that the negative return impact of a conventional reversal strategy's dynamic factor exposures has increased to a significant level over the two most recent decades. As the residual component of stock returns still exhibits a large

\footnotetext{
${ }^{16}$ More specifically, we construct a long-short systematic reversal portfolio by giving weights to stocks at the end of each month based on their estimated systematic returns during that month. For each stock $i$ and each formation month $t$-1, we estimate Equation (3.14) using stock returns over the preceding 36 months $[t-36, t-1]$. The winner (loser) portfolio of the systematic reversal strategy consists of the stocks with above (below) average systematic returns, i.e., $\hat{\beta}_{i}^{M} R M R F_{t-1}+\hat{\beta}_{i}^{S M B} S M B_{t-1}+\hat{\beta}_{i}^{H M L} H M L_{t-1}$, in spirit similar to Equation (3.2). The performance of a reversal strategy that is long in the loser portfolio and short in the winner portfolio is not presented in tabular form for the sake of brevity.
} 
reversal effect over this period, we conclude that the weak performance of conventional reversal strategies over the past two decades is largely attributable to the detrimental impact of the strategies' dynamic factor exposures over this particular period.

Table 3.2 also shows that the residual reversal strategy outperforms the conventional reversal strategy in all but one decade in our sample in terms of raw returns, and in each decade in our sample in terms of risk-adjusted returns. The Jobson and Korkie (1981) test statistics show that the difference in Sharpe ratios is statistically significant in each decade. To summarize, our subperiod results show that the residual reversal strategy exhibits a strong performance relative to the conventional reversal strategy, not only in the long run, but also during each of the eight decades in our sample period.

\subsection{Reversal Profits and Trading Costs}

Consistent with most of the literature, we find that reversal strategies yield large positive returns. The results obtained hitherto, however, ignore the impact of trading costs, such as bid-ask spreads, commissions and price impact costs. A recent strand of literature re-examines stock market anomalies after incorporating trading costs. For example, Lesmond et al. (2004) and Korajczyk and Sadka (2004) argue that momentum profits are difficult to capture because momentum strategies require frequent rebalancing, while Chordia et al. (2009) study the profitability of an investment strategy based on the postearnings-announcement drift and find that trading costs of the strategy are likely to be larger than the hypothetical profits. Directly related to our study, several studies find that a large portion of the profitability of a conventional reversal strategy disappears once trading costs are taken into account (see, e.g., Ball et al., 1995; Conrad et al., 1997; and Avramov et al., 2006). In particular, Avramov et al. (2006) find that stocks with the smallest capitalization and highest illiquidity exhibit the largest reversals. These stocks are also very expensive to trade, however. After taking trading costs into account, the authors find that a conventional reversal strategy does not yield positive net returns.

Consistent with Avramov et al. (2006) and most of the related literature, we construct equally-weighted decile and quintile reversal portfolios of stocks and estimate trading costs using the model of Keim and Madhavan (1997) to investigate if reversal profits remain significant once trading costs are taken into account. Keim and Madhavan provide estimates of trading costs for 21 
institutions from 1991 to 1993. These trading cost estimates include commissions paid as well as an estimate of the price impact (including the impact of crossing the bid-ask spread) of the trades. Since trading costs are likely to be substantially larger before this period and because we have no reliable estimates before the 1990s we perform this part of our analysis over the period of January 1990 to December 2010. Based on the Keim and Madhavan (1997) estimates, we model trading costs such that the costs of buyinitiated orders and sell-initiated orders are equal to

$$
C_{i, t}^{\text {Buy }}=0.767+0.336 D_{i}^{\text {Nasdaq }}-0.084 \ln \left(\operatorname{size}_{i, t}\right)+\frac{13.807}{P_{i, t}}
$$

and

$$
C_{i, t}^{\text {Sell }}=0.505+0.058 D_{i}^{\text {Nasdaq }}-0.059 \ln \left(\text { size }_{i, t}\right)+\frac{6.537}{P_{i, t}}
$$

respectively, where $C_{i, t}^{\text {Buy }}\left(C_{i, t}^{\text {Sell }}\right)$ is the trading cost at time $t$ in case order $i$ is a buy-initiated (sell-initiated) order; $D_{i}^{\text {Nasdaq }}$ is a dummy variable that takes the value one for stocks traded on the Nasdaq markets and is zero otherwise; size $e_{i, t}$ is the market capitalization in month $t$ of the stock traded; and $P_{i, t}$ is the price per share of the stock traded at time $t$. Furthermore, we restrict the trading costs of a single order to be nonnegative.

The profits of both reversal strategies over this recent period are shown in Table 3.3, Panel A. As discussed in the previous section, the average gross returns of both reversal strategies are lower over this period compared to those over the full 1929-2010 sample period. In fact, the return on the conventional reversal strategy is only 25 basis points per month and statistically indistinguishable from zero over the post-1990 period. Not surprisingly therefore, the net returns of the conventional reversal strategy even become negative after estimated trading costs are taken into account. These findings are consistent with the results reported by Avramov et al. (2006). The residual reversal strategy, however, earns an average gross return of 102 basis points per month over the same period. Even after trading costs are taken into account, the strategy remains highly profitable, with a net return of 66 basis points per month. We estimate that the break-even level is reached for trading 
costs of 56 basis points for a round-trip transaction. With such a high breakeven level, it seems very unlikely that trading costs prevent profitable execution of a residual reversal strategy. Examining the distribution of trading costs for the cross-section of stocks over time, we find that the $80^{\text {th }}$ percentile corresponds to roughly 60 basis points per roundtrip transaction. In other words, trading costs would only subsume the profits of the residual reversal strategy if the strategy would systematically trade in the 20 percent most illiquid stocks in our sample. The results also show that the net returns, in excess of the CRSP total return index, of the individual long (Losers) and short (Winners) portfolios of the residual reversal strategy are both significantly positive and roughly equally large. This finding indicates that the residual reversal profits are not concentrated in short positions.

We further evaluate the profitability of reversal strategies by excluding small cap stocks from our sample. Panels B and C of Table 3.3 show the results for, respectively, the largest 500 and largest 100 stocks in our sample. ${ }^{17}$ For both subsamples the net profits of the conventional reversal strategy are not significantly larger than zero. In contrast, with net returns of 60 and 73 basis points per month, the residual reversal strategy generates statistically and economically significant profits for both subsamples. The estimated break-even levels of trading costs are 46 and 47 basis points per round-trip transaction.

Besides taking into account trading costs, we also want to incorporate the effect of a potential implementation lag that might occur with a real-time application of a reversal strategy. To this end we additionally compute stock returns using return data from the daily CRSP Stock database, skipping the first trading day of each month. ${ }^{18}$ The returns of the reversal strategies with a one-day skip are presented in the third column of Table 3.3. Even after taking trading costs as well as an implementation lag into account, we find that the residual reversal strategies for the 500 and 100 largest stocks in our sample generate large net profits of 44 and 54 basis points per month, respectively. We can therefore safely conclude that it is very unlikely that real-life frictions such as trading costs and implementation lags prevent the profitable execution of residual reversal strategies.

${ }^{17}$ In order to have a sufficient large number of stocks in the portfolios, we sort stocks into quintiles instead of deciles when we evaluate the profitability of reversal strategies for the largest 500 and 100 stocks in our sample.

${ }^{18}$ By skipping the first day after portfolio formation the results should also be less affected by potential bid-ask bounce effects. 


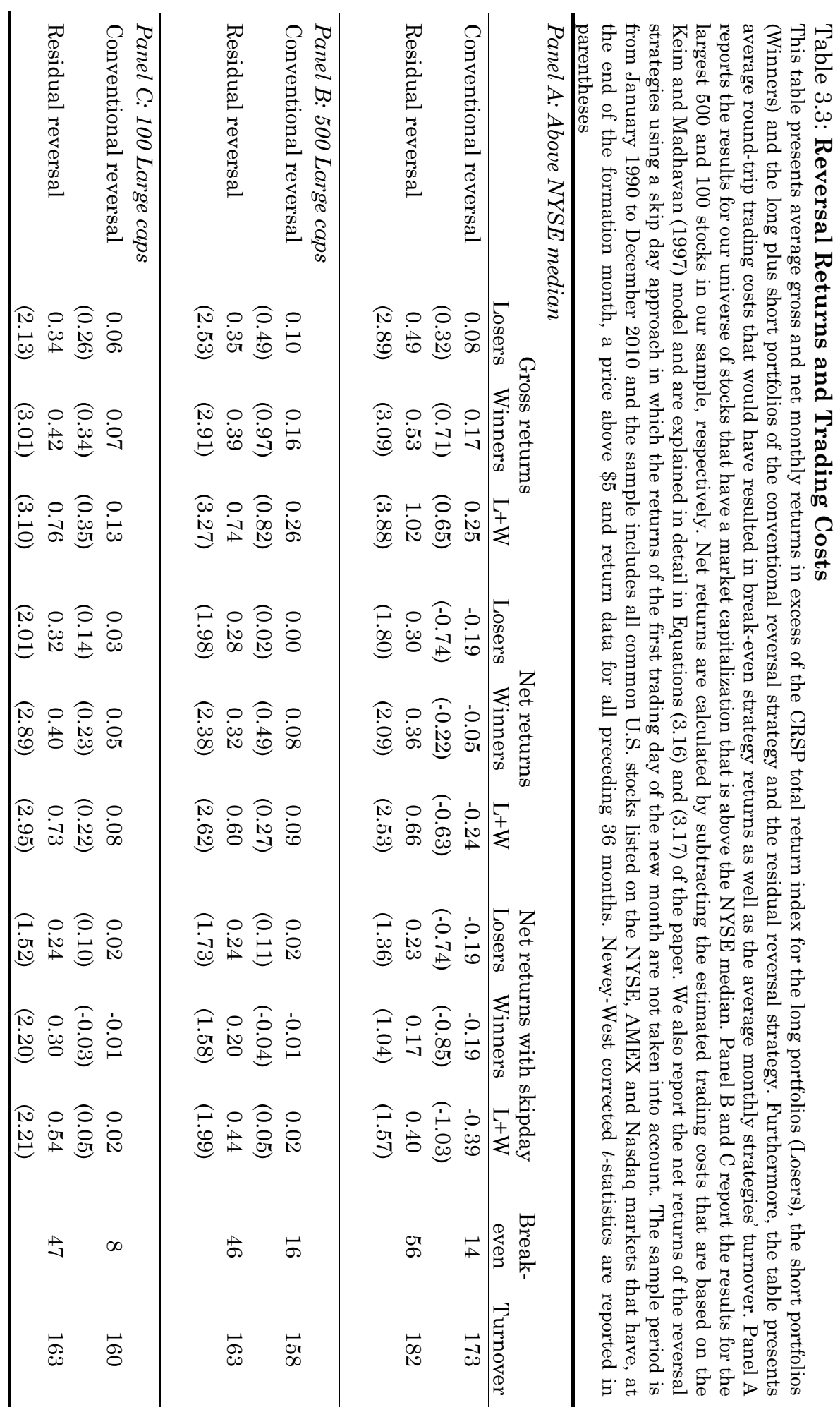


An important note we would like to make is that our approach to examine the economic significance of reversal profits is likely to be conservative. First, as Keim and Madhavan (1997) show in their study, trading style may have a significant impact on trading costs. For example, technical traders that follow momentum-like strategies and have a great demand for immediacy typically experience large bid-ask costs, since the market demand for the stocks they aim to buy is substantially larger than the supply, and vice versa for sell transactions. In their study, Keim and Madhavan (1997) also find that technical traders generally experience higher trading costs than traders following strategies that demand less immediacy, such as value traders or index managers, and adjust trading cost estimates for these styles. Lehmann (1990) argues that short-term reversal traders are liquidity providers, and likely benefit from buying (shorting) prior period losers (winners) near the bid (ask). The Keim and Madhavan (1997) model, however, does not make an adjustment for liquidity-providing trading styles, such as reversal strategies. Because reversal strategies provide liquidity, trading costs are likely to be somewhat lower than the estimates we use in this analysis.

Second, in this study we investigate naïve top-minus-bottom decile reversal strategies that are rebalanced at a monthly frequency. In a recent study, De Groot et al. (2012) show that applying a more sophisticated portfolio construction algorithm can help to significantly reduce the turnover of reversal strategies without lowering their expected returns. In their application, the authors find that more sophisticated buy/sell rules can approximately halve the negative impact of trading costs on reversal profits. By not taking into account the liquidity-providing nature of reversal trading, and by ignoring the potential efficiency gains that may be obtained with more sophisticated portfolio construction rules, our results are likely to underestimate the full profit potential of residual reversal investment strategies.

A final observation is that the higher net return of the residual reversal strategy compared to the conventional reversal strategy not only comes from its higher gross expected return, but also from incurring lower trading costs. For example, while the gross return difference between the conventional and residual reversal strategies is 77 basis points per month $(=102-25$ basis points; see Table 3.3), the difference in net returns is 90 basis points per month $(=66+24$ basis points). The reason for the lower trading costs of the residual reversal strategy is that, unlike the conventional reversal strategy, it does not trade excessively in volatile, small stocks. When stocks are ranked on 
raw past returns, stocks with the highest volatility have the greatest probability to end up in the extreme quantiles. These stocks are typically the stocks with the smallest market capitalizations. Therefore a portfolio that is long-short in the extreme quantiles is typically concentrated in the smallest stocks. However, these stocks are also the most expensive to trade, so this feature of the conventional reversal strategy is harmful to its after-cost profitability. Because the residual reversal strategy is constructed in such a way that it is neutral to the $S M B$ factor, we expect this effect to be less pronounced for the residual reversal strategy. To investigate whether this conjecture is true we consider the decile portfolios' characteristics for both reversal strategies in Table 3.4.

Consistent with the intuition that stocks with the highest volatility have the greatest probability to end up in the extreme quantiles when stocks are ranked on raw past returns, we observe that the top and bottom deciles for a conventional reversal strategy exhibit a substantially higher volatility than the mid-ranked portfolios. Furthermore, the portfolios' exposures to the $S M B$ factor are substantially larger and their ranks on market capitalization are lower. When we consider the characteristics of the top and bottom decile portfolios for the residual reversal strategy, we do not observe that the extreme deciles contain more volatile, small-cap stocks. As a consequence, the trading costs involved with the residual reversal strategy are significantly lower than the costs associated with the conventional reversal strategy. For example, the single-trip buy trading costs for loser stocks based on the conventional reversal strategy are 28 basis points, versus 18 basis points for the residual reversal strategy. Similarly, the single-trip sell costs for loser stocks based on the conventional reversal strategy are 4 basis points, compared to only 2 basis points for the residual reversal strategy.

\subsection{Follow-Up Empirical Analyses}

In this section we conduct several follow-up analyses. We first examine the comparative strength of both reversal strategies. Next, we investigate the profitability of both reversal strategies within industries. We then examine the relation between reversal strategies' dynamic factor exposures and their profitability using a non-parametric approach. This is followed by an analysis of calendar month effects. Finally, we examine the robustness of our results to using alternative portfolio weighting schemes. 


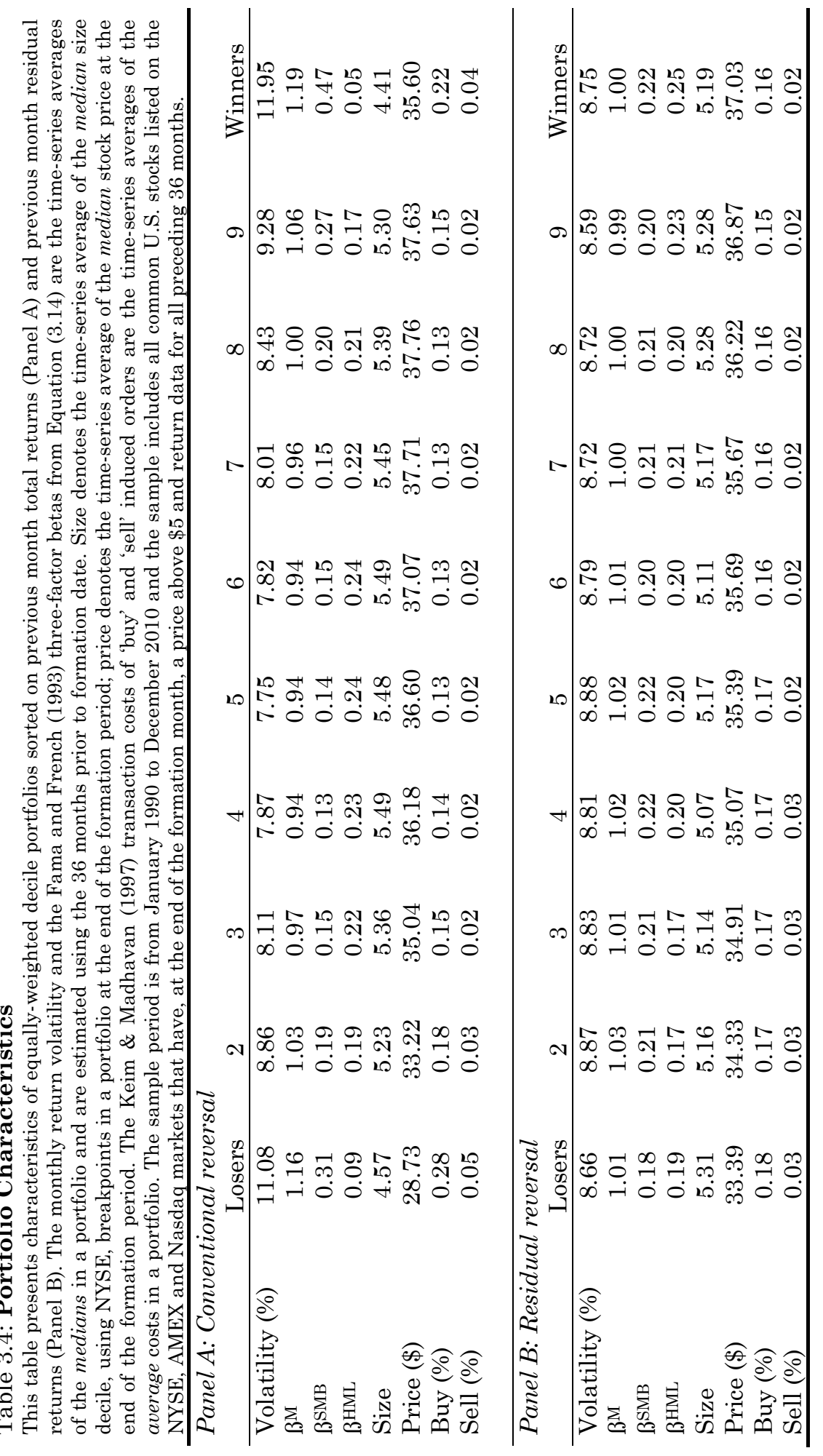




\section{A. Cross-Sectional Fama-MacBeth Regressions and Double-Sorted Portfolios}

In our next analysis we perform cross-sectional regressions in the spirit of Fama and MacBeth (1973) to investigate what portion of the predictive power of total stock returns can be attributed to the residual component of the return. These regressions are performed at the individual stock level, allowing us to control for other effects. More specifically, we estimate the following two equations every month:

$$
r_{i, t}=a_{t}+b_{1, t} z_{i, t-1}^{r}+b_{2, t} z_{i, t-1}^{\hat{\varepsilon}}+\delta_{t} X_{i, t-1}+u_{i, t}
$$

and

$$
r_{i, t}=a_{t}+b_{1, t} z_{-} L_{i, t-1}^{r}+b_{2, t} z_{-} W_{i, t-1}^{r}+b_{3, t} z_{-} L_{i, t-1}^{\hat{\varepsilon}}+b_{4, t} z_{-} W_{i, t-1}^{\hat{\varepsilon}}+\delta_{t} X_{i, t-1}+u_{i, t},
$$

where $z_{i, t-1}^{r}$ is a standardized score of stock $i$ 's return in month $t$ - $1 ; z_{i, t-1}^{\hat{\varepsilon}}$ is a standardized score of stock is standardized residual return in month $t$-1 estimated using Equation (3.14); $X_{i, t-1}$ is a vector of control variables; $z_{-} L_{i, t-1}^{r}$ and $z_{-} W_{i, t-1}^{r}\left(z_{-} L_{i, t-1}^{\hat{\varepsilon}}\right.$ and $\left.z_{-} W_{i, t-1}^{\hat{\varepsilon}}\right)$ are interaction variables that indicate the score $z_{i, t-1}^{r}\left(z_{i, t-1}^{\hat{\varepsilon}}\right)$ if stock $i$ is a loser stock or winner stock based on its return (residual return) in month $t$-1, respectively, and zero otherwise. ${ }^{19}$ Following Fama and French (2008), we include several variables in order to control for other effects that might explain the stock returns. These variables are the natural $\log$ of market capitalization, $\ln (M C)$; the natural $\log$ of the ratio between last fiscal year-end's book equity divided by market equity in December, $\ln (B / M)$; past twelve-minus-one month return, $R_{12 m 1}$; net stock issuance, $N S$; accruals, $A c / B$; growth in assets, $d A / A$; and profitability, $Y / B .{ }^{20}$ Data on firms' book values, net stock issuance, accruals, assets and profitability are obtained from the Compustat database. Since Compustat data are only available as from 1963, this analysis is performed over the July 1963 to December 2010 period.

The time-series averages of the monthly coefficient estimates are presented in Table 3.5. For the first regression specification, we observe

\footnotetext{
19 Standardization occurs in the cross-section and scores are truncated between the values -3 and 3.

${ }^{20}$ A detailed description of the exact definition of the variables can be found in Fama and French (2008).
} 


\section{Table 3.5: Cross-Sectional Fama-MacBeth (1973) Regressions}

This table presents time-series averages of monthly coefficient estimates (multiplied by 100) that follow from cross-sectional Fama and MacBeth (1973) type of regressions. The dependent variable is the monthly excess stock return. Independent variables are the standardized score of the one-month lagged stock return, $z^{r}$; the standardized score of the one-month lagged residual stock return (estimated using Equation 3.14 of the paper and scaled by the residual volatility), $z^{\varepsilon}$; interaction variables that equal $z^{r}\left(z^{\varepsilon}\right)$ if the stock is a loser stock, $z_{-} L^{r}\left(z_{-} L^{\varepsilon}\right)$ or winner stock, $z_{-} W^{r}\left(z_{-} W^{r}\right)$ based on its return (residual return) in the previous month, respectively, and zero otherwise; the natural log of market capitalization, $\ln (M C)$; the natural $\log$ of the ratio between last fiscal year-end's book equity divided by market equity in December, $\ln (B / M)$; past twelve-minus-one month return, $R_{12 m 1}$; net stock issuance, $N S$; accruals, $A c / B$; growth in assets, $d A / A$; and profitability, $Y / B$. The sample period is from July 1963 to December 2010 and the sample includes all common U.S. stocks listed on the NYSE, AMEX and Nasdaq markets that have, at the end of the formation month, a positive book-tomarket ratio, a market capitalization above the NYSE median, a price above $\$ 5$ and return data for all preceding 36 months. Newey-West corrected $t$-statistics are reported in parentheses.

\begin{tabular}{|c|c|c|c|c|c|c|}
\hline & Total & Residual & Both & Total & Residual & Both \\
\hline Constant & $\begin{array}{c}11.64 \\
(10.84)\end{array}$ & $\begin{array}{c}11.77 \\
(10.67)\end{array}$ & $\begin{array}{c}11.35 \\
(11.04)\end{array}$ & $\begin{array}{c}11.31 \\
(10.82)\end{array}$ & $\begin{array}{c}11.74 \\
(10.70)\end{array}$ & $\begin{array}{c}11.05 \\
(10.95)\end{array}$ \\
\hline$z^{r}$ & $\begin{array}{c}-0.28 \\
(-4.73)\end{array}$ & & $\begin{array}{c}0.11 \\
(1.03)\end{array}$ & & & \\
\hline$z^{\varepsilon}$ & & $\begin{array}{c}-0.35 \\
(-7.88)\end{array}$ & $\begin{array}{c}-0.44 \\
(-5.68)\end{array}$ & & & \\
\hline$z \_L^{r}$ & & & & $\begin{array}{c}-0.51 \\
(-6.70)\end{array}$ & & $\begin{array}{c}-0.24 \\
(-1.92)\end{array}$ \\
\hline$z_{-} W^{r}$ & & & & $\begin{array}{c}-0.13 \\
(-1.84)\end{array}$ & & $\begin{array}{c}0.29 \\
(2.34)\end{array}$ \\
\hline$z \_L^{\varepsilon}$ & & & & & $\begin{array}{c}-0.37 \\
(-6.02)\end{array}$ & $\begin{array}{c}-0.19 \\
(-2.06)\end{array}$ \\
\hline$z_{-} W^{e}$ & & & & & $\begin{array}{l}-0.33 \\
(-6.50)\end{array}$ & $\begin{array}{c}-0.58 \\
(-5.83)\end{array}$ \\
\hline $\ln (M C)$ & $\begin{array}{c}-0.75 \\
(-11.30)\end{array}$ & $\begin{array}{c}-0.76 \\
(-11.05)\end{array}$ & $\begin{array}{c}-0.73 \\
(-11.50)\end{array}$ & $\begin{array}{c}-0.73 \\
(-11.27)\end{array}$ & $\begin{array}{c}-0.76 \\
(-11.15)\end{array}$ & $\begin{array}{c}-0.70 \\
(-11.41)\end{array}$ \\
\hline $\ln (B / M)$ & $\begin{array}{c}0.03 \\
(0.33)\end{array}$ & $\begin{array}{c}0.04 \\
(0.46)\end{array}$ & $\begin{array}{c}0.07 \\
(0.74)\end{array}$ & $\begin{array}{c}0.05 \\
(0.48)\end{array}$ & $\begin{array}{c}0.04 \\
(0.45)\end{array}$ & $\begin{array}{c}0.08 \\
(0.87)\end{array}$ \\
\hline$R_{12 m 1}$ & $\begin{array}{c}0.68 \\
(2.58)\end{array}$ & $\begin{array}{c}0.61 \\
(2.31)\end{array}$ & $\begin{array}{c}0.53 \\
(2.11)\end{array}$ & $\begin{array}{c}0.68 \\
(2.62)\end{array}$ & $\begin{array}{c}0.62 \\
(2.37)\end{array}$ & $\begin{array}{c}0.53 \\
(2.15)\end{array}$ \\
\hline$N S$ & $\begin{array}{c}-0.83 \\
(-2.58)\end{array}$ & $\begin{array}{c}-0.91 \\
(-2.77)\end{array}$ & $\begin{array}{l}-0.88 \\
(-2.83)\end{array}$ & $\begin{array}{c}-0.88 \\
(-2.75)\end{array}$ & $\begin{array}{l}-0.90 \\
(-2.75)\end{array}$ & $\begin{array}{l}-0.92 \\
(-3.00)\end{array}$ \\
\hline$A c / B$ & $\begin{array}{c}0.08 \\
(0.26)\end{array}$ & $\begin{array}{c}0.04 \\
(0.14)\end{array}$ & $\begin{array}{c}0.13 \\
(0.42)\end{array}$ & $\begin{array}{c}0.08 \\
(0.27)\end{array}$ & $\begin{array}{c}0.04 \\
(0.13)\end{array}$ & $\begin{array}{c}0.13 \\
(0.42)\end{array}$ \\
\hline$d A / A$ & $\begin{array}{c}-0.24 \\
(-1.37)\end{array}$ & $\begin{array}{c}-0.26 \\
(-1.49)\end{array}$ & $\begin{array}{c}-0.31 \\
(-1.84)\end{array}$ & $\begin{array}{c}-0.28 \\
(-1.60)\end{array}$ & $\begin{array}{c}-0.27 \\
(-1.59)\end{array}$ & $\begin{array}{c}-0.34 \\
(-2.08)\end{array}$ \\
\hline$Y / B$ & $\begin{array}{c}0.32 \\
(0.90)\end{array}$ & $\begin{array}{c}0.28 \\
(0.82)\end{array}$ & $\begin{array}{c}0.28 \\
(0.78)\end{array}$ & $\begin{array}{c}0.37 \\
(1.03)\end{array}$ & $\begin{array}{c}0.29 \\
(0.85)\end{array}$ & $\begin{array}{c}0.33 \\
(0.91)\end{array}$ \\
\hline Adjusted R-square & 0.08 & 0.08 & 0.09 & 0.09 & 0.08 & 0.09 \\
\hline
\end{tabular}


statistically significant loadings on the z-scores of the lagged total returns $\left(z^{r}\right)$, indicating that past month stock returns have predictive power for future stock returns. However, once z-scores of lagged residual returns $\left(z^{c}\right)$ are included, all predictive power disappears. In the second regression specification, in which a distinction is made between (residual) return loser stocks and winner stocks, we observe an asymmetric total return reversal effect. The residual return reversal effect, on the other hand, is equally strong for loser stocks as for winner stocks. Including all four interaction variables results in significant reversal effects for residual return losers and winners, but no reversal effect for total return winners. This finding is in line with the results of Jegadeesh and Titman (1995a), who report that over- or underreaction to firm-specific information always contributes to the profitability of reversal strategies, while over- or underreaction to the systematic factors can either reduce or increase these profits.

We now continue our empirical analyses by constructing double-sorted rank portfolios to further investigate what portion of the predictive power of stocks' total returns can be attributed to the residual component of the return. For the sake of brevity, we do not report the results of this analysis in tabular form. To construct double-sorted rank portfolios, we start by sorting stocks into quintile portfolios based on their total returns and then subdivide each totalreturn quintile into quintiles based on the stocks' residual returns. In this way, we end up with a total of 25 portfolios that all contain an equal number of stocks. When we consider the portfolios' average returns over the investment month we observe that the returns are monotonically decreasing over the residual return quintiles within each total return quintile. The residual return loser quintile outperforms the residual return winner quintile by at least 62 basis points per month. Controlling for total returns, the loser-minus-winner spread is highly significant at 78 basis points per month. These results indicate that residual stock returns have predictive power for future stock returns above and beyond that of total stock returns.

Next, we perform a similar double-sorting procedure, but now first sorting stocks into quintiles based on their residual returns and next subdividing the stocks into quintiles based on their total returns. Interestingly, when we consider these portfolios' reversal-weighted returns over the investment month, we do not observe any return pattern at all across the portfolios sorted on total stock returns; the return spread between losers and winners is close to zero in all cases. Hence, after controlling for residual 
returns, total returns do not appear to have predictive power for future stock returns. These results corroborate our previous finding that most of the predictive power of total stock returns can be attributed to the residual component of the return.

\section{B. Within-Industry Reversal Profits}

In this section we explore the profitability of both reversal strategies within different industries. Our motivation to investigate this issue stems from the contemporaneous findings of Da et al. (2011) and Hameed et al. (2010), who report higher returns for within-industry reversal strategies. To investigate if the residualization of stock returns relative to the Fama-French factors goes above and beyond correcting for industry effects, we compare conventional and residual reversal strategies applied within each of the ten industries of French (2011). Similar to our earlier analyses, the winner (loser) portfolios consist of all the stocks with returns over the past month above (below) the crosssectional average, and the weights of stocks are set inversely proportional to the deviation of their past month return from the cross-sectional average industry return.

Table 3.6 reports the average monthly returns for both reversal strategies within each industry. The full-sample results in Panel A of Table 3.6 show that residualization not only improves the performance of a conventional reversal strategy, but also the performance of a within-industry reversal strategy. The average return increases from 0.90 to 1.12 percent per month and the Sharpe ratio doubles, from 0.99 to 1.98 . In fact, we observe that the residualization approach improves the Sharpe ratio within each of the ten different industries. In Panel B of Table 3.6 we examine the results over the post-1990 period. Comparing these results to those in Table 3.2 we observe that applying a conventional reversal strategy within industries does little to improve its weak performance over this period, with average returns increasing only marginally from 0.22 to 0.38 percent per month. The residual reversal strategy, on the other hand, continues to perform strongly over the same period, regardless of whether the strategy is applied within industries or not. For the within-industry application raw returns are slightly higher $(0.78$ percent per month versus 0.74 percent per month) and also risk-adjusted returns are much higher (Sharpe ratio of 1.35 versus 0.85 ).

These results imply that residualization offers distinct benefits that cannot be simply captured by neutralizing industry exposures and that, rather 


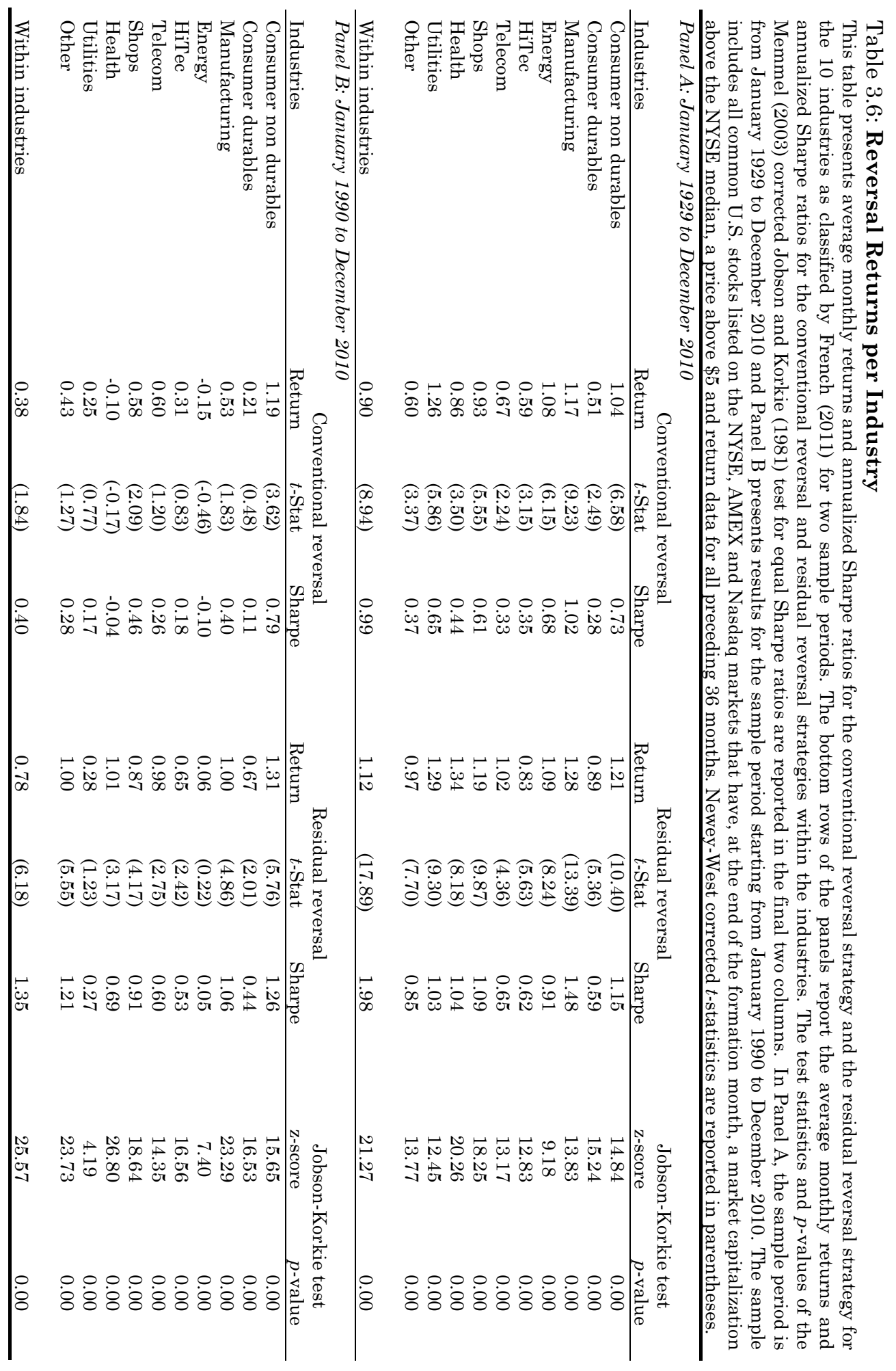


than being substitutes, the two approaches are complimentary to each other. To put it differently, a reversal strategy is in general most effective when both dynamic exposures to the Fama-French factors and dynamic exposures to industries are neutralized. This is consistent with the finding of several authors that the Fama and French factors do not suffice to describe the returns on industry portfolios (see, e.g., Fama and French, 1997).

\section{Non-Parametric Approach to Measuring Factor Exposures}

Most of our evidence reported so far on the impact of dynamic factor exposures on the profitability of reversal strategies relies on the outcomes of the conditional factor regressions in the spirit of Grundy and Martin (2001) we performed in the previous section. In this section we re-investigate the relation between reversal strategies' dynamic factor exposures and their profitability using a non-parametric approach that, unlike the factor regressions, does not rely on a linear factor structure. More specifically, with our non-parametric approach we regress the returns of the reversal strategies on dummy variables that indicate the number of Fama-French factors that revert (i.e., for which the sign of the return during the formation period and investment period are different). If reversal strategies exhibit dynamic factor exposures that are inversely related to the signs of the factor returns during the formation period, reversal profits are negatively affected by persistence in common factor returns and returns are lower when fewer factors revert.

The results of the analysis presented in Table 3.7 clearly indicate that a conventional reversal strategy exhibits dynamic factor exposures that affect its profitability: reversal profits appear to increase monotonically with the number of Fama-French factors that revert. When all Fama-French factors persist the strategy earns a negative return of -61 basis points per month. In contrast, when all Fama-French factors revert the conventional reversal strategy earns a highly positive return of 3.57 percent per month. Interestingly, the residual reversal strategy does not seem to exhibit such dynamic factor exposures as the strategy earns positive returns irrespective of the number of factors that revert, ranging between 0.70 and 1.51 percent per month. In all cases the residual reversal profits are highly significant. These results are consistent with our previous finding that a residual reversal strategy is less sensitive to the returns of common factors over the investment period than a conventional reversal strategy, resulting in less volatile returns. 


\section{Table 3.7: Reversal Returns Conditional on Factor Returns}

This table presents average monthly returns for the conventional reversal strategy and the residual reversal strategy conditional on the number of common factors that persist and revert. A factor persists (reverts) if the sign of the factor return in month $t$ is similar (opposite) to the sign of the factor return in month $t$ - 1 . The final column of the table reports the empirical probabilities of the four different states. The sample period is from January 1929 to December 2010 and the sample includes all common U.S. stocks listed on the NYSE, AMEX and Nasdaq markets that have, at the end of the formation month, a market capitalization above the NYSE median, a price above $\$ 5$ and return data for all preceding 36 months. $t$-Statistics are reported in parentheses.

\begin{tabular}{lccccc}
\hline & Conventional reversal & \multicolumn{2}{c}{ Residual reversal } & \\
& Return & $t$-Stat & Return & $t$-Stat & Probability \\
\hline All 3 factors persist & -0.61 & $(-2.08)$ & 1.00 & $(5.02)$ & 0.20 \\
1 factor reverts & -0.01 & $(-0.06)$ & 0.70 & $(5.90)$ & 0.37 \\
2 factors revert & 1.25 & $(6.27)$ & 0.85 & $(6.13)$ & 0.30 \\
All 3 factors revert & 3.57 & $(8.10)$ & 1.51 & $(4.76)$ & 0.12 \\
\hline
\end{tabular}

\section{Calendar-Month Effects}

Proceeding further, we investigate the performances of the conventional and residual reversal strategies per calendar month. Several authors document strong seasonal patterns in reversal returns (see, e.g., Grinblatt and Moskowitz, 2004). In particular, average reversal returns in January are found to be highly positive. The cited reason is the tax-loss selling effect: fund managers tend to sell small-cap loser stocks by the year-end, resulting in downward price pressure in that month, which is followed by an upward price pressure in January. Because a reversal strategy is long in small-cap loser stocks, this effect causes a large positive return for the strategy in January. We refer to Roll (1983), Griffiths and White (1993), and D'Mello et al. (2003) for a detailed discussion of this effect.

Because a residual reversal strategy is less concentrated in small-cap stocks compared to a conventional reversal strategy, we expect the January effect to have a smaller impact on the performance of a residual reversal strategy. To investigate this issue in more detail, we examine the average monthly returns during each calendar month for the conventional reversal versus the residual reversal strategy. The results of this analysis are presented in Table 3.8.

Consistent with the prior literature we observe that a large portion of the reversal profits are concentrated in January months. For example, the $t$ statistics of the conventional reversal strategy's returns exceed plus two in only four out of twelve months. By contrast, residual reversal returns have $t$ statistics larger than plus two in ten out of twelve months. Interestingly, when we consider the results of the same analysis for the post-1990 period, it even 
Table 3.8: Reversal Returns per Calendar Month

This table presents average returns for the conventional reversal strategy and the residual reversal strategy per calendar month for the sample period January 1929 to December 2010 in Panel A. Panel B presents average January returns and non-January returns for the sample period starting from January 1990 to December 2010. The sample includes all common U.S. stocks listed on the NYSE, AMEX and Nasdaq markets that have, at the end of the formation month, a market capitalization above the NYSE median, a price above $\$ 5$ and return data for all preceding 36 months. $t$-Statistics are reported in parentheses.

Panel A: January 1929 to December 2010

\begin{tabular}{lcccc} 
Month & \multicolumn{2}{c}{$\begin{array}{c}\text { Conventional reversal } \\
\text { Return }\end{array}$} & $t$-Stat & \multicolumn{2}{c}{ Residual reversal } \\
Return & $t$-Stat \\
\hline January & 2.51 & $(5.92)$ & 1.98 & $(6.76)$ \\
February & 0.56 & $(1.14)$ & 1.00 & $(3.49)$ \\
March & 1.11 & $(2.05)$ & 1.20 & $(3.03)$ \\
April & -0.14 & $(-0.38)$ & 0.23 & $(1.10)$ \\
May & 0.30 & $(0.97)$ & 0.82 & $(4.62)$ \\
June & 1.12 & $(2.25)$ & 1.12 & $(3.40)$ \\
July & 1.68 & $(3.31)$ & 1.35 & $(4.21)$ \\
August & 0.15 & $(0.25)$ & 0.60 & $(2.42)$ \\
September & 0.62 & $(1.67)$ & 0.67 & $(2.33)$ \\
October & 0.53 & $(1.18)$ & 0.83 & $(2.54)$ \\
November & -0.47 & $(-1.08)$ & 0.24 & $(1.03)$ \\
December & 0.30 & $(0.68)$ & 0.82 & $(3.48)$
\end{tabular}

Panel B: January 1990 to December 2010

\begin{tabular}{lcccc} 
& \multicolumn{2}{c}{ Conventional reversal } & \multicolumn{2}{c}{ Residual reversal } \\
Month & Return & $t$-Stat & Return & $t$-Stat \\
\hline January & 2.11 & $(2.31)$ & 2.03 & $(3.96)$ \\
Non-Januaries & 0.05 & $(0.16)$ & 0.63 & $(3.10)$ \\
\hline
\end{tabular}

appears to be the case that the conventional reversal strategy only earns positive returns in January months; the return during non-January months is an insignificant 0.05 percent. The residual reversal strategy, on the other hand, not only earns positive returns in January months, but also shows large positive returns of 0.63 percent on average in non-January months. We thus conclude that residual reversal strategies are also more robust than conventional reversal strategies during the calendar year.

\section{E. Alternative Weighting Schemes}

Throughout our study, we performed most of our analyses on return-weighted portfolios. Our reason for doing so is that, while there does not seem to be a consensus in the literature on the use of a particular weighting scheme, several important studies on the reversal effect employ a return-weighting scheme to construct reversal portfolios (see, e.g., Lehmann, 1990; Lo and 
MacKinlay, 1990; Jegadeesh and Titman, 1995a; and Da et al., 2011). However, there are also studies that employ equally-weighted portfolios instead (see, e.g., Jegadeesh, 1990; Boudoukh et al., 1994; Avramov et al., 2006; Hameed et al., 2010; Stivers and Sun, 2011; and De Groot et al., 2012), while the short-term reversal factor of French (2011) is constructed using a value-weighting scheme. To investigate the robustness of our findings to the use of alternative weighting schemes we redo all our analyses using equalweighted and value-weighted decile portfolios. For the sake of brevity the results of these analyses are not reported in tabular form in this thesis. While the results of the analyses using the alternative weighting schemes are qualitatively very similar, the results are generally the strongest for the equally-weighting scheme (e.g., the returns of the conventional and residual reversal strategies are 0.92 and 1.28 percent per month, respectively, versus 0.69 and 0.87 percent per month for the return-weighting scheme; see Table 3.1), and somewhat less pronounced using the value-weighting scheme (e.g., the returns of the conventional and residual reversal strategies are 0.53 and 0.74 percent per month, respectively). For both alternative weighting schemes the residual reversal strategy is more than thirty percent less volatile compared to the conventional reversal strategy, and also for both alternative weighting schemes the profits of the residual reversal strategy remain statistically and economically large over the most recent decades in our sample. We conclude that our results are robust to the weighting scheme used to construct reversal portfolios.

\subsection{Explanations for Short-Term Stock Reversals}

In this section we discuss alternative hypotheses that have been put forward in the academic literature for understanding the reversal anomaly and the extent to which our results are consistent with the predictions following from these explanations. The literature on short-term stock reversals provides three main explanations for the effect: (i) reversals are the result of liquidity effects (see, e.g., Jegadeesh and Titman, 1995b); (ii) reversals originate from nonsynchronous trading of small and large cap stocks (see, e.g., Lo and MacKinlay, 1990; and Boudoukh et al., 1994); and (iii) reversals are the result of investor overreaction to new information in the market (see, e.g., Lehmann, 1990; and Jegadeesh and Titman, 1995a).

Our finding that net reversal profits persist over the most recent decades in our sample, during which market liquidity dramatically increased, 
is not supportive of the explanation that reversals are induced by inventory imbalances by market makers and that reversal profits are a compensation for bearing inventory risks. Also, our finding that reversal profits are observed among the 500 and even 100 largest stocks is inconsistent with the notion that non-synchronous trading contributes to reversal profits. Only the behavioral explanation that investors tend to overreact to information and that stock price reversals originate from transitory changes in demand for immediacy by these impatient traders, does not appear to be inconsistent with our findings. Our finding that the short-term reversal effect is concentrated in the firmspecific component of stock returns is consistent with the results of Gutierrez and Pirinsky (2007), who argue that agency issues in the money management industry (i.e., institutions keeping their portfolios near a market index for reputation and career concerns) cause mispricing to be larger in the idiosyncratic return component of momentum strategies.

However, we hasten to comment that our results do not provide direct evidence in support of such a (rationalized) behavioral explanation. A formal test for competing explanations for the short-term reversal effect is beyond the scope of this chapter. An interesting avenue for future research in this stream of literature would involve an in-depth empirical investigation of the relation between reversal profits and proxies for liquidity provision and investor sentiment (e.g., the sentiment factor of Baker and Wurgler, 2006) to directly test the liquidity hypothesis versus the overreaction hypothesis. Another interesting research question that emerges from our results is, if reversals indeed originate from investor overreaction, why investors overreact to firmspecific information and not to macro information. A framework as employed by Gutierrez and Pirinsky (2007) that incorporates institutional holdings data might be used to investigate this research question.

\subsection{Conclusions}

Conventional short-term reversal strategies exhibit dynamic exposures to the Fama and French (1993) factors. These factor exposures are inversely related to factor returns over the formation month, causing the reversal strategy to be negatively exposed to the short-term momentum effect in factor returns. As a result, dynamic factor exposures not only increase the risk of a reversal strategy, but also negatively affect its profitability.

We show that a short-term reversal strategy based on residual stock returns does not exhibit these dynamic factor exposures and earns returns 
that are substantially larger than those of a conventional short-term reversal strategy. Additionally, the residual reversal strategy has a significantly lower volatility. The lower volatility together with the higher returns cause the residual reversal strategy to earn risk-adjusted returns that are twice as large as those of a conventional reversal strategy. In fact, the profits of the residual reversal strategy are statistically and economically significant after trading costs. The large residual reversal profits we document are remarkably robust over time and the cross-section of stocks.

Our results shed new light on different explanations for the reversal anomaly that have been suggested in the literature. Our finding that net reversal profits persist over the most recent decades in our sample, during which market liquidity dramatically increased, is not supportive of the explanation that reversals are induced by inventory imbalances by market makers and that reversal profits are a compensation for bearing inventory risks. Moreover, our finding that reversal profits are observed among the 500 and even 100 largest stocks is inconsistent with the notion that nonsynchronous trading contributes to reversal profits. Our findings do not appear to be inconsistent though with the behavioral argument that investors tend to overreact to information and that stock price reversals originate from transitory changes in demand for immediacy by these impatient traders (see Lehmann, 1990, and Jegadeesh and Titman, 1995a), but we immediately add that our study does not provide direct support for this hypothesis.

Apart from contributing to a better understanding of the origins of the reversal effect, our findings also have important implications for the practical implementation of reversal strategies, indicating that in order to generate returns sufficiently large enough to cover trading costs it is of crucial importance to control factor exposures. 


\section{CHAPTER 4}

\section{Mutual Fund Performance Persistence, MARKET EFFICIENCY, AND BREADTH}

NUMEROUS STUDIES HAVE been conducted to evaluate the value added of active portfolio management of mutual funds. The approach that is typically used in the literature is to test for persistence in fund performance, rank funds on past performance, and evaluate if funds with the best past performance also earn abnormal positive returns over the subsequent period. Most of the research in this stream of literature has been conducted using data for U.S. equity mutual funds going back to the early 1960s. Several studies find evidence of persistence in fund returns (see, e.g., Hendricks et al., 1993; Goetzmann and Ibbotson, 1994; Brown and Goetzmann, 1995; Elton et al., 1996; Gruber, 1996; Carhart, 1997; and Bollen and Busse, 2005). For example, Carhart (1997) reports a return spread between the best and worst performing deciles of funds of more than 8 percent per annum, and a return spread between the top decile of funds and the market portfolio of more than 2.5 percent per annum, net of fees and costs.

Interestingly, a number studies report that the persistent outperformance of the best performing funds has become weaker over time. For example, Barras, Scaillet, and Wermers (2010) report that when they investigate fund performance over time, they find that a significant portion of the fund managers in their sample shows outperformance over the first part of their sample period (up to 1996), but that almost none of the fund managers show outperformance over the most recent part of the sample (after 2006) when they control for luck.

In an earlier study, Bernstein (1998) already argued that it is becoming increasingly more difficult for fund managers to beat their benchmarks because markets have become increasingly more efficient with the passage of time. For instance, developments in technology have improved the timely accessibility to relevant information to investors so that new information is faster diffused in prices on financial markets. In his paper, Bernstein (1998) makes the interesting analogy to baseball in which the '.400 hitters' of the 
early days seem to have disappeared. ${ }^{21}$ It is unlikely, he explains, that the batters of modern times have less skill than the big hitters of yesteryear. A more likely explanation is that the average level of the defenders has increased, e.g., pitchers and basemen have become better skilled (see Gould, 1996); just like that the average investor has become better skilled in investing.

Besides a stream of literature that evaluates fund performance over time, there is also a stream of literature that evaluates fund performance across various market segments and relates performance differences to differences in efficiency across the market segments. For example, several studies report that growth funds earn larger alphas than income funds (see, e.g. Chen, Jegadeesh, and Wermers, 2000; Wermers, 2003b; and Huij and Verbeek, 2007). A common interpretation of these results is that growth fund managers can add more value through active portfolio management than income fund managers, because growth fund managers operate in a less efficient market segment. In a related study, Kallberg, Liu, and Trzcinka (2000) evaluate the performance of real estate mutual fund managers and they document that the portion of skilled managers (i.e., managers with a positive alpha) is substantially larger for real estate mutual funds than for conventional equity mutual funds. The authors relate this difference to the REIT market being less efficient than the common stock market, thereby providing REIT fund managers more opportunities to benefit from private information. And Huij and Post (2011) find that there are more skilled emerging market equity mutual funds than conventional U.S. equity mutual funds. The authors also mention that this finding might be related to differences in efficiency between the markets. Studies in this stream of literature that argue that inefficient markets provide investors more opportunities to systematically earn abnormal positive returns often build on the classic work of Grossman and Stiglitz (1980) who developed a theoretical framework showing that potential abnormal returns are larger in markets that have larger costs of gathering and processing information.

The belief that fund managers can add more value through active management in inefficient markets is not only restricted to academia: when we

${ }^{21}$ In baseball, the batting average is defined as the total number of hits divided by at bats. In modern baseball, a season's average of .300 is seen as excellent while an average of .400 or higher is seen as impossible. Since the 1870 s, there have been 35.400 hitters by 26 different baseball players. However, a season's average of .400 has not occurred since Ted Williams hit an average of .406 in 1941. See Gould (1996) for a discussion on the explanation of the disappearance of the .400 hitters. 
consider the conventional approach how fiduciary investment portfolios are managed in the industry, we observe that fiduciary managers typically allocate more active risk budget to markets that are inefficient. For example, fiduciary managers typically hire more active emerging market fund managers than developed market fund managers because they believe that fund managers can add more value through active management in (inefficient) emerging than (efficient) developed markets. In fact, it seems that it is becoming increasingly more popular to obtain exposure to developed market equities through passively managed index funds and exchange-traded funds.

While there seems to be a widespread belief in both academia and the investment management industry that active portfolio management can only add value in inefficient markets, the empirical evidence supporting this notion is actually quite scarce. Most of the evidence is restricted to the documentation of differences in performance for fund managers operating in different market segments (e.g., growth versus value, developed versus emerging markets) or fund managers over different time periods (e.g., recent versus past periods). The number of observations on which the evidence is based is therefore quite small. At the same time, most of the evidence is also indirect. That is, anecdotal rather than empirical evidence is provided on one market segment being more efficient than the other, or the market becoming increasingly more efficient over time. To the best of our knowledge, no study has yet been performed that directly measures market efficiency for multiple markets, and relates these differences to differences in the value added through active fund management across these markets. The most likely reason that such a study not yet has been conducted is that reliable fund return data outside the U.S. have been scarce up till recently. Return data on non-U.S. markets often do not go back further in time than the early 1990s for a reasonably large crosssection of funds.

However, we believe that at this moment sufficient data are available to perform an in-depth study to the relation between market efficiency and the value added of active fund management. In this study we evaluate performance persistence across different styles, regions, and asset classes using a comprehensive database of mutual funds. In the first part of this study, we study differences in performance persistence across asset classes and relate the differences to asset class' efficiency. We measure market efficiency using five different measures that are commonly used in the literature: the variance ratio test statistic, the runs test statistic, and three Ljung-Box 
portmanteau test statistics. For the purpose of our study, we make use of a database of monthly mutual fund returns that starts in January 1990 and ends in December 2010. In total, we study a fund universe consisting of 20 different asset classes, including seven bond classes, six broad equity classes covering different geographical regions, and seven sub classes within U.S. equity (i.e., small versus large cap, value versus growth, real estate versus common stock funds).

In our first analysis we find that for all asset classes in our sample there is evidence of persistence in performance that is economically as well as statistically significant. By comparing persistence in performance across the asset classes, we find that differences between asset classes can be substantial. For instance, U.S. small-cap equity winner funds outperform their peer losers by 84 basis points the following month, on average. U.S. large-cap equity winner funds outperform their peer losers by 46 basis points. And the performance persistence within the different bond-fund classes is even lower. We conclude that there is a large variability in the value added of active management across different asset classes.

Interestingly, our results indicate that active management is not restricted to only add value within relative inefficient markets as there is also value added within highly efficient markets like U.S. equity as well. Moreover, when we relate the differences in inefficiency across the markets to the levels of persistence in fund performance, we find no positive relation whatsoever. Hence, our results go against the conventional wisdom that there is more potential for active management in less developed inefficient markets.

In the second part of the chapter we provide an alternative explanation to explain differences in fund performance persistence across different markets. Our alternative explanation is inspired by the Fundamental Law of Active Portfolio Management by Grinold (1989) and Grinold and Kahn (2001), which postulates that the value added of active management depends on both managerial investment skill and the investment opportunity set. If there is more breadth, defined as the number of independent investment opportunities the portfolio manager can choose from, a skilled investment manager is more likely to outperform. In this study we postulate that performance persistence is stronger in markets that offer more investment opportunities, i.e., in markets that have a larger breadth. To measure breadth we developed three novel measures in this study. More details on these measures are provided in Section 4.1B. 
For all three of our measures we find a statistically significant positive relation between breadth and fund performance persistence. The explanatory power of breadth is also quite substantial (up to more than 50 percent). In other words, we find evidence that market breadth is an important determinant in explaining the value added of active management in a specific market segment.

We follow up our cross-sectional analyses with time series analyses in which we try to explain differences in the contribution of active portfolio management over time à la Barras, Scaillet, and Wermers (2010). The innovative feature of our study is that we perform such a time series analysis for all different market segments in our sample, thereby significantly increasing the number of observations in our study.

Consistent with most of the literature, we find that the contribution of active management is smaller over the most recent part of our sample for U.S. equity funds. Interestingly, we find that for most of the bond market segments in our study, the value added of active management has increased over time. This finding by itself is inconsistent with the notion that markets becoming increasingly more efficient over time diminish the value added of active management. When we continue our analyses and relate differences in performance persistence over time to differences in market efficiency over time, we also find no relation whatsoever.

However, when we relate differences in performance persistence over time to differences in market breadth over time, we again find a strong and positive relation. All in all, our results are inconsistent with anecdotal evidence that the added value of active management is concentrated in less efficient markets. Instead, our results indicate that managerial skill is more pronounced in markets that offer more investment opportunities.

Our study is closely related to Connor and Li (2009) who show that hedge funds have higher performance in periods when there are more different investment opportunities to produce active returns. In addition, our study is related to a recent strand of literature that looks at the portfolio concentration of active fund managers and shows that funds that hold more concentrated portfolios outperform funds that are more diversified (see, e.g., Kacperczyk et al., 2005; Cremers and Petajisto, 2009; Amihud and Goyenko, 2012; and Huij and Derwall, 2011).

At the same time, our study differs from the aforementioned studies in three important respects. First, we do not evaluate the overall performance of 
mutual funds within a specific asset class but evaluate determinants for the persistence in performance across and within asset classes. Secondly, we look at a broad number of different asset classes while these existing studies look at funds belonging to a specific asset class. And finally, we relate the performance of mutual funds to the relative efficiency of the asset classes considered, as well as to (dynamics in) the breadth offered by the different asset classes.

The remainder of this chapter is organized as follows. First we describe our methodology and explain how we measure market efficiency and breadth for the different market segments in our sample. Section 4.2 describes the data we use for this study. In Section 4.3 we discuss the empirical results, beginning by an examination of the relation between markets efficiency and performance persistence. Next, we investigate the relation between breadth and persistence in performance across the asset classes. Finally, we analyze dynamics in persistence over time using breadth as explanatory variable. We conclude in Section 4.4.

\subsection{Methodology}

In this study we evaluate the contribution of active portfolio management for mutual funds operating in different market segments, and investigate the relations with market efficiency and breadth. In this section, we shortly introduce these concepts and discuss how we measure market efficiency, breadth, and skill, respectively.

\section{A. Market Efficiency}

If markets are fully efficient and any new information is directly and also correctly incorporated in financial markets, then it would be impossible for any fund manager to persistently outperform the market. Outperformance can in this case only be achieved by sheer luck. If, on the other hand, markets are not fully efficient, it might be possible for skillful managers to exploit informational advantages and persistently outperform their peers and/or their relevant benchmarks.

In this study, we measure market efficiency using five different measures. These measures include a variance ratio test, a non-parametric runs test, and three serial correlation tests with different lags. These measures have in common that they test for return predictability by looking at autocorrelations in returns. The higher is the degree of predictability, the less efficient an asset class is considered to be. Autocorrelation-based efficiency 
measures are very standard measures and often used in the literature on market efficiencies going back to early studies such as Fama (1970). Therefore, for the sake of brevity, we refrain from a detailed discussion on the efficiency measures in the main text. For a detailed discussion on the different efficiency measures we use for our empirical analyses the reader is referred to the appendix of this chapter. ${ }^{22}$

\section{B. Breadth}

The Fundamental Law of Active Management of Grinold (1989) and Grinold and Kahn (2001) asserts that the value of active management depends on both portfolio manager skill in selecting securities and the breadth of the used investment strategies. The breadth of an investment strategy is defined as the number of independent investment bets a portfolio manager can choose to invest in. Hence, it denotes the investment opportunity set of the manager in order to achieve active returns. In this study, we use three different measures to estimate breadth within a market segment.

The first approach is the average cross-sectional return dispersion of the funds that invest in the relevant asset class. Cross-sectional volatility, or market dispersion, is a frequently used measure of the alpha potential in the market (see, e.g., Gorman et al., 2010a, 2010b). In a related study on the performance of hedge funds, Conner and $\mathrm{Li}$ (2009) show that the average hedge fund performance is positively related to market return dispersion. Return dispersion, measured by the cross-sectional standard deviation of returns, is a natural candidate measure to proxy for breadth. For example, in the extreme and unrealistic case that all securities have the same return, the cross-sectional dispersion will be zero and there will be no breadth. If, on the other hand, the securities within a market have high idiosyncratic volatility there will also be high return dispersion and there will be many opportunities for a manager to produce active returns. ${ }^{23}$

In this study, we will proxy breadth by the average cross-sectional return dispersion of all the mutual funds belonging to a specific market segment instead of by using the dispersion in returns of the underlying

\footnotetext{
${ }^{22}$ An alternative method for estimating market efficiency is by analyzing the returns to crosssectional trading strategies; see, e.g., Rouwenhorst (1999) and Van der Hart, Slagter and Van Dijk (2003). In our study, we focus on autocorrelation-based measures on indices in order to be able to use a uniform measure across all the different asset classes we consider.

${ }^{23}$ De Silva, et al. (2001) show that cross-sectional dispersion is primarily driven by the idiosyncratic volatility of the securities. In periods of extreme returns in the market there will be additional cross-sectional dispersion.
} 
securities themselves. Using mutual fund returns has the attractive property that the dispersion measure can be estimated using a uniform approach across market segments. For instance, bonds are traded much less frequently compared to equities, making it difficult to calculate the monthly bond returns and thus cross-sectional return dispersion. Moreover, De Silva et al. (2001) and Ankrim and Ding (2002) convincingly show that mutual fund return dispersion is highly correlated with the return dispersion of the underlying securities. ${ }^{24}$ For asset class $i$, the cross-sectional return dispersion is given by

$$
\sigma_{C S, i, t}=\sqrt{\frac{1}{N_{i, t}-1} \sum_{k=1}^{N_{i, t}}\left(R_{k, i, t}-R_{B_{i}, t}\right)^{2}},
$$

where $N_{i, t}$ equals the number of funds belonging to market segment $i$ at time $t$, $R_{k, i, t}$ is the return on the $k$ th fund and $R_{B_{i}, t}$ denotes the return on the benchmark.

Secondly, we measure breadth within a market segment by taking the average tracking error funds realize within the asset class. Tracking error, defined as the time-series standard deviation of fund returns in excess of the fund's benchmark (the funds' benchmarks are discussed in the next section), denotes by how much fund portfolios deviate from the benchmark. The higher is the tracking error, the more active a fund is expected to be (see, e.g., Wermers, 2003a). We conjecture that the average realized tracking error, within a market segment, proxies for breadth as it measures the opportunities for mutual fund managers to deviate from their benchmarks.

A third measure for breadth within a market segment is the average diversification effect. The diversification effect measures the degree by which adding another fund to the portfolio contributes to a better diversified portfolio. A higher value for the diversification effect implies that fund returns within a market segment are relatively less correlated and thus more dispersed. Hence, it seems that the diversification effect of adding another fund in a portfolio of funds is a good candidate to proxy for breadth within a market segment. To measure the diversification effect for the different market segments in our sample, we follow Evans and Archer (1968). At the end of each month, we perform 1,000 simulations for each market segment. In each of

\footnotetext{
${ }^{24}$ In unreported results we also use the cross-sectional dispersion of the underlying securities of the broad equity markets and the conclusions are not materially changed.
} 
these simulations we randomly draw 1 to 10 funds from the entire crosssection of funds in a specific market segment that have twelve months of past return observations and calculate the equal-weighted portfolio returns. Next, for each of the 10,000 simulated portfolios, we calculate the standard deviations of the portfolio returns using the past twelve months. Then, for each market segment we obtain portfolio standard deviations of returns related to portfolios consisting of 1 to 10 funds and take the average of the 1,000 simulations. These values are used to estimate the diversification effect per market segment. This diversification effect is estimated by the slope coefficient in the following regression:

$$
\bar{\sigma}_{i, j, t}=\alpha_{j, t}+\beta_{j, t} \frac{1}{N_{i, j, t}}+\varepsilon_{i, j, t},
$$

where $\bar{\sigma}_{i, j, t}$ is the average standard deviation of market segment $j$ in month $t$ of portfolio $i$, with $i=1,2, \ldots, 10 ; N_{i, j, t}$ denotes the number of funds in portfolio $i$ in month $t$ for market segment $j ; \alpha_{j, t}$ and $\beta_{j, t}$ are parameters to be estimated were the first corresponds to the systematic risk component that cannot be diversified away and the latter denotes the effect of diversification in which we are interested. Finally, we use the time-series averages of the slope coefficients as the relevant proxy for breadth. The higher the average slope coefficient is the higher is the diversification effect within the asset class and thus the more breadth the asset class is expected to have.

\section{Skill}

In conjunction with market efficiency and breadth, investment skill is also an unobserved variable that needs to be estimated. In this study we proxy manager skill by the persistence in fund performance in a specific market segment. Performance persistence is measured by following the traditional rank portfolio approach (see, e.g., Carhart, 1997; and Bollen and Busse, 2005). That is, we rank the funds that belong to a specific market segment at the end of each month based on their previous twelve-month return and sort the funds into quintile portfolios. Next, we compute the equally-weighted return of each quintile portfolio of funds over the subsequent month. We take the return spread between the winner and loser portfolios per market segment as a primary measure of the value added through active management in that 
market segment. In addition, we take the return spread between the winner portfolios and their benchmarks as a secondary measure of the value added through active management.

\subsection{Data}

The data we use for this study come from the Morningstar Database. The data cover monthly U.S. dollar denominated mutual fund returns from January 1990 to December 2010, resulting in a time-series of 252 monthly observations. The database includes funds that are still active as well as defunct funds and therefore the results are unlikely to suffer from a survivorship bias as described by Brown et al. (1992). We are interested in the performance of actively managed mutual funds and thus exclude funds that passively invest in an index (by visually checking the names and deleting funds with, e.g., "index", or "S\&P500" in the name). Moreover, we require a fund to have at least twelve consecutive return observations to be included in the analysis. Morningstar lists multiple share classes as separate funds even though they share the same underlying portfolio. In order not to double count returns, we eliminate multiple share classes by averaging the returns over the different share classes.

Each fund is allocated to a different market segment depending on the investment universe of the particular fund. The different market segments we consider in this study are reported in Table 4.1. The funds are grouped into a total of 20 different market segments. Six broad equity classes: 'Global equity', 'U.S. equity', 'European equity', 'Japanese equity', 'Asia-Pacific excluding Japan equity', and 'Emerging markets equity'; seven different, more focused U.S. equity style classes: small caps, mid-caps, large caps, large cap blend, large cap value, large cap growth and real-estate equity; and seven different bond classes: 'Global bonds', 'U.S. bonds', U.S. government bonds', 'U.S. high yield bonds', 'European bonds', 'European government bonds' and 'European corporate bonds'. The relevant benchmarks that are used for the different asset classes are reported in the second column of the table. The average benchmark returns and standard deviation of returns for the different benchmarks are reported in the following two columns. Over the period January 1990 to December 2010, emerging markets equity has the highest average return as well as the highest volatility of return. The U.S. government bond benchmark reports the lowest return over the same period. 


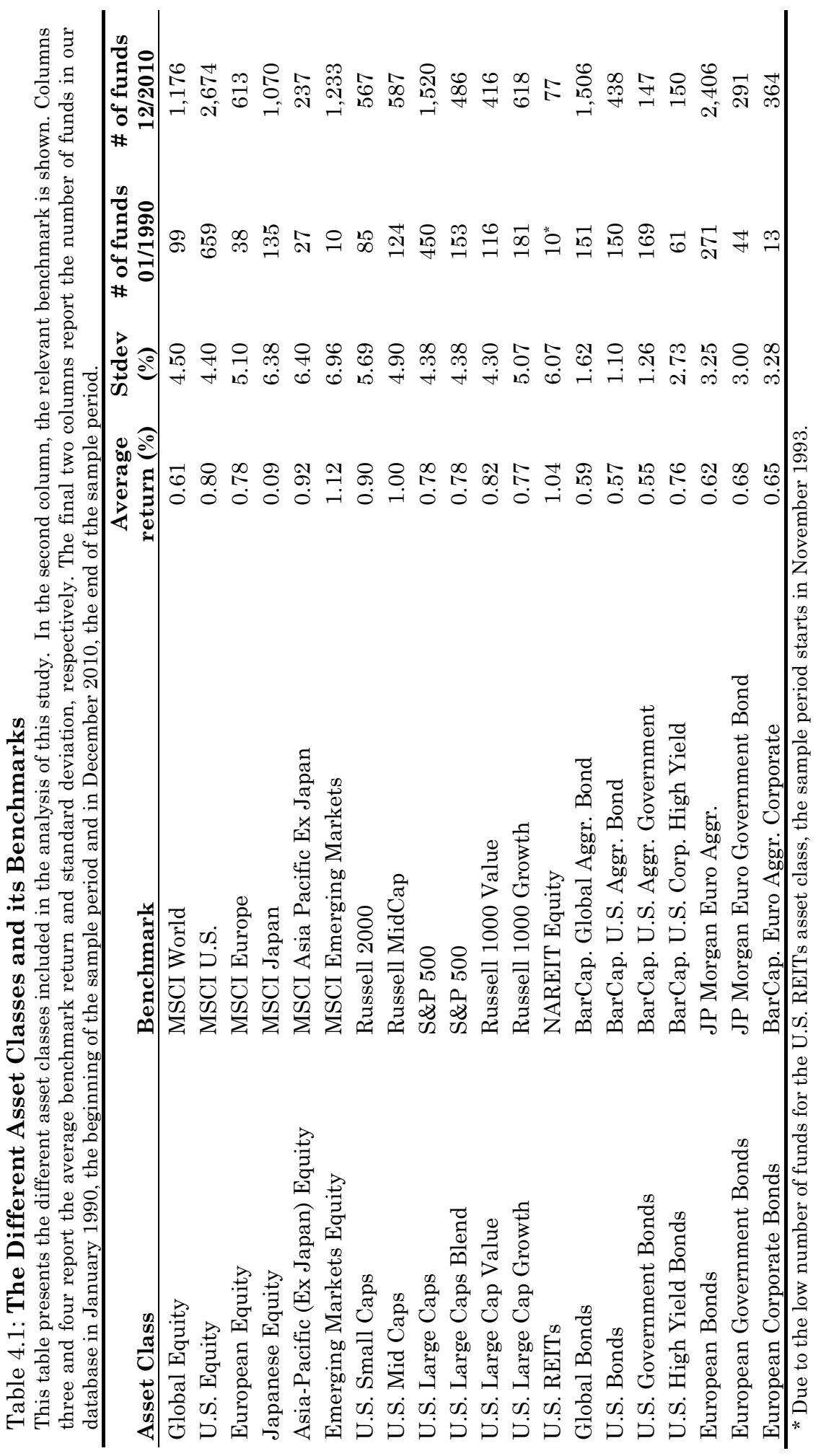


Furthermore, Table 4.1 also presents the number of funds we use in our analysis at the start of the sample period as well as at the end of the sample period. Interestingly, it can be seen that the mutual fund industry, in general, has experienced an explosive growth in the number of different funds. Except for the number of U.S. government bond funds, there has been a sharp increase in the number of funds within a market segment. Especially for the emerging markets equity class, the growth in the number of funds has been impressive, starting with only 10 back in January 1990 to 1,233 at the end of 2010. For our empirical analysis, we restrict the number of funds to be at least 10 in order to be able to accurately analyze performance persistence. Consequently, for U.S. REITs funds the sample period starts in November 1993 instead of January 1990.

\subsection{Empirical Results}

This section presents our empirical results. We begin by analyzing persistence in performance within the different market segments. Then we study if there is a relation between performance persistence and market efficiency. Next, we investigate the relation between differences in the persistence in fund performance across and within asset classes and market breadth.

\section{A. Performance Persistence across Different Market Segments}

A fair amount of research has been conducted on persistence in mutual fund performance. The vast majority of these studies are performed on U.S. equity mutual funds since, presumably, historical data is and has been widely available for the U.S. Several influential studies on the persistence in performance of U.S. equity mutual funds are, for instance, Hendricks et al. (1993), Goetzmann and Ibbotson (1994), Brown and Goetzmann (1995), Elton et al. (1996), Gruber (1996), Carhart (1997) and Bollen and Busse (2005). The literature on equity funds that have an investment scope different from U.S. common equity is much less abundant. Examples of such studies are Otten and Bams (2002) who look at the performance persistence of European equity funds; Huij and Post (2011) who examine persistence in performance of emerging markets equity funds; and Lin and Yung (2004) who study the persistence of U.S. real estate equity funds. And even though actively managed bond funds constitute a sizeable part of the mutual fund industry, studies on the persistence in bond funds is also relatively scarce. A few papers that do study persistence among bond funds are, for instance, Blake et al. 
(1993) and Huij and Derwall (2008). The data we use for our study cover many of these different asset classes. This enables us to compare the persistence in performance across the different market segments that we analyze.

Table 4.2 presents the results on persistence in performance across the different market segments. For each quintile portfolio, that is constructed by sorting funds on their past twelve-month returns, the next month equalweighted portfolio returns minus the returns on the benchmarks are shown together with a portfolio that is long in the recent winner funds and that shorts the recent loser funds. The first noticeable result is that the portfolio consisting of the funds with the lowest past twelve-month performance (the loser portfolio) persistently underperforms its benchmark the following month for each market segment. For instance, emerging markets equity fund losers, on average underperform the benchmark by 49 basis points in the following month. And the recent loser funds investing in U.S. government bonds on average underperform the benchmark by 12 basis points the following month. The portfolios consisting of recent winner funds, on the other hand, show better performance, albeit not significantly above their benchmark. ${ }^{25}$ Moreover the performance is, in general, monotonically increasing over the quintiles, indicating that the performance of the mutual funds is indeed persistent and that this persistence is present in each of the asset classes.

For almost all of the asset classes, except Asia-Pacific equities and U.S. government bonds, we find significant return spreads between the recent winner funds and the recent loser funds. Moreover, the persistence in performance differs to a great extent from one market segment to the next. For instance, U.S. small cap equity fund winners outperform their peer losers by 84 basis points, on average; almost twice the winner minus loser return spread for U.S. large cap funds (46 basis points) which itself is higher compared to the return spreads of each of the seven bond classes.

\section{B. Asset Class Efficiency}

An often heard, and perhaps, conventional wisdom is that it is easier for a portfolio manager to persistently show outperformance in less efficient markets. If this is true, the added value of active management is expected to

${ }^{25}$ If active managers, on average, own the 'market' (approximately), the average mutual fund performance before fees and other costs are taken into account will, more or less, equal the benchmark. Then after fees and other costs are subtracted, the average mutual fund will underperform the benchmark. Consequently, we do not expect to see a symmetric return distribution around the benchmark return (see, e.g., Sharpe, 1991). 
Table 4.2: Performance Persistence per Asset Class

This table presents average portfolio returns. At the end of each month, all funds belonging to a certain asset class are sorted into quintiles based on the previous twelve-month return. The reported returns are the equal weighted portfolio returns over the following month minus the return on the benchmark. The final column reports the returns of a portfolio that is long in the recent winner portfolio and is short the portfolio consisting of recent loser funds. The sample period is from January 1991 to December 2010. $t$-Statistics are reported within brackets.

\begin{tabular}{|c|c|c|c|c|c|c|}
\hline Asset Class & Losers & 2 & 3 & 4 & Winners & W-L \\
\hline \multirow{2}{*}{ Global Equities } & -0.26 & -0.08 & -0.09 & 0.04 & 0.32 & 0.58 \\
\hline & {$[-2.36]$} & {$[-1.26]$} & {$[-1.33$} & {$[0.49]$} & [2.13] & [3.20] \\
\hline \multirow{2}{*}{ U.S. Equities } & -0.24 & -0.12 & -0.04 & 0.09 & 0.35 & 0.60 \\
\hline & {$[-1.79]$} & {$[-1.35]$} & {$[-0.57]$} & {$[0.81]$} & {$[1.73]$} & {$[2.51]$} \\
\hline \multirow{2}{*}{ European Equities } & -0.32 & -0.21 & -0.25 & -0.22 & -0.05 & 0.27 \\
\hline & {$[-4.00]$} & {$[-3.64]$} & {$[-4.25]$} & {$[-3.33]$} & {$[-0.48]$} & {$[2.26]$} \\
\hline \multirow{2}{*}{ Japanese Equities } & -0.25 & -0.12 & -0.07 & 0.03 & 0.37 & 0.63 \\
\hline & {$[-1.89]$} & {$[-1.46]$} & {$[-0.82]$} & {$[0.24]$} & {$[1.81]$} & [2.83] \\
\hline \multirow{2}{*}{ Asia-Pacific Equities } & -0.29 & -0.13 & -0.12 & -0.11 & -0.10 & 0.19 \\
\hline & {$[-2.38]$} & {$[-1.58]$} & {$[-1.48]$} & {$[-1.33]$} & {$[-0.91]$} & [1.27] \\
\hline \multirow{2}{*}{ Emerging Markets Equities } & -0.49 & -0.37 & -0.26 & -0.17 & 0.06 & 0.55 \\
\hline & {$[-2.84]$} & {$[-2.78]$} & {$[-2.14]$} & {$[-1.41]$} & {$[0.35]$} & {$[2.80]$} \\
\hline \multirow{2}{*}{ U.S. Small Cap Equities } & -0.41 & -0.17 & -0.01 & 0.13 & 0.43 & 0.84 \\
\hline & {$[-2.90]$} & {$[-1.68]$} & {$[-0.22]$} & {$[1.54]$} & {$[3.01]$} & [3.43] \\
\hline \multirow{2}{*}{ U.S. Mid Cap Equities } & -0.44 & -0.26 & -0.19 & 0.00 & 0.22 & 0.66 \\
\hline & {$[-3.65]$} & {$[-3.54]$} & {$[-2.99]$} & {$[0.02]$} & {$[1.23]$} & {$[2.62]$} \\
\hline \multirow{2}{*}{ U.S. Large Cap Equities } & -0.28 & -0.18 & -0.11 & -0.01 & 0.18 & 0.46 \\
\hline & {$[-2.83]$} & {$[-3.18]$} & {$[-2.56]$} & {$[-0.03]$} & {$[1.52]$} & {$[2.52]$} \\
\hline \multirow{2}{*}{ U.S. Large Cap Blend Equities } & -0.29 & -0.16 & -0.11 & -0.02 & 0.11 & 0.39 \\
\hline & {$[-3.72]$} & {$[-3.77]$} & {$[-2.75]$} & {$[-0.29]$} & {$[1.55]$} & {$[3.56]$} \\
\hline \multirow{2}{*}{ U.S. Large Cap Value Equities } & -0.30 & -0.19 & -0.12 & -0.11 & -0.01 & 0.29 \\
\hline & {$[-4.26]$} & {$[-4.07]$} & {$[-2.87]$} & {$[-2.29]$} & {$[-0.14]$} & [3.04] \\
\hline \multirow{2}{*}{ U.S. Large Cap Growth Equities } & -0.17 & -0.13 & -0.06 & 0.05 & 0.25 & 0.42 \\
\hline & {$[-1.78]$} & {$[-1.81]$} & {$[-0.80]$} & {$[0.57]$} & {$[1.89]$} & {$[2.45]$} \\
\hline \multirow{2}{*}{ U.S. REITs } & -0.17 & -0.08 & -0.05 & 0.01 & 0.10 & 0.28 \\
\hline & {$[-1.85]$} & {$[-1.85]$} & {$[-1.17]$} & {$[0.14]$} & {$[1.17]$} & [2.18] \\
\hline \multirow{2}{*}{ Global Bonds } & -0.23 & -0.11 & -0.08 & -0.07 & 0.04 & 0.27 \\
\hline & {$[-2.54]$} & {$[-2.05]$} & {$[-1.66]$} & {$[-1.23]$} & {$[0.51]$} & [2.14] \\
\hline \multirow{2}{*}{ U.S. Bonds } & -0.18 & -0.11 & -0.07 & -0.04 & 0.01 & 0.18 \\
\hline & {$[-3.58]$} & {$[-3.58]$} & {$[-3.43]$} & {$[-2.09]$} & {$[0.24]$} & [3.54] \\
\hline \multirow{2}{*}{ U.S. Government Bonds } & -0.12 & -0.10 & -0.08 & -0.08 & -0.06 & 0.06 \\
\hline & {$[-2.40]$} & {$[-2.74]$} & {$[-2.71]$} & {$[-3.33]$} & {$[-1.53]$} & [0.71] \\
\hline \multirow{2}{*}{ U.S. High Yield Bonds } & -0.36 & -0.14 & -0.10 & -0.06 & 0.02 & 0.38 \\
\hline & {$[-7.25]$} & {$[-4.12]$} & {$[-2.62]$} & {$[-1.18]$} & {$[0.34]$} & {$[5.45]$} \\
\hline \multirow{2}{*}{ European Bonds } & -0.29 & -0.19 & -0.15 & -0.08 & -0.02 & 0.26 \\
\hline & {$[-3.88]$} & {$[-3.59]$} & {$[-3.29]$} & {$[-1.95]$} & {$[-0.51]$} & [4.16] \\
\hline \multirow{2}{*}{ European Government Bonds } & -0.24 & -0.14 & -0.10 & -0.09 & -0.03 & 0.20 \\
\hline & {$[-4.11]$} & {$[-3.55]$} & {$[-2.91]$} & {$[-2.49]$} & {$[-0.79]$} & {$[2.85]$} \\
\hline \multirow{2}{*}{ European Corporate Bonds } & -0.33 & -0.16 & -0.12 & -0.11 & 0.04 & 0.36 \\
\hline & {$[-4.68]$} & {$[-4.06]$} & {$[-3.06]$} & {$[-2.94]$} & {$[0.65]$} & [4.39] \\
\hline
\end{tabular}


be higher in, for instance, emerging markets which are generally perceived to be less efficient than more developed markets like the U.S. (academic evidence is summarized by Bekaert and Harvey, 2002). An argument in favor of this conjecture is that these markets are followed by less analysts resulting in lower confidence of the 'true' prices and information is expected to diffuse more gradually. Hence, as skillful managers are expected to be able to exploit these inefficiencies, persistence in performance is expected to be higher in inefficient markets. In this subsection, we analyze the relation between the persistence in performance and asset class efficiency using the measures discussed in detail in the appendix.

The five different efficiency test statistics (the variance ratio test statistic, the runs test statistic and three Ljung-Box portmanteau test statistics) and their relative rankings are reported for each asset class in Panel A of Table 4.3. Also, we report the overall ranking that is based on the average of the five individual rankings. The benchmark with the most random monthly return pattern (rank equals 1) is the S\&P 500. Hence, as for both the U.S. large cap equity and the U.S. large cap blend equity classes the S\&P 500 is the relevant benchmark, these are the found to be the market segments that are the most efficient. This is not surprising given that the U.S. equity market, and in particular the large cap segment, is very well developed with an enormous number of investors participating in trading every day including many institutional, professional investors, as well as many analysts that follow the securities. Other asset classes, besides U.S. equity, that are considered to be amongst the most efficient are Japanese equity and global equity (of which the U.S. and Japanese equity markets are a big part of). AsiaPacific equity and emerging markets equity are the least efficient equity classes and are only considered to be more efficient than the U.S. corporate high yield bond class: according to our measures the most inefficient market we incorporate in our study. The bond classes turn out to be less efficient compared to the equity classes with a similar geographical focus. While the U.S. government bond class is the most efficient bond class, the U.S. corporate high yield bond class is the least efficient bond class (or any other class). Also, the U.S. bond classes seem to be more efficient than the corresponding European bond classes.

Using these results as input, we next investigate if market efficiency is an important determinant for skillful managers to add value in a persistent manner. If market efficiency is indeed an important determinant for skillful 


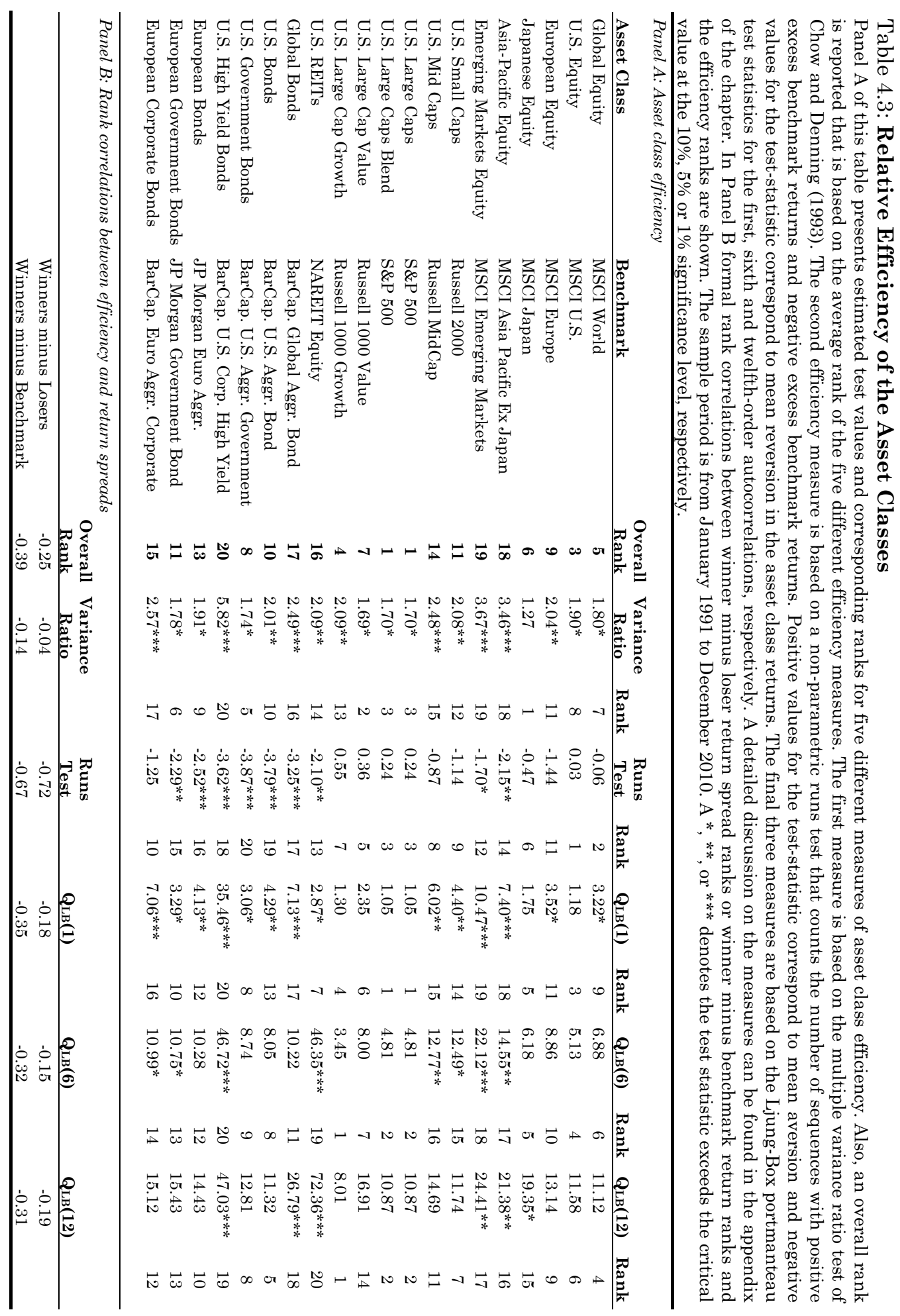


portfolio managers to persistently outperform the benchmark and/or their peers, we expect to see that persistence is more prevalent among bond fund managers and emerging markets equity fund managers than among, for instance, U.S. equity fund managers. To test this conjecture, we calculate rank correlations between the efficiency measures and the outperformance of recent winner funds compared to their peer losers and compared to their benchmark. These rank correlations are shown in Panel B of Table 4.3. Interestingly, the correlation between the overall efficiency rank (note that relatively efficient asset classes have a low number) and the average winner minus loser return spread rank (asset classes with high average return spreads have large numbers) equals -0.25; not a positive number what would be expected if persistence is stronger in less efficient markets. Similar results hold for the outperformance of recent winners against their benchmark and also for the different efficiency measures separately.

Hence, we do not find evidence consistent with the conventional wisdom that the added value of active management is mostly prevalent within inefficient markets. This can also be seen in Figure 4.1 in which the asset class' ranks of the return spreads between past winners and past losers is plotted against the overall efficiency ranks. The dots are scattered around the graph without seeing a clear pattern. In fact, if persistence is higher within less efficient markets, the dots are expected to be located mostly within the lower left and upper right quadrants. Clearly, no such pattern exists. And if at all there would be a relation, it seems to be a negative one.

\section{Breadth}

In this subsection we continue our empirical analyses and investigate if the observed differences in the contribution of active management across different market segments can be explained by differences in market breadth. For each of the market segments the three breadth measures (the average crosssectional return dispersion, the average fund' tracking errors and the average diversification effect) are reported in Table 4.4, Panel A. Also, we report the corresponding ranks (a high number corresponds to relatively more breadth within the asset class) as well as the overall breadth rank that is based on the average rank of the three breadth measures. Not surprisingly, the emerging markets equity class and the global equity class are the asset classes for which the breadth is found to be the most prevalent. U.S. large cap blend equity, on the other hand, is the equity class that is considered to have the least amount 
Figure 4.1: Performance Persistence vs. Market Efficiency

This figure plots the ranks of the return spread between past winners and past losers versus the overall efficiency ranks. The solid line represents the estimated linear relation between the two. The dashed horizontal (vertical) line is equal to the median spread rank (median efficiency rank).

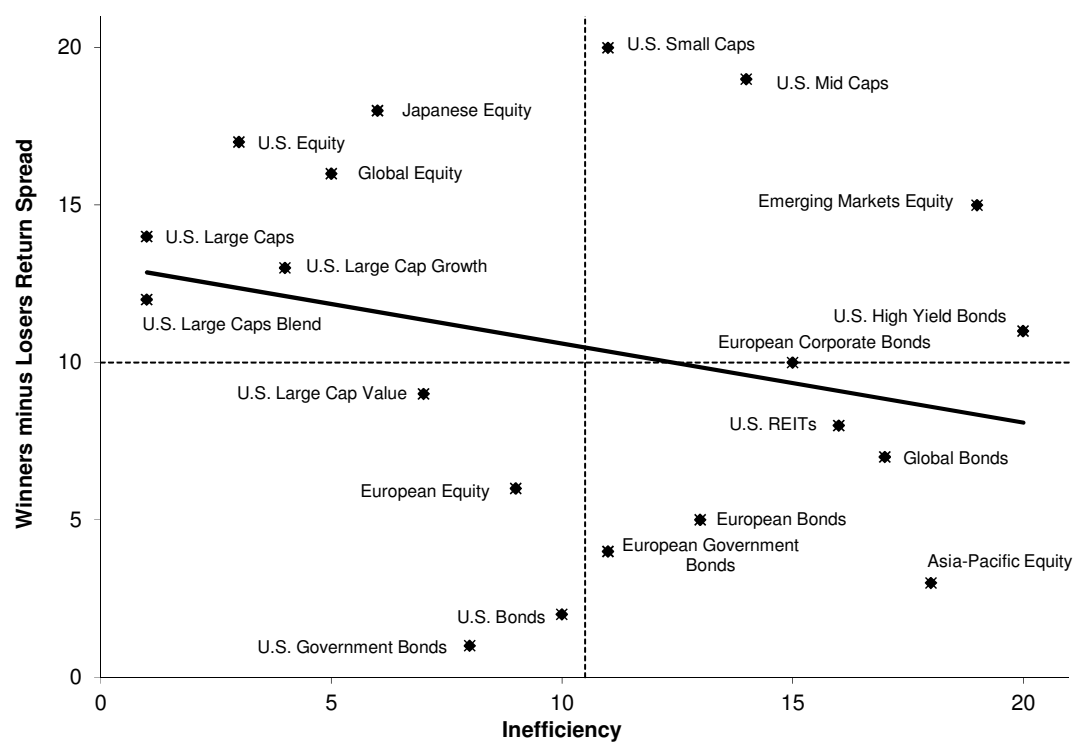

of breadth, even lower than two of the bond classes. In general, the bond classes score low on breadth. This is to be expected since the returns on fixedincome securities can be explained to a large extent by just a few factors (see, e.g., Knez et al., 1994), while the idiosyncratic component of equity returns is relatively higher. The bond classes in which breadth is most prevalent are global bonds and European corporate bonds. U.S. government bonds and U.S. bonds provide investors the least amount of breadth.

In Figure 4.2, the past winners minus losers return spread ranks are plotted against the overall breadth ranks of the market segments. Contrary to the figure on market efficiency, a clear positive relation seems to exist between breadth and persistence in performance. Asia-Pacific equity is the big outlier as persistence in performance is relatively low while the estimated market breadth is relatively high.

In Panel B of Table 4.4, we present results of more formal tests on the relation between performance persistence across market segments, measured by the rank of the past winners minus past losers return spreads, and the breadth of the market segments. First, the rank correlation is highly positive and equals 0.69 in case of the overall breadth rank. Also the rank correlations 


\section{Table 4.4: Breadth and Performance Persistence}

Panel A of this table presents estimated values and corresponding ranks for three different measures of asset class breadth. Also, an overall rank is reported that is based on the average rank of the three different breadth measures. The measures of breadth are the time-series averages of monthly cross-sectional mutual fund return dispersions, time-series averages of twelve-month tracking errors and the times-series average diversification effect. A detailed discussion on the measures can be found in Section 4.1 of the chapter. In Panel B (Panel C) formal tests of the relation between winner minus loser return spread ranks (winner minus benchmark return ranks), based on Table 4.2, and the four breadth measures are shown. These tests include rank correlations; OLS regression estimates, in which the return rank is regressed on a constant and one of the four breadth ranks; and X2 statistics corresponding to contingency tables using median ranks. The sample period is from January 1991 to December 2010. t-Statistics are reported within brackets.

\begin{tabular}{|c|c|c|c|c|c|c|c|c|}
\hline \multicolumn{2}{|c|}{ Panel A: Asset class breadth } & $\begin{array}{c}\text { Overall } \\
\text { Rank }\end{array}$ & $\begin{array}{c}\text { CS } \\
\text { Disp. }\end{array}$ & Rank & $\begin{array}{l}\text { Tracking } \\
\text { Error (\%) }\end{array}$ & Rank & $\begin{array}{c}\text { Div. } \\
\text { Effect }\end{array}$ & Rank \\
\hline \multicolumn{2}{|l|}{ Global Equity } & 19 & 2.64 & 19 & 2.17 & 18 & 0.66 & 17 \\
\hline \multicolumn{2}{|l|}{ U.S. Equity } & 14 & 2.41 & 15 & 2.19 & 19 & 0.49 & 12 \\
\hline \multicolumn{2}{|l|}{ European Equity } & 12 & 1.95 & 11 & 1.56 & 11 & 0.48 & 11 \\
\hline \multicolumn{2}{|l|}{ Japanese Equity } & 16 & 2.50 & 16 & 2.12 & 17 & 0.52 & 14 \\
\hline \multicolumn{2}{|l|}{ Asia-Pacific Equity } & 16 & 2.37 & 14 & 1.96 & 14 & 0.72 & 19 \\
\hline \multicolumn{2}{|c|}{ Emerging Markets Equity } & 20 & 3.08 & 20 & 2.57 & 20 & 0.83 & 20 \\
\hline \multicolumn{2}{|l|}{ U.S. Small Caps } & 14 & 2.58 & 18 & 2.07 & 15 & 0.51 & 13 \\
\hline \multicolumn{2}{|l|}{ U.S. Mid Caps } & 18 & 2.51 & 17 & 2.08 & 16 & 0.53 & 16 \\
\hline \multicolumn{2}{|l|}{ U.S. Large Caps } & 10 & 1.97 & 12 & 1.63 & 12 & 0.38 & 8 \\
\hline \multicolumn{2}{|c|}{ U.S. Large Caps Blend } & 6 & 1.55 & 9 & 1.25 & 8 & 0.30 & 6 \\
\hline \multicolumn{2}{|c|}{ U.S. Large Cap Value } & 7 & 1.54 & 8 & 1.38 & 9 & 0.32 & 7 \\
\hline \multicolumn{2}{|c|}{ U.S. Large Cap Growth } & 13 & 2.11 & 13 & 1.74 & 13 & 0.39 & 9 \\
\hline \multicolumn{2}{|l|}{ U.S.REITs } & 10. & 1.43 &. .7. & .07 &... & 0.72 & 18 \\
\hline \multicolumn{2}{|l|}{ Global Bonds } & 9 & 1.57 & 10 & 1.48 & 10 & 0.43 & 10 \\
\hline \multicolumn{2}{|l|}{ U.S. Bonds } & 2 & 0.57 & 1 & 0.40 & 2 & 0.11 & 2 \\
\hline \multicolumn{2}{|c|}{ U.S. Government Bonds } & 1 & 0.73 & 2 & 0.33 & 1 & 0.10 & 1 \\
\hline \multicolumn{2}{|c|}{ U.S. High Yield Bonds } & 4 & 0.92 & 4 & 0.82 & 5 & 0.24 & 4 \\
\hline \multicolumn{2}{|l|}{ European Bonds } & 5 & 0.94 & 5 & 0.89 & 6 & 0.14 & 3 \\
\hline \multicolumn{2}{|c|}{ European Government Bonds } & 3 & 0.73 & 3 & 0.66 & 3 & 0.27 & 5 \\
\hline \multicolumn{2}{|c|}{ European Corporate Bonds } & 8 & 0.97 & 6 & 0.74 & 4 & 0.53 & 15 \\
\hline Panel B: Relation 2 & th winners $m$ & $\begin{array}{c}\text { osers retur } \\
\text { Overall } \\
\text { Rank }\end{array}$ & \multicolumn{2}{|c|}{$\begin{array}{c}\text { CS } \\
\text { Disp. }\end{array}$} & \multicolumn{2}{|c|}{ Tracking Error } & \multicolumn{2}{|c|}{ Div. Effect } \\
\hline \multicolumn{2}{|c|}{ Pearson's rank correlation } & 0.69 & \multicolumn{2}{|c|}{0.78} & \multicolumn{2}{|c|}{0.76} & \multicolumn{2}{|c|}{0.48} \\
\hline & Intercept & $\begin{array}{c}3.25 \\
{[1.59]}\end{array}$ & & & $\begin{array}{r}2.51 \\
{[1.37}\end{array}$ & & & \\
\hline OLS Regressions & Slope & $\begin{array}{c}0.70 \\
{[4.04]}\end{array}$ & & & $\begin{array}{r}0.76 \\
{[4.98}\end{array}$ & & & \\
\hline & $\begin{array}{l}\text { Adjusted R- } \\
\text { squared }\end{array}$ & 0.45 & & & 0.56 & & & \\
\hline $\begin{array}{l}\text { Contingency } \\
\text { Tables }\end{array}$ & $\begin{array}{l}X^{2} \\
p \text {-value }\end{array}$ & $\begin{array}{c}5.56 \\
(0.02)\end{array}$ & & & $\begin{array}{r}7.20 \\
(0.01\end{array}$ & & & \\
\hline
\end{tabular}




\section{Table 4.4 - Continued from previous page}

Panel A of this table presents estimated values and corresponding ranks for three different measures of asset class breadth. Also, an overall rank is reported that is based on the average rank of the three different breadth measures. The measures of breadth are the time-series averages of monthly cross-sectional mutual fund return dispersions, time-series averages of twelve-month tracking errors and the times-series average diversification effect. A detailed discussion on the measures can be found in Section 4.1 of the chapter. In Panel B (Panel C) formal tests of the relation between winner minus loser return spread ranks (winner minus benchmark return ranks), based on Table 4.2, and the four breadth measures are shown. These tests include rank correlations; OLS regression estimates, in which the return rank is regressed on a constant and one of the four breadth ranks; and X2 statistics corresponding to contingency tables using median ranks. The sample period is from January 1991 to December 2010. t-Statistics are reported within brackets.

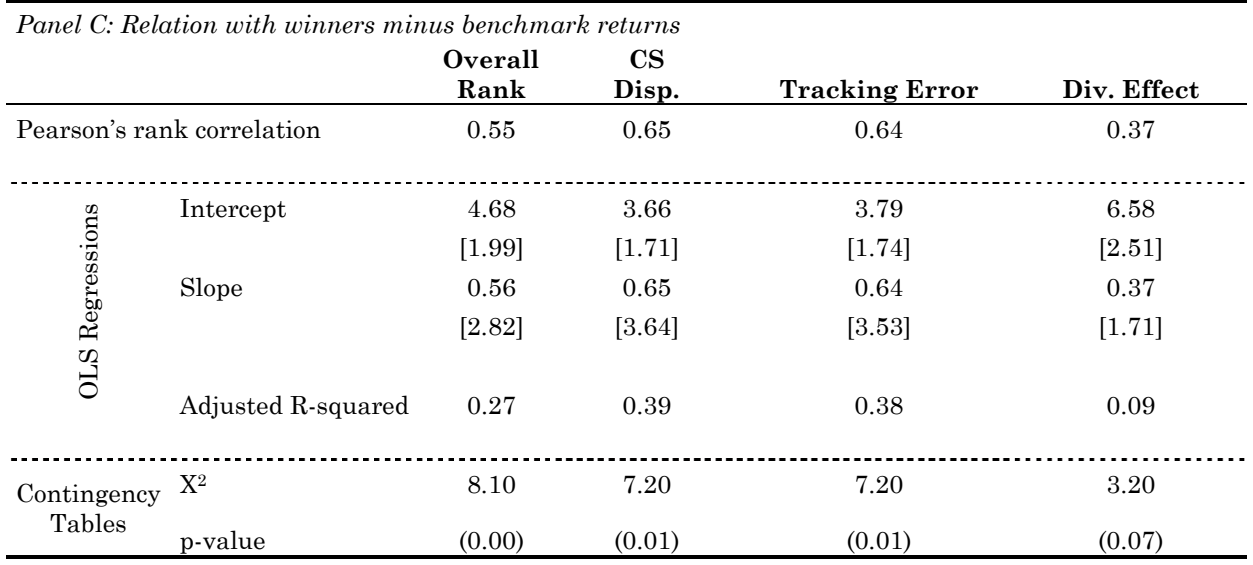

with the separate breadth measures are highly positive and are between 0.48 for the diversification effect and 0.78 for the cross-sectional return dispersion variable. The slope estimates of the OLS regressions are all significantly positive. For instance, using the overall breadth rank as explanatory variable, the estimated slope equals 0.70 (with a $t$-statistic of 4.04) and it can explain forty-five percent of the variability in performance persistence across the market segments (the estimated regression line corresponds to the solid line in the graph of Figure 4.2). As a final formal test, we also provide the $\mathrm{X}^{2}$ teststatistics of the contingency tables. Again, we can conclude that there is a significant positive relation between breadth and persistence in performance. This can also be seen from Figure 4.2, in which the big majority of the market segments are located in either the lower left or upper right quadrants, while only few are located in the upper left and lower right quadrants.

For the sake of robustness, we also present similar test results on the relation between breadth and persistence in performance, but this time use the rank on the return spread between past winners and their benchmark. The results, presented in Panel $\mathrm{C}$ of the table, are qualitatively similar. Again, we 


\section{Figure 4.2: Performance Persistence vs. Return Dispersion}

This figure plots the ranks of the return spread between past winners and past losers versus the overall breadth ranks. The solid line represents the estimated linear relation between the two. The dashed horizontal (vertical) line is equal to the median spread rank (median breadth rank).

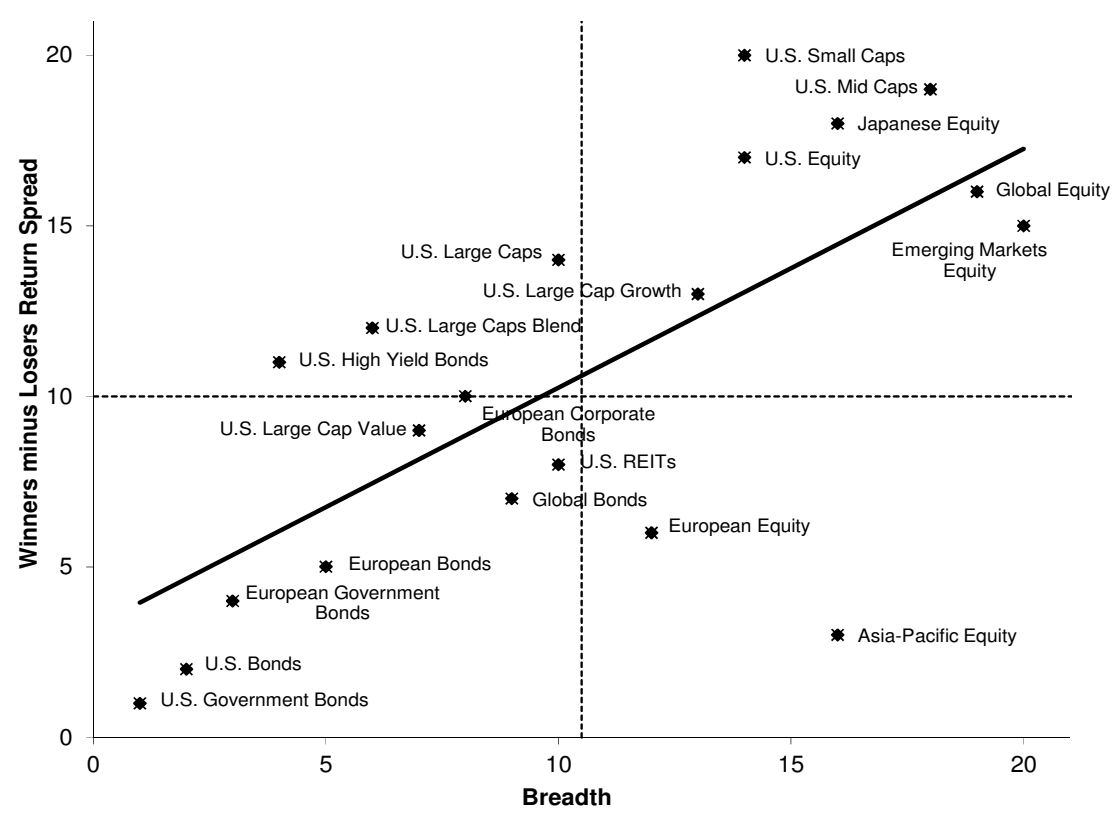

find high positive rank correlations, significantly positive slope coefficients and significant $\mathrm{X}^{2}$ statistics. Hence, from these results, we conclude that market breadth is indeed an important determinant for the differences in persistence that is found across the different market segments in our sample.

\section{Breadth and Persistence over Time}

In the previous subsection, we showed that there is a positive relation between breadth and performance persistence across market segments. Clearly, breadth within a market segment can change over time; however, in the previous analysis we ignored any potential dynamics in breadth within the market segments. Bernstein (1998), for instance, shows that the crosssectional return dispersion of U.S. equity mutual funds has declined over the period from 1969 to 1997. In another study, De Silva et al. (2001) show that the return dispersion of U.S. equity mutual funds is much higher in the years before the burst of the tech-bubble, hence following the sample period of Bernstein (1998). 
In Figure 4.3 twelve-month moving average cross-sectional return dispersions are plotted for each of the asset classes separately. In line with earlier studies (see, e.g., Bernstein, 1998; Campbell et al., 2001; De Silva et al., 2001; and Connor and Li, 2009), we find clear evidence of dynamics in crosssectional mutual fund return dispersions and thus dynamics in breadth within the market segments. In the early 1990s, the first years of our sample period, cross-sectional return dispersion is decreasing for the equity classes. In the years before the burst of the tech-bubble, there is a sharp increase and a similar decline around the time of the burst. Starting at the end of 2007, crosssectional dispersions are again increasing with the peak occurring in 2009. Interestingly, within this period, the same pattern of increasing breadth, followed by a decrease, holds for both equity funds as well as bond funds.

As breadth is a driving force in explaining differences in performance persistence across market segments and breadth within market segments is changing over time, the natural question to ask is whether persistence in performance within a market segment is also related to these dynamics in breadth. If so, we expect to see stronger (weaker) persistence in performance in periods in which breadth is relatively high (low). In a first approach to analyze this conjecture we use a non-parametric method in which we sort the monthly observations on the cross-sectional return dispersion within the market segments. That is, we divide the sample into three equal sized but different states-of-nature of low, medium and high dispersion months and calculate, per state-of-nature, the average return spreads between past winners and past losers as well as the benchmark adjusted return of past winner funds. The results of this analysis are reported in Table 4.5.

Comparing the winners-minus-losers return spread of high-dispersion months with low-dispersion months, we find that persistence in performance is indeed higher in periods of more breadth in the market. On average, the return spread in high-dispersion months is 64 basis points while in lowdispersion months the return spread is only 26 basis points, on average. Moreover, in seventeen out of the twenty market segments, return spreads are higher in months with high dispersion compared to months with low dispersion. The results are similar for the benchmark adjusted performance of recent winners, albeit somewhat less strong. Interestingly, on average the winners do not persistently outperform their benchmarks in periods with low to mediocre breadth. However, the outperformance is persistent in periods with relatively high breadth and equals 27 basis points per month. Hence, we 


\section{Figure 4.3: Cross-Sectional Return Dispersion per Asset Class}

In the three panels below, the twelve-month moving average cross-sectional return dispersions for each of the asset classes are plotted. The return dispersion is measured using Equation (4.1) in the text. In Panel A, the six broad equity classes are plotted, Panel B plots the seven U.S. equity classes and Panel $\mathrm{C}$ plots the seven broad bond classes. The sample period is from December 1990 to December 2010.

\section{Panel A: Broad Equity Classes}

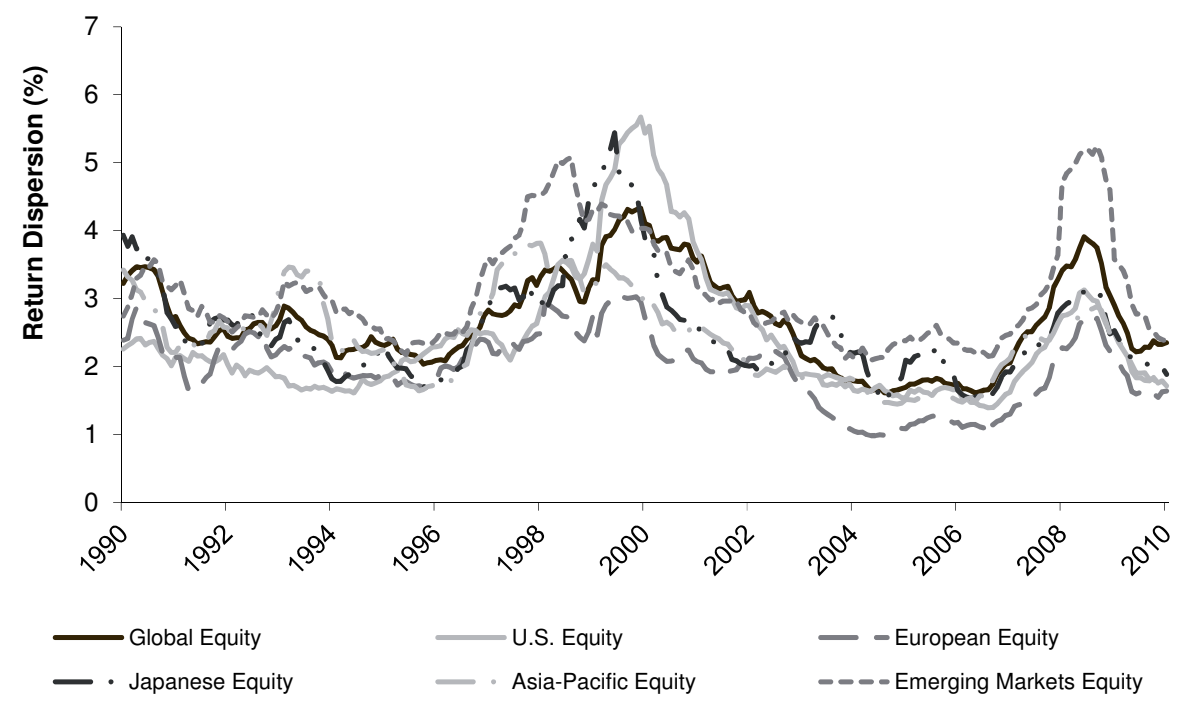

\section{Panel B: U.S. Equity Classes}

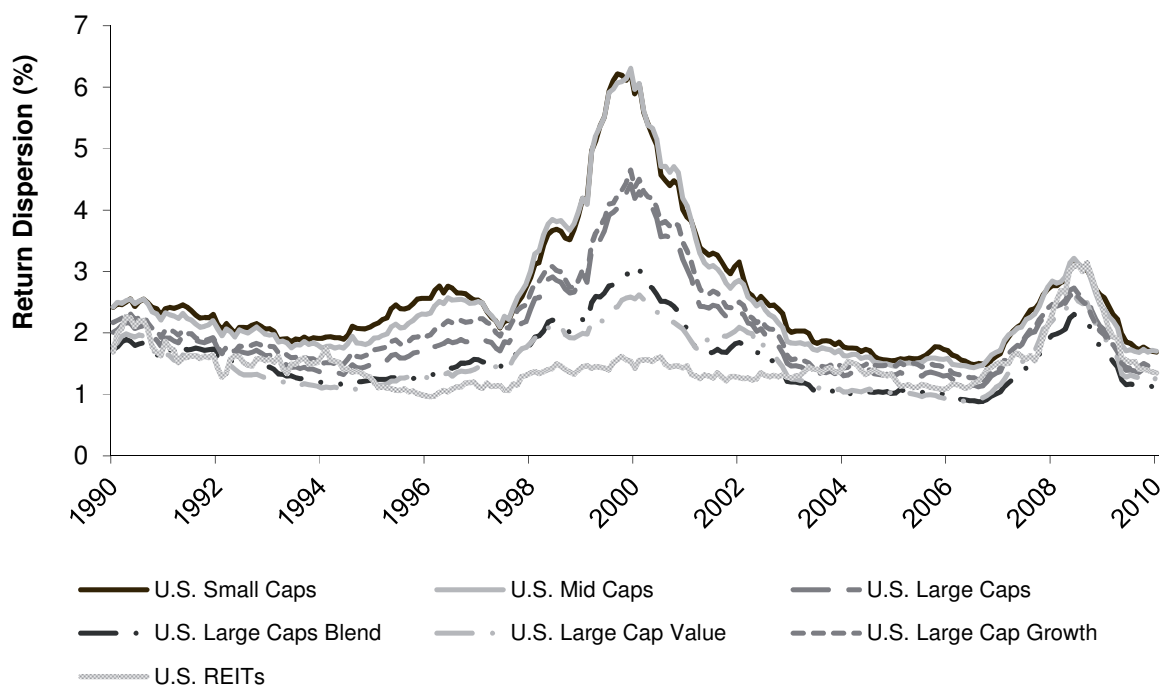

Continues on next page 


\section{Figure 4.3 - Continued from previous page}

In the three panels below, the twelve-month moving average cross-sectional return dispersions for each of the asset classes are plotted. The return dispersion is measured using Equation (4.1) in the text. In Panel A, the six broad equity classes are plotted, Panel B plots the seven U.S. equity classes and Panel C plots the seven broad bond classes. The sample period is from December 1990 to December 2010.

\section{Panel C: Broad Bond Classes}

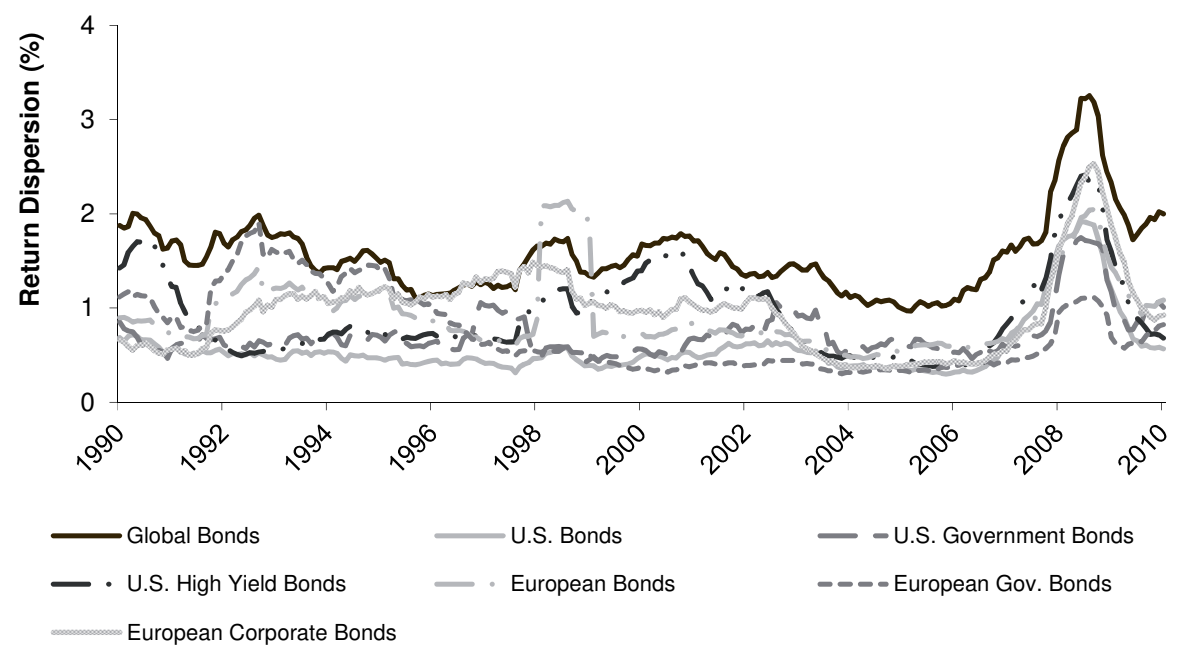

conclude that breadth indeed is an important determinant for persistence in performance. Not only to explain differences in persistence across market segments, but also the dynamics in persistence within market segments over time.

In a final analysis, we perform cross-sectional Fama and MacBeth (1973) type of regressions and pooled OLS regressions to be able to account for dynamics in breadth and its relation with mutual fund performance persistence. We estimate the following two regressions:

$$
R_{k, t}^{W-L}=\alpha+\beta_{k}^{\text {Bench }} R_{B_{k}, t}^{2}+\beta_{k}^{\text {Disp }} \sigma_{k, t}^{C S}+\beta_{k}^{\text {Effic }} I E_{k}+\varepsilon_{k, t},
$$

and

$$
R_{k, t}^{W-B}=\alpha+\beta_{k}^{\text {Bench }} R_{B_{k}, t}^{2}+\beta_{k}^{\text {Disp }} \sigma_{k, t}^{C S}+\beta_{k}^{E f f i c} I E_{k}+\varepsilon_{k, t},
$$




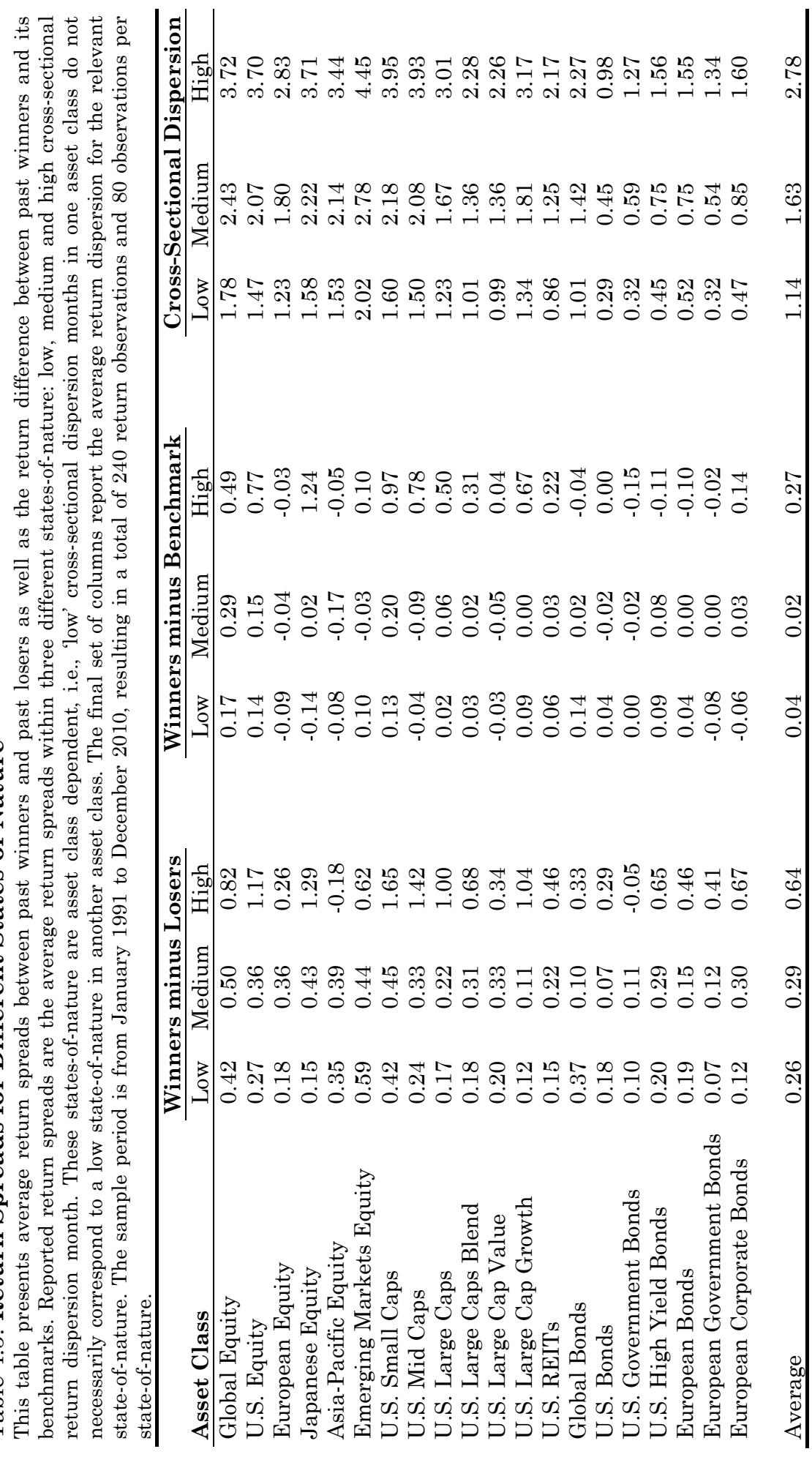


Table 4.6: Regression Results: Breadth and Performance Persistence

This table presents estimated coefficients of monthly Fama-MacBeth (1973) type of regressions (FM) and pooled OLS regressions. The dependent variable is the monthly past winners minus past losers return spread (W-L) of each asset class or the past winners return above its benchmark return (W-B). Explanatory variables are the demeaned cross-sectional return dispersion of the asset classes, the squared returns on the asset class' benchmarks and a dummy variable that equals one in case the asset class belongs to the ten most inefficient asset classes and is zero otherwise. The sample period is January 1991 to December 2010. The pooled OLS regressions include time fixed effects. $t$-Statistics are reported within brackets.

\begin{tabular}{lcccccc}
\hline & \multicolumn{2}{c}{ Winners minus Losers } & & \multicolumn{2}{c}{ Winners minus Benchmark } \\
\cline { 2 - 3 } \cline { 5 - 6 } & FM & OLS & & FM & OLS \\
\hline Constant & 0.31 & -0.01 & & 0.21 & -0.83 \\
& {$[4.63]$} & {$[-0.02]$} & & {$[3.79]$} & {$[-2.32]$} \\
Cross-Sectional Dispersion & 0.19 & 0.59 & & 0.24 & 0.42 \\
& {$[1.88]$} & {$[14.50]$} & & {$[3.23]$} & {$[12.83]$} \\
(Benchmark Return) ${ }^{2} * 100$ & 0.64 & -0.23 & & -0.57 & -0.28 \\
& {$[2.18]$} & {$[-3.07]$} & & {$[-2.02]$} & {$[-4.67]$} \\
Inefficiency Dummy & 0.00 & -0.12 & & -0.07 & -0.17 \\
& {$[-0.04]$} & {$[-2.21]$} & & {$[-1.60]$} & {$[-3.74]$} \\
& & & & & \\
Adjusted R-squared & 0.29 & 0.35 & & 0.27 & 0.29 \\
\hline
\end{tabular}

where $R_{B_{k}, t}$ is the excess benchmark return of market segment $k$ at time $t, k=$ $1,2, . ., 20 ; \quad \sigma_{k, t}^{C S}$ is the demeaned contemporaneous cross-sectional return dispersion for market segment $k$ at time $t$; and $I E_{k}$ is a dummy variable that equals one in case market segment $k$ belongs to the ten least efficient market segments (which follows from Table 4.3) and is zero otherwise. The variables to be explained are the return spreads between past winners and past losers, $R_{k, t}^{W-L}$, and the return difference between past winners and their benchmark return, $R_{k, t}^{W-B}$.

The estimated coefficients on the different regressions are reported in Table 4.6. Consistent with our earlier results, we again find a positive relation between persistence in performance on the one hand and breadth, measured by the cross-sectional return dispersion, on the other hand, even after controlling for extreme benchmark returns and market efficiency.

\subsection{Conclusions}

The Fundamental Law of Grinold (1989) and Grinold and Kahn (2001) puts forward that the value of active management depends on the skill of the manager and the breadth of the investment strategy. A competing hypothesis states that that the value added of active management is low in developed markets and that active managers are better able to produce alpha in, for 
instance, emerging markets as these markets are much less efficient. In this study we analyze what the effect is of both types of market conditions on the persistence in the performance of actively managed mutual funds.

Using a comprehensive database of mutual funds from a broad range of market segments, we find that performance persistence is positively related to breadth that is present within a market segment. That is, asset classes with more breadth show stronger persistence in returns compared to asset classes for which breadth is relatively scarce. Moreover, we find that breadth is also important in explaining dynamics in persistence; in periods with more breadth, past winner funds outperform to a larger extent than in periods with less breadth. Interestingly, we do not find evidence that market efficiency is an important determinant of performance persistence among mutual fund managers.

\subsection{Appendix}

In this appendix, we discuss the measures of market efficiency we use for this study. In total, we will consider five different measures to estimate efficiency within the different asset classes. The measures we use are a variance ratio test, a non-parametric runs test and three serial correlation tests. All these measures have in common that we use the sample period monthly returns of the relevant benchmarks, which are reported in Table 4.1.

The variance ratio test, developed by Lo and MacKinlay (1988), is a widely used test for random walk behavior in financial markets. The idea behind the test is that if the natural logarithm of a monthly price index, $Y_{t}$, follows a random walk, a necessary condition for an asset to be weak-form efficient (see Fama, 1970), return variances should increase proportionally to the observation interval, $q$. The variance ratio, $V R(q)$, of asset class $j$ is defined as

$$
V R_{j}(q)=\frac{V A R[q]}{q \operatorname{VAR}[1]}
$$

where $\operatorname{VAR}[q]=\frac{1}{m_{j}} \sum_{t=q+1}^{T_{j}}\left(Y_{j, t}-Y_{j, t-q}-q \hat{\mu}_{j}\right)^{2}, \quad m_{j}=q\left(T_{j}-q+1\right)\left(1-\frac{q}{T_{j}}\right), \quad T_{j}$ is equal to the length of the sample period, in months, and $\hat{\mu}_{j}=\frac{1}{T_{j}}\left(Y_{j, T_{j}}-Y_{j, 1}\right)$. A variance ratio greater (less) than one, implies positive (negative) autocorrelation in the 
benchmark return series. The standard normal test statistic, $Z_{j}(q)$, for the null hypothesis of a random walk is estimated as

$$
Z_{j}(q)=\frac{V R_{j}(q)-1}{\sqrt{\phi_{j}(q)}}
$$

where $\phi_{j}(q)=\frac{2(2 q-1)(q-1)}{3 q T_{j}}$. Following Chow and Denning (1993) we use the multiple variance ratio test. This test considers the maximum absolute value of the test statistics in Equation (A2) for $q=1,2, . ., 12$. Hence, the multiple variance ratio test we use in this study is defined as

$$
Z_{j}^{*}(q)=\max _{1 \leq i \leq 12}\left|Z_{j}\left(q_{i}\right)\right|
$$

The second measure we use in order to test the randomness of the sequence of the monthly benchmark returns for the particular asset classes is a non-parametric runs test. If the successive change in the returns behaves randomly, this is an indication of weak-form efficiency. However, if the behavior is not random, then the asset class return is predictable and therefore expected to be less efficient.

The monthly return series of the asset classes are divided into two different types: positive excess returns and negative excess returns. A sequence of (at least one) positive (negative) return(s) is counted as a single run. We make use of the Wald-Wolfowitz runs test which is approximately normal with an expected number of runs, $E\left[M_{j}\right]$, and is equal to

$$
E\left[M_{j}\right]=\frac{2 N_{j}^{U p} N_{j}^{\text {Down }}+N_{j}^{U p}+N_{j}^{\text {Down }}}{N_{j}^{U p}+N_{j}^{\text {Down }}}
$$

where $N_{j}^{U p}$ and $N_{j}^{\text {Down }}$ is the observed number of positive monthly returns and negative monthly returns of benchmark $j$, respectively. The variance equals

$$
\sigma_{M_{j}}^{2}=\frac{2 N_{j}^{U p} N_{j}^{\text {Down }}\left(2 N_{j}^{U p} N_{j}^{\text {Down }}-N_{j}^{U p}-N_{j}^{\text {Down }}\right)}{\left(N_{j}^{U p}+N_{j}^{\text {Down }}\right)^{2}\left(N_{j}^{U p}+N_{j}^{\text {Down }}-1\right)} .
$$


If the actual number of runs is significantly greater or smaller than expected, it simply indicates that the sequence does not appear to be random as there is mean reversion or mean aversion, respectively.

Finally, we estimate asset class efficiency using serial correlation tests. The Ljung-Box portmanteau statistic is used to test whether the return series of the relevant benchmarks are white noise. The $\mathrm{Q}^{\mathrm{LB}}(s)$-statistic at lag $s$ is a test statistic with the null hypothesis that there is no autocorrelation in the monthly returns up to order $s$ and is given by

$$
Q_{j}^{L B}(s)=T_{j}\left(T_{j}+2\right) \sum_{k=1}^{s} \frac{r_{j, k}^{2}}{T_{j}-k},
$$

where $T_{j}$ is the number of months of the sample of asset class $j$ and $r_{j, k}$ is the sample autocorrelation coefficient of the benchmark of asset class $j$ with lag $k$. We restrict the analysis to the first, sixth and twelfth-order autocorrelations.

A final note we make is that for this study we are not so much interested in testing whether markets are efficient or not, however, we are interested in the relative efficiency of the different asset classes we consider in this study. Therefore, we will use the relevant rankings of the efficiency test statistics for the empirical analyses. 



\section{CHAPTER 5}

\section{MANAGERIAL TURNOVER AND THE BEHAVIOR OF MUTUAL FUND INVESTORS}

IN RECENT YEARS, the mutual fund industry has grown to an enormous size with over 4,500 equity mutual funds registered in the U.S. managing in total approximately $\$ 5.7$ trillion (see Investment Company Institute, 2011b). As a result of the sheer number of funds and the relative ease of monitoring fund performance, ${ }^{26}$ the industry has become extremely competitive. First, a vast amount of empirical evidence shows that investors chase past fund performance (see e.g. Chevalier and Ellison, 1997; Sirri and Tufano, 1998; Zheng, 1999; and Del Guercio and Tkac, 2002); the mechanism of fund investors to 'vote with their feet' and discipline (poorly performing) fund managers. And secondly, there is evidence of a high annual turnover rate of portfolio managers which is estimated to be 14 to 18 percent (see Ding and Wermers, 2009).

Khorana (2001) examines the performance of funds subsequent to manager changes and finds that underperforming funds tend to do better after the underperforming manager is replaced. Hence, the internal governance mechanism, or the disciplining behavior of fund companies, seems to be an effective tool of fund companies in order to increase the future performance of the fund. Confirming evidence on the effectiveness of disciplining poorly performing managers is provided in the study by Jin and Scherbina (2011) who show that the new manager is more likely to sell-off momentum losers at a higher rate compared to existing managers.

Even though disciplining underperforming fund managers results in subsequent higher expected performance, surprisingly little is known on how this disciplining effect is perceived by the fund investors. We argue, however, that a better understanding of the behavior of mutual fund investors following manager changes is needed. First, the highly authoritative study of Berk and Green (2004) assumes rationality of mutual fund investors, but the question arises whether such a theoretical assumption is too stringent for explaining

26 The track record of fund performance can nowadays be easily found on the funds' webpages. Moreover, Morningstar categorizes funds based on their performance relative to their peers. 
the behavior of these investors in reality. Second, investor behavior has implications for the persistence in mutual fund performance as several studies have shown the effect of fund flows on future fund performance. And finally, investor behavior has implications on how efficiently capital markets are functioning.

In this chapter, we fill in this void in the literature and study the behavior of mutual fund investors following managerial turnover and address several questions. First, how do mutual fund investors perceive manager replacements? And second, is the behavior of investors following the change in management rational or not? For this purpose we will closely look at open-end mutual funds, i.e. funds with the feature that enables investors to allocate new capital to the fund as well as redeem their shares any time at the asset value, and examine capital flows to funds subsequent to a managerial replacement. 27,28

Within the rational framework of Berk and Green (2004) and Dangl et al. (2008), managerial replacements would imply an immediate response by mutual fund investors depending on the expected level of skill of the new portfolio manager. For instance, if the new manager is expected to have more (less) investment skills compared to the replaced manager, investors will supply capital to (withdraw capital from) the fund.

Using a sample of actively managed domestic U.S. equity mutual funds and managerial replacements between 1993 and 2006, we find results that are inconsistent with this rational framework. For instance, a main finding of our study is that flows to funds which have disciplined their poorly performing managers are lower compared to similar performing funds without a recent change in management. Importantly, however, and in line with earlier studies (see, e.g., Khorana, 2001; and Jin and Scherbina, 2011), we find that persistence in fund performance is stronger for funds without a change in management as poorly performing funds with a management change subsequently perform better. Hence, even though the effectiveness of the

\footnotetext{
27 The papers by Chevalier and Ellison (1999a) and Kostovetsky and Warner (2011) also briefly look at flows subsequent to managerial replacements. Chevalier and Ellison (1999a) use only a small sample of funds with managerial replacements in the period 1992-1994 and find no statistically significant effect on the fund flows. Kostovetsky and Warner (2011) find no effect for the full sample and a positive flow response for the funds with the lowest flows in the previous year.

28 The amount of literature on the determinants of top management replacements and stock price reactions for public corporations is much more extensive (see, e.g., amongst others, Warner et al., 1988; Weisbach, 1988; Khanna and Poulsen, 1995; and Huson et al., 2004).
} 
internal governance mechanism of fund companies seems warranted, this is not picked up as such by the funds' investors.

Investors' rationality also implies stronger flow sensitivity to past performance and manager changes for younger and smaller funds (see, e.g., Berk and Green, 2004; and Dangl et al., 2008). Interestingly, however, we do not find such evidence as the results are very similar for funds that are small in size as for funds that are among the largest in terms of their assets under management. Moreover, we find very similar results for institutional investors as for retail investors. This holds even though institutional investors, who are often better informed investors as they are able to monitor the funds more closely, are commonly perceived to demonstrate behavior which is more consistent with rationality.

Our findings show important new insights with respect to investor behavior and the functioning of capital markets. Overall, we conclude from the results that investors are not behaving rationally in response to managerial turnovers and, as a result, we also conclude that capital markets are not functioning fully efficient. Indeed, the assumption of Berk and Green (2004) and Dangl et al. (2008) that mutual fund investors behave rationally is not supported by the findings of our study. The results are, however, consistent with Gervais et al. (2005) who argue that firing a manager is perceived as a bad signal (or retaining a manager is seen a positive signal) by the mutual fund investor.

Our study is closely related to a recent paper by Wermers et al. (2008) who also study mutual fund investors' behavior surrounding managerial replacements. Using a sample of closed-end mutual funds, the authors find that prior to replacement fund shares trade at an increasing discount as fund performance worsens but stops responding after further poor performance. They argue that this is consistent with learning about managerial investment skill and anticipation of a possible change in management. However, as the assets under management remain fixed with closed-end funds, investors' updates of managerial ability can only cause price changes (and no capital injections or withdrawals). Hence, their results do not necessarily translate to the open-end fund market. Our study contributes to this stream of literature by analyzing investor behavior with respect to open-end mutual funds.

Other related studies examining managerial turnovers in the mutual fund industry look at the determinants of management changes and/or the performance subsequent to these managerial replacements (see e.g. Khorana, 
1996; Chevalier and Ellison, 1999a; Khorana, 2001; Ding and Wermers, 2009; Jin and Scherbina, 2011; and Kostovetsky and Warner, 2011) or look at the behavior of managers in the period before their replacement (Hu et al., 2011). These studies, however, do not evaluate the behavior of mutual fund investors surrounding manager changes; the focus of our study.

Finally, our study has implications for theoretical models important to the mutual fund literature. Perhaps the most well-known model on mutual fund performance persistence is the abovementioned study by Berk and Green (2004), which has been extended to also include managerial turnover by Dangl et al. (2008). An important pillar for the conclusions reached by these two studies is that mutual fund investors are assumed to behave according to their rational expectations. As mentioned, this assumption is inconsistent with our empirical findings.

The remainder of the chapter is organized as follows. In the next section, we first develop the hypotheses that are tested further on in the chapter. Section 5.2 describes the data and sample choices used for this study. Next, Section 5.3 discusses the methodology and main empirical results, including various robustness checks. Concluding remarks and some further discussion on the findings and implications for management companies, are given in Section 5.4.

\subsection{Theory and Hypotheses}

In this section, we develop the hypotheses on the effects of mutual fund manager replacements on subsequent fund flows. These hypotheses will be tested in the empirical analyses discussed in Section 5.3. As a first starting point for developing our hypotheses we follow the model of Dangl et al. (2008). As this model has several simplifying assumptions that may not resemble reality, ${ }^{29}$ we also develop an alternative hypothesis.

\section{A. Rational Expectations}

The model of Dangl et al. (2008) is an extension of the seminal paper by Berk and Green (2004). As in the Berk and Green model, it is assumed that (1) mutual funds compete for the investors' capital; (2) there are decreasing returns to scale; and (3) investors learn about managerial ability only via past performance. Moreover, investors are assumed to be able to freely move money into or out of a fund. In contrast however to the Berk and Green model, which

29 This is also admitted by the authors. 
does not differentiate between the management company and the portfolio manager, Dangl et al. (2008) explicitly differentiate between the two; introducing the opportunity for the management company to fire the manager. ${ }^{30}$ Management companies will fire a portfolio manager if the expected investment skill of the manager falls below a certain threshold in order not to lose market share.

Within the rational expectations framework of Dangl et al. (2008), investors optimally allocate their capital in such a way that the marginal expected excess return of another dollar invested in the fund equals zero. Hence, besides a positive performance-flow relation (as investors update their beliefs about managerial ability upwards (downwards) after observing a strong (poor) performance of the manager), the model also predicts instantaneous flow responses following managerial replacements. That is, flows are positive (negative) if the expected ability level of the new manager is higher (lower) compared to the departing manager, ceteris paribus.

As the authors also state in their paper, the above predictions are quite strong since in reality the investment skill of the manager is not the only determinant of the performance of the fund. Several papers provide evidence that the performance of a fund can only be partly attributed to the responsible manager. For instance, Chevalier and Ellison (1999b) show that the level of education of the manager positively influences the performance of a fund; Baks (2003) shows that 10 to 50 percent of the performance of a fund can be attributed to the fund manager; and Bär et al. (2011) show that the composition of the team plays a role in the implemented fund strategy and its performance.

Moreover, the assumption that investors can freely move capital into or out of a fund will in reality seem to be too strict. First, investors may be locked into their positions due to sales loads, redemption fees, and/or capital gains taxes. Secondly, the presence of search costs will also lower the flow sensitivity (see e.g. Sirri and Tufano, 1998; and Hortaçsu and Syverson, 2004).

Combining the rational expectations framework from Dangl et al. (2008) and the above stated regularities, the following hypotheses emerge.

30 Clearly, it is also possible to demote or promote the manager or that the manager voluntarily leaves to work for another company (see, e.g., an interesting working paper by Deuskar et al., 2011, who show that it are especially poorly performing managers that leave to manage a hedge fund); these alternatives are however not modelled. In our study we include all managerial replacements, irrespective of whether the manager is fired, gets promoted or leaves the fund on a voluntary basis. 
Hypothesis 1a:

Poorly performing funds that have a change in management subsequently have higher flows compared to similar performing funds for which the manager is retained. 31

Hypothesis 2:

Strongly performing funds that have a change in management subsequently have lower flows compared to similar performing funds for which the manager is retained. ${ }^{32}$

\section{B. Signalling}

Firing or retaining a manager can, however, also comprise of signals to mutual fund investors which are important for the flow responses. First, Gervais et al. (2005) argue that when some managers are fired by the management company, this is a positive signal to poorly performing managers that are retained within the same family. This is because if the management company has more information on the manager's ability level than mutual fund investors, firing managers boosts the credibility of retention decisions of other managers. It is optimal for the management company to fire managers with low ability. Hence, if there are two managers in the fund family with identical performance but only one manager is fired, this signals to investors that the retained manager has a higher ability compared to the fired manager.

Secondly, firing a manager can also be seen as a bad signal. ${ }^{33}$ For instance, investors may become scared of scandals or fraudulent behavior that will reach the surface (such as market timing and late trading charges, see e.g. Mahoney, 2004; and Zitzewitz, 2006). Or, it may also be the case that firing the manager is just the first step in becoming clean and that there are other troublesome employees within the investment team.

Hence, if the positive signal for retained managers and/or the bad signal investors infer from firing the manager are important determinants, we will

\footnotetext{
31 This hypothesis is also consistent with the predictions of Lynch and Musto (2003). The authors argue that the performance-flow relation is convex since a poor past performance is less predictive of future performance than strong past performance. This is the case as poorly performing funds are more inclined to change their strategy. Replacing its manager can be perceived as a signal that the fund is indeed changing its course.

32 Managers of strongly performing funds are less likely to be fired or demoted but more likely to be promoted to a larger fund within the fund family or to leave a fund voluntarily to work for a different fund company.

${ }^{33}$ We thank George Loewenstein for providing us with this insight.
} 
have the following expected flow responses for poorly performing funds, which is opposite of Hypothesis 1a:

Hypothesis $1 \mathrm{~b}$ :

Poorly performing funds that have a change in management subsequently have lower flows compared to similar performing funds for which the manager is retained.

\subsection{Data and Sample Characteristics}

In this section we first describe our data and sample selection. Then we shortly explain how fund flows are estimated. Finally, we provide some first impressions on the data we use for the analysis.

\section{A. Data Source and Fund Selection}

We use the 2008 edition of the CRSP Survivor Bias Free Mutual Fund Database as the source of information on manager names, fund performance and other fund characteristics. We extract monthly returns and monthly values of total net assets under management (TNA). Moreover, we make use of the annual data on the names of the portfolio managers and the date these managers first became responsible for the fund performance. In order to control for other fund characteristics, we also extract annual data on expense ratios, loads, management fees, portfolio turnover, the historical starting date of the funds and the reported investment objective of the funds. Key inputs for our study are manager names and the dates the managers became responsible. Since manager information is only available in CRSP starting from 1993, ${ }^{34}$ our sample period starts in 1993 and ends in 2007.

The analysis is performed on actively managed domestic U.S. equity mutual funds. Following common practice in the literature, we exclude bond funds, mortgage backed funds, balanced funds, money market funds, flexible funds, international funds and specialised funds. To be included, a fund needs to fulfil the 'Strategic Insights Objective Codes'35 or 'Lipper Objective Codes'36 requirements at least half of the years the fund is alive during the sample period. Next to that, a fund needs to have no missing return observations and

\footnotetext{
${ }^{34}$ In the beginning of the sample, CRSP reports the month in which the new manager became responsible for the fund, however, from 1998 only the year of replacement is reported.

35 The included objective codes are AGG, GMC, GRI, GRO, ING and SCG.

36 The included objective codes are EI, EIEI, G, GI, I, LCCE, LCGE, LCVE, MC, MCCE, MCGE, MCVE, MLCE, MLGE, MLVE, SCCE, SCGE and SCVE.
} 
no missing TNA observations during the year to be included in that year's sample. This restriction is needed in order to be able to estimate the fund flows. Isolated fund year observations are excluded from the analysis.

Inspection of the data on the manager names and their starting date variables reveals that for many observations CRSP is inconsistent in its reporting. Names of managers might be written in full one year, while for another year the given name is abbreviated. For instance, if 'Timothy' is the reported name in a certain year, the same manager might be named 'Tim' or ' $T$ ' in a different year. Another problem with the names variable is that typing errors are not uncommon. The starting date variable, the reported date a manager took control over the fund, has consistency problems as well. There are often different starting dates assigned to the same manager for the same fund. Hence, using the raw CRSP data on managerial information is unreliable and therefore many manager change observations that are likely due to an error are excluded from the analysis. In order to exclude these dubious manager changes, a computer algorithm is used first to detect the commonly made errors. Next, the dataset is thoroughly checked by visual inspection.

CRSP reports for the responsible management a single name, two names, three names or an anonymous team. We assign an observation in a particular year for a particular fund as one where a management change occured if it obeys the following: it should be clear from the names that there is a new manager (or team of managers). Hence the new and/or former management should not be anonymous; the new management should not be part of the old management; and, importantly, the date the new management took over should be consistently reported each year the fund is in the CRSP tapes. If an observation does not obey at least one these requirements, the fund year observations is assigned to the control group.

\section{B. Fund Flows}

CRSP does not report the flows to the funds but these need to be estimated. We estimate flows by taking the differences in TNA over two consecutive years, adjusting for internal growth due to returns on investments and mergers with other funds. Hence, the dollar flow or absolute flow is given by

$$
\text { AbsoluteFlow }_{i, t}=T N A_{i, t}-\left(1+R_{i, t}\right) T N A_{i, t-1}-M_{i, t} \text {, }
$$


where $T N A_{i, t}$ is the total net assets of fund $i$ at the end of year $t, R_{i, t}$ is the return of fund $i$ belonging to year $t$ and $M_{i, t}$ refers to the growth in total net assets due to mergers.

Small funds will in general have smaller in or outflows than large funds and since the analysis is performed at the individual fund level we will concentrate our results on relative flows defined as

$$
\text { RelativeFlow }_{i, t}=\frac{T N A_{i, t}-\left(1+R_{i, t}\right) T N A_{i, t-1}-M_{i, t}}{\left(1+R_{i, t}\right) T N A_{i, t-1}},
$$

in which the absolute flow measure is scaled by $\left(1+R_{i, t}\right) T N A_{i, t-1} \cdot 37$

\section{First Impressions of the Data}

Our fund selection criteria outlined above, results in a sample of 53,120 fund year observations from 9,083 distinct funds. ${ }^{38}$ This includes funds as small as $\$ 100,000$ that just recently started. For our analysis, these small start-up funds entail a problem since they can easily grow by a few thousands of percents or more over a single year, completely distorting the results. These funds are often opened to the public after are certain period of relative strong performance in which the management company used their own capital in order to have a positive track-record (see Evans, 2010). For this reason we impose funds to have a TNA above $\$ 50$ million at the end of the previous year and to be at least 2 years old to be included in the sample. ${ }^{39}$ Finally, we delete the fund year observations that have extreme growth by also excluding the observations belonging to the cross-sectional top $1 \%$ of relative fund flows for that year.

Table 5.1 reports summary statistics of our sample before and after we impose these restrictions to the data. By imposing the restriction that funds

37 This measure uses a slightly different measure from what is traditionally used in the literature (see e.g. Chevalier and Ellison, 1997; Sirri and Tufano, 1998; Zheng, 1999; and Del Guercio and Tkac, 2002). The reason is that this scaling ensures that the estimated relative flows can never be lower than -1 (see Berk and Tonks, 2007; and Bris et al., 2007). Results are, however, very similar irrespective of which scaling is used. Moreover, the conclusions are also qualitatively the same if we use absolute flows, but statistical inferences are much noisier.

38 Mutual fund companies often offer different share classes to various types of investors but share the same underlying portfolio. In CRSP, each share class is treated as a separate fund, assigning it a unique identification code. As we are interested in how investors react to managerial replacements by means of fund flows, treating each share class separately will not lead to double-counting problems.

${ }^{39}$ Our results are qualitatively similar if we impose funds to have a TNA of at least $\$ 5$ million by the end of previous year. 
need to have at least $\$ 50$ million of total net assets under management and be at least 2 years old we 'lose' almost 30,000 fund year observations. Although this more than halves the sample, it decreases the aggregate assets under management by only 2 percent. Importantly, the average relative fund flows decrease from an extremely high 10,000 percent to a more sensible 11 percent per year. Deleting the fund years with the most extreme relative fund flows drops the average relative fund flows to 7 percent and the standard deviation by almost 20 percent. While this excludes again the relatively smaller funds, it has no significant effect on the distribution of the turnover and different expense variables.

The final sample consists of 23,567 fund year observations and 1,760 management change observations. Hence, approximately 7.5 percent of the fund years in our sample are recorded as an observation in which a management change occurred. This statistic is lower than what is found by Ding and Wermers (2009), who report 14 to 18 percent but use a more detailed database from different sources that are not available to us. Also, this statistic is lower compared to the statistic of Bessler et al. (2008), who find 19 percent managerial turnover per annum but use the 'raw' CRSP database, including for instance anonymous teams and ignoring the many inconsistencies.

Figure 5.1 plots the number of funds and number of manager changes each year for our sample period. There is a steady increase in the number of funds over the whole range of the sample period. The same pattern occurs for the number of manager changes up to the year 2000. However, in the years 2001, 2003 and 2005, the number of manager changes is lower compared to the year before despite the growing number of funds. A possible explanation for this is that funds are increasingly likely to report anonymous teams instead of manager names as the ones that are responsible for the portfolio (see Bär et al., 2005; and Massa et al., 2010).

\subsection{Empirical Results}

In this section, the empirical results of our analyses are reported. First, we use a sorting approach to study the behavior of mutual fund investors subsequent to managerial replacements. Next, we use multivariate regression techniques in order to simultaneously correct for other fund characteristics. This is followed by several robustness checks. Finally, we study the behavior of retail and institutional investors separately. 


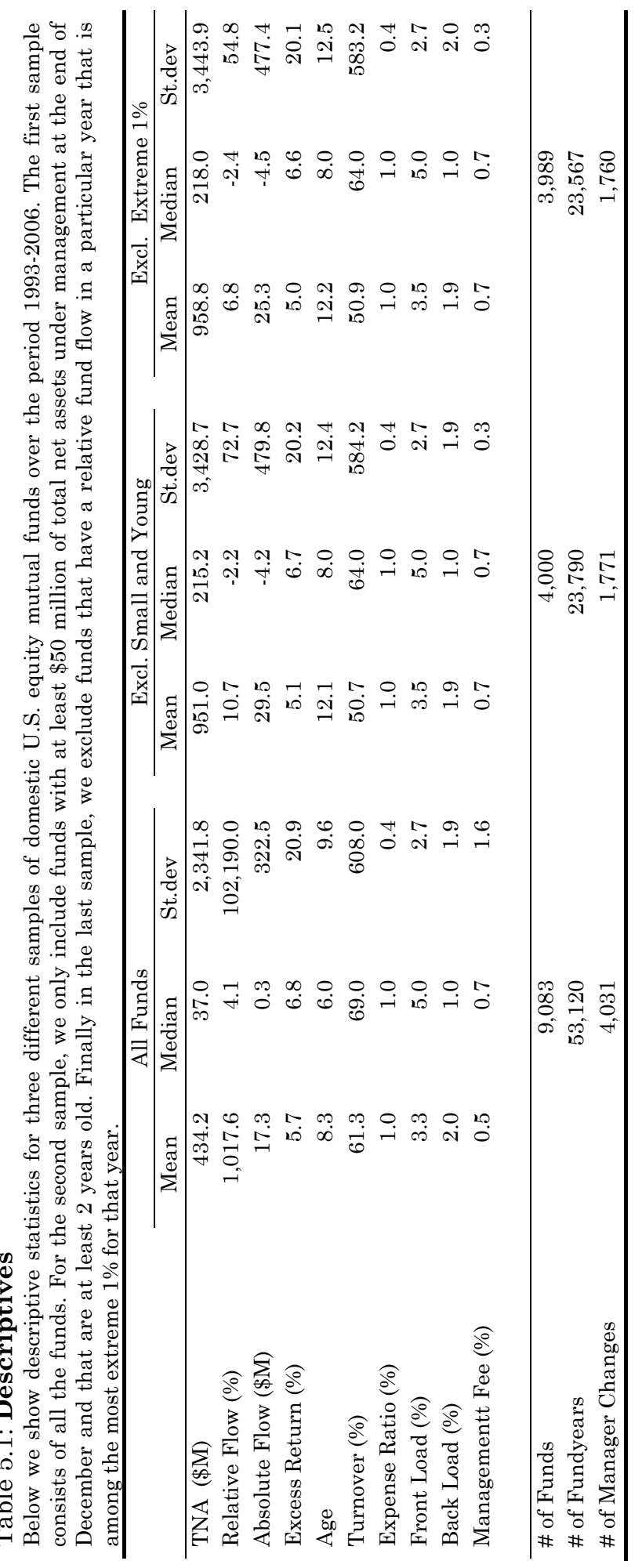


Figure 5.1: Number of Funds and Manager Changes over the Years

Below we show the number of funds and management changes for the period 1993-2006. The sample consists of domestic U.S. equity mutual funds with at least $\$ 50$ million of total net assets under management at the end of December and that are at least 2 years old. Funds that have a relative fund flow in a particular year that is among the most extreme $1 \%$ are excluded for that year.

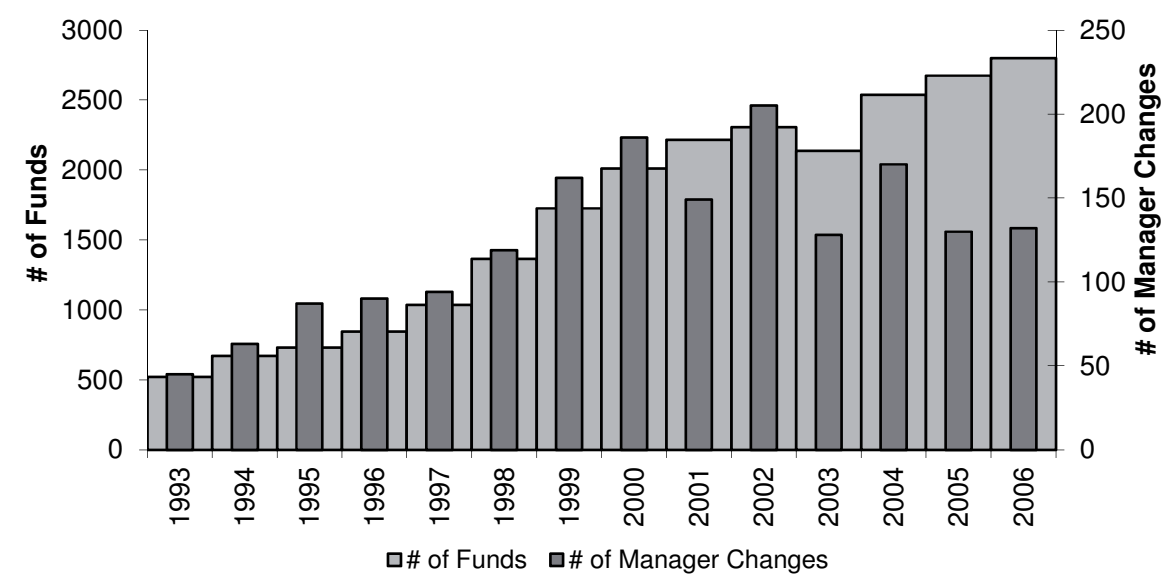

\section{A. Sorting Funds on Size and Past Performance}

In Section 5.1 of this chapter, we developed hypotheses on the expected flow responses by mutual fund investors for funds that recently experienced a manager change. Since the expected investment ability of the manager is updated based on the past performance of the fund and the predicted investors' responses depend largely on these expectations, we sort funds based on their past year performance. Moreover, since flows are correlated with the size of the fund, we also correct for this by sorting funds on the total net assets under management. As a result, we make use of a triple-sorting routine in which at the end of each year we first sort funds on their size. Next, within each size segment we sort funds on their past 12-month performance. And finally we differentiate between funds with a management change and funds without a change in management. The funds are assigned to a portfolio depending on their size, past performance and whether or not the manager is retained. In total, we end up with $30(3 \times 5 \times 2)$ different portfolios of funds. For each of these portfolios we estimate equal weighted returns and fund flows over the year subsequent to this sorting procedure. The results are reported in Table 5.2.40

${ }^{40}$ Our results are qualitatively similar if we use risk-adjusted or investment objective adjusted returns for evaluating past performance and/or subsequent performance instead of raw returns. 
From the first set of columns, it can be seen that for funds which retained their manager (w/o), there is evidence of persistence in performance and mostly so among the medium sized and large funds. Interestingly, there is not an increasing pattern visible in returns over the performance quintiles for funds with (w) a change in management. This is consistent with the findings of Khorana (2001) who also finds that poorly performing funds do better subsequent to replacing the manager. At first sight, this seems consistent with the idea that managers with no skill are replaced by managers with higher skill and managers with high skill are replaced by managers that are not so highly skilled. Moreover, it is consistent with the findings of Jin and Scherbina (2011) who show that new managers sell off loser stocks (inherited from their predecessors) at a higher rate compared to continuing managers, boosting the performance. ${ }^{41}$

In the second and third set of columns the relative flows and absolute flows are reported, respectively. On average, in the year following a managerial replacement, flows to these funds are significantly lower compared to funds that retained their manager. That is, funds on average have net outflows of 3.4 percent ( $\$ 40.4$ million) subsequent to a manager change, while funds with continuing managers grow by 2.3 percent ( $\$ 18.3$ million). The findings are quantitatively very similar for the different size segments when looking at the relative flows and are qualitatively similar when looking at the absolute flows

Even more interesting, for the purpose of our study, are the average reported flows for the different performance quintiles. Not surprisingly, for funds without a change in management we find strong evidence of investors chasing past performance. The spread in flows between recent winner funds and recent loser funds is, however, very similar for funds that did have a managerial replacement. For instance, small loser funds with a manager change have net outflows of 20.5 percent ( $\$ 20.5$ million) while small winner funds of which the manager is replaced have net money inflows of 15.5 percent ( $\$ 21.8$ million), a spread of 36.0 percent (\$37.2 million). For funds without a management change the spread is 36.2 percent ( $\$ 37.7$ million).

\footnotetext{
${ }^{41}$ Note that the average performance for small and medium sized funds is higher subsequent to managerial replacements compared to funds without a change in management, while for large funds the opposite holds (although not significantly so). It is beyond the scope of this study to find the reasons driving this result. Possibly, however, large funds are more likely to find an in-house replacement than smaller funds. In-house replacements are less likely to sell off the loser stocks compared to new managers from outside the management company (Jin and Scherbina, 2011).
} 


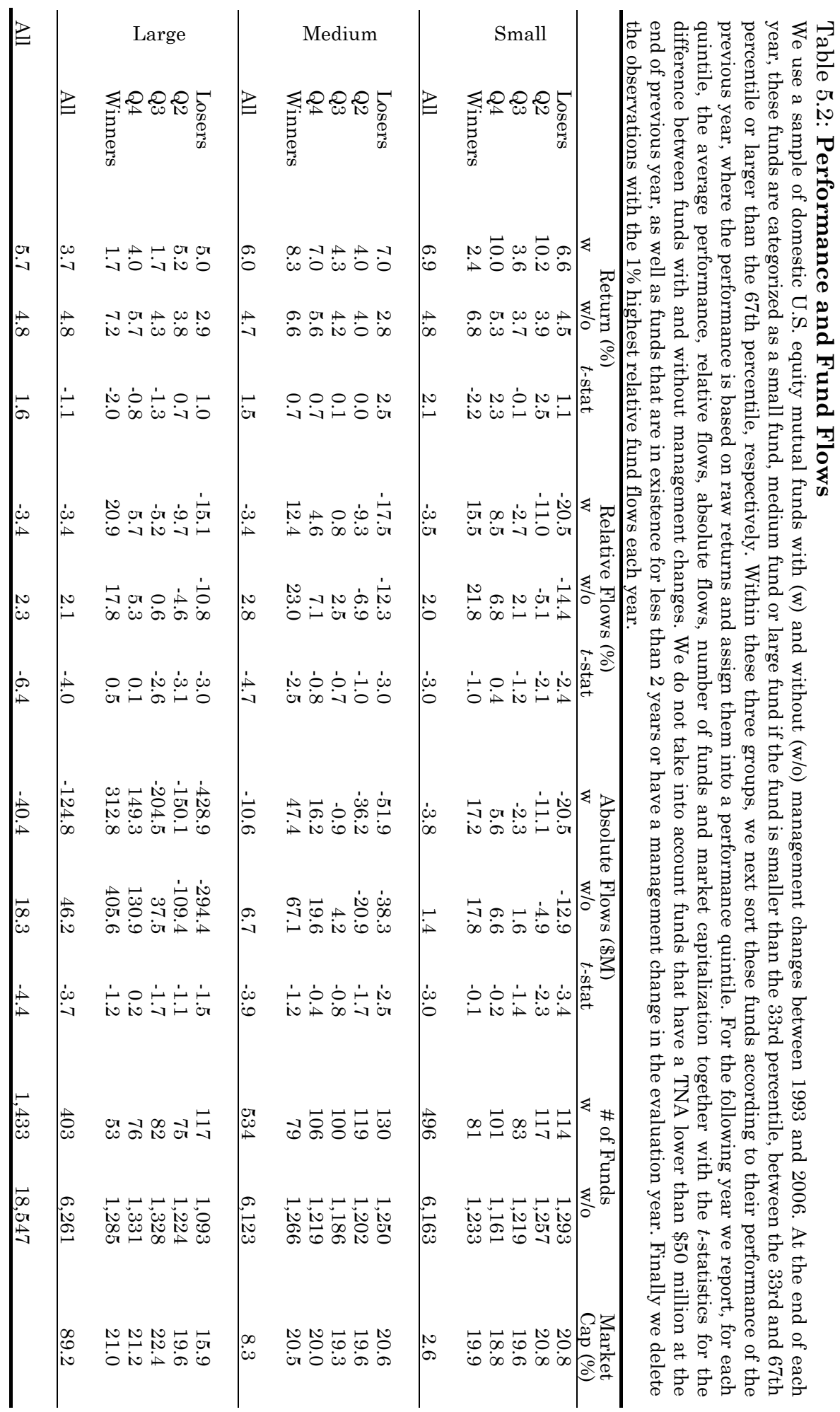


Hence, our two hypotheses that follow from Dangl et al. (2008) do not seem to hold simultaneously since then we expect to find a much lower spread for funds with a management change. Moreover, Hypothesis 1a states that poorly performing funds have higher flows after a managerial replacement compared to poorly performing funds without a change in management. We find strong evidence, however, that the opposite holds. That is, after replacing the poorly performing manager flows are lower than if the poorly performing manager is retained. Next to that, flows to winner funds are also lower subsequent to manager changes; however, these results are somewhat weaker. In conclusion, the evidence on flow responses subsequent to managerial replacements is in line with the alternative, signalling hypothesis. That is, the results are consistent with the argument of Gervais et al. (2005) who state that retaining a poorly performing manager is a positive signal for this manager. And the replacement of a poorly performing manager is perceived as a negative signal by mutual fund investors.

In the above analysis, we control for the size of funds as well as their performance in studying the flow responses of mutual fund investors to managerial replacements. To rule out possible other reasons that could drive the results, we also look at several fund and portfolio characteristics. Fund characteristics include, for instance, the age of the fund, expense ratios and portfolio turnover. Portfolio characteristics include return volatility and exposures to known investment styles. We find that funds with a recent manager change have significantly higher expense ratios and load fees. Moreover, funds with new managers, on average, take more risks. Still, even though we find some differences in characteristics between the two groups of funds, it is unlikely to result in flow differences of the magnitude reported in Table 5.2.42 In the next subsection, however, we use a more formal test procedure and control for other fund characteristics simultaneously.

\section{B. Multivariate Regression Analysis}

The analysis using the sorting routine provides our first evidence that mutual fund investors respond negatively to manager changes by allocating less capital to these funds compared to similarly performing funds without a change in management. While this analysis does not impose any kind of structure on the performance-flow relation, the approach is too crude to

${ }^{42}$ For the sake of brevity, we do not elaborate more on other characteristics. The interested reader, however, is referred to the appendix for a more detailed discussion on these findings. 
simultaneously correct for other fund characteristics. For this reason, the next analysis uses multivariate regressions to study flows subsequent to managerial replacements. More specifically, we make use of Fama and MacBeth (1973) type of regressions as well as pooled OLS regressions and estimate the linear model given by

$$
\text { RelativeFlow }_{\mathrm{i}, \mathrm{t}}=f\left(\begin{array}{l}
\text { Performance }_{i, t-1}, \text { Risk }_{i, t-1}, \text { TNA }_{i, t-1}, \\
\text { Age }_{i, t-1}, \text { Expense }_{i, t-1}, \text { Turnover }_{i, t-1}, \text { Flow }_{i, t-1} \\
\text { ObjectiveFlow }_{i, t}, \text { ManagerChange }_{i, t-1}
\end{array}\right),
$$

where RelativeFlow ${ }_{i, t}$ is defined in Equation (5.2).

Following Sirri and Tufano (1998), we allow for a piece-wise linear relation between a fund's performance ranking, relative to other funds with the same investment objective, and the fund flows. The standard deviation of past 12-month returns is used as the measure of risk. Other fund characteristics that we control for are the size of the fund, measured by the natural log of total net assets; the natural log of the age of the fund; an expense variable that is defined as the expense ratio plus one-seventh of frontand back end loads; previous year portfolio turnover; and lagged flow. This latter variable is particularly useful for controlling for omitted fund characteristics. In order to control for flow variations within different investment styles, we include average objective flows in year $t$. The objective flow is defined as the average flow to all funds sharing the same investment objective. Finally, we include a dummy variable that takes the value of one if a fund experienced a manager change in year $t$-1 and zero otherwise.

We analyze two different models that differ in their flexibility on the performance-flow relation for funds with a management change compared to funds without a change in management. In Model 1 the manager change dummy $(M C D)$ is interacted with five performance quintile dummies that corresponds to the piece-wise linear structure on the performance-flow relation. In Model 2 we allow for a different intercept and a different piecewise linear structure by including the management change variable as a dummy intercept as well as a slope dummy for the five different performance segments. The results are shown in Table 5.3.

For both Model 1 and Model 2 (which differentiates in how the manager change variable is used), the familiar convex relation between past performance and subsequent fund flows is shown. Next to that, the control 
variables are mostly in line with the existing literature on fund flows. For instance, flows are higher for funds with less volatile returns and that have lower expenses, and younger funds grow at a faster rate than older funds. Portfolio turnover does not seem to have a significant effect on fund flows. Probably, investors are not so much sensitive to turnover itself, but to the costs associated with higher turnover. This is, however, already controlled for by including the expense variable. Somewhat surprisingly, we find a positive relation with lagged assets under management, while most empirical studies on fund flows find a negative relation. This difference is likely due to our sample restrictions that exclude the many small and young funds from the analysis.

The bottom half of the table reports the estimated coefficients on the manager change variable. In Model 1, in which the management change dummy is interacted with the five performance quintile dummies, the coefficients are all negative. For instance, funds that belong to the 20 percent of funds with the worst past performance that replaced its manager have flows that are at least 3 percent lower compared to funds without a replacement. And recent winner funds even receive 3 to 6 percent (depending on the method used) lower flows in case there is a new manager. Hence, there is strong evidence that investors have a preference for funds that retained their manager compared to funds of which the manager is replaced, supporting our earlier results.

Interestingly, if we allow for more flexibility in Model 2, we find no significant coefficients on the interaction variables except for the winner funds in the pooled OLS regression. Hence, the sensitivity of flows to past performance is very similar for funds with a management change as for funds with no such a change. However, the significant negative coefficients that are estimated for the intercept dummy means that these funds do have flows that are in the order of 5 percentage points lower. The performance-flow relation of Model 2, estimated using the Fama-MacBeth regression, is also plotted in Figure 5.2. From the figure, it is clearly visible that the estimated graph for funds with a management change (dashed line) lies below the graph for funds without a change in management (solid line) for all performance rankings and that the slopes are very similar.

Summarizing, we find evidence of lower flows to funds with a manager change, even after correcting for other fund characteristics. The results using both regression methodologies provide qualitatively very similar results. 


\section{Table 5.3: Full Sample Regressions}

We run two different cross-sectional Fama-MacBeth regressions and two pooled OLS regressions each year from 1994 to 2007 on a sample of domestic U.S. equity mutual funds. The dependent variable is the relative net asset flow, defined as $\left(T N A_{i, t}-\left(1+R_{i, t}\right) * T N A_{i, t-1}\right) /$ $\left(\left(1+R_{i, t}\right) * T N A_{i, t-1}\right)$. Independent variables are a fund's fractional rank within a year based on previous year return using a piecewise linear structure over five quintiles taking a value between 0 and 0.2 ; the standard deviation of previous year monthly returns; the natural log of total net assets at the end of previous year; the natural log of the years the fund is in existence; yearly expenses, defined as the previous year expense ratio plus one seventh of previous year front- and back end load; previous year turnover ratio; lagged flow; and the objective flow. In Model 1 we also include five cross-terms between a dummy variable (MCD) that takes the value 1 in a year a fund has replaced its manager and 0 otherwise and a performance quintile dummy. In Model 2 we include the MCD variable separately as well as with cross-terms with the five piecewise performance rankings. For the Fama-MacBeth regressions, the reported coefficients and adjusted $R^{2}$ are time-series averages of the crosssectional regressions. The pooled OLS regressions include time fixed effects. $t$-Statistics are shown in brackets and are corrected for clustering per fund in the pooled OLS regressions. We do not take into account funds that have a TNA lower than $\$ 50$ million at the end of previous year, as well as funds that are in existence for less than 2 years or have a management change in the evaluation year. Finally we delete the observations with the $1 \%$ highest relative fund flows each year.

\begin{tabular}{|c|c|c|c|c|}
\hline & \multicolumn{2}{|c|}{ Model 1} & \multicolumn{2}{|c|}{ Model 2} \\
\hline & FM & OLS & FM & OLS \\
\hline Intercept & $\begin{array}{l}-0.087 \\
{[-0.65]}\end{array}$ & $\begin{array}{l}0.012 \\
\lceil 0.38\rceil\end{array}$ & $\begin{array}{l}-0.076 \\
{[-0.63]}\end{array}$ & $\begin{array}{l}0.013 \\
{[0.41]}\end{array}$ \\
\hline \multirow[t]{2}{*}{ Bottom Quintile Rank } & 0.441 & 0.451 & 0.428 & 0.436 \\
\hline & 「4.49] & $\lceil 6.38\rceil$ & 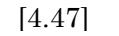 & 「5.88] \\
\hline \multirow[t]{2}{*}{ 2nd Quintile Rank } & 0.341 & 0.305 & 0.345 & 0.314 \\
\hline & $\lceil 6.72\rceil$ & $\lceil 5.21\rceil$ & $\lceil 7.16\rceil$ & $\lceil 5.14\rceil$ \\
\hline \multirow[t]{2}{*}{ 3rd Quintile Rank } & 0.277 & 0.236 & 0.283 & 0.244 \\
\hline & $\lceil 4.35\rceil$ & [4.15] & $\lceil 4.22\rceil$ & [4.15] \\
\hline \multirow{2}{*}{ 4th Quintile Rank } & 0.401 & 0.307 & 0.389 & 0.281 \\
\hline & $\lceil 4.78\rceil$ & $\lceil 4.86\rceil$ & [4.41] & 「4.33] \\
\hline \multirow[t]{2}{*}{ Top Quintile Rank } & 1.175 & 1.100 & 1.198 & 1.146 \\
\hline & [7.10] & [10.70] & [6.99] & $\lceil 10.94\rceil$ \\
\hline \multirow[t]{2}{*}{ Standard Deviation } & -0.846 & -0.073 & -0.833 & -0.070 \\
\hline & $\lceil-1.20\rceil$ & $\lceil-0.38\rceil$ & $\lceil-1.20]$ & [-0.36] \\
\hline \multirow[t]{2}{*}{ Ln(TNA) } & 0.005 & 0.009 & 0.006 & 0.009 \\
\hline & $\lceil 2.58\rceil$ & [4.44] & $\lceil 2.74\rceil$ & $\lceil 4.44\rceil$ \\
\hline \multirow[t]{2}{*}{ Ln(Age) } & -0.058 & -0.073 & -0.058 & -0.073 \\
\hline & {$[-10.28]$} & [-17.58] & $\lceil-10.41\rceil$ & [-17.58] \\
\hline \multirow[t]{2}{*}{ Expenses } & -0.020 & -0.042 & -0.020 & -0.042 \\
\hline & {$[-1.58]$} & 「-7.43] & 「-1.56] & $\lceil-7.43\rceil$ \\
\hline \multirow[t]{2}{*}{ Turnover } & 0.001 & 0.003 & 0.001 & 0.003 \\
\hline & $\lceil 0.21\rceil$ & $\lceil 0.68\rceil$ & $\lceil 0.20\rceil$ & 「0.67] \\
\hline \multirow[t]{2}{*}{ Lagged Flow } & 0.042 & 0.000 & 0.042 & 0.000 \\
\hline & $\lceil 2.68\rceil$ & $\lceil 0.86\rceil$ & $\lceil 2.68\rceil$ & $\lceil 0.86\rceil$ \\
\hline \multirow[t]{2}{*}{ Objective Flow } & 0.302 & 0.282 & 0.247 & 0.281 \\
\hline & {$[0.42]$} & [2.40] & [0.39] & [2.39] \\
\hline \multirow[t]{2}{*}{ MCD * Bottom Quintile Dummy } & -0.031 & -0.038 & & \\
\hline & $\begin{array}{l}{[-3.69]} \\
-0.045\end{array}$ & $\begin{array}{l}|-3.44| \\
-0.051\end{array}$ & & \\
\hline MCD * 2nd Quintile Dummy & $\lceil-2.85\rceil$ & 「-3.59] & & \\
\hline \multirow[t]{2}{*}{ MCD * 3rd Quintile Dummy } & -0.043 & -0.034 & & \\
\hline & [-2.03] & 「-2.06] & & \\
\hline \multirow[t]{2}{*}{ MCD * 4th Quintile Dummy } & -0.016 & -0.012 & & \\
\hline & [-0.68] & 「-0.60] & & \\
\hline MCD * Top Quintile Dummy & $\begin{array}{l}-0.059 \\
{[-2.40]}\end{array}$ & $\begin{array}{l}-0.030 \\
{[-0.93]}\end{array}$ & & \\
\hline
\end{tabular}




\section{Table 5.3 - Continued from previous page}

We run two different cross-sectional Fama-MacBeth regressions and two pooled OLS regressions each year from 1994 to 2007 on a sample of domestic U.S. equity mutual funds. The dependent variable is the relative net asset flow, defined as $\left(T N A_{i, t}-\left(1+R_{i, t}\right) * T N A_{i, t-1}\right) /$ $\left(\left(1+R_{i, t}\right) * T N A_{i, t-1}\right)$. Independent variables are a fund's fractional rank within a year based on previous year return using a piecewise linear structure over five quintiles taking a value between 0 and 0.2 ; the standard deviation of previous year monthly returns; the natural log of total net assets at the end of previous year; the natural log of the years the fund is in existence; yearly expenses, defined as the previous year expense ratio plus one seventh of previous year front- and back end load; previous year turnover ratio; lagged flow; and the objective flow. In Model 1 we also include five cross-terms between a dummy variable (MCD) that takes the value 1 in a year a fund has replaced its manager and 0 otherwise and a performance quintile dummy. In Model 2 we include the MCD variable separately as well as with cross-terms with the five piecewise performance rankings. For the Fama-MacBeth regressions, the reported coefficients and adjusted $\mathrm{R}^{2}$ are time-series averages of the crosssectional regressions. The pooled OLS regressions include time fixed effects. $t$-Statistics are shown in brackets and are corrected for clustering per fund in the pooled OLS regressions. We do not take into account funds that have a TNA lower than $\$ 50$ million at the end of previous year, as well as funds that are in existence for less than 2 years or have a management change in the evaluation year. Finally we delete the observations with the $1 \%$ highest relative fund flows each year.

\begin{tabular}{|c|c|c|c|c|}
\hline & \multicolumn{2}{|c|}{ Model 1} & \multicolumn{2}{|c|}{ Model 2} \\
\hline & FM & OLS & FM & OLS \\
\hline MCD & & & $\begin{array}{l}-0.047 \\
{[-2.14]}\end{array}$ & $\begin{array}{l}-0.052 \\
{[-2.39]}\end{array}$ \\
\hline MCD * Bottom Quintile Rank & & & $\begin{array}{l}0.109 \\
{[0.62]}\end{array}$ & $\begin{array}{l}0.127 \\
{[0.77]}\end{array}$ \\
\hline MCD * 2nd Quintile Rank & & & $\begin{array}{l}-0.044 \\
{[-0.22]}\end{array}$ & $\begin{array}{l}-0.108 \\
{[-0.71]}\end{array}$ \\
\hline MCD * 3rd Quintile Rank & & & $\begin{array}{l}0.026 \\
{[0.12]}\end{array}$ & $\begin{array}{l}0.011 \\
{[0.06]}\end{array}$ \\
\hline MCD * 4th Quintile Rank & & & $\begin{array}{l}0.103 \\
{[0.41]}\end{array}$ & $\begin{array}{l}0.444 \\
{[1.89]}\end{array}$ \\
\hline MCD * Top Quintile Rank & & & $\begin{array}{l}-0.606 \\
{[-1.46]}\end{array}$ & $\begin{array}{l}-0.990 \\
{[-2.17]}\end{array}$ \\
\hline \# of Funds & 19,964 & 19,964 & 19,964 & 19,964 \\
\hline \# of Manager Changes & 1,426 & 1,426 & 1,426 & 1,426 \\
\hline Adjusted R-squared & 0.193 & 0.126 & 0.193 & 0.126 \\
\hline
\end{tabular}

Hence, the results are not sensitive to the method used, strengthening our conclusions.

\section{Robustness Tests}

While it follows from the literature on the performance-flow relation that mutual fund investors are most sensitive to raw returns, using alphas controls for taken risks and are better in estimating the skill of the portfolio manager. From Dangl et al. (2008), it follows that the difference between the expected ability level of the departing manager and the new manager is an important determinant of the flow responses to managerial replacements. Hence, as a robustness test, we perform multivariate regressions to analyze the behavior of 


\section{Figure 5.2: Sensitivities of Flows to Performance}

The Fama-MacBeth regression estimation results from Table 5.3, Model 2 is shown below. We show the sensitivity of relative fund flows for an average fund with (dashed line) and without (solid line) a management change on the ranking based on previous year returns. With an average fund, we mean a fund with average size, age, return volatility, expenses and turnover.

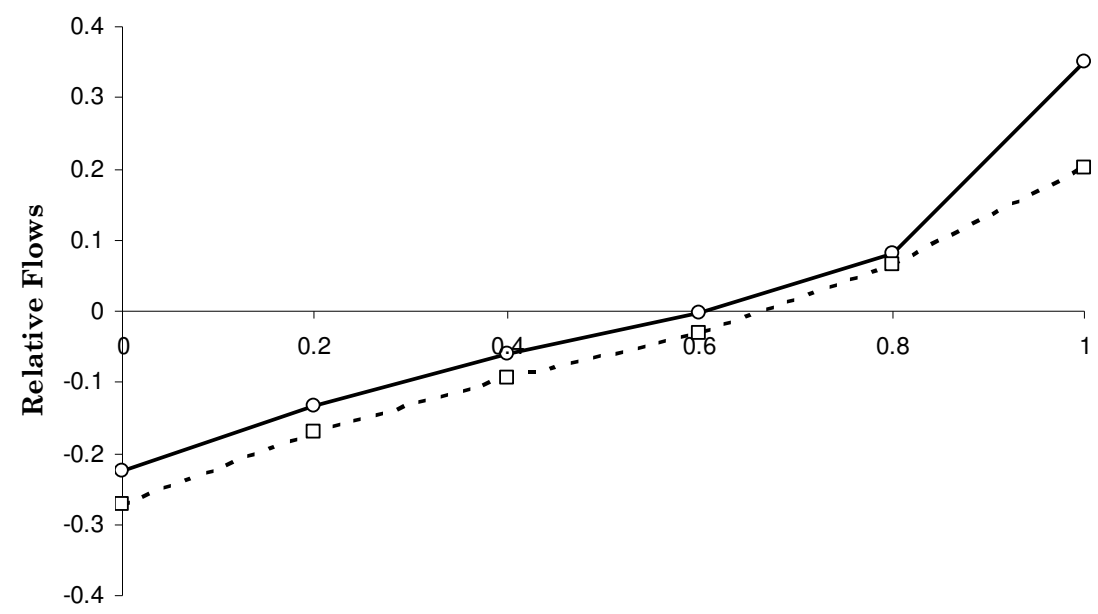

Performance Ranking

mutual fund investors following managerial replacements. In this analysis, we use Carhart (1997) four-factor alphas instead of raw returns as the relevant past performance measure. The Carhart alphas are estimated using past twelve-month returns. The results are shown in the first pair of columns of Table 5.4.

As expected, the positive performance-flow relation is less pronounced compared to using raw returns. However, this is similar for funds with a management change. Again we find that all coefficients on the management change dummy are negative of which the big majority is significant. Hence, the results are very robust to the performance measure used.

Our fund sample with managerial replacements is likely to differ from the control sample in its distribution on team composition. That is, the control sample includes funds that do not report the portfolio manager or team of managers. For the sample of funds with manager changes, on the other hand, the portfolio manager is known by definition. Moreover, since the sample of funds with manager changes only consists of funds that changed the whole team and not just part of the management, the control sample consists of relatively more team-managed funds. Both these differences can have an effect 


\section{Table 5.4: Robustness Regressions}

We run two different cross-sectional Fama-MacBeth regressions and two pooled OLS regressions each year from 1994 to 2007 on a sample of domestic U.S. equity mutual funds. The first pair of columns uses the full sample of funds whereas the second pair of columns uses a subsample including only single managed funds. The dependent variable is the relative net asset flow, defined as $\left(T N A_{i, t}-\left(1+R_{i, t}\right) * T N A_{i, t-1}\right) /\left(\left(1+R_{i, t}\right) * T N A_{i, t-1}\right)$. Independent variables are defined as is explained in Table 5.3 (Model 1) except for the performance measure in the first pair of columns where the four-factor alpha of Carhart (1997) is used instead of previous year return. For the Fama-MacBeth regressions, the reported coefficients and adjusted $\mathrm{R}^{2}$ are time-series averages of the cross-sectional regressions. The pooled OLS regressions include time fixed effects. $t$-Statistics are shown in brackets and are corrected for clustering per fund in the pooled OLS regressions. We do not take into account funds that have a TNA lower than $\$ 50$ million at the end of previous year, as well as funds that are in existence for less than 2 years or have a management change in the evaluation year. Finally we delete the observations with the $1 \%$ highest relative fund flows each year.

\begin{tabular}{|c|c|c|c|c|}
\hline & \multicolumn{2}{|c|}{4 Factor Alpha } & \multicolumn{2}{|c|}{ Single Managed Funds } \\
\hline & FM & OLS & FM & OLS \\
\hline \multirow[t]{2}{*}{ Intercept } & 0.065 & 0.055 & 0.012 & 0.038 \\
\hline & {$[0.73]$} & {$[1.70]$} & [0.13] & {$[0.90]$} \\
\hline \multirow[t]{2}{*}{ Bottom Quintile Rank } & 0.341 & 0.296 & 0.499 & 0.561 \\
\hline & {$[2.98]$} & {$[3.80]$} & {$[4.55]$} & {$[6.31]$} \\
\hline \multirow[t]{2}{*}{ 2nd Quintile Rank } & 0.332 & 0.291 & 0.286 & 0.232 \\
\hline & {$[6.18]$} & {$[4.57]$} & {$[3.11]$} & {$[3.11]$} \\
\hline \multirow{2}{*}{ 3rd Quintile Rank } & -0.046 & -0.056 & 0.289 & 0.245 \\
\hline & {$[-0.76]$} & {$[-0.96]$} & {$[3.86]$} & {$[3.07]$} \\
\hline \multirow[t]{2}{*}{ 4th Quintile Rank } & 0.293 & 0.244 & 0.428 & 0.365 \\
\hline & {$[4.41]$} & {$[3.74]$} & {$[3.71]$} & {$[3.82]$} \\
\hline \multirow[t]{2}{*}{ Top Quintile Rank } & 0.756 & 0.805 & 1.122 & 1.092 \\
\hline & [5.08] & {$[8.02]$} & {$[4.44]$} & [6.67] \\
\hline \multirow[t]{2}{*}{ Standard Deviation } & -0.053 & -0.541 & -0.493 & -0.054 \\
\hline & {$[-0.08]$} & {$[-2.78]$} & {$[-0.70]$} & {$[-0.17]$} \\
\hline \multirow[t]{2}{*}{$\operatorname{Ln}(\mathrm{TNA})$} & 0.009 & 0.012 & 0.000 & 0.005 \\
\hline & [3.59] & {$[5.55]$} & {$[-0.05]$} & {$[1.75]$} \\
\hline \multirow[t]{2}{*}{ Ln(Age) } & -0.061 & -0.080 & -0.056 & -0.071 \\
\hline & {$[-10.02]$} & {$[-18.62]$} & {$[-12.40]$} & {$[-12.83]$} \\
\hline \multirow[t]{2}{*}{ Expenses } & -0.024 & -0.045 & -0.014 & -0.027 \\
\hline & {$[-1.83]$} & {$[-7.98]$} & {$[-0.89]$} & {$[-3.48]$} \\
\hline \multirow[t]{2}{*}{ Turnover } & 0.009 & 0.010 & 0.001 & 0.007 \\
\hline & [1.19] & {$[2.10]$} & {$[0.07]$} & [1.11] \\
\hline \multirow[t]{2}{*}{ Lagged Flow } & 0.046 & 0.000 & 0.056 & 0.001 \\
\hline & {$[2.71]$} & [1.03] & {$[3.61]$} & [4.11] \\
\hline \multirow[t]{2}{*}{ Objective Flow } & -0.177 & 0.536 & -0.188 & 0.105 \\
\hline & {$[-0.27]$} & [4.19] & {$[-0.48]$} & {$[0.66]$} \\
\hline \multirow[t]{2}{*}{ MCD * Bottom Quintile Dummy } & -0.040 & -0.034 & -0.034 & -0.045 \\
\hline & {$[-2.14]$} & {$[-2.42]$} & {$[-2.76]$} & {$[-3.20]$} \\
\hline \multirow[t]{2}{*}{ MCD * 2nd Quintile Dummy } & -0.050 & -0.061 & -0.036 & -0.043 \\
\hline & {$[-3.73]$} & {$[-4.35]$} & {$[-1.51]$} & {$[-2.06]$} \\
\hline \multirow[t]{2}{*}{ MCD *3rd Quintile Dummy } & -0.031 & -0.033 & -0.045 & -0.056 \\
\hline & {$[-2.69]$} & {$[-1.72]$} & {$[-2.31]$} & {$[-3.65]$} \\
\hline \multirow[t]{2}{*}{ MCD * 4th Quintile Dummy } & -0.006 & -0.038 & -0.009 & -0.011 \\
\hline & {$[-0.18]$} & {$[-1.82]$} & {$[-0.43]$} & {$[-0.40]$} \\
\hline \multirow[t]{2}{*}{ MCD * Top Quintile Dummy } & -0.063 & -0.023 & -0.068 & -0.055 \\
\hline & {$[-1.99]$} & {$[-0.78]$} & {$[-2.09]$} & {$[-1.54]$} \\
\hline \# of Funds & 19,964 & 19,964 & 8,571 & 8,571 \\
\hline \# of Manager Changes & 1,426 & 1,426 & 925 & 925 \\
\hline Adjusted R-squared & 0.136 & 0.074 & 0.201 & 0.147 \\
\hline
\end{tabular}


on our results. For instance, Bär et al. (2005) show that team-managed funds on average receive higher flows compared to funds that are single managed. On the other hand, Massa et al. (2010) show that anonymously managed funds experience lower inflows than funds that disclose their manager name(s). In order to control for these influences we perform another robustness test.

The second pair of columns of Table 5.4 reports the results of multivariate regressions on a sample that only consists of single managed funds (both the manager change sample and the control sample). Hence, in this sample the effects on different team compositions will not play a role. Again, the results are very similar to our earlier analyses on the full sample. Funds that replaced their manager have lower flows compared to funds within the same performance range that retained their manager.

\section{Retail vs. Institutional Mutual Funds}

Institutional investors in general have more sophisticated evaluation techniques and are better able to monitor mutual funds than retail investors do. Hence, managerial turnover is likely to induce less uncertainty for institutional investors than for retail investors. Moreover, institutional investors are expected to rely less on behavioral biases in making investment decisions than retail investors do (see Del Guercio and Tkac, 2002). As a consequence, this can result in different flow sensitivities for the two types of investors. In order to compare the flows in response to managerial replacements, we separate the sample into funds that cater to retail investors and funds that cater to institutional investors and perform several regressions. The results are shown in Table 5.5.

In line with what is found in earlier studies (see e.g. James and Karceski, 2006; and Keswani and Stolin, 2008), we find a positive relation between past performance and subsequent fund flows for both type of funds. If we first look at the separate samples, it can be seen that both retail investors and institutional investors respond to managerial replacements by allocating less capital to these funds compared to funds that retained their manager. Interestingly, the estimation results of the combined sample shows that the flows are even 2 to 5 percent lower for funds that cater to institutional investors compared to retail investors if the fund changed its manager. 


\section{Table 5.5: Retail vs. Institutional Funds}

We run two different cross-sectional Fama-MacBeth regressions and two pooled OLS regressions each year from 1994 to 2007 on a sample of domestic U.S. equity mutual funds. The first (second) pair of columns uses a sample of funds that are catered exclusively to retail (institutional) investors, whereas the final pair of columns uses the full sample of funds. The dependent variable is the relative net asset flow, defined as $\left(T N A_{i, t}-\left(1+R_{i, t}\right) * T N A_{i, t-1}\right) /$ $\left(\left(1+R_{i, t}\right) * T N A_{i, t-1}\right)$. Independent variables are a fund's fractional rank within a year based on previous year return using a piecewise linear structure over five quintiles taking a value between 0 and 0.2 ; the standard deviation of previous year monthly returns; the natural log of total net assets at the end of previous year; the natural log of the years the fund is in existence; yearly expenses, defined as the previous year expense ratio plus one seventh of previous year front end load and back end load; previous year turnover ratio; lagged relative flow; the objective flow; and five cross-terms between a dummy variable (MCD) that takes the value 1 in a year a fund has replaced its manager and 0 otherwise and a performance quintile dummy. The final pair of columns also includes an institutional dummy as well as a cross-term between the institutional dummy and the MCD. For the Fama-MacBeth regressions, the reported coefficients and adjusted $\mathrm{R}^{2}$ are time-series averages of the cross-sectional regressions. The pooled OLS regressions include time fixed effects. $t$-Statistics are shown in brackets and are corrected for clustering per fund in the pooled OLS regressions. We do not take into account funds that have a TNA lower than $\$ 50$ million at the end of previous year, as well as funds that are in existence for less than 2 years or have a management change in the evaluation year. Finally we delete the observations with the $1 \%$ highest relative fund flows each year.

\begin{tabular}{|c|c|c|c|c|c|c|}
\hline & \multicolumn{2}{|c|}{ Retail } & \multicolumn{2}{|c|}{ Institutional } & \multicolumn{2}{|c|}{ Combined Sample } \\
\hline & FM & OLS & FM & OLS & FM & OLS \\
\hline \multirow[t]{2}{*}{ Intercept } & 0.025 & 0.043 & -0.055 & 0.048 & -0.026 & 0.054 \\
\hline & {$[0.32]$} & [1.24] & {$[-0.33]$} & [0.68] & {$[-0.23]$} & {$[1.72]$} \\
\hline \multirow[t]{2}{*}{ Bottom Quintile Rank } & 0.437 & 0.416 & 0.355 & 0.632 & 0.448 & 0.579 \\
\hline & [3.61] & {$[5.45]$} & [2.13] & {$[3.11]$} & {$[4.52]$} & {$[6.41]$} \\
\hline \multirow[t]{2}{*}{ 2nd Quintile Rank } & 0.334 & 0.269 & 0.345 & 0.295 & 0.345 & 0.490 \\
\hline & [7.11] & [4.29] & [2.43] & {$[2.30]$} & {$[6.56]$} & {$[5.20]$} \\
\hline \multirow[t]{2}{*}{ 3rd Quintile Rank } & 0.328 & 0.319 & 0.052 & 0.069 & 0.273 & 0.386 \\
\hline & [4.21] & [5.32] & {$[0.45]$} & [0.53] & {$[4.27]$} & [4.15] \\
\hline \multirow[t]{2}{*}{ 4th Quintile Rank } & 0.419 & 0.274 & 0.368 & 0.369 & 0.404 & 0.498 \\
\hline & [3.93] & [4.03] & [3.58] & {$[2.62]$} & {$[4.74]$} & [4.90] \\
\hline \multirow[t]{2}{*}{ Top Quintile Rank } & 1.245 & 1.276 & 0.977 & 0.601 & 1.174 & 1.423 \\
\hline & {$[6.02]$} & [10.51] & {$[5.23]$} & {$[3.28]$} & {$[6.96]$} & [10.71] \\
\hline \multirow[t]{2}{*}{ Standard Deviation } & -1.081 & -0.306 & -0.643 & 0.664 & -0.832 & -0.377 \\
\hline & {$[-1.45]$} & {$[-1.41]$} & {$[-0.58]$} & [1.58] & {$[-1.18]$} & {$[-0.33]$} \\
\hline \multirow[t]{2}{*}{ Ln(TNA) } & 0.003 & 0.007 & -0.005 & 0.003 & 0.003 & 0.007 \\
\hline & {$[1.57]$} & {$[3.19]$} & {$[-0.73]$} & {$[0.58]$} & {$[1.66]$} & {$[3.51]$} \\
\hline \multirow[t]{2}{*}{ Ln(Age) } & -0.052 & -0.068 & -0.087 & -0.120 & -0.062 & -0.076 \\
\hline & {$[-10.42]$} & {$[-15.24]$} & {$[-5.92]$} & {$[-10.34]$} & {$[-10.58]$} & {$[-18.01]$} \\
\hline \multirow[t]{2}{*}{ Expenses } & -0.038 & -0.053 & 0.024 & -0.047 & -0.035 & -0.055 \\
\hline & {$[-3.37]$} & {$[-8.15]$} & {$[0.91]$} & {$[-2.60]$} & {$[-2.97]$} & {$[-9.16]$} \\
\hline \multirow[t]{2}{*}{ Turnover } & 0.000 & 0.003 & -0.006 & 0.006 & 0.001 & 0.860 \\
\hline & {$[-0.03]$} & {$[0.54]$} & {$[-0.40]$} & {$[0.52]$} & {$[0.18]$} & {$[0.62]$} \\
\hline \multirow[t]{2}{*}{ Lagged Flow } & 0.053 & 0.001 & 0.078 & 0.000 & 0.042 & 0.002 \\
\hline & {$[3.60]$} & {$[2.95]$} & {$[2.43]$} & {$[0.34]$} & {$[2.70]$} & [0.89] \\
\hline \multirow[t]{2}{*}{ Objective Flow } & -0.149 & 0.312 & 0.517 & 0.219 & 0.236 & 0.238 \\
\hline & {$[-0.31]$} & {$[2.24]$} & {$[0.52]$} & {$[1.00]$} & {$[0.40]$} & {$[2.40]$} \\
\hline
\end{tabular}




\section{Table 5.5 - Continued from previous page}

We run two different cross-sectional Fama-MacBeth regressions and two pooled OLS regressions each year from 1994 to 2007 on a sample of domestic U.S. equity mutual funds. The first (second) pair of columns uses a sample of funds that are catered exclusively to retail (institutional) investors, whereas the final pair of columns uses the full sample of funds. The dependent variable is the relative net asset flow, defined as $\left(T N A_{i, t}-\left(1+R_{i, t}\right) * T N A_{i, t-1}\right) /$ $\left(\left(1+R_{i, t}\right) * T N A_{i, t-1}\right)$. Independent variables are a fund's fractional rank within a year based on previous year return using a piecewise linear structure over five quintiles taking a value between 0 and 0.2 ; the standard deviation of previous year monthly returns; the natural log of total net assets at the end of previous year; the natural log of the years the fund is in existence; yearly expenses, defined as the previous year expense ratio plus one seventh of previous year front end load and back end load; previous year turnover ratio; lagged relative flow; the objective flow; and five cross-terms between a dummy variable (MCD) that takes the value 1 in a year a fund has replaced its manager and 0 otherwise and a performance quintile dummy. The final pair of columns also includes an institutional dummy as well as a cross-term between the institutional dummy and the MCD. For the Fama-MacBeth regressions, the reported coefficients and adjusted $\mathrm{R}^{2}$ are time-series averages of the cross-sectional regressions. The pooled OLS regressions include time fixed effects. $t$-Statistics are shown in brackets and are corrected for clustering per fund in the pooled OLS regressions. We do not take into account funds that have a TNA lower than $\$ 50$ million at the end of previous year, as well as funds that are in existence for less than 2 years or have a management change in the evaluation year. Finally we delete the observations with the 1\% highest relative fund flows each year.

\begin{tabular}{|c|c|c|c|c|c|c|}
\hline & \multicolumn{2}{|c|}{ Retail } & \multicolumn{2}{|c|}{ Institutional } & \multicolumn{2}{|c|}{ Combined Sample } \\
\hline & FM & OLS & FM & OLS & FM & OLS \\
\hline MCD * Bottom Quintile Dummy & $\begin{array}{l}-0.024 \\
{[-2.581}\end{array}$ & $\begin{array}{c}-0.039 \\
{[-3.62]}\end{array}$ & $\begin{array}{l}-0.026 \\
{[-1.09]}\end{array}$ & $\begin{array}{l}-0.046 \\
{[-1.31]}\end{array}$ & $\begin{array}{l}-0.027 \\
{[-3.03]}\end{array}$ & $\begin{array}{l}-0.033 \\
{[-2.67]}\end{array}$ \\
\hline MCD * 2nd Quintile Dummy & $\begin{array}{l}-0.020 \\
{[-1.19]}\end{array}$ & $\begin{array}{l}-0.023 \\
{[-1.55]}\end{array}$ & $\begin{array}{l}-0.116 \\
{[-3.42]}\end{array}$ & $\begin{array}{l}-0.105 \\
{[-2.93]}\end{array}$ & $\begin{array}{l}-0.037 \\
{[-2.20]}\end{array}$ & $\begin{array}{l}-0.038 \\
{[-2.67]}\end{array}$ \\
\hline MCD * 3rd Quintile Dummy & $\begin{array}{l}-0.041 \\
{[-1.57]}\end{array}$ & $\begin{array}{l}-0.040 \\
{[-2.34]}\end{array}$ & $\begin{array}{l}-0.089 \\
{[-0.74]}\end{array}$ & $\begin{array}{l}0.012 \\
{[0.22]}\end{array}$ & $\begin{array}{l}-0.041 \\
{[-1.76]}\end{array}$ & $\begin{array}{l}-0.025 \\
{[-1.61]}\end{array}$ \\
\hline MCD * 4th Quintile Dummy & $\begin{array}{l}-0.022 \\
{[-1.08]}\end{array}$ & $\begin{array}{l}0.012 \\
{[0.53]}\end{array}$ & $\begin{array}{l}-0.029 \\
{[-0.38]}\end{array}$ & $\begin{array}{l}-0.093 \\
{[-2.40]}\end{array}$ & $\begin{array}{l}-0.014 \\
{[-0.65]}\end{array}$ & $\begin{array}{l}-0.002 \\
{[-0.05]}\end{array}$ \\
\hline MCD * Top Quintile Dummy & $\begin{array}{l}-0.054 \\
{[-1.94]}\end{array}$ & $\begin{array}{l}-0.047 \\
{[-1.26]}\end{array}$ & $\begin{array}{l}-0.038 \\
{[-0.66]}\end{array}$ & $\begin{array}{c}-0.053 \\
{[-0.90]}\end{array}$ & $\begin{array}{l}-0.051 \\
{[-2.02]}\end{array}$ & $\begin{array}{l}-0.025 \\
{[-0.67]}\end{array}$ \\
\hline Institutional Dummy & & & & & $\begin{array}{l}-0.047 \\
{[-4.18]}\end{array}$ & $\begin{array}{l}-0.036 \\
{[-4.03]}\end{array}$ \\
\hline MCD * Institutional Dummy & & & & & $\begin{array}{l}-0.023 \\
{[-0.74]}\end{array}$ & $\begin{array}{l}-0.050 \\
{[-2.06]}\end{array}$ \\
\hline \# of Funds & 14,732 & 14,732 & 5,232 & 5,232 & 19,964 & 19,964 \\
\hline \# of Manager Changes & 1,127 & 1,127 & 299 & 299 & 1,426 & 1,426 \\
\hline Adjusted R-squared & 0.232 & 0.168 & 0.115 & 0.070 & 0.196 & 0.127 \\
\hline
\end{tabular}

\subsection{Conclusions}

In this chapter, we study the response of mutual fund investors subsequent to managerial replacements. More specifically, we empirically analyze the capital flows to funds that recently changed its management and compare this to funds of which the manager is retained. For this purpose, we use a sample of open-end domestic U.S. equity mutual funds and analyze manager changes in the years from 1993 to 2006 . We develop and test alternative hypotheses and 
document several interesting findings on flows subsequent to managerial replacements.

First, we find that funds that changed its management have significantly lower flows in the subsequent year compared to funds that retained its management. While our sample of funds of which the manager has continued on average grows by 2.3 percent per year, funds with a management change have on average net outflows of 3.4 percent of its assets under management.

Moreover, we find that the best performing funds that changed their manager have lower flows compared to similarly performing funds of which the manager is retained. On top of that, we also find that poorly performing funds have lower flows after a change in management. These results are inconsistent with the predictions following from the rational expectations framework of Dangl et al. (2008) as their model predicts, compared to the control sample, a lower flow-spread and higher flows for poorly performing funds if the manager is replaced. On the other hand, the results are consistent with the signalling hypothesis. Hence, it seems that firing a poorly performing manager is either inferred as a bad signal by mutual fund investors, or inferred as a positive signal on poorly performing funds within the same family of which the manager is retained. On the grounds that replacing a poorly performing manager subsequently results in a better performance, it is doubtful whether either of these signal interpretations is justified.

Our conclusions are robust to the inclusion of other fund characteristics such as size, age, and expenses. Also, the conclusions hold for different subsamples of funds. For instance, results are similar for small, medium and large funds and single managed funds. Moreover, the conclusions are insensitive to the methodology that is used. Interestingly, the results are also very similar for institutional funds and retail funds.

Finally, our results have implications for the mutual fund industry and for management companies in specific. First, it is well known that investors chase past fund performance, however, after a management change, the flows to strong performing funds are relatively lower. Hence it might pay-off for management companies to upgrade the contract of the portfolio manager in order to retain the manager. ${ }^{43}$ Secondly, in order to prevent lower flows subsequent to firing a manager, it might be optimal not to report the name of

${ }^{43}$ Deuskar et al. (2011) show that mutual funds try to retain strong performing managers by allowing them to simultaneously manage the mutual fund as well as a hedge fund. 
the responsible manager even though anonymously managed funds receive lower flows (see Massa et al., 2010). These would be interesting topics for further research.

\subsection{Appendix}

In this appendix we examine characteristics of funds with and funds without a recent change in management. Next, we discuss whether differences in characteristics between the two groups of funds can explain the empirical finding that funds with a management change have lower flows compared to funds without a change in management. We use the same sorting procedure as is explained in the main text of the chapter, however, instead of looking at flows we look at fund characteristics such as size, age and expenses, and portfolio characteristics such as return volatility and exposures to known investment styles. The results are reported in Table 5.A1.

In Panel A of the table, we report average fund characteristics of the funds belonging to the 30 different portfolios sorted on size, past performance and having had a recent manager change or not. First, there is clear evidence that mutual funds with a management change are relatively older. This is not surprising as the likelihood of having at least one manager replacement is increasing in the number of years a fund is in existence. However, even though the literature suggests a negative relation between flows and the age of a fund, we find it hard to believe this will drive our results. Perhaps more important are the expenses investors face. Both the total loads and the expense ratio are significantly higher for funds with a management change. This is likely to explain part of the big differences in flows that we find. Interestingly (but arguably less important than expenses), also the portfolio turnover in the year subsequent to replacement is significantly higher, consistent with the findings of Jin and Scherbina (2011).

Besides characteristics of the fund, we also look at portfolio characteristics, including the return volatility and exposures to the market, size, value and momentum factors. Factor exposures are estimated by using the four factor model of Carhart (1997) given by

$$
r_{i, t}=\alpha_{i}+\beta_{i}^{M} R M R F_{t}+\beta_{i}^{S M B} S M B_{t}+\beta_{i}^{H M L} H M L_{t}+\beta_{i}^{W M L} W M L_{t}+\varepsilon_{i, t},
$$

where $r_{i, t}$ is the return of fund $i$ in month $t$ in excess of the one-month U.S. Treasury bill rate; $R M R F_{t}$ is the excess market return; $S M B_{t}$ is the return on a 


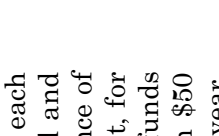
记

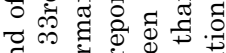

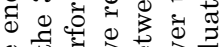

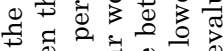

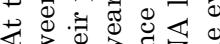
4 过 $\&$ \& 0 . สิ 0 on 5 उ

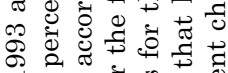
论 बह

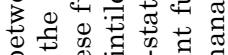

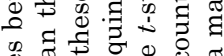
๘

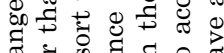

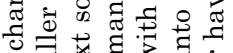

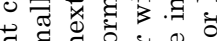

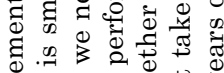

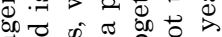
政

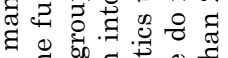
원 올

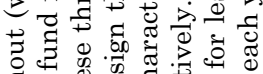

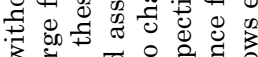

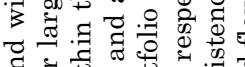

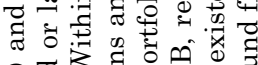

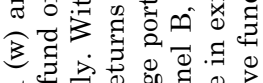
of 굴

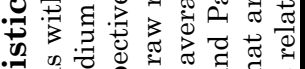

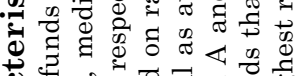

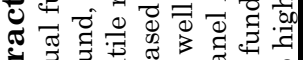

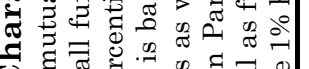
5

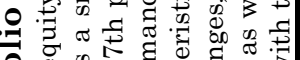

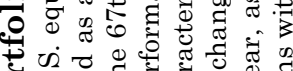

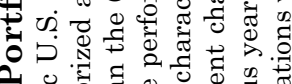

a.

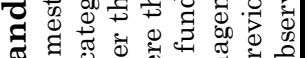

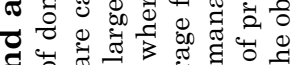

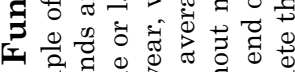

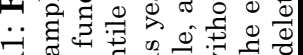
4 16.

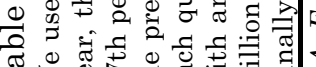

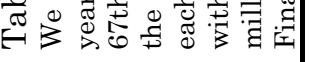

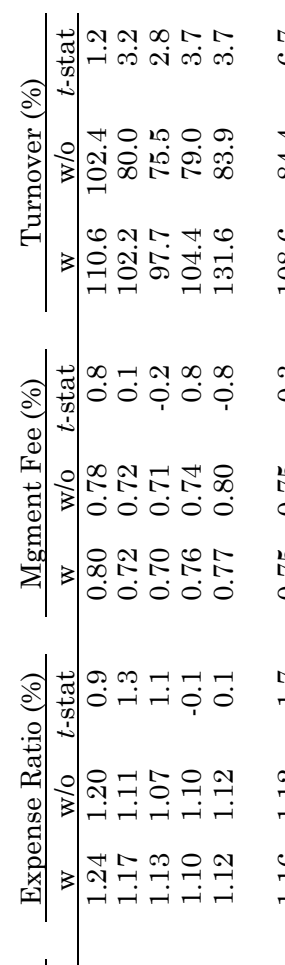

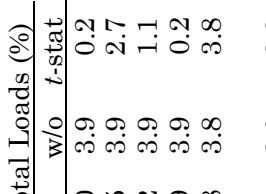

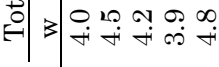

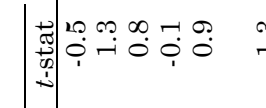

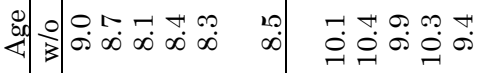

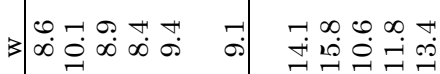

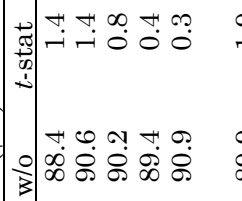 3

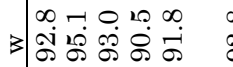

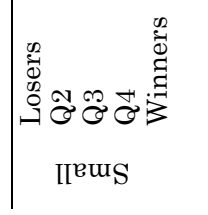

气.

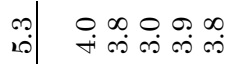

이요

ช่

mo o. os

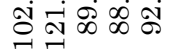

ㅇํㅇ

ㄱ․ㄴ둥

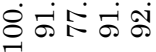

कृ

ㄱ.

ㄷ․ㄴㅇㅛ 0

$000 \div$

다요 00000

$\begin{array}{lll}9 & 9 & 0 \\ 0 & 0 & 0 \\ 0 & 0 & 0\end{array}$

足

붕 하요웅 00000 $\begin{array}{lllll}\infty & 9 & 0 & 0 \\ 0 & 0 & 0 & 0 & 0 \\ 0 & 0 & 0 & 0 & 0\end{array}$

ㄴำ $\infty$ नஈं0

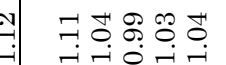

뭄

동요

00000

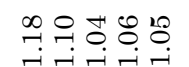

욱

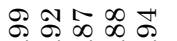
00000

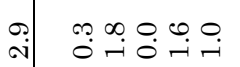

๓

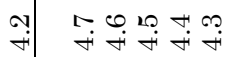


10

承

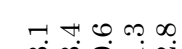

வி

ㅇ..ㅁ.

の几4几

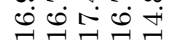

$\stackrel{\infty}{\rightarrow}$

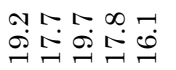

0 0 ค

ఠ]

ด 0 ค i.

อ. ก ᄂ 旅

$\stackrel{10}{10}$

ชิ जी की की की की

우 우

के เి

कุ̀.

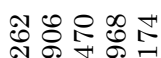
की तो जी

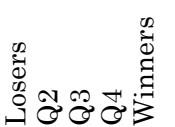

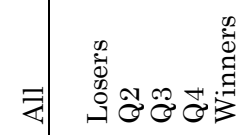

unțpəN

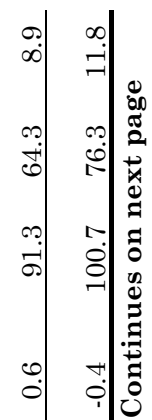

Ðே!

பே.

$\circ 0$

ㅇ.

๑ே.

ตุ

0

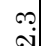

ง

$\stackrel{10}{+}$

$\stackrel{\infty}{+}$

๓

ง ซำ

ن.

$+$

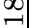

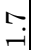

p.

ี

10
10
-7
-7

10
60

คิ

ә.̊.
专 


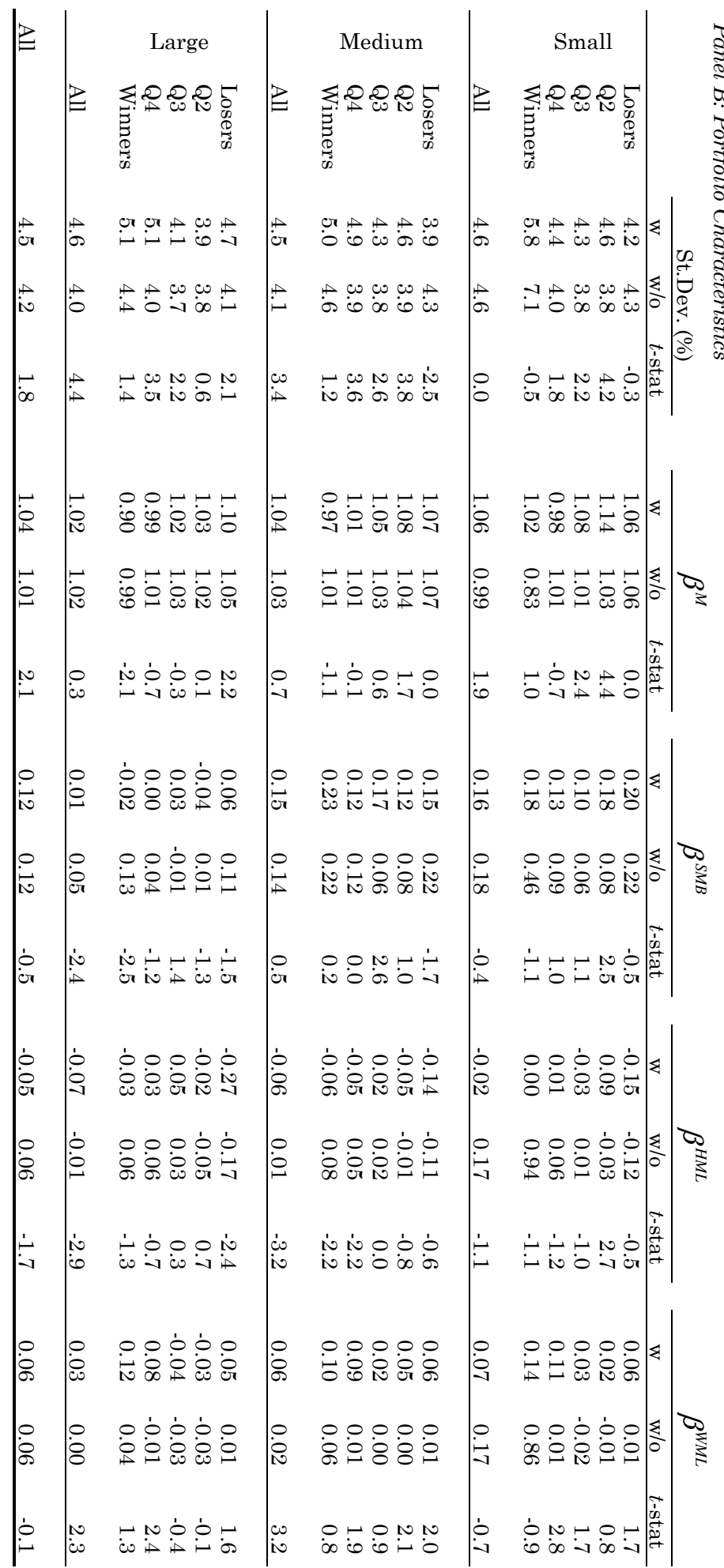

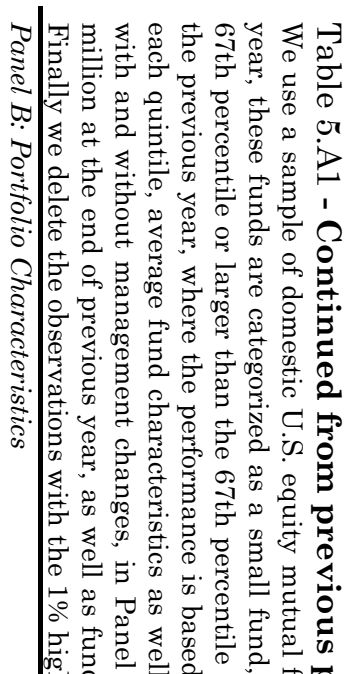

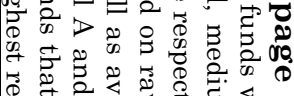

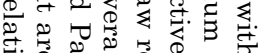

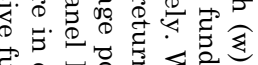

स.

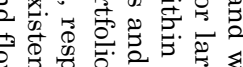

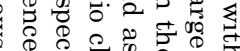

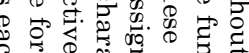

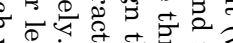

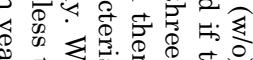

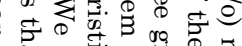

है के क्षे

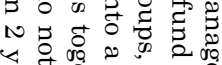

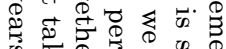

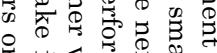

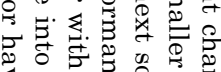

বे

๑ के के

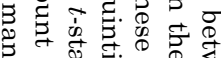

5 त t. 0

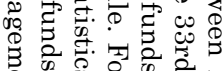

范

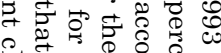

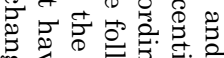

品 0

F. क्षे

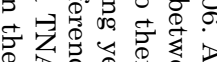

○

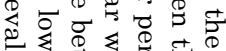

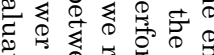

ث.

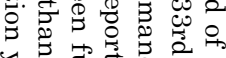

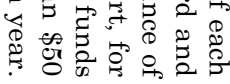


zero-investment portfolio that is long in small caps and shorts large caps; $H M L_{t}$ is the return on a zero-investment portfolio that is long high book-tomarket stocks and shorts low book-to-market stocks; WML $L_{t}$ captures the oneyear momentum factor. ${ }^{44}$ These factor exposures are estimated using twelve months of returns in the year following the change in management. The results are shown in Panel B of Table 5.A1.

First, we find evidence that new managers on average take slightly more risks as can be seen from the standard deviation in returns as well as the average exposures to the market. This is in line with numerous papers on career concerns for mutual fund managers showing that younger managers take more risks as manager turnover, on average, goes hand in hand with rejuvenation (see, e.g., Chevalier and Ellison, 1999a). Secondly, we find evidence that new managers have a higher exposure to the momentum factor, very much in line with the selling-off of inherited momentum losers by new managers (see Jin and Scherbina, 2011).

Summarizing, we find evidence that some characteristics differ between funds with and funds without a recent change in management. For instance, funds with new managers are more expensive and are slightly more risky. While these findings can possibly explain some of the flow differences we find, we find it very unlikely that these findings can explain away all differences.

\footnotetext{
${ }_{44}$ The monthly returns on the benchmark portfolios are taken from Kenneth French's website at http://mba.tuck.dartmouth.edu/pages/faculty/ken.french/data_library.html and the riskfree rates are taken from Ibbotson Associates.
} 



\section{CHAPTER 6 SUMMARY AND CONCLUSIONS}

THIS THESIS IS a bundle of four different studies on risks and opportunities in financial markets. In this final chapter, I will provide a short summary of the research that is conducted and discuss some implications that follow from the results of the studies.

In the first study of this thesis, presented in detail in Chapter 2, we examine four different risk measures that are found in the academic literature; the regular market beta and three downside betas. First, we discuss the theoretical implications of the three downside risk measures, i.e. the semivariance (SV) beta of Bawa and Lindenberg (1977), the asymmetric response model (ARM) beta of Harlow and Rao (1989) and the downside covariance (DC) beta of Ang et al. (2006a). It follows that both the ARM and the DC beta measures have some theoretical drawbacks and as a result their economic justification is not immediately clear. For instance, the ARM beta, in general, does not measure pure downside risk but mixes upside deviations and downside deviations from the return threshold. The implied pricing kernel that follows from this measure violates convexity; a necessary condition for decreasing absolute risk aversion. Moreover, the DC beta is inconsistent with non-satiation and risk aversion; two basic criteria for investor preferences. The theoretical justification of semi-variance beta, on the other hand, is warranted. The implied pricing kernel following from SV beta exhibits properties consistent with necessary conditions for non-satiation, global risk aversion and decreasing absolute risk aversion.

In the empirical analysis we use monthly U.S. stock returns from January 1926 to December 2010, estimate the stocks' (downside) betas and next examine the cross-sectional explanatory power of the four beta measures on future stock returns. We find that SV beta explains a significant part of the cross-sectional variation of U.S. stock returns and dominates the other downside- and regular beta measures. For instance, the downside beta premium is estimated to be roughly four to seven percent per annum, depending on the model specification, compared with a premium of zero to three percent for regular beta. 
Hence, the results suggest that investors dislike downside risk. Downside risk, when properly defined and estimated, is a driving force behind stock prices. Risk aversion thus not only helps to explain why stocks yield higher average returns than safer asset classes, but also why high-risk stocks yield higher average returns than low-risk stocks, ceteris paribus.

In Chapter 3 we study the risks and profitability of a conventional short-term reversal strategy. Conventional reversal strategies are long in stocks with the lowest past-month return and short in stocks with the highest past-month return. Consequently, the long-short reversal portfolio exhibits dynamic exposures to the Fama and French (1993) factors and implicitly bets against the short-term momentum effect in factor returns. As a result of these dynamic factor exposures, the conventional reversal strategy's profitability is negatively affected while at the same time the exposures significantly contribute to the risks involved.

Based on these insights, we introduce a short-term reversal strategy that is based on residual returns that does not exhibit such dynamic factor exposures. We find that the residual reversal strategy vastly improves upon the conventional reversal strategy. That is, the residual reversal strategy earns higher returns that are substantially less volatile than the returns of the conventional strategy. Importantly, we find that the residual reversal strategy exceeds any reasonable levels of trading costs by a wide margin. And even though reversal strategies generate high portfolio turnover, we find that residual reversal strategies yield significantly positive returns of more than seven percent per annum net of trading costs.

Interestingly, our results shed new light on several alternative explanations that have been put forward in the academic literature to rationalize the reversal effect. For instance, our findings are not supportive to the explanation that reversal profits are liquidity driven and are a compensation for bearing inventory risks. Furthermore, our results are inconsistent with the notion that non-synchronous trading contributes to reversal profits. Our results are not inconsistent, however, with the behavioral explanation that market prices tend to overreact to information in the short run.

In Chapter 4 of this thesis, we examine the potential for active portfolio management to add value in different asset classes. For this study, we use a comprehensive dataset of mutual funds with an investment objective in one of twenty different asset classes we consider, including seven bond classes, six 
equity classes belonging to different geographical regions and seven U.S. equity classes with a different focus on stock characteristics. Using monthly mutual fund returns from January 1990 to December 2010, we analyze the persistence in mutual fund performance. We argue that persistence in performance is a proxy for the added value of active management. Next, we examine if, and by how much, performance persistence can be explained by market efficiency and the investment opportunity set.

First, we find performance persistence in each of the different asset classes. Importantly, however, we find that the persistence in performance in one asset class can be severely higher compared to other asset classes. Interestingly, contrary to the conventional wisdom that active management can add more value in less efficient markets, we do not find any relation between persistence in performance and market efficiency across the different asset classes. Consistent with the 'law of active management' of Grinold and Kahn (2001), we find that breadth, indicating the number of independent investment opportunities that is available in an asset class, is significantly positively related to persistence in mutual fund performance. Moreover, we also find that breadth drives dynamics in persistence within asset classes. In periods in which the number of independent investment opportunities is relatively high, the added value of past winner funds is higher.

The results of this study have several important implications. First, the results contribute to the debate in the academic literature and the investment practice on the value that is added by engaging in active management. And furthermore, these results can be an important input factor for (institutional) investors like pension funds in their allocation decision and on deciding on their active risk budgeting.

Finally, in Chapter 5 of this thesis, we study the behavior of mutual fund investors following the replacements of portfolio managers. Analyzing the behavior of mutual fund investors is important for several reasons. First, if investors are behaving rationally and there are decreasing returns to scale in the mutual fund industry, this might explain why performance persistence is often found to be short-lived (see, e.g., Berk and Green, 2004). Secondly, this is important for the remuneration scheme of portfolio managers and the effectiveness of the principal-agent relation between fund managers and the fund investors. And third, the behavior of mutual fund investors is important for the effectiveness of mutual fund companies in disciplining their (poorly performing) managers. 
Using a sample of U.S. equity mutual funds and manager changes from 1993 to 2006, we find strong evidence that mutual fund investors respond to replacements of portfolio managers. Interestingly, the behavior of the mutual fund investors is not consistent with rational behavior. This is because the capital flows are lower to funds of which the poorly performing manager is replaced compared to similar performing funds without a change in management. Hence, even though poorly performing funds with a change in management perform better subsequently to this change, consistent with the conjecture that a new manager is hired with more investment skills, a replacement is perceived as a bad signal by mutual fund investors. In case investors behave according to rational expectations it is expected that more capital is flowing to these funds with a poor past performance compared to the funds without a change in management.

In summary, this thesis provides several new insights into risks and opportunities in financial markets. First, we find that investors dislike downside risk and that downside risk is priced in U.S. equity markets. Secondly, we find that conventional short-term reversal strategies exhibit significant dynamic risk exposures. Eliminating these exposures provides investors an interesting opportunity to outperform the market portfolio. The potential for active managers to persistently add value and outperform their benchmarks depends on the number of independent investment opportunities, or breadth, available to the manager, not, however, market efficiency. And finally, the replacement of active managers by a new manager is not going unnoticed by mutual fund investors. In general, these fund investors seem to dislike managerial replacements, even if poorly performing managers are replaced. 


\section{SAMENVATTING (SUMmaRY In DUTCH)}

DIT PROEFSCHRIFT IS een bundel van vier verschillende studies naar risico's en kansen binnen financiële markten. In dit laatste hoofdstuk zal een korte samenvatting worden weergegeven over de onderzoeken die zijn verricht en enkele implicaties worden aangehaald die volgen uit de resultaten van de verschillende studies.

In de eerste studie van dit proefschrift, wat staat beschreven in Hoofdstuk 2, onderzoeken we vier verschillende risico maatstaven die beschreven worden in de academische literatuur; de standaard marktbèta en drie neerwaarts-risico bèta's. Eerst bediscussiëren we de theoretische implicaties van de drie neerwaarts-riscico maatstaven, betreffende de semivariantie (SV) bèta van Bawa en Lindenberg (1977), de asymmetrische reactiemodel (ARM) bèta van Harlow en Rao (1989) en de neerwaarts co-variantie (NC) bèta van Ang et al. (2006a). Het komt er op neer dat zowel de ARM-bèta en NC-bèta maatstaven enkele theoretische minpunten bevatten met als gevolg dat de economische rechtvaardiging van deze maatstaven niet gelijk duidelijk is. Zo meet de ARM-bèta in het algemeen niet het zuivere neerwaarts risico, maar vermengt opwaartse afwijkingen van het referentie-rendement met neerwaartse afwijkingen. De geïmpliceerde prijzingskernel dat volgt uit deze maatstaf schendt convexiteit; een noodzakelijke conditie voor afnemende absolute risico-aversie. Tegelijkertijd is de NC-bèta inconsistent met onverzadiging en risico-aversie; twee basis principes voor de voorkeuren van investeerders. De theoretische rechtvaardiging van semi-variantie bèta, aan de andere kant, is wel gewaarborgd. De geïmpliceerde prijzingskernel dat volgt uit de SV-bèta etaleert eigenschappen die consistent zijn met noodzakelijke condities voor onverzadiging, globale risico-aversie en afnemende absolute risico-aversie.

In de empirische analyse gebruiken we maandrendementen van Amerikaanse aandelen beginnend in januari 1926 en eindigend in december 2010. We schatten de (neerwaartse) bètas van de aandelen en onderzoeken de cross-sectionele verklaringskracht van de vier verschillende bèta maatstaven op toekomstige rendementen. We vinden dat de SV-bèta een significant deel van de cross-sectionele variatie in de Amerikaanse aandelenrendementen kan verklaren en dat deze maatstaf de andere neerwaarts bèta's en standaard marktbèta domineert. Zo wordt de neerwaarts-risico premie geschat op 
ongeveer vier tot zeven procent per jaar, afhankelijk van de specificatie van het model, vergeleken met een premie van nul tot drie procent voor standaard marktbèta.

Derhalve suggereren de resultaten dat investeerders een afkeer hebben voor neerwaarts risico. Neerwaarts riscio, wanneer deze op de correcte manier gedefinieerd en geschat wordt, is een drijvende kracht achter de totstandkoming van aandeelprijzen. Risico-aversie helpt dus niet alleen te verklaren waarom aandelen gemiddeld hoger renderen dan veiligere beleggingsvormen, maar helpt ook te verklaren waarom hoog-risico aandelen gemiddeld beter renderen dan laag-risico aandelen, ceteris paribus.

In Hoofdstuk 3 worden de risico's en winstgevendheid van een conventionele korte-termijn reversal strategie onderzocht. Conventionele reversal strategieën zijn long in aandelen met het laagste afgelopen maandsrendement and short in aandelen met het hoogste afgelopen maandsrendement. Als gevolg hiervan, etaleert de long-short portefeuille dynamische gevoeligheden naar de Fama en French (1993) factoren en 'gokt' impliciet tegen het korte-termijn momentum effect in factorrendementen. Door deze dynamische factorgevoeligheden wordt de winstgevendheid van de conventionele reversal strategie negatief beïnvloed terwijl tegelijkertijd de gevoeligheden een significante bijdrage leveren aan de betreffende risico's.

Voortbordurend op deze inzichten, introduceren we een korte-termijns reversal strategie welke gebaseerd is op residuele rendementen en niet zulke dynamische factorgevoeligheden elateert. We vinden dat de residuele reversal strategie zeer veel verbeteringen laat zien ten opzichte van de conventionele reversal strategie. Dat wil zeggen, de residuele reversal strategie verdient hogere rendementen die substantieel minder volatiel zijn dan de rendementen van een conventionele strategie. Een belangrijke bevinding is dat de residuele reversal strategie elk redelijk niveau van de geschatte kosten die handelen teweegbrengt met een ruime marge overtreffen. En hoewel reversal strategieën hoge portefeuille-omzet genereren, tonen we aan dat residuele reversal strategieën significant positieve rendementen verdienen van meer dan zeven procent per jaar.

Wat interessant is, is dat onze resultaten nieuw licht werpen op enkele alternatieve verklaringen die naar voren zijn gekomen in de academische literatuur om het reversal effect te kunnen rationaliseren. Zo ondersteunen onze bevindingen bijvoorbeeld niet de verklaring dat reversal winsten liquiditeitsgedreven zijn en een compensatie zijn voor het dragen van 
voorraadrisico's. Tevens zijn onze resultaten inconsistent met de notie dat nietsynchroon handelen bijdraagt aan reversal winsten. Onze resultaten zijn echter niet inconsistent met de gedragswetenschappelijke verklaring dat marktprijzen de neiging hebben om op de korte termijn over te reageren op informatie.

In Hoofdstuk 4 van deze dissertatie, gaan we in op de potentie voor actief vermogensbeheer om in verschillende beleggingscategorieën waarde toe te voegen. Voor deze studie maken we gebruik van een veelomvattende dataset bestaande uit beleggingsfondsen die een investeringsfocus hebben in één van de twintigtal verschillende beleggingscategorieën die wij onderzoeken. Deze beleggingscategorieën bestaan uit zeven verschillende obligatie-categorieën, zes aandeel-categorieën met een verschillende geografische focus, en zeven Amerikaanse aandelen-categorieën die van elkaar verschillen op basis van hun karakteristieken. Gebruikmakend van maandelijkse rendementen van deze beleggingsfondsen, beginnend in januari 1990 tot en met december 2010, analyseren we de persistentie in de prestaties van de fondsen. We beredeneren dat persistentie in de prestatie een benadering is voor de waarde dat actief vermogensbeheer kan toevoegen. Vervolgens onderzoeken we of, en in hoeverre, de persistentie in prestaties kan worden verklaard door de efficientie van de verschillende markten en de investeringskansen die een beleggingscategorie biedt.

Ten eerste vinden we dat er persistentie in de fondsprestaties is in elk van de beleggingscategorieën. We vinden echter dat de persistentie in sommige beleggingscategorieën veel sterker is in vergelijking met andere categorieën. Interessant is dat onze resultaten de conventionele wijsheid, dat ervan uitgaat dat actief vermogensbeheer met name waarde kan toevoegen in minder efficiënte markten, tegenspreekt. We vinden namelijk geen enkel verband tussen de mate van persistentie in een beleggingscategorie en de mate van de geschatte efficiëntie van de categorie. Consistent met de 'law of active management' (de wet van actief vermogensbeheer) van Grinold en Kahn (2001), vinden we wel dat breadth, wat het aantal onafhankelijke investeringsmogelijkheden binnen een beleggingscategorie aangeeft, significant positief gerelateerd is aan de mate van persistentie in de fondsprestaties. Bovendien vinden we dat breadth een drijvende kracht is voor de dynamiek in de mate van persistentie binnen een beleggingscategorie. In perioden waarin het aantal beleggingskansen relatief hoog is, is de toegevoegde waarde van recente winnaar-fondsen ook hoger. 
De resultaten van deze studie hebben enkele belangrijke implicaties. Ten eerste dragen de resultaten bij aan het debat over de toegevoegde waarde van actief vermogensbeheer dat gevoerd wordt in zowel de academische literatuur als in de praktijk. Daar komt bij dat de resultaten een belangrijke bron kunnen zijn voor (institutionele) investeerders, zoals bijvoorbeeld pensioenfondsen, voor het komen tot een allocatie beslissing en in hun besluit over hun actief risico budget.

Tenslotte onderzoeken we in Hoofdstuk 5 van dit proefschrift het gedrag van investeerders in beleggingsfondsen volgend op een wisseling van portefeuille managers. Het analyseren van het gedrag van investeerders in beleggingsfondsen is belangrijk om verscheidene redenen. Ten eerste, als investeerders rationeel gedrag vertonen en er sprake is van afnemende schaalopbrengsten in de industrie van vermogensbeheer, dan zou dit kunnen verklaren waarom persistentie in de prestatie van fondsen slechts een kortstondig leven beschoren is (zie, bijvoorbeeld, Berk en Green, 2004). Daarnaast is dit belangrijk voor de bezoldiging van portefeuille managers en de effectiviteit van de principaal-agent relatie tussen fondsmanagers en de investeerders in het fonds. En ten derde, het gedrag van investeerders van beleggingsfondsen is belangrijk voor de effectiviteit van fondshuizen in het disciplineren van hun (slecht presterende) managers.

We vinden, gebruikmakend van een steekproef van Amerikaanse aandelenfondsen en managerwisselingen van 1993 tot en met 2006, sterk bewijs dat investeerders van beleggingsfondsen reageren op vervangingen van portefeuille managers. Opvallend is dat het gedrag van investeerders van beleggingsfondsen niet consistent is met rationeel gedrag. Deze conclusie volgt uit de bevinding dat geldstromen naar fondsen waarvan de slecht presterende manager is vervangen lager zijn in vergelijking met fondsen met eenzelfde prestatie maar waarvan de manager is behouden. Dus hoewel slecht presterende fondsen met een wisseling in haar management beter presteren volgend op deze wissel, hetgeen consistent is met het argument dat een nieuwe manager is aangenomen met meer bedrevenheid, wordt een vervanging door investeerders gezien als een slecht signaal. In het geval investeerders zich gedragen naar rationele verwachtingen, zouden we verwachten dat er juist meer kapitaal vloeit naar deze fondsen met een slechte prestatie in vergelijking met de fondsen waarin geen wisseling in management heeft plaatsgevonden 
Kort samengevat bevat deze dissertatie verschillende nieuwe inzichten in de risico's en kansen binnen financiële markten. Ten eerste vinden we dat investeerders een afkeer hebben voor neerwaarts risico en dat neerwaarts risico geprijst is in de Amerikaanse aandelenmarkten. Ten tweede vinden we dat conventionele korte-termijn reversal strategieën significante dynamische factorgevoeligheden etaleren. Het elimineren van deze factorgevoeligheden verschaft investeerders een interessante kans om de marktportefeuille te verslaan. De potentie voor actieve vermogensbeheerders om persistent waarde toe te voegen en hun benchmarks te verslaan is afhankelijk van het aantal onafhankelijke beleggingsmogelijkheden, of breadth, voorhanden. Het is echter niet afhankelijk van de mate van efficientie van de markt waarin de actieve vermogensbeheerder belegt. Ten slotte, de vervanging van een portefeuille manager door een nieuwe gaat niet ongemerkt voorbij aan de fondsbeleggers. In het algemeen kan gezegd worden dat deze fondsbeleggers een afkeer hebben naar wisselingen in management, zelfs als slecht presterende portefeuille managers worden vervangen. 



\section{BIBLIOGRAPHY}

Amihud, Y., (2002), "Illiquidity and Stock Returns: Cross-Section and Time-Series Effects", Journal of Financial Markets, 5, 31-56.

Amihud, Y., and R. Goyenko, (2012), "Mutual Fund's $R^{\wedge} 2$ as Predictor of Performance", $N Y U$ Working Paper, No. FIN-08-046. Available at SSRN: http:ssrn.com/abstract=1354533.

Ang, A., J. Chen, and Y. Xing, (2006a), "Downside Risk", Review of Financial Studies, 19, 1191-1239.

Ang, A. J., R. Hodrick, Y. Xing, and X. Zhang, (2006b), "The Cross-Section of Volatility and Expected Returns", Journal of Finance, 61, 259-299.

Ankrim, E. M., and Z. Ding, (2002), "Cross-Sectional Volatility and Return Dispersion", Financial Analysts Journal, 58, 67-73.

Artzner, P., F. Delbaen, J. M. Eber, and D. Heath, (1999), "Coherent Measures of Risk", Mathematical Finance, 9, 203-228.

Avramov, D., T. Chordia and A. Goyal, (2006), "Liquidity and Autocorrelations in Individual Stock Returns", Journal of Finance, 61, 2365-2394.

Baker, M., and J. Wurgler, (2006), "Investor Sentiment and the Cross-Section of Stock Returns", Journal of Finance, 61, 1645-1680.

Baks, K. P., (2003), “On the Performance of Mutual Fund Managers”, Working Paper.

Ball, R., S. P. Kothari, and C. Wasley, (1995), "Can we Implement Research on Stock Trading Rules?”, Journal of Portfolio Management, 21, 54-63.

Banz, R. W., (1981), "The Relationship between Return and Market Value of Common Stocks", Journal of Financial Economics, 9, 3-18.

Bär, M., A. Kempf, and S. Ruenzi, (2005), "Team Management and Mutual Funds", CFR Working Paper, No. 05-10. Available at SSRN: http://ssrn.com/abstract=809484.

Bär, M., A. Kempf, and S. Ruenzi, (2011), "Is a Team Different from the Sum of its Parts? Evidence from Mutual Fund Managers”, Review of Finance, 15, 359-396.

Barras, L., O. Scaillet, and R. Wermers, (2010), "False Discoveries in Mutual Fund Performance: Measuring Luck in Estimated Alphas”, Journal of Finance, 65, 179-216. 
Bawa, V. S., and E. B. Lindenberg, (1977), "Capital Market Equilibrium in a Mean-Lower Partial Moment Framework", Journal of Financial Economics, 5, 189-200.

Bekaert, G., and C. R. Harvey, (2002), "Research in Emerging Markets Finance: Looking to the Future”, Emerging Markets Review, 3, 429-448.

Berk, J. B., and R., Green, (2004), "Mutual Fund Flows and Performance in Rational Markets", Journal of Political Economy, 112, 1269-1296.

Berk, J. B., and I. Tonks, (2007), "Return Persistence and Fund Flows in the Worst Performing Mutual Funds", Working Paper, No. 13042, NBER.

Bernstein, P. L., (1998), “Where, Oh Where Are the .400 Hitters of Yesteryear?", Financial Analysts Journal, 54, 6-14.

Bessler, W., D. Blake, P. Lückoff, and I. Tonks, (2008), "Why is Persistent Mutual Fund Performance so Difficult to Achieve? The Impact of Management Turnover and Fund Flows", Working Paper.

Black, F. S., M. C. Jensen, and M. S. Scholes, (1972), "The Capital Asset Pricing Model: Some Empirical Tests", Studies in the Theory of Capital Markets, Praeger, New York.

Blake, C. R., E. J. Elton, and M. J. Gruber, (1993), "The Performance of Bond Mutual Funds", Journal of Business, 66, 371-403.

Blitz, D., J. Huij, S. D. Lansdorp, and M. Verbeek, (2012), "Short-Term Residual Reversal", forthcoming in Journal of Financial Markets. Available at SSRN: http://ssrn.com/abstract=1911449.

Blitz, D., J. Huij, and M. Martens, (2011), "Residual Momentum", Journal of Empirical Finance, 18, 506-521.

Bollen, N. P. B., and J. A. Busse, (2005), "Short-Term Persistence in Mutual Fund Performance", Review of Financial Studies, 18, 569-597.

Boudoukh, J., M. P. Richardson, and R. E. Whitelaw, (1994), "A Tale of Three Schools: Insights on Autocorrelations of Short-Horizon Stock Returns", Review of Financial Studies, 7, 539573.

Bris, A., H. Gulen, P. Kadiyala, and P.R. Rau, (2007), "Good Stewards, Cheap Talkers, or Family Men? The Impact of Mutual Fund Closures on Fund Managers, Flows, Fees, and Performance", Review of Financial Studies, 20, 953-982.

Brown, S. J, and W. N. Goetzmann, (1995), "Performance Persistence", Journal of Finance, 50, 679-698. 
Brown, S. J., W. N. Goetzmann, R. G. Ibbotson, and S. A. Ross, (1992), "Survivorship Bias in Performance Studies", Review of Financial Studies, 5, 553-580.

Campbell, J. Y., M. Lettau, B. Malkiel, and Y. Xu, (2001), "Have Individual Stocks Become More Volatile? An Empirical Exploration of Idiosyncratic Risk", Journal of Finance, 56, 143.

Carhart, M., (1997), "On the Persistence of Mutual Fund Performance", Journal of Finance, $52,57-82$.

Chen, H. L., N. Jegadeesh, and R. Wermers, (2000), "The Value of Active Mutual Fund Management: An Examination of the Stockholdings and Trades of Fund Managers", Journal of Financial and Quantitative Analysis, 35, 343-368.

Chen, H. L., and W. De Bondt, (2004), "Style Momentum Within the S\&P-500 Index", Journal of Empirical Finance, 11, 483-507.

Chen, N. F., R. Roll, and S. A. Ross, (1986), "Economic Forces and the Stock Market", Journal of Business, 59, 383-403.

Chevalier, J., and G. Ellison, (1997), "Risk Taking by Mutual Funds as a Response to Incentives", Journal of Political Economy, 105, 1167-1200.

Chevalier, J., and G. Ellison, (1999a), "Career Concerns of Mutual Fund Managers", Quarterly Journal of Economics, 114, 389-432.

Chevalier, J., and G. Ellison, (1999b), "Are Some Mutual Fund Managers Better than Others? Cross-Sectional Patterns in Behavior and Performance”, Journal of Finance, 54, 875-899.

Chordia, T., A. Goyal, G. Sadka, R. Sadka, and L. Shivakumar, (2009), "Liquidity and the PostEarnings-Announcement Drift”, Financial Analysts Journal, 65, 18-32.

Chow, K. V., and K. C. Denning, (1993), “A Simple Multiple Variance Ratio Test”, Journal of Econometrics, 58, 385-401.

Cochrane, J. H., (2011), "Discount Rates", American Finance Association Presidential Speech. http://faculty.chicagobooth.edu/john.cochrane/research/Papers/AFA_pres_speech.pdf.

Connor, G., and L. S. Li, (2009), "Market Dispersion and the Profitability of Hedge Funds", Working Paper.

Conrad, J. S., M. Gultekin, and G. Kaul, (1997), "Profitability of Short-Term Contrarian Strategies: Implications for Market Efficiency”, Journal of Business and Economic Statistics, 15, 379-386. 
Cremers, M., M. A. Ferreira, P. P. Matos, and L. T. Starks, (2011), "The Mutual Fund Industry Worldwide: Explicit and Closet Indexing, Fees and Performance", Working Paper. Available at SSRN: http:/ssrn.com/abstract=1830207.

Cremers, M., and A. Petajisto, (2009), "How Active is your Fund Manager? A New Measure that Predicts Performance", Review of Financial Studies, 22, 3329-3365.

Da, Z., Q. Liu, and E. Schaumburg, (2011), "Decomposing the Short-Term Return Reversal". Working Paper. Available at SSRN: http://ssrn.com/abstract=1551025.

Dangl, T., Y. Wu, and J. Zechner, (2008), "Market Discipline and Internal Governance in the Mutual Fund Industry", Review of Financial Studies, 21, 2307-2343.

Davis, J., E. F. Fama, and K. R. French, (2000), "Characteristics, Covariances and Average Returns: 1929-1997”, Journal of Finance, 55, 389-406.

De Bondt, W. F. M., and R. Thaler, (1985), “Does the Stock Market Overreact?", Journal of Finance, 40, 793-805.

De Groot, W. A., J. Huij, and W. Zhou, (2012), "Another Look at Trading Costs and Short-Term Reversal Profits", Journal of Banking and Finance, 36, 371-382.

Del Guercio, D., and P. A. Tkac, (2002), "The Determinants of the Flow of Funds of Managed Portfolios: Mutual Funds vs. Pension Funds", Journal of Financial and Quantitative Analysis, 37, 523-557.

De Silva, H., S. Sapra and S. Thorley, (2001), "Return Dispersion and Active Management", Financial Analysts Journal, 57, 29-42.

Deuskar, P., J. M. Pollet, Z. J. Wang, and L. Zheng, (2011), "The Good or the Bad? Which Mutual Fund Managers Join Hedge Funds?", forthcoming in Review of Financial Studies. Available at SSRN: http://ssrn.com/abstract=1362629.

Ding, B., and R. Wermers, (2009), "Mutual Fund Performance and Governance Structure: The Role of Portfolio Managers and Boards of Directors", Working Paper. Available at SSRN: http://ssrn.com/abstract $=683721$.

D'Mello, R., S. Ferris, and C. Y. Hwang, (2003), "The Tax-Loss Selling Hypothesis, Market Liquidity, and Price Pressure around the Turn-of-the-Year", Journal of Financial Markets, 6, 73-98.

Elton, E. J., M. J. Gruber, and C. R. Blake, (1996), "The Persistence of Risk-Adjusted Mutual Fund Performance", Journal of Business, 69, 133-157. 
Evans, J. L., and S. H. Archer, (1968), "Diversification and the Reduction of Dispersion: An Empirical Analysis”, Journal of Finance, 23, 761-767.

Evans, R. B., (2010), "Mutual Fund Incubation”, Journal of Finance, 65, 1581-1611.

Fama, E. F., (1970), "Efficient Capital Markets: A Review of Theory and Empirical Work", Journal of Finance, 25, 383-417.

Fama, E. F., and K. R. French, (1992), "The Cross-Section of Expected Stock Returns", Journal of Finance, 47, 427-465.

Fama, E. F., and K. R. French, (1993), "Common Risk Factors in the Returns on Stocks and Bonds”, Journal of Financial Economics, 33, 3-56.

Fama, E. F., and K. R. French, (1996), "Multifactor Explanations of Asset Pricing Anomalies", Journal of Finance, 51, 55-84.

Fama, E. F., and K. R. French, (1997), "Industry Cost of Equity", Journal of Financial Economics, 43, 153-193.

Fama, E. F., and K. R. French, (2008), "Dissecting Anomalies", Journal of Finance, 63, 16531678.

Fama, E. F., and J. MacBeth, (1973), "Risk, Return, and Equilibrium: Empirical Tests", Journal of Political Economy, 81, 607-636.

Fisher, L., (1966), "Some New Stock Market Indexes", Journal of Business, 39, 191-225.

French, K. R., (1980), "Stock Returns and the Weekend Effect", Journal of Financial Economics, 8, 55-69.

French, K. R. (2011), Fama and French Factors, from the website http://mba.tuck.dartmouth.edu/pages/faculty/ken.french/data_library.html

Gervais, S., A. W. Lynch, and D. K. Musto, (2005), "Fund Families as Delegated Monitors of Money Managers", Review of Financial Studies, 18, 1139-1169.

Goetzmann, W. N., and R. Ibbotson, (1994), "Do Winners Repeat? Patterns in Mutual Fund Behaviour", Journal of Portfolio Management, 20, 9-18.

Gorman, L. R., S. G. Sapra and R. A. Weigand, (2010a), "The Cross-Sectional Dispersion of Stock Returns, Alpha and the Information Ratio", Journal of Investing, 19, 113-127. 
Gorman, L. R., S. G. Sapra and R. A. Weigand, (2010b), "The Role of Cross-Sectional Dispersion in Active Portfolio Management", Working Paper. Available at SSRN: http://ssrn.com/abstract=1266225.

Gould, S. J. (1996), "Full House: The Spread of Excellence from Plato to Darwin”, New York: Crown Publishers.

Griffiths, M., and R. White, (1993), "Tax Induced Trading and the Turn-of-the-Year Anomaly: An Intraday Study", Journal of Finance, 48, 575-598.

Grinblatt, M. and T. J. Moskowitz, (2004), "Predicting Stock Price Movements from Past Returns: the Role of Consistency and Tax-Loss Selling", Journal of Financial Economics, $71,541-579$.

Grinold, R. C., (1989), "The Fundamental Law of Active Management”, Journal of Portfolio Management, 15, 30-37.

Grinold, R. C. and R. Kahn, (2001), “Active Portfolio Management: A Quantitative Approach for Producing Superior Returns and Controlling Risk”, McGraw-Hill, New York.

Grossman, S. J., and J. E. Stiglitz, (1980), "On the Impossibility of Informationally Efficient Markets”, American Economic Review, 70, 393-408.

Gruber, M. J., (1996), "Another Puzzle: The Growth in Actively Managed Mutual Funds", Journal of Finance, 51, 783-810.

Grundy, B. D., and J. S. Martin, (2001), "Understanding the Nature of the Risks and the Source of the Rewards to Momentum Investing", Review of Financial Studies, 14, 29-78.

Gultekin, M., and S. Gultekin, (1983), "Stock Market Seasonality: International Evidence", Journal of Financial Economics, 12, 469-481.

Gutierrez Jr., R. C., and C. A. Pirinsky, (2007), "Momentum, Reversal, and the Trading Behaviors of Institutions", Journal of Financial Markets, 10, 48-75.

Hameed, A., J. Huang, and G. M. Mian, (2010), "Industries and Stock Return Reversals". Working Paper. Available at SSRN: http://ssrn.com/abstract=1570566.

Harlow, W. V., and R. K. S. Rao, (1989), "Asset Pricing in a Generalized Mean-Lower Partial Moment Framework: Theory and Evidence", Journal of Financial and Quantitative Analysis, 24, 285-311.

Hendricks, D., J. Patel, and R. Zeckhauser, (1993), "Hot Hands in Mutual Funds: Short-Run Persistence of Relative Performance, 1974-1988”, Journal of Finance, 48, 93-130. 
Hogan, W. W., and J. M. Warren, (1974), "Toward the Development of an Equilibrium CapitalMarket Model Based on Semi-variance", Journal of Financial and Quantitative Analysis, 9, 1-11.

Hortaçsu, A., and C. Syverson, (2004), "Product Differentiation, Search Costs, and Competition in the Mutual Fund Industry: A Case Study of S\&P 500 Index Funds", Quarterly Journal of Economics, 119, 403-456.

Hu, P., J. R. Kale, M. Pagani, and A. Subramanian, (2011), "Fund Flows, Performance, Managerial Career Concerns, and Risk-Taking”, Management Science, 57, 628-646.

Huij, J., and J. Derwall, (2008), "Hot Hands in Bond Funds", Journal of Banking and Finance, $32,559-572$.

Huij, J., and J. Derwall, (2011), "Global Equity Fund Performance, Portfolio Concentration, and the Fundamental Law of Active Management", Journal of Banking and Finance, 35, 155-165.

Huij, J., and S. D. Lansdorp, (2012), "Mutual Fund Performance Persistence, Market Efficiency, and Breadth", Working Paper.

Huij, J., S. D. Lansdorp, and M. Verbeek, (2012), "Managerial Turnover and the Behavior of Mutual Fund Investors", Working Paper.

Huij, J., and G. T. Post, (2011), "On the Performance of Emerging Markets Equity Mutual Funds”, Emerging Markets Review, 12, 238-249.

Huij, J., and M. Verbeek, (2007), "Cross-Sectional Learning and Short-Run Persistence in Mutual Fund Performance”, Journal of Banking and Finance, 31, 973.997.

Huson, M. R., P. H. Malatesta, and R. Parrino, (2004), "Managerial Succession and Firm Performance", Journal of Financial Economics, 74, 237-275.

Investment Company Institute, (2011a), "Worldwide Mutual Fund Assets and Flows, Fourth Quarter 2010”. Available at http://www.ici.org/research/stats/worldwide/.

Investment Company Institute, (2011b), "Investment Company Fact Book: A Review of Trends and Activity in the Investment Company Industry", www.icifactbook.org.

Jacob, B. I., and N. Levy, (1988), "Disentangling Equity Return Regularities: New Insights and Investment Opportunities”, Financial Analysts Journal, 44, 18-43.

Jagannathan, R.., and Z. Wang, (1998), "An Asymptotic Theory for Estimating Beta-Pricing Models Using Cross-Sectional Regression”, Journal of Finance, 53, 1285-1309. 
Jahankhani, A., (1976), "E-V and E-S Capital Asset Pricing Models: Some Empirical Tests", Journal of Financial and Quantitative Analysis, 11, 513-528.

James, C., and J. Karceski, (2006), "Investor Monitoring and Differences in Mutual Fund Performance", Journal of Banking \& Finance, 30, 2787-2808.

Jegadeesh, N., (1990), "Evidence of Predictable Behavior of Security Returns", Journal of Finance, 45, 881-898.

Jegadeesh, N., and S. Titman, (1993), "Returns to Buying Winners and Selling Losers: Implications for Stock Market Efficiency”, Journal of Finance, 48, 65-91.

Jegadeesh, N. and S. Titman, (1995a), "Overreaction, Delayed Reaction, and Contrarian Profits", Review of Financial Studies, 8, 973-993.

Jegadeesh, N. and S. Titman, (1995b), "Short-Horizon Return Reversals and the Bid-Ask Spread”, Journal of Financial Intermediation, 4, 116-132.

Jensen, M. C., (1968), “The Performance of Mutual Funds in the Period 1945-1965”, Journal of Finance, 23, 389-416.

Jin, L., and A. Scherbina, (2011), "Inheriting Losers”, Review of Financial Studies, 24, 786-820.

Jobson, J. D., and B. M. Korkie, (1981), "Performance Hypothesis Testing with the Sharpe and Treynor Measures”, Journal of Finance, 36, 889-908.

Kacperczyk, M., C. Sialm, and L. Zheng, (2005), "On the Industry Concentration of Actively Managed Equity Mutual Funds", Journal of Finance, 60, 1983-2011.

Kallberg, J. G., C. L. Liu, and C. Trzcinka, (2000), "The Value Added from Investment Managers: An Examination of Funds of REITs", Journal of Financial and Quantitative Analysis, 35, 387-408.

Keim, D. B., (1983), "Size-related Anomalies and Stock Return Seasonality: Further Empirical Evidence", Journal of Financial Economics, 12, 13-32.

Keim, D. B., and A. Madhavan, (1997), "Transaction Costs and Investment Style: An InterExchange Analysis of Institutional Equity Trades", Journal of Financial Economics, 46, 265-292.

Keswani, A., and D. Stolin, (2008), "Which Money is Smart? Mutual Fund Buys and Sells of Individual and Institutional Investors", Journal of Finance, 63, 85-118.

Khanna, N., and A. B. Poulsen, (1995), "Managers of Financially Distressed Firms: Villains or Scapegoats?", Journal of Finance, 50, 919-940. 
Khorana, A., (1996),. "Top Management Turnover: an Empirical Investigation of Mutual Fund Managers", Journal of Financial Economics, 40, 403-427.

Khorana, A., (2001), "Performance Changes Following Top Management Turnover: Evidence from Open-End Mutual Funds", Journal of Financial and Quantitative Analysis, 36, 371 393.

Knez, P. J., R. Litterman, and J. Scheinkman, (1994), "Explorations into Factors Explaining Money Market Returns", Journal of Finance, 49, 1861-1882.

Korajczyk, R. A., and R. Sadka, (2004), “Are Momentum Profits Robust to Trading Costs?", Journal of Finance, 59, 1039-1082.

Kostovetsky, L., and J. B. Warner, (2011), "You're fired! New Evidence on Portfolio Manager Turnover", Simon School Working Paper, No. FR 11-11. Available at SSRN: http://ssrn.com/abstract=1785896.

Kraus, A., and R. H. Litzenberger, (1976), "Skewness Preference and the Valuation of Risk Assets", Journal of Finance, 31, 1085-1100.

Lee, W. Y., and R. K. S. Rao, (1988), "Mean Lower Partial Moment Valuation and Lognormally Distributed Returns", Management Science, 34, 446-453.

Lehmann, B., (1990), "Fads, Martingales and Market Efficiency", Quarterly Journal of Economics, 105, 1-28.

Lesmond, D. A., M. J. Schill, and C. Zhou, (2004), "The Illusory Nature of Momentum Profits", Journal of Financial Economics, 71, 349-380.

Levy, H., (1992), "Stochastic Dominance and Expected Utility: Survey and Analysis", Management Science, 38, 555-593.

Lin C. Y., and K. Yung, (2004), "Real Estate Mutual Funds: Performance and Persistence", Journal of Real Estate Research, 26, 69-93.

Lintner, J., (1965a), "Security Prices and Maximal Gains from Diversification", Journal of Finance, 20, 587-615.

Lintner, J., (1965b), "The Valuation of Risk Assets and the Selection of Risky Investments in Stock Portfolios and Capital Budgets", Review of Economics and Statistics, 47, 13-37.

Lo, A. W., and A. C. MacKinlay, (1988), "Stock Market Prices Do Not Follow Random Walks: Evidence from a Simple Specification Test”, Review of Financial Studies, 1, 41-66. 
Lo, A. W., and A. C. MacKinlay, (1990), "When are Contrarian Profits Due to Stock Market Overreaction?”, Review of Financial Studies, 3, 175-205.

Lynch, A. W., and D. K. Musto, (2003), "How Investors Interpret Past Fund Returns”, Journal of Finance, 53, 1589-1622.

Mahoney, P. G., (2004), "Manager-Investor Conflicts in Mutual Funds", Journal of Economic Perspectives, 18, 161-182.

Markowitz, H., (1952), "Portfolio Selection”, Journal of Finance, 7, 77-91.

Markowitz, H., (1959), Portfolio Selection: Efficient Diversification of Investments, Wiley, New York.

Massa, M., J. Reuter, and E. Zitzewitz, (2010), "When Should Firms Share Credit with Employees? Evidence from Anonymously Managed Mutual Funds”, Journal of Financial Economics, 95, 400-424.

Memmel, C., (2003), "Performance Hypothesis Testing with the Sharpe Ratio", Finance Letters, $1,21-23$.

Moskowitz, T. J., and M. Grinblatt, (1999), “Do Industries Explain Momentum?", Journal of Finance, 54, 1249-1290.

Mossin, J., (1966), “Equilibrium in a Capital Asset Market”, Econometrica, 34, 768-783.

Otten, R., and D. Bams, (2002), "European Mutual Fund Performance”, European Financial Management, 8, 75-101.

Petersen, M. A., (2009), "Estimating Standard Errors in Finance Panel Data Sets: Comparing Approaches", Review of Financial Studies, 22, 435-480.

Post, G. T., P. van Vliet, and S. D. Lansdorp, (2012), "Sorting Out Downside Beta", Working Paper. Available at SSRN: http://ssrn.com/abstract=1980614.

Price, K., B. Price, and T. J. Nantell, (1982), "Variance and Lower Partial Moment Measures of Systematic Risk: Some Analytical and Empirical Results", Journal of Finance, 37, 843855 .

Reinganum, M. R., (1981), "A New Empirical Perspective on the CAPM”, Journal of Financial and Quantitative Analysis, 16, 439-462.

Roll, R., (1983), "Vas ist das? The Turn-of-the-Year Effect and the Return Premium of Small Firms", Journal of Portfolio Management, 9, 18-28. 
Rosenberg, B., K. Reid, and R. Lanstein, (1985), "Persuasive Evidence of Market Inefficiency", Journal of Portfolio Management, 11, 9-11

Rouwenhorst, K. G., (1999), "Local Return Factors and Turnover in Emerging Stock Markets", Journal of Finance, 54, 1439-1464.

Rouwenhorst, K. G., (2005), "The Origins of Mutual Funds", In The Origins of Value. The Financial Innovations that Created Modern Capital Markets (Editors: Goetzmann, W. G. and K. G. Rouwenhorst), Oxford University Press, 249-270.

Shanken, J. A., (1992), "On the Estimation of Beta-Pricing Models", Review of Financial Studies, 5, 1-33.

Shanken, J. A., and G. Zhou, (2007), "Estimating and Testing Beta Pricing Models: Alternative Methods and their Performance in Simulations", Journal of Financial Economics, 84, 4086.

Sharpe, W. F., (1964), "Capital Asset Prices: A Theory of Market Equilibrium”, Journal of Finance, 19, 425-442.

Sharpe, W. F., (1966), "Mutual Fund Performance”, Journal of Business, 49, 119-138.

Sharpe, W. F., (1991), "The Arithmetic of Active Management", Financial Analysts Journal, 47, 7-9.

Sirri, E. R., and P. Tufano, (1998), "Costly Search and Mutual Fund Flows", Journal of Finance, 53, 1589-1622.

Stivers, C., and L. Sun, (2011), "New Evidence on Short-Term Reversals in Monthly Stock Returns: Overreaction or Illiquidity?", Working Paper. Available at SSRN: http://ssrn.com/abstract=1911506.

Van der Hart, J., E. Slagter, and D. Van Dijk, (2003), "Stock Selection Strategies in Emerging Markets", Journal of Empirical Finance, 10, 105-132.

Warner, J. B., R. L. Watts, and K. H. Wruck, (1998), "Stock Prices and Top Management Changes", Journal of Financial Economics, 20, 461-492.

Weisbach, M. S., (1988), "Outside Directors and CEO Turnover", Journal of Financial Economics, 20, 431-460.

Wermers, R., (2003a), "Are Mutual Fund Shareholders Compensated for Active Management Bets?", Working Paper. 
Wermers, R., (2003b), "Is Money Really "Smart"? New Evidence on the Relation Between Mutual Fund Flows, Manager Behavior, and Performance Persistence", Working Paper.

Wermers, R. R., Y. Wu, and J. Zechner, (2008), "Portfolio Performance, Discount Dynamics, and the Turnover of Closed-End Fund Managers", Working Paper. Available at SRRN: http://ssrn.com/abstract $=687142$.

Zheng, L., (1999), "Is Money Smart? A Study of Mutual Fund Investors' Fund Selection Ability", Journal of Finance, 54, 901-933.

Zitzewitz, E., (2006), "How Widespread Was Late Trading in Mutual Funds?", American Economic Review, 96, 284-289. 


\section{TINBERGEN InSTITUTE RESEARCH SERIES}

The Tinbergen Institute is the Institute for Economic Research, which was founded in 1987 by the Faculties of Economics and Econometrics of the Erasmus University Rotterdam, University of Amsterdam and VU University Amsterdam. The Institute is named after the late Professor Jan Tinbergen, Dutch Nobel Prize laureate in economics in 1969. The Tinbergen Institute is located in Amsterdam and Rotterdam. The following books recently appeared in the Tinbergen Institute Research Series:

492 A.N. HALSEMA, Essays on Resource Management: Ownership, Market Structures and Exhaustibility

493 R.E. VLAHU, Three Essays on Banking

494 N.E. VIKANDER, Essays on Teams and the Social Side of Consumption

495 E. DEMIREL, Economic Models for Inland Navigation in the Context of Climate Change

496 V.A.C. VAN DEN BERG, Congestion pricing with Heterogeneous travellers

497 E.R. DE WIT, Liquidity and Price Discovery in Real Estate Assets

498 C. LEE, Psychological Aspects of the Disposition Effect: An Experimental Investigation

499 MHA. RIDHWAN, Regional Dimensions of Monetary Policy in Indonesia

500 J. GARCIA, The moral herd: Groups and the Evolution of Altruism and Cooperation

501 F.H. LAMP, Essays in Corporate Finance and Accounting

502 J. SOL, Incentives and Social Relations in the Workplace

503 A.I.W. HINDRAYANTO, Periodic Seasonal Time Series Models with applications to U.S. macroeconomic data

$504 \quad$ J.J. DE HOOP, Keeping Kids in School: Cash Transfers and Selective Education in Malawi

505 O. SOKOLINSKIY, Essays on Financial Risk: Forecasts and Investor Perceptions

506 T. KISELEVA, Structural Analysis of Complex Ecological Economic Optimal Management Problems 
507 U. KILINC, Essays on Firm Dynamics, Competition and Productivity

508 M.J.L. DE HEIDE, R\&D, Innovation and the Policy Mix

509 F. DE VOR, The Impact and Performance of Industrial Sites: Evidence from the Netherlands

$510 \quad$ J.A. NON, Do ut Des: Incentives, Reciprocity, and Organizational Performance

$511 \quad$ S.J.J. KONIJN, Empirical Studies on Credit Risk

512 H. VRIJBURG, Enhanced Cooperation in Corporate Taxation

513 P.ZEPPINI, Behavioural Models of Technological Change

514 P.H.STEFFENS, It's Communication, Stupid! Essays on Communication, Reputation and (Committee) Decision-Making

515 K.C. YU, Essays on Executive Compensation - Managerial Incentives and Disincentives

516 P. EXTERKATE, Of Needles and Haystacks: Novel Techniques for Data-Rich Economic Forecasting

517 M. TYSZLER, Political Economics in the Laboratory

518 Z. WOLF, Aggregate Productivity Growth under the Microscope

519 M.K. KIRCHNER, Fiscal Policy and the Business Cycle-The Impact of Government Expenditures, Public Debt, and Sovereign Risk on Macroeconomic Fluctuations

520 P.R. KOSTER, The cost of travel time variability for air and car travelers

521 Y.ZU, Essays of nonparametric econometrics of stochastic volatility

522 B.KAYNAR, Rare Event Simulation Techniques for Stochastic Design Problems in Markovian Setting

523 P. JANUS, Developments in Measuring and Modeling Financial Volatility

524 F.P.W. SCHILDER, Essays on the Economics of Housing Subsidies

525 S. M MOGHAYER, Bifurcations of Indifference Points in Discrete Time Optimal Control Problems

526 C. ÇAKMAKLI, Exploiting Common Features in Macroeconomic and Financial Data

527 J. LINDE, Experimenting with new combinations of old ideas 
528 D. MASSARO, Bounded rationality and heterogeneous expectations in macroeconomics

529 J. GILLET, Groups in Economics

530 R. LEGERSTEE, Evaluating Econometric Models and Expert Intuition

531 M.R.C. BERSEM, Essays on the Political Economy of Finance

532 T. WILLEMS, Essays on Optimal Experimentation

533 Z. GAO, Essays on Empirical Likelihood in Economics

534 J. SWART, Natural Resources and the Environment: Implications for Economic Development and International Relations

535 A. KOTHIYAL, Subjective Probability and Ambiguity

536 B. VOOGT, Essays on Consumer Search and Dynamic Committees

537 T. DE HAAN, Strategic Communication: Theory and Experiment

538 T. BUSER, Essays in Behavioural Economics

539 J.A. ROSERO MONCAYO, On the importance of families and public policies for child development outcomes

540 E. ERDOGAN CIFTCI, Health Perceptions and Labor Force Participation of Older Workers

541 T.WANG, Essays on Empirical Market Microstructure

542 T. BAO, Experiments on Heterogeneous Expectations and Switching Behavior 
Investing in financial securities inevitably involves risks on the one hand and opportunities on the other hand. This thesis bundles four different studies on risks and/or opportunities in financial markets. In one study, we examine the cross-sectional explanatory power of different risk-measures in pricing U.S. stocks and find that investors dislike downside risk. In the second study, we show that conventional short-term reversal strategies exhibit dynamic exposures to systematic risks. Eliminating these risk exposures vastly improves the opportunity to exploit investors' overreaction exhibited in stock-price movements. Furthermore, this thesis shows that the potential for an 'active' manager to add value beyond passively investing in the index is not related to the efficiency of markets. It is, however, positively related to the number of independent investment opportunities, or breadth, available to the active manager. Finally, this thesis provides a study to the behavior of mutual fund investors subsequent to a replacement of the fund manager. We find that investors perceive turnover of bad performing managers as a bad signal as capital flowing to (withdrawn from) these funds is subsequently lower (higher).

Simon D. Lansdorp was born on March the 18 th, 1983 in Epe, the Netherlands. After graduating from high school, Simon continued to study Business Economics at the Erasmus University Rotterdam. In 2008, he obtained a Master's degree in Economics from the Tinbergen Institute and subsequently carried out his doctoral research. In 2009, Simon joined Robeco Asset Management to conduct part-time research for the Quantitative Strategies department. His research has been presented at top international conferences around the world and a spin-off of this research is forthcoming in the Journal of Financial Markets. Currently, Simon works on a full-time basis for Robeco; doing research related to, e.g., quantitative equity strategies. 